\title{
PARTITIONING OF SUBSURFACE EVAPORATION IN WATER LIMITED ENVIRONMENTS
}

Enrico Balugani 


\title{
PARTITIONING OF SUBSURFACE EVAPORATION IN WATER LIMITED ENVIRONMENTS
}

\author{
DISSERTATION
}

to obtain

the degree of doctor at the Universiteit Twente,

on the authority of the rector magnificus, prof. dr. ir. A. Veldkamp,

on account of the decision of the Doctorate Board

to be publicly defended

on Wednesday 1 September 2021 at 14.45 hours

by

\section{Enrico Balugani}

born on the 19th of November, 1982

in Cesena, Italy 
This dissertation has been approved by:

Supervisor:

Prof. dr. ir. M.W. Lubczynski

Co-supervisor:

Dr. K. Metselaar

ITC dissertation number 399

ITC, P.O. Box 217, 7500 AE Enschede, The Netherlands

$\begin{array}{ll}\text { ISBN: } & 978-90-365-5212-7 \\ \text { DOI: } & 10.3990 / 1.9789036552127 \\ \text { Cover design: } & \text { Balugani Enrico and Job Duim } \\ \text { Printed by: } & \text { CTRL-P, Hengelo }\end{array}$

(C) 2021 Enrico Balugani, The Netherlands. All rights reserved. No parts of this thesis may be reproduced, stored in a retrieval system or transmitted in any form or by any means without permission of the author. Alle rechten voorbehouden. Niets uit deze uitgave mag worden vermenigvuldigd, in enige vorm of op enige wijze, zonder voorafgaande schriftelijke toestemming van de auteur. 


\section{Graduation Committee:}

Chairman / secretary:

Supervisor:

Co-supervisor:

Committee Members: prof. dr. F.D. van der Meer

prof. dr. ir. M.W. Lubczynski

dr. K. Metselaar

prof. dr. ir. A. Stein

prof. dr. Z. Su

prof. dr. J. Samper-Calvete

prof. dr. M. Petitta

prof. dr. M.F.P. Bierkens 


\begin{abstract}
Semi-arid areas cover a quarter of the terrestrial surface. With climate change they are expected to increase in size and aridity. Almost all these areas, consist of bare, or seasonally bare, soils, where soil evaporation $\left(E_{\mathrm{ss}}\right)$ represents the dominant, discharging component of water balances, with large contribution originated from groundwater $\left(E_{g}\right)$ next to unsaturated zone contribution $\left(E_{u}\right)$. The $E_{\mathrm{ss}}$ is typically assumed to be relevant only when the topsoil gets wet after a rain event. However when a dry soil layer (DSL) develops at the topsoil, the evaporation from deeper soils used to be assumed as negligible. This study provides theoretical and experimental frameworks for sourcing (separation) of $E_{g}$ and $E_{u}$, and proves that $E_{s s}$ and particularly $E_{g}$ are substantially underestimated by commonly applied models, which either disregard the formation of a DSL, or assume only diffusion flow of water vapour through it. The underestimation depends nonlinearly on the thickness of the DSL: at $1 \mathrm{~cm}$ the Fick diffusion estimates are acceptable; at $10 \mathrm{~cm}$ the estimates are already one order of magnitude less than the measured $(0.03$ $\mathrm{mm} \mathrm{d}^{-1}$, instead of $0.3 \mathrm{~mm} \mathrm{~d}^{-1}$ ); at $50+\mathrm{cm}$ the standard estimates are three orders of magnitude less than measured; e.g. in this study, the experimental $E_{g}$ in dry evaporative field condition, consistently exceeded $1 \mathrm{~mm} \mathrm{~d}^{-1}$. This leads to the conclusion that the dynamics and processes within the DSL are critical to understand and quantify evaporation from groundwater in the presence of a DSL.
\end{abstract}




\section{Acknowledgements}

My gratitude goes to all people that contributed, both directly and indirectly, to the making of this thesis. First and foremost, to the two people that sustained me closely in this project, my supervisors Maciek Lubczynski, with his tenacity, patience and commitment, and Klaas Metselaar, with his wisdom, organization vision and friendly support. I would have not make it to the end without them. Then, to Prof. Bob Su, for his advice and timely support to my PhD project.

To Prof. Sjoerd van der Zee for his kindness, his advices on modelling and scientific thinking in general, and the support to the wild ideas I had. To Toon Leijnse, who also helped me wrap my head around the numerical modelling of physical processes. To the rest of the "Sardon's hell crew": Alain Pascal Frances, Leonardo Reyes-Acosta, and Tanvir Hassan, for the help in all things related to the field part of this study, from management, to material borrowing, to actually digging the hard rock. Other people got to dig to help me: Chandra Prasad Ghimire and Marco Paglione. To Yijian Zeng, for discussions about soil hydrology, arid areas, food, culture, and life in general. All these people are among my best friends.

To Christiaan van der Tool, for the help with the partitioning field study, and for his never ending kindness. To Harm Gooren, for his fundamental help, both practical and theoretical, in the laboratory experiment in Wageningen. To Boudewijn de Smeth, for his support in laboratory at ITC, and for his nice comments. To Murat Ucer for the help with the sensors and technological equipment. To Rainer Helmig, Klaus Mosthaf, and the rest of the Stuttgart University that helped me with the DuMux model: it was just one week, but I learned so much, and I still bring that attitude with me. To José Martínez Fernández and to the people at CIALE, Salamanca University, for their logistic support and nice time passed together. To Guido Baroncini Turicchia, for hosting me for one month during field work and introducing me to everything Salamanca-related. To Lucidio (Lucio) Calvo Herrero and Ana Maria Garcia Herrero, for letting me go around and dig holes in their properties, for the wonderful food, and for the classes in taxidermy. To Dani Or, that gave me very insightful comments during a conference in Utrecht, and helped me feel I was not alone in my path.

The community at ITC was great, with a lot of nice people that helped me go through the PhD. I want to thank, especially, Tina Butt-Castro, who welcomed me when I first arrived, after 14 hours of car driving, and in general kept a motherly eye on me during the whole stay. Anke de Koning and Loes Colenbrander were very kind with the bureaucracy nightmare that I am. To my ever changing rock band in Enschede: Mireia Romaguera ( $\mathrm{I}$ 'm still listening to that Textures album you gave me), Mustafa Gokmen, Yiannis Delikostidis, Özgün, and Juancho, plus the fan-base, Mr. Rafa Pimentel Leiva, who also introduced me to the secrets of Granada and to Flamenquín. To the team of 
Run For Fun: Wan Bakx, Simon Engelberts, and Roelof Schoppers; running was what helped me go through solitude and depression in Colombia. To all the rest of my fantastic friends I met in Esnchede: Marshall X Ma, Joris Timmerman, Juan Francisco Sanchez Moreno, Divyiani Kohli, Adriana Guatame, Maria Fernanda (with the French Marriage), Xuelong Chen, Nuria Pardo, Julia Leventi (with Fun at Ikea), Ying Huang, Nick Hamm (with the Sausage project), Mariela Yevenes, Maria Elisa Tosi (and the coloured cube), Konstatinos Nizamis (bro'), Fouad Alkhaier (with the recipe for falafel), Meisam Yousofzade, Ying Jing, Etefa Rundassa, Basil the Cat, Fede Figueroa (with the recipe for Mexican tortillas), Girma Adera, Joon Waralitte, Idham Effendi, César Cisneros, Yuliana Ginting, Gabriel Vatin, Valentina Spanu, Alejandra Larrazábal.

I want also to thank the people not directly involved with my PhD project or with life in Enschede, but that really helped me get to the end. Diego Marazza and Prof. Andrea Contin of Bologna University helped me get back on my feet, and fall in love with science (and maybe with life at large) again. Maybe the best that could happen to me. Niccolò Masi had a big role in reigniting my passion for science. Alisar Kiwan and Chiara Samorí, also from Bologna University, kicked me in the ass when I most needed it. The people at Analytical Chemistry and EMRG in CIRSA, Ravenna, for the support during these stressful months. To my students at Environmental Sciences in Bologna University: you also helped a lot. To my safe abode in Colombia: Lucila Gómez, Rafael Díaz, Mónica Díaz, and the rest of my ex-family there. And to my safe abode in the low land of Romagna: Luna and Valentina Zannoni.

Finally, the most important people of all: Rossella Scarpellini, my beloved mother, and that crazy person that is my sister, Ambra, for their support and encouragement. 


\section{Table of Contents}

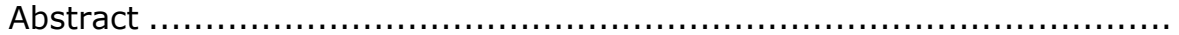

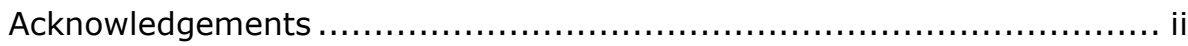

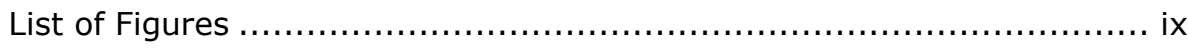

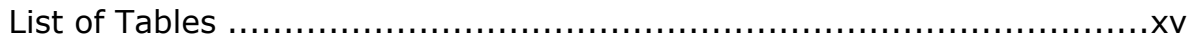

List of symbols and abbreviations ................................................

Chapter 1 General Introduction ............................................... 7

1.1 Scientific Background .................................................. 8

1.1.1 Evapotranspiration process in semi-arid and arid areas......... 8

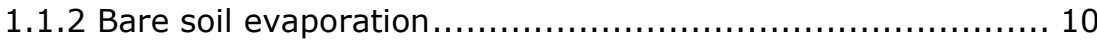

1.1.3 Estimating soil evaporation in field conditions................... 13

1.1.4 Modelling soil evaporation ...................................... 14

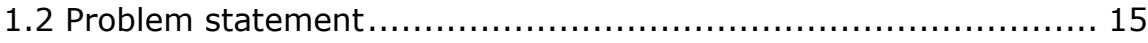

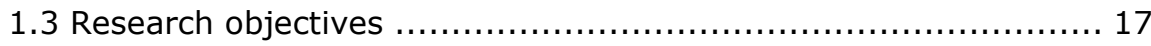

1.3.1 Main objective ................................................. 17

1.3.2 Specific objectives ................................................ 17

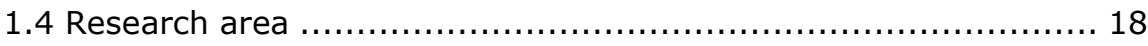

1.5 Structure of the thesis .................................................. 20

Chapter $2 \mathrm{~A}$ framework for sourcing of evaporation between saturated and unsaturated zone in bare soil condition ......................................... 23

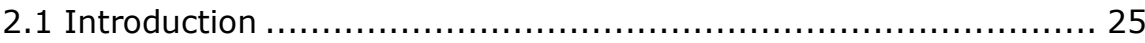

2.1 .1 Basic concepts................................................. 25

2.1.2 Evaporation conceptual models in a sourcing context ......... 26

2.1.3 Measurement techniques for sourcing of $E_{s s} \ldots \ldots \ldots \ldots \ldots \ldots \ldots . \ldots \ldots$

2.1.4 Aim of the study ............................................... 29

2.2 Methodology: the proposed sourcing framework ...................... 30

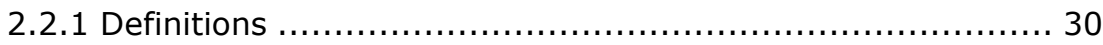

2.2.2 Application to the conceptual models........................... 33

2.2.3 The Hydrus1D model.............................................. 34

2.2 .4 The SOURCE package ......................................... 35

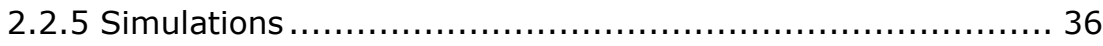

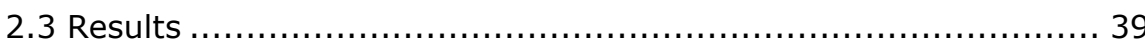

2.3.1 Quasi-steady state: "shallow" and "deep" water table simulations .................................................................. 39

2.3.2 Water table fluctuation simulations .......................... 42

2.3.3 "Bucket" method simulations..................................... 44 
2.4 Discussion ........................................................... 44

2.4.1 Quasi-steady state: "shallow" and "deep" water table

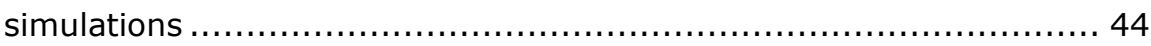

2.4.2 Water table fluctuation simulations ....................... 46

2.4.3 "Bucket" method simulations ............................. 47

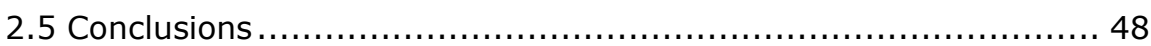

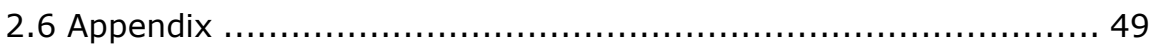

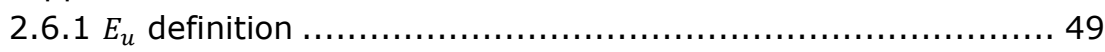

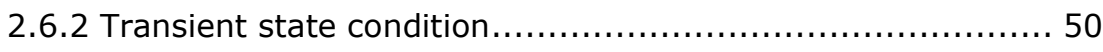

2.6.3 The Hydrus1D model ..................................... 52

Chapter 3 Groundwater and unsaturated zone evaporation and transpiration

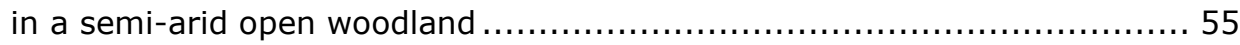

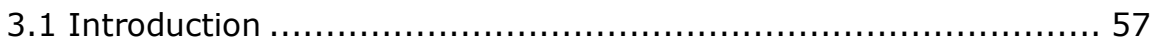

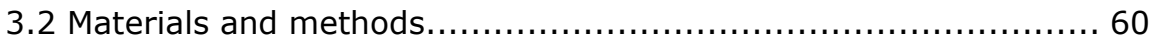

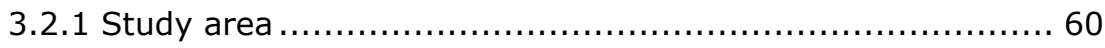

3.2.2. Partitioning and sourcing framework ...................... 61

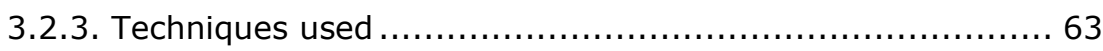

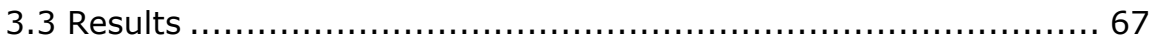

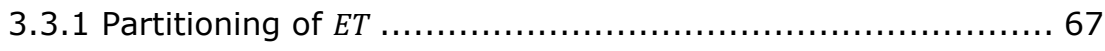

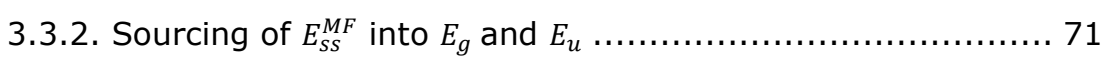

3.3.3. Relative relevance of sourced components ................. 72

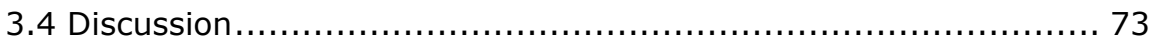

3.4.1. ET partitioning in semi-arid areas ....................... 73

3.4.2. Sourcing of $E_{S S}^{M F}$ and $E_{S S}^{M F}$ into groundwater and unsaturated zone

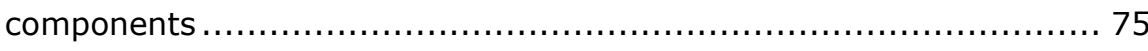

3.4.3. The relevance of $E_{g}$ in semi-arid climate................... 79

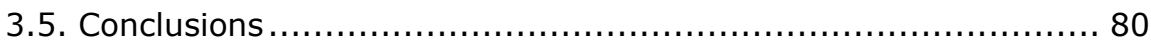

Chapter 4 Testing three approaches to estimate soil evaporation through a

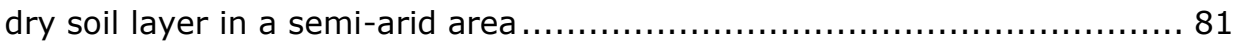

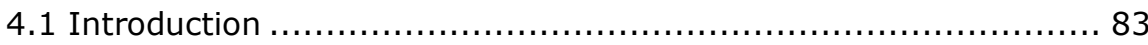

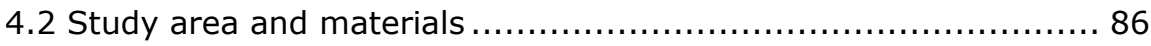

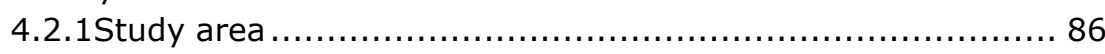

4.2.2 Groundwater measurement and modelling .................. 87

4.2.3 Micrometeorological measurements....................... 88

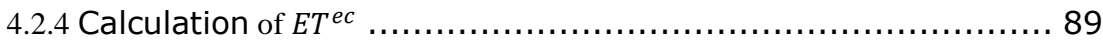

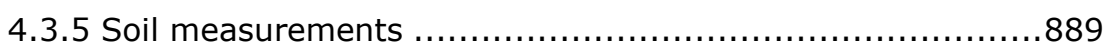


4.3 Conceptual models and methods: .......................................900

4.3.1 Testing DA conceptual model assumption ......................900

4.3.2 Testing NSRE conceptual model assumption ...................911

4.3.3 Testing the applicability of the PS conceptual model ........... 92

4.3.4 Comparison of the three conceptual models ..................... 95

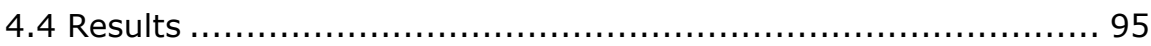

4.4.1 Field measurements .......................................... 95

4.4.2 Testing DA conceptual model assumption ....................... 97

4.4.3 Testing NSRE conceptual model assumption ..................... 98

4.4.4 Testing the applicability of the PS conceptual model ..........100

4.4.5 Comparison of the three conceptual models ....................101

4.5 Discussion....................................................................... 101

4.5.1 Testing daily-average conceptual model assumption ..........101

4.5.2 Testing NSRE conceptual model assumption ...................102

4.5.3 Testing the applicability of the pore-scale conceptual model 103

4.5.4 Comparison of the three conceptual models .....................104

4.5.5 Potential causes of $E_{f}<E^{e c}$ in elevated terrain with deep water table..... 106

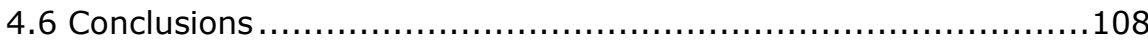

4.7 Appendix ................................................................

4.7.1 $E T^{e c}$ dependence on wind direction..............................109

4.7.2 $E T^{e c}$ dependence on topography .............................111

4.7.3 $E T^{e c}$ measurements quality and related error...................113

Chapter 5 Evaporation through a Dry Soil Layer: Column Experiments.115

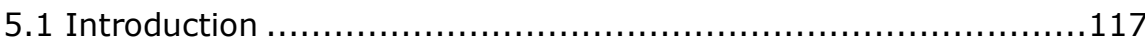

5.2 Materials and methods............................................... 119

5.2.1 Soil columns' design .......................................... 119

5.2.2 Diffusion flow in a thick DSL .................................. 121

5.2.3 Radiative Cycles and Stable Wind Effects on Vapour Transport

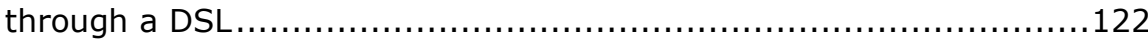

5.2.4 Barometric pressure fluctuation effects on vapour transport

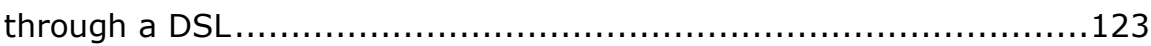

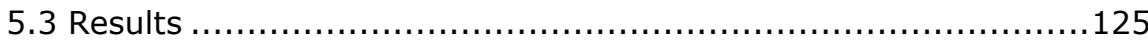

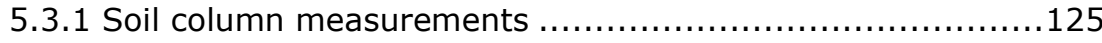


5.3.2 Evaluation of diffusion, wind speed, and daily cycles effects on vapour transport through a DSL .......................................... 125

5.3.3 Barometric pressure fluctuations effects on vapour transport

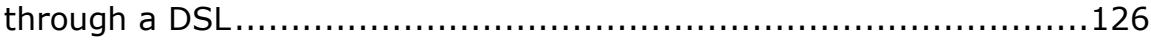

5.4 Discussion................................................................. 131

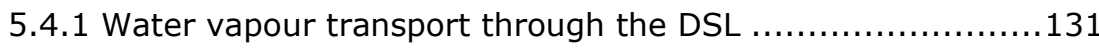

5.4.2 Possible limitations of the study ................................. 134

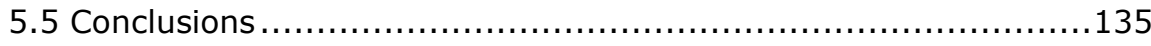

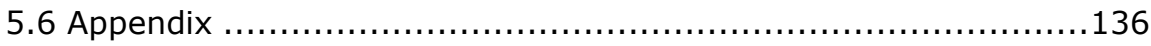

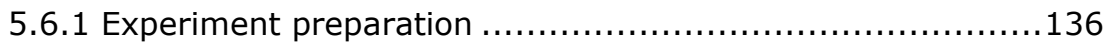

5.6.2 Tukey Test results........................................... 137

5.6.3 Evaporation rates and top-soil temperature relationship .....138

Chapter 6 Lysimeter and In-situ Field Experiments to Study Soil Evaporation through a Dry Soil Layer under Semi-Arid Climate...............................141

6.1 Introduction ............................................................ 143

6.2 Materials and methods................................................ 146

6.2.1 Field lysimeter and in-situ measurements .....................146

6.2.2 Theoretical framework ....................................... 148

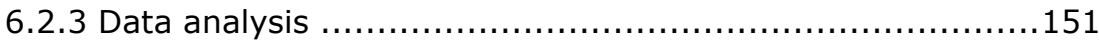

6.2.4 Simulation of the lysimeter and in-situ soil evaporation with Hydrus1D and SOURCE package ............................................ 153

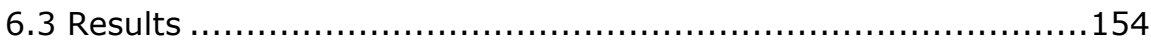

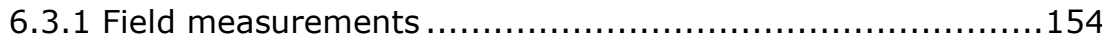

6.3.2 Correlation between environmental variables ..................157

6.3.3 Correlation between forcing factors of transport processes and

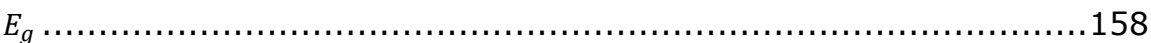

6.3.4 Correlation between evaporation rates and explanatory variables

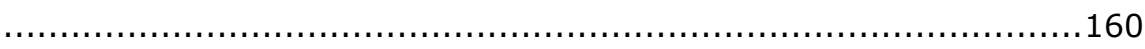

6.3.5 Comparison with the Hydrus1D model estimates................163

6.4 Discussion.................................................................... 165

6.4.1 Measurements of evaporation through a thick DSL and comparison with soil profile measurements ...............................165

6.4.2 Relevance of different transport processes .....................166

6.4.3 Limitations and further studies ...................................169

6.5 Conclusions and recommendations .....................................170

Chapter 7 Concluding remarks .............................................. 


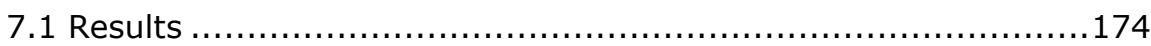

7.2 Limitations ........................................................... 176

7.3 Final conclusions and future research ............................. 178

Bibliography.................................................................. 181

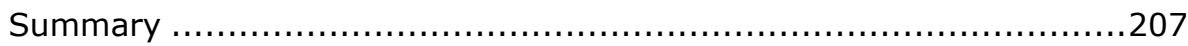

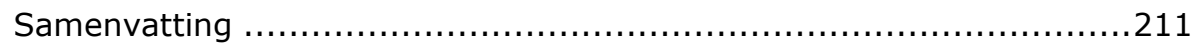




\section{List of Figures}

Figure 1.1: Schematic representation of a soil water balance in a water limited environment. $P$ is precipitation, Int is interception (which, in the absence of open water bodies or dew, is equal to surface evaporation $E s), I$ is infiltration of rain into the soil, $R_{0}$ is surface runoff, $R$ is recharge, $Q_{i n}$ and $Q_{\text {out }}$ are the lateral groundwater flow input and output into and from an assessed part of the saturated zone, and $E_{u}, E_{g}, T_{u}, T_{g}$ are the unsaturated and groundwater evaporation, and the unsaturated and groundwater transpiration components, respectively. In the figure, the lower boundary of the saturated zone is defined by the impermeable bedrock.

Figure 1.2: Schematics of the soil saturations during S2 evaporation: a) as observed in laboratory experiments close to hydrostatic equilibrium, with a shallow water table (modified after Shokri and Salvucci, 2011); b) in the presence of a zero-flux plane, as in Brutsaert (2014b), with a deeper water table; water below the zero-flux plane moves downward, so only the water above it is considered in the evaporation process. The soil material profile is divided into three zones: (1) saturated zone, delimited by the water table and overlain by the capillary fringe, bounded at the top by a drying front; (2) capillary driven zone, where water moves upward by capillary forces from the drying front to the vaporization plane where it evaporates; and (3) a dry soil layer (DSL), where water moves only as water vapour. The black line is an example of the soil water saturation profile. $L_{c}$ is the critical length at which capillary forces are too small to sustain hydraulic continuity (Or et al., 2013). Notice that the vaporization plane is referred by Brutsaert (2014b) as the (secondary) drying front.

Figure 1.3: The Trabadillo study area: (a) location of the study area in Spain; (b) altitudinal map of the Sardon catchment, with the position of the weather station installed and the boundary of the La Mata sub-catchment highlighted; (c) the appearance of the study area in September; (d) the appearance of the study area at the beginning of May.

Figure 1.4: potential evapotranspiration $\left(E T_{p}\right)$ and precipitation $(P)$ in the Trabadillo study area, Spain, for the period 1 October 2008 to 30 September 2015 (a hydrological year in Spain lasts from 1 October to 30 September). $P$ was measured in-situ with a tipping bucket. $E T_{p}$ was calculated daily with Penman Monteith equation (Monteith, 1980), using data acquired in-situ with a weather station. 18

Figure 2.1: Graphic representation of $E_{g}$ in closed soil column with falling water table; $\theta_{r}$ is residual water content; $\theta_{\text {sat }}$ is saturation water content; the two curves represent two soil moisture profiles with depth, at the beginning $\left(t_{1}\right)$ and at the end $\left(t_{2}\right)$ of the groundwater evaporation $\left(E_{g}\right.$ - area between the two curves marked by vertical line shading) process, corresponding to water table 
decline from $Z_{W T 1}$ to $Z_{W T 2}$ respectively; a) is water converted to unsaturated zone water due to falling water table (squared grid).

Figure 2.2: Graphic representation of $E_{u}$ under stable evaporative conditions and large $Z_{W T}$, i.e. absent saturated zone; $\theta_{r}$ is residual water content; $\theta_{\text {sat }}$ is saturation water content; the two curves represent two soil moisture profiles with depth, at the beginning $\left(t_{1}\right)$ and at the end $\left(t_{2}\right)$ of the unsaturated zone evaporation ( $E_{u}$ - area between the two curves marked by vertical line shading) process. 32

Figure 2.3: Flowchart showing the implementation of the proposed framework in the SOURCE package. 36

Figure 3.1: QuickBird image of the $22 \mathrm{~km}$ maximum footprint (MF) study area, showing the position of the eddy covariance $(E C)$ tower and of the piezometers close to the tower; the black dots are the tree canopies. The image is projected in WGS 84 - UTM zone 29N (metres). 61

Figure 3.2: Picture of the eddy covariance (EC) tower (upper part) and schematic example of the subdivision for the upscaling procedure (lower part): (a) bare soil, where we assumed only subsurface evaporation $\left(E_{s S}\right)$ was present (no tree transpiration $T_{s S}$ ); (b) canopy areas, where we assumed only $T_{s s}$ was present (no $E_{s s}$ ); (c) EC tower position; (d) an example of EC tower footprint, (e) wind direction implying the presented footprint direction.

Figure 3.3: Flowchart of the partitioning framework. The Hydrus1D model was run for every $1 \mathrm{~m}^{-2}$ of the $Z_{W T}$ map within the maximum footprint (MF) study area. 64

Figure 3.4: Precipitation ( $P$, black bars) and potential evapotranspiration ( $E T_{p}$, gray line) calculated with Penman-Monteith method. The measurements start on DOY 211 of year 2009 (30 July, 2009) and stop on DOY 310 of 2010 (27 December 2010). 68

Figure 3.5: Upscaled $T_{s s}^{M F}$ for the maximum footprint MF study area, for the dry summers 2009 (dashed line) and 2010 (solid line), i.e. for the periods from DOY 190 (9 July) to DOY 255 (12 September).

Figure 3.6: Water table depth $\left(Z_{W T}\right)$ plotted together with soil moisture saturation measured at four depths, starting at DOY 160 year 2009 (9 June) until DOY 85 year 2010 (26 March). In the period between DOY 290 and 345 (17 October and 11 December) for 2009 the piezometer was dry: in this period water table level was, hence, deeper than $3.6 \mathrm{~m}$. The few days gap in soil moisture data for dry summer 2010 was due to low battery. The bars represent the precipitation events $(P)$. 69

Figure 3.7: EC tower evapotranspiration measurements ( $E T^{e c}$, diamonds) and precipitation ( $P$, black bars) compared to subsurface evaporation $\left(E_{S s}^{M F}\right.$, gray solid line) and subsurface transpiration ( $T_{S s}^{M F}$, shaded black line at the bottom) 
defined for the maximum footprint area (MF) for the dry summer 2009, DOY 200-250 (from 19 July to 7 September when sap flow measurements were available) and for the year 2010, DOY 0-280 (from 1 January to 7 October). The shaded areas represent periods when the EC tower data was unavailable or incomplete. 70

Figure 3.8: Sourcing of subsurface evaporation $\left(E_{S S}^{M F}\right)$ in the maximum footprint (MF) study area, for: the dry summer 2009 (from 19 July to 7 September) and the year 2010 (from 1 January to 17 September). The $E_{s s}^{M F}$ is represented by black line, groundwater evaporation $\left(E_{g}^{M F}\right)$ by dashed line and unsaturated zone evaporation $\left(E_{u}^{M F}\right)$ by gray line with circles. 72

Figure 3.9: Evapotranspiration measurements from the EC tower $\left(E T^{e c}\right)$ and subsurface evaporation $\left(E_{s S}^{M F}\right)$ for five different averaged water table depths in the maximum footprint (MF) study area. The dataset is shown for 4 periods of year 2010. The period before DOY 90 is not shown because model results are not dependent on water table depth due to very moist top soil. The bars aside the graphs show the median values of the time series of $E T^{e c}$ and $E_{s S}^{M F}$ for each period. 78

Figure 4.1: Study area $(2 \times 2 \mathrm{~km})$ : the left map shows the measurements taken in the study area around the eddy covariance station and the altitude; the right map shows the depth of the groundwater table (in $\mathrm{m}$ b.g.s.) on August 21, 2010, after Frances et al. (2015). Both soil moisture and matric potential profiles are so close to the weather station that the symbols would superimpose.

Figure 4.2: La Mata catchment during dry season: Sardon River in the foreground, then bare soil and further away scattered trees; all in the gentlysloping landscape.

Figure 4.3: Daily evaporation measured by the eddy covariance tower (Eec) and daily rainfall data. Periods in which the EC tower had data gaps are shown with grey shade. 96

Figure 4.4: POT (polymer tensiometer) and daily rainfall measurements near the weather station, Figure 4.2. The dry seasons (from grass senescence to first heavy rains) are coloured.

Figure 4.5: Semi-log plot of $E^{e c}$ versus time. The $E^{e c}$ dataset was divided into three subsets with different dry conditions each starting at different Julian date of the drying periods: DOY 211 (30 July 2009, orange dots), DOY 119 (29 April 2010, blue squares), DOY 161 (10 June 2010, grey diamonds). 98

Figure 4.6: Comparison between $E_{f}$ and $E T^{e c}$ for: a) 13 July 2010, with predominant wind coming from west, i.e. from the river valley, with shallow ZWT (0.5-2 m b.g.s.); b) 26 September 2010, with predominant wind coming from the south, i.e. from the higher terrain, with deep $Z W T$ (7-10 m b.g.s.); 
the spike of $E_{f}$ in 26 September 2010 at 10:00 is due to the wind temporarily coming from the river valley. 99

Figure 4.7: Difference between $E_{f}$ and $E^{e c}\left(E_{f}-E^{e c}\right.$, in $\mathrm{mm}$ per half hour) plotted against various wind directions; $\mathrm{N}$ is north, $\mathrm{E}$ is east, $\mathrm{S}$ is south and $\mathrm{W}$ is west. Positive values found in the west, i.e. towards the valley with shallow water table $\left(200-300^{\circ}\right)$ mean that $E_{f}>E^{e c}$, while negative values found in the east, i.e. towards the higher elevated area with deep water table (50-100 $)$ mean that $E_{f}<E^{e c}$. 100

Figure 4.8: $E T_{\text {norm }}$ from Equation 4.8 plotted against wind direction for the whole half hourly dataset (the bars indicate the standard error, i.e. a measure of the variation within the class). A wind direction $0^{\circ}$ means wind from the north, $90^{\circ}$ from the east, $180^{\circ}$ from the south and $270^{\circ}$ from the west. ...111

Figure 5.1: Geometry and experimental setup of the short $(1 \mathrm{~m})$ and long (2 m) columns: A - radiative lamp, B - fan, C - water table, D - Mariotte bottle, E - digital balance, F - gravel layer (5 cm thick) and d - diameter of a column; the numbers at the right sides of the columns represent depths of installation of the temperature and soil moisture/matric potential sensors. The arrows in the Mariotte bottles indicate the direction of the water flow from the bottles to the columns.

Figure 5.2: Cumulative evaporation [mm] for experimental Tests T2-4 and T68 in short and long columns as explained in Table 5.1. .125

Figure 5.3: Boxplot of the evaporation rates for experimental Tests as per Table

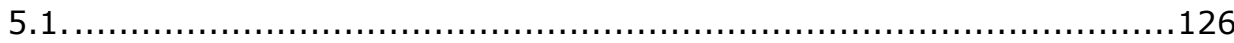

Figure 5.4: Scatterplot of the hourly evaporation rates $\left(E_{h}\right)$ expressed in daily rates, versus the hourly changes in barometric pressure $\left(\Delta p_{h}\right)$ for both columns and the best linear fits for the positive and negative relations. The red lines show the intersection point between the two relations, and the designated quadrants to determine them.

.128

Figure 5.5: Hourly time series of the evaporation rates $\left(E_{h}\right)$ and barometric pressure changes $\left(\Delta p_{h}\right)$ for the short column T6 Test; the red circles correspond to the rare cases of positive $\Delta P h$ and negative $E_{h}$. Note that: (i) $\Delta p_{h}$ had zero mean; and (ii) the average $E_{h}$ was positive and $E_{h}$ behavior was symmetrical to $\Delta p_{h}$ whenever the latter had negative values. .129

Figure 5.6: Hourly evaporation rates, measured and modelled using Equation 5.8, calibrated using short column T2, T3 and T4 evaporation dataset. The evaporation is presented for the T2 Test in the calibration period, 22 November - 3 December 2011 for the: a) short column (e.g. calibration dataset); b) long column (e.g. validation dataset). .130 
Figure 5.7: Hourly evaporation rates, measured and modelled using Equation 5.8, calibrated using short column T2, T3 and T4 evaporation dataset. The evaporation is presented for the T6 Test in the validation period, 5 January 13 January 2012, for the: a) short column; b) long column.

Figure 5.8: Scatterplot of the top boundary temperatures and related evaporation rates for the different experimental tests for both short and long column. The experimental test name is indicated for the short column data.

Figure 6.1: Monitoring setup: a) Sardon study site (A - in-situ soil monitoring profile; B - piezometers; C - lysimeter); D - weather station.); b) schema of the lysimeter column ( $\mathrm{E}$ - depth markers of matric potential and temperature sensors; F - Mariotte bottle; G - lysimeter weighing device; $\mathrm{H}$ - Mariotte bottle weighing device; I - water table inside the column) ; c) schema of the in-situ soil monitoring profile ( $L$-infrared radiometer; $M$ - POT matric potential sensor; N - MPS1 matric potential sensors; and O - Hydraprobe soil moisture and temperature sensor); d) location of the Sardon catchment in Spain. ..147

Figure 6.2: The dataset collected during dry season 2012 (23 May to 11 June): a) wind speed $(u)$ and net short wave radiation $\left(S_{n}\right) ;$ b) relative humidity $(R H)$ and air temperature $\left.\left(T_{a}\right) ; c\right)$ atmospheric pressure $\left(p_{a t m}\right)$ and precipitation $(P)$; d) in-situ soil moisture $\left(\theta_{\text {depth }}\right) ;$ e) in-situ soil temperature $\left(T_{s, \text { depth }}\right) ; f$ ) lysimeter soil temperature $\left.\left(T_{L, \text { depth }}\right) ; \mathrm{g}\right)$ cumulative lysimeter groundwater evaporation $\left(E_{g}\right)$ measured by the Mariotte bottle. .155

Figure 6.3: Dataset collected during dry season 2015 (9 to 28 August 2015): a) wind speed $(u)$ and net short wave radiation $\left(S_{n}\right) ;$ b) relative humidity $(R H)$ and air temperature $\left.\left(T_{a}\right) ; c\right)$ atmospheric pressure $\left(p_{a t m}\right)$ and precipitation $(P)$; d) in-situ soil moisture $\left(\theta_{\text {depth }}\right) ;$ e) in-situ soil temperature $\left.\left(T_{\text {s,depth }}\right) ; \mathrm{f}\right)$ lysimeter soil matric potential $\left(\Psi_{L, \text { depth }}\right)$; sensors at depths 10 and $5 \mathrm{~cm}$ not shown because too negative); g) lysimeter cumulative evaporation measurement. .157

Figure 6.4: Comparison of temporal variations of environmental variables and evaporation rates during 10 days (24 May to 3 June 2012): a) potential drivers of water vapour fluxes acquired at hourly frequency, after normalization ( $X$ is the variable measurement, $\bar{X}$ the average of the variable over the period considered, $\sigma$ is the standard deviation of the variable in the same period); b) evaporation rates acquired at 5 min frequency by the Mariotte bottle $\left(E_{g}\right) ; \mathrm{c}$ ) the evaporation rates measured by the Mariotte bottle, standardized and filtered (high pass) for daily fluctuations ( $E_{g, 05}$ average of groundwater evaporation and its standard deviation, $\sigma_{0.5}$, in the time window $0.5 \mathrm{~d}$ ). Notice that $R H$ is displayed with reversed values, i.e. $-R H$. Note also that, in the Sardon study area, the local summer time (as presented) is $\sim 2.5 \mathrm{~h}$ ahead of the solar time. .158 
Figure 6.5: Daily variations of $E_{g}$ rates (measured and estimated) and temperatures inside the lysimeter during the example days 24 May and 25 May 2012: a) standardized and filtered (daily high pass) measured atmospheric pressure $\left(p_{a t m}\right)$, soil temperature at $10 \mathrm{~cm}\left(T_{L, 10,0.5}\right)$, and lysimeter $E_{g, 0.5}$, together with lysimeter evaporation estimated by modelling ( $E_{L}$ - estimated $E_{g}$ using soil temperature variation model; $E_{L B^{-}}$estimated $E_{g}$ using soil temperature variation combined with barometric effect model); solar noon is indicated with grey dotted lines; b) temperatures measured in the lysimeter profile at different hours of the same days. Note that in the Sardon study area, the local time is $\sim 2.5 \mathrm{~h}$ ahead of the solar time. 161

Figure 6.6: Cumulative groundwater evaporation rates: $E_{g}$ - measured; $E_{L}$ estimated $E_{g}$ using soil temperature variation model; $E_{L B}$ - estimated $E_{g}$ using soil temperature variation combined with barometric effect model; 'HYDRUS1D in-situ' and 'HYDRUS1D lysimeter'- predicted $E_{g}$ by the Hydrus1D model with SOURCE package for the in-situ and lysimeter soil profiles respectively for: a) the calibration period (23 May to 11 June 2012) and b) the validation period (5 August to 21 October 2015). 


\section{List of Tables}

Table 2.1: Soil hydraulic parameters used for the "field" and "standard" sandy loam materials: $\theta_{r}$ is residual water content, $\theta_{s}$ is saturated water content, a and $\mathrm{n}$ are parameters of the water retention function in the van GenuchtenMualem model, $\mathrm{K}_{\mathrm{s}}$ is saturated hydraulic conductivity, I is tortuosity parameter in the conductivity function in the van Genuchten-Mualem model, $\mathrm{S}_{\mathrm{y}}$ is specific yield (calculated using the other parameters by the van Genuchten-Mualem model).

Table 2.2: Cumulative $E_{g} / E_{s s}$ (groundwater evaporation/subsurface evaporation) ratio for 30 days simulations with rainy event occurring at the day 7 of simulation, for three different water table depths $\left(Z_{W T}\right)$, with either liquid-only water flow (L) or liquid and vapour water flow (Lv) and using either van Genuchten-Mualem (GM) or Brooks and Correy (BC) soil hydraulic models; n.c. means not converged. 39

Table 2.3: Comparison of the sourcing of $E_{g}$ in "field" sandy loam soil with $Z_{W T}$ $=2.0 \mathrm{~m}$, performed by the "bucket" method used by Wilson et al. (2001) and the SOURCE package.

Table 3.1: Partitioning and sourcing of estimated subsurface evapotranspiration $\left(E T_{S S}^{M F}\right)$ vs evapotranspiration measured by the EC tower $\left(E T^{e c}\right)$ for: the dry summer (period from 29 July to 7 September, DOY 210250) 2009; the dry summer 2010; and for the period between DOY 30 and 280 of the year 2010 (from 30 January to 7 October). 73

Table 3.2: Summary of the partitioning studies conducted in arid and semiarid areas for comparison with this study. The symbol 'n.r.' means 'not reported'..... 75

Table 3.3: Median evaporation rates: median values of evaporation (in $\mathrm{mm} \mathrm{d}$ $\left.{ }^{1}\right)$ for the time series shown in Figure 3.9.... 79

Table 4.1: Literature review table of studies of soil evaporation where a DSL was present; all conducted in sandy soils unless otherwise stated, all have found the model to properly fit the measurements unless otherwise stated. Mod. stands for "modified version of the NSRE model". For more literature about DSL effects on evaporation reported in studies, see Wang (2015). ... 84

Table 4.2: Comparison of the $E^{e c}$ values with the evaporation calculated using the pore-scale conceptual model for the same time of the day, with a fixed DSL $\left(E_{C Z}\right)$ and with a $Z_{D S L}$ determined by $Z W T$ and $L c\left(E_{V Z}\right)$; in $\mathrm{mm} \mathrm{d}^{-1}$. Subscript stands for relative error. 100

Table 5.1: Sequence of experimental tests and their description. WTH - water table height measured from the bottom of the column, $\mathrm{U}$ - wind speed. Every time the WTH was raised, the first 5 days of the Mariotte bottle weight datasets 
were considered as the equilibration period, so were not used in the

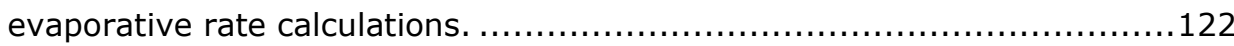

Table 5.2: Comparison of measured (experimental) average daily evaporation rates as in the Tests (Table 5.1), with evaporation rates calculated using: (i) diffusion only (Equation 5.1); (ii) the sum of diffusion and direct barometric pumping effect (substituting $Z_{\text {DSL }}$ of the Equation 5.3 in the Equation 5.1); (iii) the sum of diffusion flow and effect of barometric pressure fluctuation calculated using Equation 5.9, calibrated using the short column dataset (results are the same for both columns). All evaporations are in $\mathrm{mm} \mathrm{d}^{-1}$. The $Z_{D S L}$ for every experimental Test is also shown for completeness. .127

Table 5.3: Tukey test results of the comparison between: i) different tests in the two columns; ii) different tests in the short column; and iii) different tests in the long column. The difference between evaporation rates of any pair of two experimental tests is considered statistically significant (in bold) if $p<0.05$. 


\section{List of symbols and abbreviations}

\begin{tabular}{|c|c|}
\hline$\alpha$ & dispersivity coefficient \\
\hline$\alpha_{G M}$ & $\begin{array}{l}\text { van Genuchten Mualem (1980) model } \\
\text { parameter }\end{array}$ \\
\hline$\Delta L_{\text {pump }}$ & $\begin{array}{l}\text { deepest layer of gas phase mixed with } \\
\text { air above the soil surface }\end{array}$ \\
\hline$\Delta p_{a t m}$ & amplitude of pressure change \\
\hline$\Delta p_{h}$ & hourly barometric pressure changes \\
\hline$\Delta_{t}$ & $\begin{array}{l}\text { discrete time differential of a variable, i.e. } \\
\text { value of the variable at a time } t \text { minus the } \\
\text { variable value at time } t-1\end{array}$ \\
\hline$\Delta \theta_{\mathrm{f}-\mathrm{r}}$ & $\begin{array}{l}\text { amount of water exchanged between } \\
\text { saturated and unsaturated zone due to rising } \\
\text { or falling of water table }\end{array}$ \\
\hline$\Delta \theta_{\text {rise }}$ & $\begin{array}{l}\text { increase in soil moisture at a certain depth due } \\
\text { to rise of the water table }\end{array}$ \\
\hline$\Delta_{z}$ & $\begin{array}{l}\text { discrete spatial differential of a variable on the } \\
\text { vertical axis, i.e. value of the variable at a } \\
\text { depth } z \text { minus the variable value at depth } z-1\end{array}$ \\
\hline$\Delta C_{v}$ & $\begin{array}{l}\text { difference between vapour concentration at } \\
\text { the vaporization plane and at the soil surface }\end{array}$ \\
\hline$\Delta S_{\text {unsat }}$ & $\begin{array}{l}\text { change in water stored in the unsaturated zone } \\
\text { between two points in time }\end{array}$ \\
\hline$\theta$ & soil water content \\
\hline$\theta_{\text {depth }}$ & soil water content measured at a certain depth \\
\hline$\theta_{i}$ & $\begin{array}{l}\text { initial condition for the soil moisture vertical } \\
\text { profile }\end{array}$ \\
\hline$\theta_{\text {sat }}$ & $\begin{array}{l}\text { soil water content at saturationwhen the soil is } \\
\text { air-dry }\end{array}$ \\
\hline$\kappa$ & characteristic timescale of soil drying \\
\hline$\Xi_{m}$ & $\begin{array}{l}\text { correction for stability used in the estimation } \\
\text { of wind velocity profile for the eddy covariance } \\
\text { tower measurements }\end{array}$ \\
\hline$\rho_{a}$ & air density \\
\hline$\sigma$ & standard deviation \\
\hline$\sigma_{i}$ & moving standard deviation with time window $i$ \\
\hline$\phi$ & soil porosity \\
\hline$\Psi_{L, \text { depth }}$ & Matric potential measured in the lysimeter \\
\hline$\Psi_{s, \text { depth }}$ & Matric potential measured in the soil \\
\hline$\omega$ & angular frequency \\
\hline $\begin{array}{l}A_{1}, A_{2}, A_{3}, A_{4}, A_{5}, A_{6}, A_{7} \\
\text { C }\end{array}$ & $\begin{array}{l}\text { empirical parameters } \\
\text { clay }\end{array}$ \\
\hline
\end{tabular}




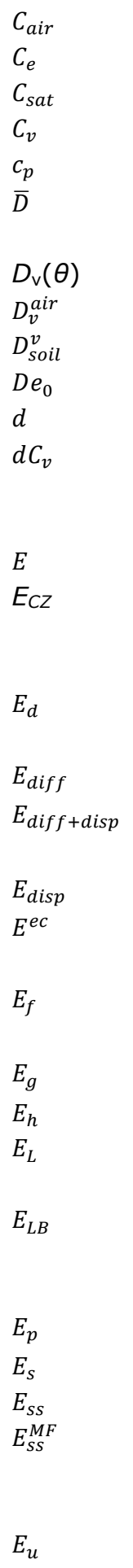

water vapour concentration in air water vapour transport coefficient saturated water vapour concentration water vapour concentration heat capacity liquid-saturation weighted-mean diffusivity of air in soil

diffusivity of water vapour through the soil diffusion coefficient of water vapour in free air diffusion coefficient of water vapour in the soil desorptivity

zero-flux plane depth

difference between water vapour fraction at saturation (in the soil) and in the air above the soil surface

\section{evaporation rate}

version of the pore-scale conceptual model for the second stage of evaporation, with defined thickness of the air-dry soil layer total evaporation of a drying event in the DA model

water vapour diffusion rate

water vapour mechanical dispersion, combined with water vapour diffusion water vapour mechanical dispersion evaporation rate obtained by measurements with an eddy covariance tower HYDRUS1D-simulated footprint evaporation rate.

groundwater evaporation rate hourly evaporation rates

Evaporation rate estimates obtained using the soil temperature variation model (Chapter 6) Evaporation rate estimates obtained using the soil temperature variation model and the barometric effect model (Chapter 6 )

evaporative potential rate

surface evaporation rate sub-surface evaporation rate sub-surface evaporation rate estimated for the maximum footprint area of an eddy covariance tower

unsaturated zone evaporation rate 


\begin{tabular}{|c|c|}
\hline$E_{V Z}$ & $\begin{array}{l}\text { version of the pore-scale conceptual model } \\
\text { incorporating the characteristic length for the } \\
\text { second stage of evaporation }\end{array}$ \\
\hline$E_{0}$ & parameter in the DA model \\
\hline ET & evapotranspiration rate \\
\hline$E T^{e c}$ & $\begin{array}{l}\text { evapotranspiration rate measured by an eddy } \\
\text { covariance tower }\end{array}$ \\
\hline$E T_{g}$ & groundwater evapotranspiration rate \\
\hline$E T_{\text {norm }}$ & normalised evapotranspiration \\
\hline$E T_{p}$ & potential evapotranspiration rate \\
\hline$E T_{s}$ & surface evapotranspiration rate \\
\hline$E T_{S S}$ & sub-surface evapotranspiration rate \\
\hline$E T_{u}$ & unsaturated zone evapotranspiration rate \\
\hline$E T_{0}$ & Priestley-Taylor potential evapotranspiration \\
\hline$f$ & arbitrary function \\
\hline $\mathrm{GW}_{\text {in }}$ & lateral groundwater inflow \\
\hline $\mathrm{GW}_{\text {out }}$ & lateral groundwater outflow \\
\hline$g$ & arbitrary function \\
\hline$H$ & sensible heat flux \\
\hline$h$ & arbitrary function \\
\hline$h_{b}$ & air entry value \\
\hline$i$ & width of time window (in days) \\
\hline$I$ & $\begin{array}{l}\text { water entering the column from the top } \\
\text { boundary }\end{array}$ \\
\hline$I_{e}$ & effective infiltration \\
\hline Int & rainwater intercepted by plants \\
\hline$k_{1}, k_{1}^{\text {inverse }}, k_{1}^{\text {direct }}, k_{2}, k_{3}, k_{4}$ & empirical parameters \\
\hline$k_{K}$ & von Kármán constant \\
\hline$K_{s}$ & saturated hydraulic conductivity \\
\hline $\mathrm{L}$ & 'liquid-only' simulation \\
\hline$L$ & $\begin{array}{l}\text { actual distance travelled by water vapour by } \\
\text { diffusion }\end{array}$ \\
\hline$L_{c}$ & $\begin{array}{l}\text { thickness of the intermediary zone by a } \\
\text { characteristic length }\end{array}$ \\
\hline Lv & coupled flows of heat, vapour and liquid water \\
\hline$l$ & $\begin{array}{l}\text { tortuosity parameter in the conductivity } \\
\text { function in the van Genuchten-Mualem model }\end{array}$ \\
\hline$n$ & number of samples in a statistic \\
\hline$n_{G M}$ & $\begin{array}{l}\text { van Genuchten Mualem (1980) model } \\
\text { parameter }\end{array}$ \\
\hline$P$ & precipitation \\
\hline$p$ & number of explanatory variables in a statistic \\
\hline$p_{\text {atm }}$ & atmospheric pressure \\
\hline$p_{0}$ & average surface pressure \\
\hline
\end{tabular}




\begin{tabular}{|c|c|}
\hline$p_{s}$ & saturated vapour pressure \\
\hline$p_{w}$ & $\begin{array}{l}\text { vapour pressure above the soil/lysimeter } \\
\text { surface }\end{array}$ \\
\hline$Q_{v}$ & vapour flow, \\
\hline$Q_{\text {in }}$ & lateral groundwater flow input \\
\hline Qout & lateral groundwater flow output \\
\hline$q_{\mathrm{L}}$ & flux density of liquid water \\
\hline$q_{\llcorner\Theta}$ & thermal liquid water flux density \\
\hline$q_{\mathrm{L \psi}}$ & isothermal liquid water flux density \\
\hline$q_{\mathrm{v}}$ & flux density of water vapour \\
\hline$q_{\mathrm{v} \Theta}$ & thermal water vapour flux density \\
\hline$q_{\mathrm{v} \psi}$ & isothermal water vapour flux density \\
\hline$R$ & water converted to saturated zone water \\
\hline$R_{0}$ & surface run off \\
\hline$r$ & $\begin{array}{l}\text { slope of the tangential line drawn to the } \\
\text { groundwater level curve }\end{array}$ \\
\hline RH & air relative humidity \\
\hline S & sand \\
\hline$S_{g}$ & $\begin{array}{l}\text { volumetric gas phase content in the soil } \\
\text { material }\end{array}$ \\
\hline$S_{n}$ & net short wave radiation \\
\hline$S_{y}$ & specific yield \\
\hline S1 & first stage of evaporation \\
\hline S2 & second stage of evaporation \\
\hline SI & sandy loam \\
\hline St & silt \\
\hline$s$ & $\begin{array}{l}\text { difference in the observed groundwater levels } \\
\text { over the } 24 \mathrm{~h} \text { period }\end{array}$ \\
\hline$T$ & transpiration rate \\
\hline$T_{a}$ & air temperature measured at $2 \mathrm{~m}$ height \\
\hline$T_{g}$ & groundwater transpiration rate \\
\hline$T_{L, \text { depth }}$ & temperature measured in the lysimeter \\
\hline$T_{\text {rad }}$ & radiometrically derived surface temperature \\
\hline$T_{s, \text { depth }}$ & temperature measured in the in-situ soil profile \\
\hline$T_{s, \text { vap }}$ & soil temperature at vaporization plane \\
\hline$T_{s s}$ & sub-surface transpiration rate \\
\hline$T_{u}$ & unsaturated zone transpiration rate \\
\hline$T_{S S}^{M F}$ & $\begin{array}{l}\text { transpiration estimated for the maximum } \\
\text { footprint area for an eddy covariance tower }\end{array}$ \\
\hline$t$ & time \\
\hline$u$ & wind speed \\
\hline $\bar{u}$ & wind speed averaged over a day \\
\hline$u^{*}$ & friction velocity \\
\hline
\end{tabular}




\begin{tabular}{|c|c|}
\hline$|V|$ & $\begin{array}{l}\text { the positive measure of the pore-scale velocity } \\
\text { of the gas phase } V\end{array}$ \\
\hline$X$ & a given variable \\
\hline $\bar{X}$ & $\begin{array}{l}\text { average of a given variable over the period } \\
\text { considered }\end{array}$ \\
\hline$X_{i}$ & $\begin{array}{l}\text { high pass filtered for a time window of width } i \\
\text { of a given variable }\end{array}$ \\
\hline $\bar{X}_{l}$ & $\begin{array}{l}\text { running mean for a time window of width } i \text { of } \\
\text { a given variable }\end{array}$ \\
\hline$\overline{\bar{X}}_{i}$ & $\begin{array}{l}\text { low pass filtered for a time window of width } i \\
\text { of a given variable }\end{array}$ \\
\hline$X_{m}^{t}$ & modelled value of a variable at time $t$ \\
\hline$X_{N}$ & $\begin{array}{l}\text { normalized and standardized of a given } \\
\text { variable }\end{array}$ \\
\hline$X_{0}^{t}$ & observed value of a variable at time $t$ \\
\hline$\overline{X_{0}}$ & $\begin{array}{l}\text { the mean of the observed variable over the } \\
\text { whole experiment }\end{array}$ \\
\hline$z$ & the vertical axis positive upward \\
\hline$Z_{\text {bot }}$ & soil model bottom boundary \\
\hline$Z_{D S L}$ & the depth of the vaporization plane \\
\hline$Z_{\text {top }}$ & soil model upper boundary \\
\hline$Z_{W T}$ & $\begin{array}{l}\text { depth from the ground surface to the water } \\
\text { table }\end{array}$ \\
\hline$z_{0}$ & roughness length \\
\hline$z_{0 m}$ & roughness length for momentum \\
\hline$z_{0 h}$ & roughness length for heat \\
\hline BC & Brooks and Corey (1964) soil hydraulic model \\
\hline $\mathrm{CHD}$ & cyclic heat dissipation method \\
\hline DA & daily-average \\
\hline DSL & air-dry soil layer \\
\hline EC & eddy covariance \\
\hline GW & $\begin{array}{l}\text { van Genuchten-Mualem for water retention } \\
\text { and conductivity in soils }\end{array}$ \\
\hline HFD & heat field deformation method \\
\hline$M B$ & Mariotte bottle weight \\
\hline MF & $\begin{array}{l}\text { Maximum Footprint area for an eddy } \\
\text { covariance tower }\end{array}$ \\
\hline$N S E$ & Nash-Sutcliffe efficiency coefficient \\
\hline NSRE & $\begin{array}{l}\text { numerical solution to the Richards' } \\
\text { equation conceptual model }\end{array}$ \\
\hline NTG & natural thermal gradient \\
\hline PdV & Philip and de Vries equations \\
\hline PS & pore-scale conceptual model \\
\hline TDP & thermal dissipation probes \\
\hline
\end{tabular}


VPD

WRC

WT

WTF

WTH air vapour pressure deficit

Water retention curve

Water table

Water table depth fluctuation method to estimate groundwater evaporation

water table height in a soil column, above the bottom boundary of the column 
Chapter 1

General Introduction 


\subsection{Scientific Background}

\subsubsection{Evapotranspiration process in semi-arid and arid areas}

The importance of determining all the water fluxes in a water balance of a soil, especially in semi-arid and arid areas, where water resources are scarce, is recognized (Qubaja et al., 2020). An accurate estimation of soil evaporation fluxes in such dry environments has many benefits: a good understanding of soil moisture dynamics improves not only quantitative assessment of water resources (Renzullo et al., 2014), but also conservative agricultural practices (Yaseen et al., 2020; Gwate et al., 2019; Jiang et al., 2019), ecosystem services management (Rotenberg and Yakir, 2010; De Laurentiis et al., 2019; Huang et al., 2016) and estimates of greenhouse gas emissions from soils (Smith et al., 2003; Ganot et al., 2014). Besides, estimates of groundwater losses through evaporation can help design sustainable groundwater extraction systems (Chenini and Mammou, 2010; Badreldin et al., 2017) and small scale water storage systems like sand dams and underground dams (Lasage et al., 2008; Quilis et al., 2009; Lafayette et al., 2019). This is especially relevant when considering that: (i) more than half of the terrestrial surface is arid or semi-arid and mostly bare (Katata et al., 2007; Verstraete and Schwartz, 1991; Warren, 1996); (ii) drylands are expected to increase in both extent and aridity in coming decades (Schlaepfer et al., 2017; Polade et al., 2017); and (iii) the demand for the limited groundwater resources is increasing (Scanlon et al., 2002; Guemarzi et al., 2019).

The water balance of a soil is the sum of its water input, output and storage change (Hillel, 2004; Brutsaert, 2005). In this thesis, soil refers to a system composed of a solid phase (soil mineral particles, soil organic matter), a liquid phase (mostly water) and a gaseous phase. Water can enter a soil as infiltration from the soil surface (the interface with the atmosphere), or laterally from the surrounding soil and from the parent material. Water exits a soil through lateral movement, percolation into the parent material, evaporation to the atmosphere, or uptake by plant roots. Water in a soil occupies the space between solid particles (soil porosity); a soil is defined as saturated by water if all pore volumes are occupied by the liquid phase (water) and unsaturated if liquid and gaseous phases are present in the pores. Water in a soil is subject to upward capillary forces, driven by differences in water pressure and downward gravity forces. The water that is not lost by evapotranspiration from the unsaturated zone and that moves downward, eventually reaching the saturated zone and accumulating over there as groundwater storage, is called recharge.

The liquid water that evaporates when directly in contact with the atmosphere is the surface evaporation $\left(E_{s}\right)$; it consists of evaporation from dew covering the soil, evaporation from open water bodies and evaporation of rain drops which hit the plants, wetting their leaves (interception). The water that 
reaches the soil surface starts to infiltrate, while the excess above maximum infiltration rate flows over the soil surface as Hortonian runoff. The water infiltrated into a soil can be taken up by plant roots (transpiration, $T$ ) but also lost by evaporation to the atmosphere as water vapour (subsurface evaporation, $E$ ). The sum of evaporation and transpiration processes is referred to as subsurface evapotranspiration ( $E T_{s s}$, Figure 1.1). The sum of surface evaporation $\left(E_{s}\right)$ and subsurface evapotranspiration $\left(E T_{s S}\right)$ represents total (actual) evapotranspiration (ET, Equation 1.1).

The subsurface evapotranspiration affects either the unsaturated zone by direct evaporation of soil moisture and by shallow root water uptake $\left(E T_{u}\right)$, or the saturated zone by upward water flux evaporated at the surface and by deep root groundwater uptake $\left(E T_{g}\right)$, Equation 1.1. $E T_{u}$ and $E T_{g}$ can be, then, sourced into their evaporation and transpiration components (Equation 1.2). The subdivision of $E T$ into $E$ and $T$ components is called partitioning, while the subdivision between groundwater and unsaturated zone fluxes is called sourcing.

$\begin{array}{ll}E T=E_{S}+E T_{S S}=E_{S}+E T_{u}+E T_{g} & \text { (ET partitioning) } \\ E T=E_{S}+\left(E_{u}+T_{u}\right)+\left(E_{g}+T_{g}\right) & \text { (ET sourcing) }\end{array}$

where $E_{u}, E_{g}, T_{u}, T_{g}$ are the unsaturated zone and groundwater evaporation, and the unsaturated zone and groundwater transpiration components, respectively (Figure 1.1).

Accurate evapotranspiration $(E T)$ calculations depend on the separate quantification of evaporation and transpiration components of ET (Lubczynski, 2000; Dhungel et al., 2019). The contribution of transpiration to the overall $E T$ depends among others on the proportion of vegetation cover (grass, shrub or trees) to bare soil (Qubaja et al., 2020; Adams et al., 2010; Villegas et al., 2015; Wei et al., 2017; Breshears, 2006). Considering vegetation, the largest water consumers are trees, so the overall transpiration of a given area depends on tree density and tree species type and composition. Arid and semi-arid areas are usually characterized by a savannah type of vegetation, in the Mediterranean climate typically represented by sparsely vegetated woodlands with a mosaic of individual trees and grasslands, with the latter turning into bare land for most part of a year. As in water limited environments the distances between trees are typically large, the evaporation from bare soils and grasslands is often the most important component of a hydrological balance (Lawrence et al., 2006; Wang, 2015).

An environment is considered to be water limited whenever the ratio of annual precipitation and potential evapotranspiration (explained in Section 1.1.2) ranges between 0.3 and 0.75 . Water limited environments are associated with arid or semi-arid areas. Water limited environments are characterized by long dry seasons with little or no precipitation (Parsons and Abrahams, 1994; Guswa et al., 2004) and large seasonal and daily changes in 
air temperature, relative humidity and erratic but intense precipitation. In the wet season the precipitation supplies water to intermittent streams that dry up in dry seasons. In dry seasons, the surface water is therefore generally scarce or not available for evaporation, while the soil moisture is depleted by evaporation or plant transpiration. The $E T_{g}$ often becomes the most important component of ET (Lubczynski, 2000; Lubczynski and Gurwin, 2005). During dry seasons, plants with shallow roots, especially grasses, tend to become dormant, senesce or wilt, so that $E T_{g}$ is driven mainly by vapour flow from bare soil $\left(E_{g}\right)$ and $T_{g}$ of deep-rooted plants tapping groundwater.

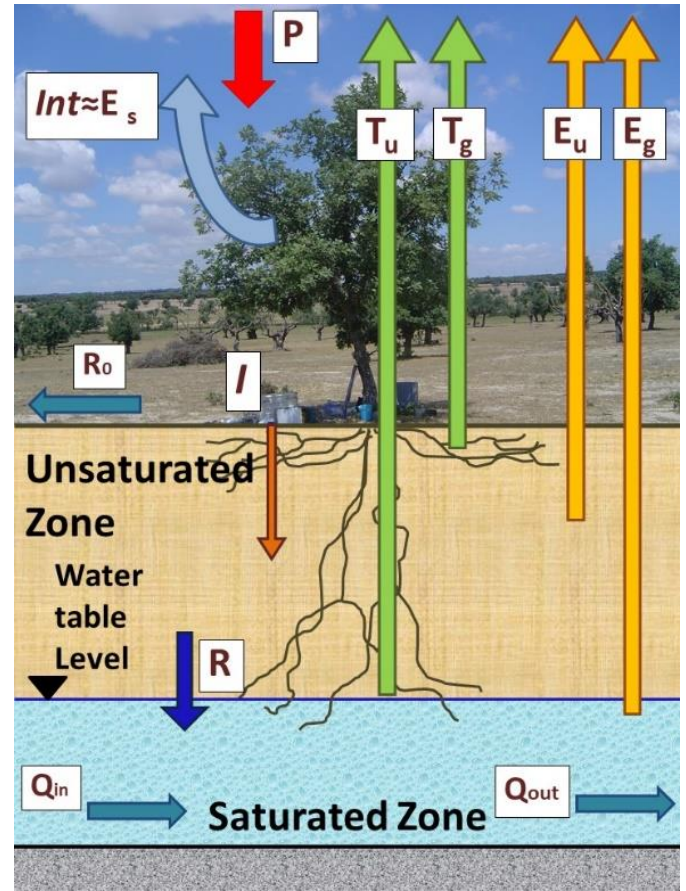

Figure 1.1: Schematic representation of a soil water balance in a water limited environment. $P$ is precipitation, Int is interception (which, in the absence of open water bodies or dew, is equal to surface evaporation $E_{S}$ ), $I$ is infiltration of rain into the soil, $R_{0}$ is surface runoff, $R$ is recharge, $Q_{\text {in }}$ and $Q_{\text {out }}$ are the lateral groundwater flow input and output into and from an assessed part of the saturated zone, and $E_{u}, E_{g}, T_{u}, T_{g}$ are the unsaturated and groundwater evaporation, and the unsaturated and groundwater transpiration components, respectively. In the figure, the lower boundary of the saturated zone is defined by the impermeable bedrock.

\subsubsection{Bare soil evaporation}

The evaporation of water from a soil depends on three conditions: (i) supply of sufficient energy for the phase transition (liquid to vapour); (ii) appropriate 
conditions for removal of water vapour from the gas phase in contact with the evaporating surface, referred to as vaporization plane in Figure 1.2, and from the soil surface (i.e. a way to prevent water vapour from saturating the air close to the evaporating surface); and (iii) availability of water in a soil (Schlünder, 1988; Shahraeeni et al., 2012; Suzuki and Maeda, 1968). The first two conditions are generally determined by meteorological factors, such as air temperature, humidity, solar radiation, wind speed; they, together, determine the evaporation rate that would occur if sufficient water was available, which is usually referred to as potential evaporation $\left(E_{p}\right)$. The combination of potential evaporation with the potential transpiration of plants is called potential evapotranspiration ( $\left.E T_{p}\right)$.

The rate of evaporation is constrained by either the potential evaporation at certain meteorological conditions, or by the availability of water in the soil, whichever is smaller (Van Brakel, 1980; Yiotis et al., 2006). Some of the conditions that affect the evaporation process are: (a) depth of groundwater table from the soil surface; (b) heterogeneity of a soil profile; (c) isothermal or non-isothermal soil conditions; (d) stability of atmospheric evaporative conditions, i.e. constant, fluctuating, or changing.

The process of evaporation from a porous medium (e.g. the soil), starting from near saturation conditions, is thought to consist of two main stages (Or et al., 2013; Brutsaert, 2014b): initially a high, relatively constant rate of evaporation, with the rate determined by the capillary water flow driven by potential evaporation (S1); followed by a lower and gradually decreasing evaporation rate, with the rate determined by the water vapour transport process in the porous medium (S2). During S1, the moisture is abundant in the porous medium close to its surface and is available for evaporation processes. Liquid water moves upward by capillary flow from the front of the saturated part of the porous medium, called a drying front (also referred as primary drying front, see Figure 1.2a; Yiotis et al., 2006; Shokri et al., 2008; Shokri et al., 2010) to the vaporization plane, which at S1 is at the ground surface, and evaporates. As the evaporation process continues, air starts invading some pores at the porous medium surface, in the order determined by their size, from the largest to the smallest pore (Wilkinson, 1986; Shaw, 1987). Therefore, the moisture content close to the surface decreases, the capillary pressure becomes more negative, until the liquid continuity between the drying front and the porous medium surface is disrupted, initiating the development of the air-dry soil layer (DSL) starting from the ground surface downward. This marks the beginning of S2, when water rises by capillary liquid flow from the saturated part of the porous medium delimited by the drying front and evaporates at the vaporization plane (also referred by some authors as the secondary drying front, the bottom boundary of the DSL), from where it moves to the ground surface as vapour. 


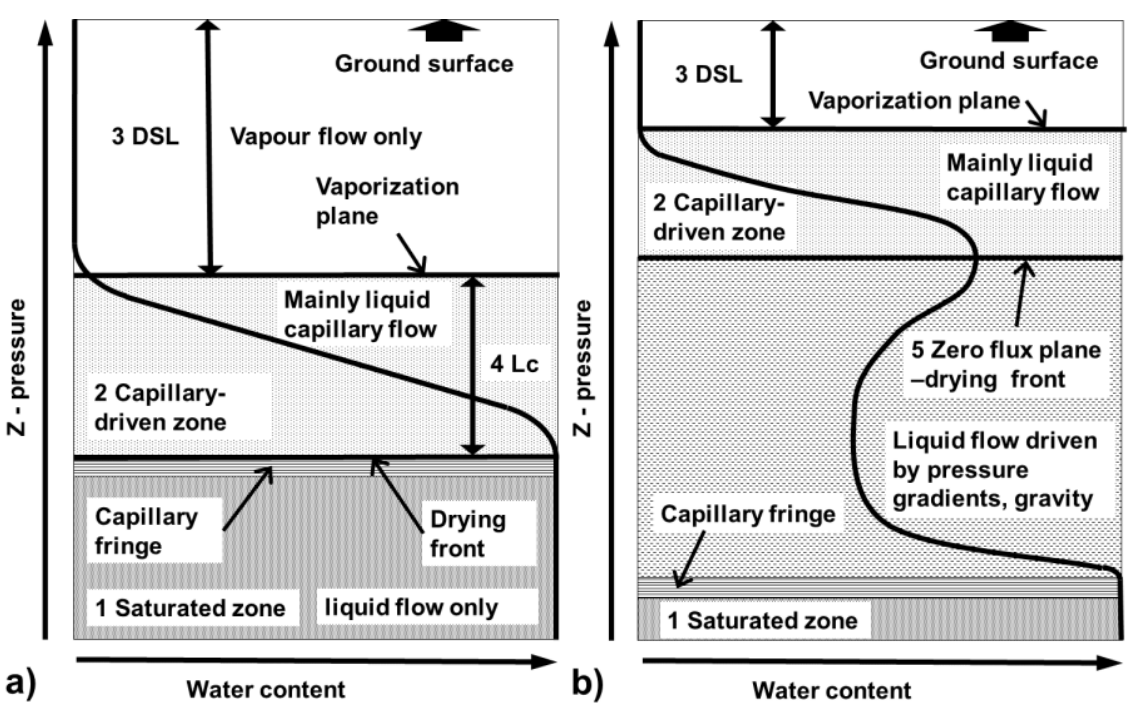

Figure 1.2: Schematics of the soil saturations during S2 evaporation: a) as observed in laboratory experiments close to hydrostatic equilibrium, with a shallow water table (modified after Shokri and Salvucci, 2011); b) in the presence of a deeper water table, some days after a rain event, as in Brutsaert (2014b); water below the zero-flux plane (indicated with 5 in figure) moves downward, so only the water above it is considered in the evaporation process. The two profiles are not in scale, with soil profile shown in b) deeper than the soil in a). The soil material profile is divided into three zones: (1) saturated zone, delimited by the water table and overlain by the capillary fringe, bounded at the top by a drying front; (2) capillary driven zone, where water moves upward by capillary forces from the drying front to the vaporization plane where it evaporates; and (3) a dry soil layer (DSL), where water moves only as water vapour. The black line is an example of the soil water saturation profile. $L_{c}$ ( 4 in the figure) is the critical height above the drying front at which capillary forces become too small to sustain hydraulic continuity (Or et al., 2013). Notice that the vaporization plane is referred by Brutsaert (2014b) as the (secondary) drying front.

According to Gardner and Fireman (1958), evaporation from a water table decreases with increasing water table depth. The hypothetical depth at which groundwater stops evaporating is called extinction depth (Shah et al., 2007). The estimated extinction depth is dependent on the way soil moisture flow is calculated, i.e., either considering only isothermal liquid water flow, or including water vapour transport, or thermal fluxes, etc. In case of a deep water table, with the soil initially wetted by a precipitation event, soil moisture either moves upward due to evaporation, or downward due to gravity and pressure forces, i.e. drainage (Figure 1.2b, Brutsaert, 2014b). Close to the soil surface the upward capillary forces are stronger than gravity, and liquid water 
moves upward; with increasing depth, however, the capillary forces decrease until they are in equilibrium with the downward gravity and pressure forces, defining a zero flux plane where water moves neither downward nor upward. The soil moisture below the zero flux plane will infiltrate downward, mainly by gravity forces (Zeng et al., 2009a).

In nature, evaporation processes will seldom follow the linear scenario as projected in Figure 1.2a. Field evaporative conditions change constantly, with cyclic variations, long term trends and random fluctuations. The cyclic variations can have different periods: daily, due to the Earth rotation; synoptic, due to atmospheric circulation; and seasonal, due to Earth orbit around the Sun. Precipitation events tend to concentrate in certain periods of the year, with some variations in their duration and intensity. This results in the presence of, for example, cycles of drying and wetting, condensation inside the soil, temperature gradients in a soil profile affecting water fluxes, formation of dew at the soil surface. The details at which these processes should be studied depend on the accuracy needed for the evaporation flux estimates. In the case of semi-arid areas and water limited environments, where evaporative conditions vary widely both daily and seasonally and where water is scarce, there is a need for accurate determination of evaporation.

\subsubsection{Estimating soil evaporation in field conditions}

There are two types of methods to estimate soil evaporation in the field, direct and indirect. The direct methods for the estimate of soil evaporation in the field are: (a) the gas chamber method, a relatively novel methodology for evaporation measurement, borrowed from studies of $\mathrm{CO}_{2}$ soil respiration (Qubaja et al., 2020; Lafayette et al., 2019); and (b) the soil lysimeter, i.e. a weighed column filled with the same soil as in the field, and subject to similar boundary conditions (Lopez-Urrea et al., 2006). The gas chamber method consists of placing a closed system, for example a transparent bucket, on top of a soil, and then measure the gas $\left(\mathrm{CO}_{2}, \mathrm{H}_{2} \mathrm{O}\right.$, etc...) concentration changes in the air trapped in a soil. The lysimeter method is based on direct measurement of mass change of a soil column, providing instant information on the amount of water stored and on the measurement of water discharged from the watersaturated part of the soil at the bottom of a column. The difference in weight between the wet column and the dry column gives the amount of water stored in the soil column. The evaporation from the column $(E)$ is the discharge from the top boundary, given as the decrease in weight in the column after subtracting the discharge from the bottom boundary and adding the input of water from the top boundary due to rain. $E$ can be sourced into $E_{g}$ and $E_{u}$ with a Mariotte bottle connected to the bottom of the column to keep the water level inside the lysimeter fixed: a decrease in weight of the lysimeter is identified as $E_{g}$ if the Mariotte bottle's weight decreases as well, and as $E_{u}$ otherwise. A lysimeter experiment in laboratory conditions is described in 
Chapter 5, while the same experimental setup placed in field conditions is presented in Chapter 6.

The indirect methods to estimate soil evaporation in the field are: (a) the measurement of groundwater fluctuations (to assess $E_{g}$ only); (b) the measurement of soil moisture variations in the soil profile; and (c) the measurement of water vapour fluxes in the atmosphere above a bare soil. The groundwater fluctuation method is based on the assumption that, in a closed system (e.g. a valley), the daily changes in $E T_{p}$ will result in a decrease in water table depth during a day, followed by a stabilization, or even a rise, due to lateral fluxes, of the water table during the night. Soil moisture variations at different depths can also be used to assess $E$, as they can inform about changes in unsaturated zone water storage (the "bucket method", Rushton et al., 2006); alternatively the flow of water through the soil can be modelled with a dedicated numerical model (Simunek et al., 2009). These two types of measurement techniques are described in detail in Chapter 2. The third method estimates the flow of water vapour from the soil to the atmosphere using micrometeorological methods, like the eddy covariance method, which allows direct observation of exchange of gas, energy and momentum (Baldocchi et al., 1988; Baldocchi and Meyers, 1988; Businger, 1986), or by using simultaneous measurements of vertical air temperature and humidity gradients to partition the energy balance (the Bowen ratio, Bowen, 1926; also Monteith and Unsworth, 2013). The eddy covariance method is considered in Chapters 3 and 4.

\subsubsection{Modelling soil evaporation}

Bare soil evaporation modelling is a complex task, due to the strong coupling between subsurface and atmospheric conditions, with the main issues being: the partial differential nature of the flow equations in the soil domain; difficulty in the solution of the Navier-Stokes equations in the atmospheric domain; and the exchange of heat and water between the two domains (Mosthaf et al., 2011; Mosthaf et al., 2014; Vanderborght et al., 2017; Fetzer et al., 2017). Different scientific communities focus on different aspects of evaporation, and parameterize the process in different ways. Hydrologists are usually interested in modelling subsurface fluxes at a scale relevant for their field studies, often by decreasing the level of detail in order to increase flexibility; soil physicists tend to study evaporation at the pore scale and in controlled conditions, while atmospheric scientists focus more on the atmosphere above the soil surface. When the focus is on the soil domain, the liquid water flow in the saturated and unsaturated zone is modelled using the Richards equation (1931) or the Philip and de Vries (PdV) equations (1957), usually in a form that considers only isothermal liquid water flow. These set of equations have been modified to include thermal water fluxes and/or water vapour diffusion (Simunek et al., 
2009; Saito et al., 2006); or to account separately for liquid and gaseous phases flow (Zeng et al., 2011b). When the focus is on the atmospheric domain, instead, the subsurface domain is usually simplified as a "resistance" term for the potential evaporation (Vanderborght et al., 2017; Lehmann et al., 2018), which is estimated by calculating the surface energy balance. That approach requires various assumptions, such as that: the effect of the air-dry layer on evaporation is negligible; the PdV equations can be linearized using an exponential decay function; the liquid water flow is isothermal; the effect of gravity is negligible; and the depth of the zero flux plane changes little as evaporation proceeds (Brutsaert, 2014b).

\subsection{Problem statement}

In hydrological studies addressing ET partitioning, the focus is usually on either soil evaporation or plants transpiration; this leads, first, to the determination of the overall evapotranspiration flux, then the determination of one of the two components, i.e. evaporation or transpiration, the other term is usually estimated as the difference between the studied component (e.g. transpiration only) and the other components of the water balance (soil moisture changes, precipitation and groundwater recharge; Baldocchi and Meyers, 1991; Paço et al., 2009). This is mostly due to the difficulty in reliably measuring the individual ET components at the ecosystem scale (Qubaja et al., 2020; Dhungel et al., 2019).

Only few studies tried to source evaporation, especially in semi-arid and arid areas, where bare soil evaporation is often neglected, particularly during the dry season (Wilson et al., 2001; Williams et al., 2004; Yaseef et al., 2010). Since there has not been a clear definition of the unsaturated and groundwater evaporation, these two fluxes were often lumped together and confused. The groundwater component of evaporation, $E_{g}$, is typically underestimated or even neglected, resulting in inaccurate estimates of net groundwater recharge that determines the sustainability of groundwater resources (Lubczynski, 2000; Lubczynski and Gurwin, 2005; Lubczynski, 2011; Reyes-Acosta and Lubczynski, 2011). A proper definition of the soil water balance should, therefore, focus on sourcing the evaporation between unsaturated and saturated components, considering different evaporative conditions.

Accurate evaporation modelling should include all the relevant processes responsible for the transport of water in the soil and across its surface. However, due to the complexity of the task, some physical processes that may be relevant in semi-arid areas are either ignored or simplified, mainly due to: laboratory experiments proving that a certain process is negligible; and assumptions and simplifications based on less arid conditions. The omission of physical processes can result in substantial underestimation of the evaporation from semi-arid and arid areas, both in shallow (1-5 m below ground soil, b.g.s., 
Sun et al., 2016) and in deep water table conditions (5-100 m b.g.s., Scanlon et al., 2007; Li et al., 2014).

Most of the insights on these processes come from laboratory experiments, which, as discussed in Section 1.1.2, may not be representative of field conditions that: (i) undergo wide changes in evaporative conditions at different time scales; (ii) have the soil moisture profile affected by water table depths that change dynamically and may range from less than one to several hundred meters. Other possible field conditions not accounted for in laboratory experiments are the presence of organic matter coating the soil particles and flush-type or continuous biological activity changing the soil medium properties and the water flow dynamics.

The simplification or the omission of several transport processes for water vapour in the soil profile may be based on assumptions that do not hold in semi-arid conditions, due to extremely low soil moisture, large changes in the soil temperature profile, etc. (Vanderborght et al., 2017). An example of the simplifications of the soil evaporation process that was shown not to be justified in semi-arid and arid areas is the omission or simplification of the DSL in the evaporation phase S2. Most atmospheric-focussed studies tend to ignore it on the basis that, at daily averaging, its effects seem to be negligible (Assouline et al., 2013; Brutsaert, 2014a), or to simplify it as a resistance term representing the coupling between the soil and the atmosphere at the soil surface (McColl et al., 2017a; McColl et al., 2017b; Mccoll et al., 2019). However, the field studies focussed on subsurface fluxes in the semi-arid areas show non-negligible effects of the DSL on the evaporation process, especially when the DSL thickness is more than $5 \mathrm{~cm}$ (Sun et al., 2016; Wang, 2015). Several studies demonstrated also that in arid, desert zones, evaporation can take place even from a very deep water table or deep soil moisture conditions. The evaporation from deep water tables is mainly due to upward water vapour flow through the mostly dry, tens to hundred meters thick, unsaturated zone (Walvoord et al., 2002; Scanlon et al., 2003; Scanlon et al., 2007; Li et al., 2014), showing the relevance of the usually neglected late $S 2$ evaporation and also the relevance of $E_{g}$.

Various studies have shown the inability of subsurface flow models to adequately represent the evaporation vapour flow in semi-arid and arid areas. Philip and de Vries (1957) included water vapour flow in their equations with an enhancement vapour transport term; however, there is a lack of evidence which supports this term (Ho and Webb, 1996; Webb and Ho, 1998). The inclusion of possibly relevant processes, such as vapour diffusion, thermaldriven water fluxes and gas phase advection, has been proposed (Saito et al., 2006; Zeng et al., 2011b; Vanderborght et al., 2017; Fetzer et al., 2017; Du et al., 2018). Subsurface flow models based on laboratory observations show that the vapour transport through a DSL can be explained by Fick's diffusion only (Grifoll et al., 2005; Grifoll, 2013), even though various field studies indicate that other relevant processes should be taken into account (Davarzani 
et al., 2014; Zeng et al., 2011b; Deol et al., 2014; Haghighi and Or, 2013; Rose and Guo, 1995). Another problem of most subsurface water flow models is the function used to represent the relationship between soil moisture and matric pressure potential (the soil water retention curve); the most used relationships are those from Brooks and Corey (1964) or from Van Genuchten (1980), but neither of them fit very dry soil conditions (Fayer and Simmons, 1995; Webb, 2000; Khlosi et al., 2008; Lu et al., 2008).

\subsection{Research objectives}

\subsubsection{Main objective}

The main objective of this research is to define a method to estimate separately the two components of soil evaporation, i.e. unsaturated zone evaporation $\left(E_{u}\right)$ and groundwater evaporation $\left(E_{g}\right)$, in semi-arid conditions.

\subsubsection{Specific objectives}

- Formulate a framework for the sourcing of subsurface evaporation into unsaturated and groundwater evaporation, and implement it in a subsurface, sourcing flow model (Chapter 2).

- Test the implemented framework in the field, and compare it with other methodologies to assess the contribution of the sourced evaporation and transpiration fluxes on the overall evapotranspiration (Chapter 3).

- Test the validity of the assumptions underlying three methods used to estimate soil evaporation in the presence of a dry soil layer (DSL). The tested assumptions are as follow: (a) that DSL has a negligible effect on soil evaporation; (b) that DSL can be approximated as a soil layer with soil moisture close to residual values; and (c) that water vapour flow through the DSL can be modelled using only Fick's diffusion (Chapter 4).

- Determine the main water vapour transport processes through a thick (>5 $\mathrm{cm}$ ) DSL under laboratory conditions resembling a semi-arid climate, with different water table depths. The two related objectives are to: (a) test the hypothesis that Fick's diffusion is the main process of water vapour transport in the DSL; and (b) test the correlation of late S2 evaporation rates with changes in solar radiation, wind speed and atmospheric pressure (Chapter 5).

- Validate findings of the laboratory experiment under field conditions (Chapter 6). 


\subsection{Research area}
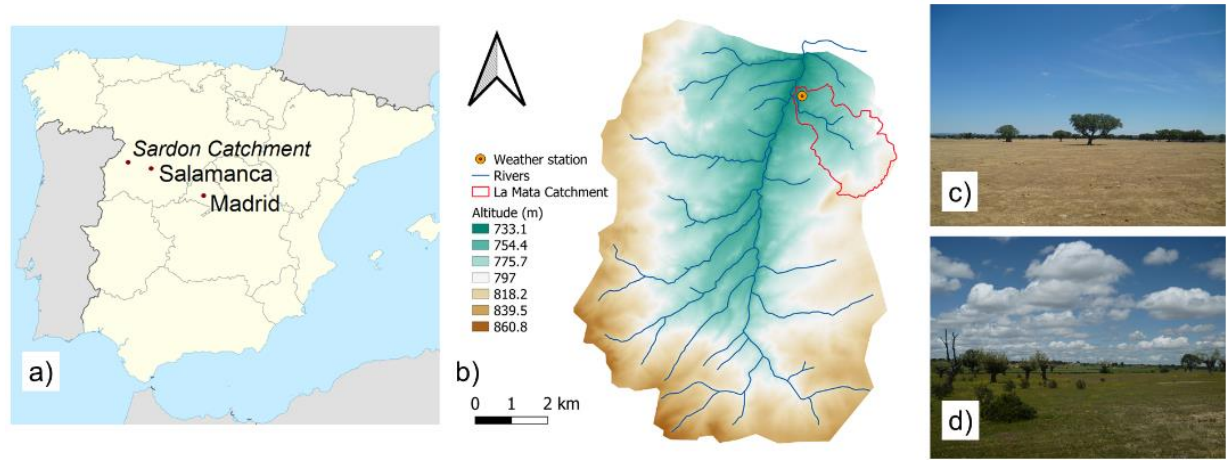

Figure 1.3: The study area: (a) location of the study area in Spain; (b) altitudinal map of the Sardon catchment, with the position of the weather station installed and the boundary of the La Mata sub-catchment highlighted; (c) the appearance of the study area in September; (d) the appearance of the study area at the beginning of May.

To achieve the research objectives highlighted in Section 1.3, a welldocumented semi-arid study area was selected in base of its climate, vegetation, morphology, hydrogeology, and data availability. The selected area (Figure 1.3) is located in the northern part of the Sardon Catchment, in the central-western part of the Iberian Peninsula, west of Salamanca, Castilla y León (Spain; latitude: 41.1172; longitude: 6.1471). The area has already been extensively investigated (Lubczynski and Gurwin, 2005; Mahmoudzadeh et al., 2012; Reyes and Lubczynski, 2013; Frances et al., 2014; Hassan et al., 2014; Reyes-Acosta and Lubczynski, 2014; Reyes-Acosta et al., 2015).

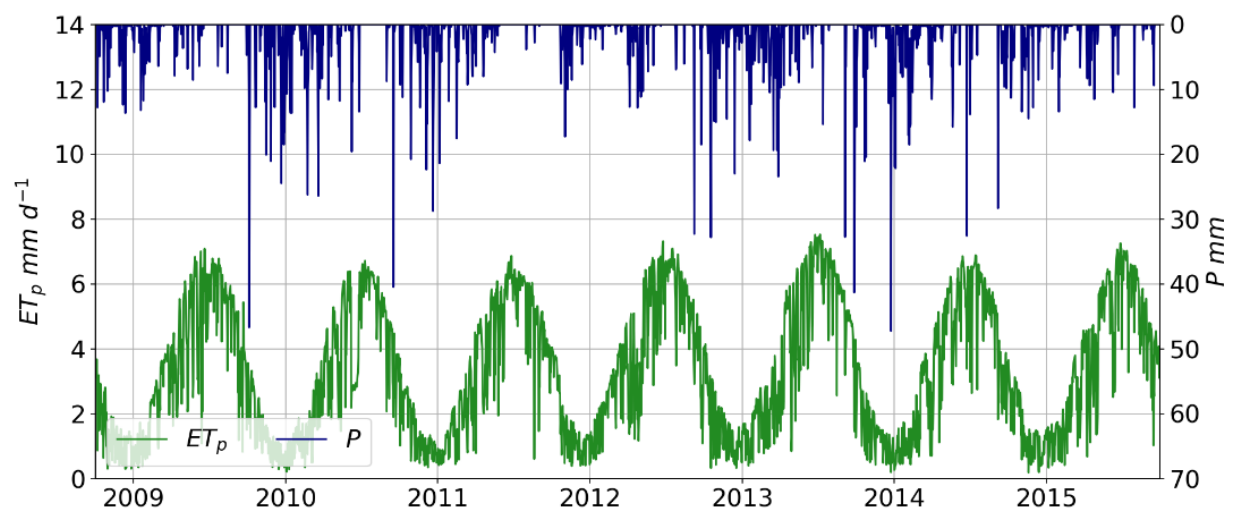

Figure 1.4: potential evapotranspiration $\left(E T_{p}\right)$ and precipitation $(P)$ in the study area, Spain, for the period 1 October 2008 to 30 September 2015 (a hydrological year in Spain lasts from 1 October to 30 September). $P$ was 
measured in-situ with a tipping bucket. $E T_{p}$ was calculated daily with Penman Monteith equation (Monteith, 1980), using data acquired in-situ with a weather station.

The semi-arid climate of the Sardon Catchment is typical of the central part of the Iberian Peninsula, with a mean yearly precipitation of $543 \mathrm{~mm}$ year-1 (1951-2012; the hydrological year goes from 1 October to 30 September, Hassan et al., 2014) and most of the rain events concentrated in spring (MarchMay, DOY 75-135) and fall (October-December, DOY 285-345); the difference in precipitations between years can be high, with driest years $300 \mathrm{~mm}_{\text {year }}{ }^{-1}$ and wettest years $900 \mathrm{~mm}$ year ${ }^{1}$. Figure 1.4 shows the daily potential evapotranspiration $\left(E T_{p}\right)$ and the daily precipitation $(P)$ in the area recorded in the period October 2008 - September 2016. The area experiences large differences in meteorological conditions between winter and summer. Winters are cold and humid, with relative humidity $(R H)$ often at $100 \%$, mean air temperature $\left(T_{a}\right) \sim 5{ }^{\circ} \mathrm{C}, 0.5 \mathrm{~mm} \mathrm{~d}^{-1} E T_{p}$, frequent but mild precipitation ( $P$ $<100 \mathrm{~mm} \mathrm{month}^{-1}$ ) and average wind speed $(u) \sim 2 \mathrm{~m} \mathrm{~s}^{-1}$. The summers (the dry season, June-September, day of the year DOY 165-265) are warm and dry, with $R H$ decreasing to $20 \%$ during a day, a mean $T_{a} \sim 20^{\circ} \mathrm{C}$, rare rainfall showers $\left(P<20 \mathrm{~mm}\right.$ month $\left.{ }^{-1}\right)$ and $u \sim 1.5 \mathrm{~m} \mathrm{~s}^{-1}$.

The morphology of the study area is typical for the Spanish Meseta: a rugged, savannah-like (dehesa) landscape with gentle slopes (mean slope = 2; Figure 3.2). The local geology is dominated by weathered and fractured granite (Lubczynski and Gurwin, 2005). The land cover consists of open woodland and sparse grasses that are green only for a short period between early spring and early summer (i.e. March-May) and which are predominately consumed by livestock while green so there are minimal senesced grasses present during the remainder of the year, leaving the soil essentially bare. Two tree species are dominant: evergreen oak (Quercus ilex) and broad-leaved deciduous oak (Quercus pyrenaica). Both are able to extract water not only from the unsaturated zone but also from the saturated zone using tap roots (David et al., 2007; Reyes-Acosta and Lubczynski, 2014).

The water table is shallow: 0-3 m b.g.s. in the valleys and 5-10 m b.g.s. in the hills (see Section 3.2.1). The water table change has a yearly amplitude of $2 \mathrm{~m}$ (Hassan et al., 2014), shallowest at the end of spring (March-April) and then getting deeper when the rain stops (end of May), reaching a maximum depth at the end of dry summer beginning of autumn (September-October), when the precipitation events become frequent enough to start to recharge the aquifer again. The area is sparsely populated $\left(1\right.$ person $\left.\mathrm{km}^{-2}\right)$ and the main activity, i.e. non-intensive farming, has low impact on the groundwater levels (Lubczynski and Gurwin, 2005).

The soil sampling campaign demonstrated that the soils in the area are the result of the weathering of the underlying granitic rocks. The thickness of the 
soil changes spatially, thinner in the upland $(0.5-1 \mathrm{~m})$ and thicker in the valleys ( $>3 \mathrm{~m}$ ). The soil texture does not change spatially in the area; it is essentially sandy $(80 \%)$ with some gravel (percentage varies with depth) and silt (10\%).

\subsection{Structure of the thesis}

Chapter 2: A framework of evapotranspiration partitioning and sourcing was developed to define both components of subsurface soil evaporation, i.e.: unsaturated zone evaporation $\left(E_{u}\right)$ and groundwater evaporation $\left(E_{g}\right)$. The framework was, then, implemented in a post-processing package (SOURCE) written in the Python language, to be used in combination with Hydrus1D, a one dimensional numerical model for water flow and solute transport in variably saturated porous media. A set of numerical experiments was performed to study the sourcing of subsurface evaporation in semi-arid conditions with various water table depths and some methods to estimate, separately, $E_{u}$ and $E_{g}$.

Chapter 3: The SOURCE package was tested in a field experiment to partition and source evapotranspiration in the semi-arid Sardon study area in Spain. The evapotranspiration was directly measured with an eddy covariance system; the tree transpiration was estimated using sap flow measurements and sourced into groundwater and unsaturated zone components using deuterium stable isotope; and subsurface evaporation was estimated and sourced into $E_{u}$ and $E_{g}$ using Hydrus1D model applying the SOURCE postprocessing package. The framework was able to partition and source $E T$ in the study area, even though the quality of Hydrus1D estimates decreased during the dry season when a DSL developed.

Chapter 4: Three methods to estimate evaporation through a DSL were tested against the evaporation measurements collected in a semi-arid area as explained in Chapter 3. The three methods were: (1) evaporation estimate as a daily average, with soil characteristics represented as a resistance term; (2) evaporation estimate by applying the numerical solution of the Philip and de Vries equations (1957) in a computer model (Hydrus1D+SOURCE); and (3) evaporation estimate by assuming hydrostatic equilibrium through the soil profile, with water moving through the DSL by diffusion only. None of the methods could model the evaporation dynamics observed by the eddy covariance system, with the main cause identified as the presence of a DSL in the area during the dry season.

Chapter 5: A laboratory experiment was designed to study the process of evaporation in the presence of a DSL, inspired by similar studies designed to determine the processes influencing $\mathrm{CO}_{2}$ soil respiration rates. The experiment consisted of directly measuring evaporation from soil columns with a DSL in the upper part of the soil; the correlations between the evaporation and various possible driving factors (temperature gradients, water vapour concentration 
gradients, pressure changes) were analysed to identify the main process responsible for the transport of water vapour through the DSL. The study explored also the relation between different DSL thicknesses and evaporation rates.

Chapter 6: The laboratory experiment as in Chapter 5 was tested under field evaporative conditions and compared to a numerical simulation performed with Hydrus1D and the SOURCE package. The experiment results were also compared with in-situ soil matric potential measurements to validate the results obtained in the laboratory. To do so, the soil column experiment was adapted to field conditions, i.e. was exposed to weather conditions changing daily and annually, including rain events. The experiment was placed in the semi-arid Sardon study area presented in Chapters 3 and 4 and the correlations between the evaporation and various possible driving factors were analysed (as in Chapter 5). The validity of the results was assessed by comparing the correlations found in the laboratory and the in-situ measurements. 


\section{Chapter 2}

A framework for sourcing of evaporation between saturated and unsaturated zone in bare soil condition 
A framework for sourcing of evaporation between saturated and unsaturated zone in bare soil condition

\section{Abstract:}

Sourcing subsurface evaporation $\left(E_{s s}\right)$ into groundwater $\left(E_{g}\right)$ and unsaturated zone $\left(E_{u}\right)$ components received so far little scientific attention despite its importance in water management and agriculture. We propose a novel sourcing framework, with its implementation in a dedicated postprocessing software called SOURCE (used along with Hydrus1D model), to: study evaporation sourcing dynamics, define quantitatively "shallow" and "deep" water table conditions, and test applicability of water table fluctuation (WTF) and "bucket" methods for estimation of $E_{g}$ and $E_{u}$ separately.

For the "shallow" and "deep" water table we proposed $E_{g}=0.95 E_{s s}$ and $E_{g}=0$ criteria's respectively. The assessment of the WTF method allowed sourcing very small fluxes otherwise neglected by standard hydrological methods. The sourcing with SOURCE software was more accurate than standard "bucket" method mainly because of greater flexibility in spatio-temporal discretization. This study emphasized dry condition relevance of groundwater evaporation, which should be analysed applying coupled flow of heat, water vapour and liquid water.

This Chapter is based on:

Balugani, E., Lubczynski, M.W. and Metselaar, K., (2016), A framework for sourcing of evaporation between saturated and unsaturated zone in bare soil condition. Hydrological Sciences Journal, 61(11): 1981-1995. 


\subsection{Introduction}

\subsubsection{Basic concepts}

Evaporation from bare soil is a large component in the water budget of arid and semi-arid areas; it can amount to $50-70 \%$ of total precipitation in a year (Baldocchi and $\mathrm{Xu}, 2007$ ). The ET is the sum of two different processes: (i) direct evaporation, $E$, which is a physical process of water removal from groundwater (groundwater evaporation), from soil (soil evaporation), from leaves (wet canopy evaporation or interception loss), from surface water bodies (pan evaporation), and (ii) transpiration of plants, $T$, which is a physiological process.

Partitioning of ET (see Section 1.1.1, Equations 1.1, 1.2, 1.3) is relevant to understand the role of plants in the water budget and is required to develop water management strategies e.g. in irrigation, groundwater protection, but also in stabilization of slopes. Recent attempts to partition ET have been stimulated by development of new techniques such as: (i) eddy covariance and Bowen ratio methods for measurement of total ET of a specific area (Brutsaert and Chen, 1995; Williams et al., 2004); (ii) sap flow techniques for measurement of $T$ (Cavanaught et al., 2010; Miller et al., 2010a); (iii) isotopic composition of the vapour to investigate the origin of the water vapour, i.e. estimate either $T$ or $E$ (Williams et al., 2004) and (iv) soil moisture profiling and lysimeters to estimate under-canopy evaporation (Wilson et al., 2001; Wang et al., 2010). The partitioning, however, cannot explain how much of the infiltrated rain water remains in the upper soil, being potentially available for plants, crops and soil evaporation, and how much reaches the saturated zone or capillary fringe hydraulically connected with water table. The knowledge of the source (sourcing) of evapotranspired water (i.e. the water storage zone affected by evaporation discharge) is vital for agriculture and water management activities.

The definitions of the partitioned and sourced water budget fluxes is explained in Section 1.1 and Equations 1.1, 1.2, and 1.3. In this Chapter, the subsurface components of evaporation $\left(E_{S S}\right)$ and transpiration $\left(T_{s S}\right)$ are introduced as:

$E_{s s}=E_{u}+E_{g}$

$T_{s s}=T_{u}+T_{g}$

where $E_{S S}$ and $T_{S S}$ are the subsurface evaporation and transpiration, respectively. However, the definitions given in Lubczynski and Gurwin (2005) for these fluxes have still to be expressed as quantitative, physical formulas specifying the conditions for which they hold, and have to be analysed in terms of their practical implications.

The sourcing of subsurface fluxes is already known in scientific literature. For example Williams et al. (2004) sourced tree transpiration in order to assess the effect of tree water uptake on groundwater resources. In areas that 
A framework for sourcing of evaporation between saturated and unsaturated zone in bare soil condition

experience water scarcity, the estimation of $E_{u}$ is important to understand the amount of unsaturated zone water effectively available to plants (Rockström, 2003), while the estimation of $E_{g}$ is required for sustainable use of groundwater resources. Knowing separate estimates of $E_{u}, E_{g}, T_{g}$ and $T_{u}$ is also important to understand the upward water fluxes in the soil profile, helping in the control and mitigation of salinization effects (Shah et al., 2007; Gran et al., 2011).

The water scarcity of arid and semi-arid climates increases the importance of groundwater resources. Without an accurate groundwater budget, aquifers cannot be exploited in a sustainable manner. The accuracy of a groundwater budget depends on determination of the $E_{g}$ that directly affects that budget. Neglecting $E_{g}$ by assuming $E=E_{u}$ can result in substantial water budget errors (Lubczynski, 2000, 2011; Lubczynski, 2009).

In this paper, we focus only on evaporation from soils with no vegetation (bare soil), and more precisely on sourcing $E_{s S}$ into $E_{g}$ and $E_{u}$, to understand the movement and availability of water in the subsurface. The sourcing of $E_{s s}$ in bare soils is particularly relevant in playas, dry lakes, arid areas where vegetation is absent or seasonally dormant (e.g. deserts, open woodlands and savannahs during dry seasons, see Cavanaugh et al., 2010), bare soil areas divided by patches of crops, and recently ploughed agricultural fields.

\subsubsection{Evaporation conceptual models in a sourcing context}

To explain the idea of sourcing, we show it using three types of conceptual models of evaporation: steady state, quasi-steady state and transient model.

\subsubsection{Steady state models}

The steady state condition occur when evaporative conditions and water table depth $\left(Z_{W T}\right)$ are both constant in time; the latter can for example occur in a wetland, where a shallow water table is in direct contact with soil surface so that the groundwater inflow balances the evaporation. In such case the rate of $E_{S S}$ depends on the evaporative condition at the soil surface (Hillel, 1998) and on the depth of the water table $\left(Z_{W T}\right)$. As shown by Gardner and Fireman (1958) and Ripple et al. (1972), when $Z_{W T}$ is so close to the surface that the upward water flow is not constrained by the soil hydraulic properties, $E_{S S}$ is equal to $E_{g}$ and to the potential evaporation $E_{p}$ (in such case, the water table is referred as "shallow"); with increasing $Z_{W T}$, the $E_{S S}$ decreases until it reaches an asymptotic value very close to zero at a depth that depends on soil hydraulic properties and that can be called "evaporation extinction depth", the term used by Shah et al. (2007), which matches the concept of zero flux plane (Section 1.1.2, Figure 1.2b, Zeng et al., 2009a; in such case, the water table is referred as "deep"). 


\subsubsection{Quasi-steady state models}

Meteorological and hydrological conditions are never steady state. The quasisteady state condition is assumed when the evaporative conditions are constant in time while the $Z_{W T}$ is allowed to change with time, for example in case of a no-flow boundary at the bottom of a closed column in laboratory conditions. In such case the three $Z_{W T}$ conditions (shallow, intermediate and deep water table) occur sequentially as a natural consequence of drying; these are similar to the two stages of evaporation (constant rate $\mathrm{S1}$, falling rate or early S2, and slow rate or late S2) distinguished after an infiltration event in a soil with a relatively shallow water table (Bavel and Hillel, 1976; Miyazaki, 1993; Brutsaert and Chen, 1995).

If the water table is shallow (e.g. $\sim 0.5 \mathrm{~m}$ deep with sand to clay materials), the evaporation will be at its potential maximum value, and $E_{g}=E_{p}$ because the water evaporates directly at the surface. These condition $\left(E_{g}=E_{p}\right)$ are often referred as "shallow water table", and are typical of wetlands (as in Sanderson and Cooper, 2008). The water evaporation results in a decline of the water table; at a certain $Z_{W T}$ the water will start to flow upward by capillarity from the saturated zone to the ground surface to be evaporated, so $E_{g} \leq E_{p}$, and $E_{g}$ will depend on the unsaturated hydraulic conductivity of the soil material and the gradient in water potential. If $Z_{W T}$ reaches a depth from which the liquid-water films cannot reach the ground surface anymore, $E_{g}$ becomes zero (Hillel, 2004). We will refer to these conditions as "deep water table" condition, and to the conditions that are neither "shallow" nor "deep" as "intermediate". When $E_{g}=0$, then $E=E_{u}$, and $E_{u}=P-R_{0}-I_{e}$, where $P$ is precipitation, $R_{0}$ is runoff, and $I_{e}$ is the "effective infiltration" (Zeng et al., 2009a), i.e. the water which continues to seep downward until it eventually reaches the aquifer and, hence, leaves the unsaturated zone and enters the saturated zone.

\subsubsection{Transient models including thermal and water vapour fluxes}

The assumption of steady evaporative conditions made for quasi-steady state models very often does not hold as temperature, humidity and solar radiation vary over large ranges in short (daily) and long (yearly) temporal scales. For example, in a desert, the soil skin temperature (the temperature at ground surface) can change by up to $40{ }^{\circ} \mathrm{C}$ over a day (Prigent et al., 1999) while in the lower soil profile is more stable. This creates strong soil temperature gradients which form and change every day, resulting in a continuous heat flow through the soil (the soil temperature gradients fluctuate during the year as well in response to changes in the daily average temperature at the soil surface). In such conditions, even if there is no hydraulic contact between the capillary fringe and the soil surface, i.e. groundwater-originated liquid-water films cannot reach ground surface, water is still able to evaporate from a certain depth of subsurface and to reach the surface in the form of vapour 
A framework for sourcing of evaporation between saturated and unsaturated zone in bare soil condition

driven by pressure, temperature and concentration gradients, passing through a dry soil layer (Gowing, Konukcu and Rose, 2006). Including the effects of changes in temperature throughout the profile, and including water vapour formation and flow, results in a set of highly nonlinear equations, and has to be solved using numerical methods.

\subsubsection{Measurement techniques for sourcing of $E_{s s}$}

$E_{g}$ can be measured by any method able to measure $E_{s s}$ (e.g. using eddy covariance methods or lysimeters) under the "shallow water table assumption", i.e. when $E_{u}=0$ and $E_{s s}=E_{g}$ (see Equation 2.1). Also the $E_{u}$ can be measured by any method able to measure $E_{S S}$ under the "deep water table assumption", i.e. when $E_{g}$ is assumed equal to zero so that the $E_{s s}=E_{u}$. Nevertheless, to use these two assumptions, a clearer definition of "shallow" and "deep" water table conditions is needed. For intermediate water table depth condition, in between "shallow" and "deep" conditions, the individual flux contributions of $E_{u}$ and $E_{g}$ in $E_{s s}$ are unknown and need to be sourced and measured with dedicated methods. In this Section, we focus on the measurement techniques that can contribute to the sourcing of the intermediate water table depth conditions.

Soil moisture sensor profiles can be used to estimate $E_{s s}$. The soil moisture sensors measure changes of water content in the unsaturated zone at different depths, which are integrated over the profiles to obtain the total change in unsaturated zone water storage (Rushton et al., 2006; this method will be referred from now on as "bucket model" method or just "bucket" method). However, this method is not very accurate: first, because of its assumption that the soil moisture in a layer of soil is equal to the soil moisture measured by a sensor positioned in that layer (which is often not realistic); second, because the low unsaturated zone water content in arid and semi-arid areas is usually beyond the detection threshold of most of soil moisture sensors (Vereecken et al., 2008); third, the probe measurement of soil moisture gives no information on the vapour flow in the soil (Lubczynski, 2009).

Stable-isotope profiling can be used to detect and quantify water fluxes in the soil, i.e. to perform sourcing of $E_{s S}$ (Walker et al., 1988; Allison, 1998). The method is based on the principle of isotopic fractionation of water molecules during evaporation. The evaporating water vapour is usually enriched in lighter isotopes, while remaining liquid water becomes increasingly enriched in heavier isotopes as the evaporating process goes on. In the "standard method" (Allison et al., 1983; Barnes and Allison, 1984, 1988), the knowledge of isotopic fractionation of soil moisture in the soil profile was used to simulate the liquid water fluxes in the soil, the dynamics of the vaporization plane and finally to estimate $E_{S S}$. In that method, however, the unsaturated zone water flow was not directly measured. Isotopes can also be injected in the soil and 
used as tracers to quantify the upward flow of liquid water in the soil profile (Scanlon and Milly, 1994; Scanlon, 2000; Scanlon, Keese and Reedy, 2003; Kwicklis et al., 2006). However, Grunberger et al. (2011) showed that, when the water fluxes are small (e.g. less than $10^{-1} \mathrm{~m} \mathrm{y}^{-1}$ ), the two methods (injection method and stable-isotope method) estimates of $E_{s s}$ do not compare well.

Another method that can be used to estimate $E_{g}$ in water budget studies is the "water table fluctuation method" (White, 1932; Loheide et al., 2005), which relies on the assumption that, in a valley landscape, the daily cycle of groundwater evapotranspiration from a shallow phreatic aquifer will result in a daily fluctuation of the water table (Lautz, 2008). In principle, this method can be used to calculate $E_{g}$ when: (a) water table is not "deep"; (b) the related fluctuation magnitude is big enough to be detected by water level recorders (pressure transducer and logger); (c) no vegetation influences that fluctuation; (d) the study takes place in a discharge area (only in discharge areas the water evaporated during the day can be replenished during the night from upstream areas); (e) when all other influences like barometric, Earth and Moon tides are filtered out. This method, however, to the best of our knowledge, has never been used to determine $E_{g}$ yet.

\subsubsection{Aim of the study}

There are many theoretical, laboratory and field studies on evaporation from bare soil; many of them source the evaporating water, either by focussing on unsaturated zone water or on groundwater, assuming the other source to be negligible. A more general approach, applicable to different evaporative conditions, should take into account both the water stored in the unsaturated zone and the water stored in the aquifer. An example is the use of a model, like in the study by Shah et al. (2007), to obtain an analytical expression for the relationship between $E_{g}$ and $E_{u}$, which can be later applied to the aquifer model in order to source the $E_{g}$ component of the water balance. Another possibility is to directly couple a numerical, vadose zone model to the aquifer model, in order to predict the water fluxes in the unsaturated zone, and dynamically adjust the sourcing depending on the evaporative conditions and water availability (Twarakavi et al., 2008).

None of the above mentioned measurement techniques for sourcing, however, takes into account heat and water vapour flow next to the liquid flow in the subsurface. Moreover, to clarify the evaporation sourcing framework, it is fundamental to define non-ambiguously the basic concepts necessary to formulate the $E_{s s}$ sourcing framework, i.e. to define the evaporative contributions of the two compartments (saturated and unsaturated zone) to the $E_{s s}$, the assumptions for "shallow" and "deep" water table, the term 
A framework for sourcing of evaporation between saturated and unsaturated zone in bare soil condition

"evaporation extinction depth" and the role of soil hydraulic properties in the water vapour transfer.

The aim of this Chapter is to propose a framework for the sourcing of $E_{S S}$ and to implement it as a post-processing package for Hydrus1D model, in order to show the consequences of the sourcing on evaporation, notably to refine calculation of groundwater recharge. In the sourcing framework, we take into account the vapour and heat flow along with capillary flow and evaluate their effect on the sourcing definitions. The Chapter is structured as follows: (a) synthesis and formulation of a sourcing framework; (b) implementation of a sourcing method based on the formulated framework; (c) analysis of case studies of sourcing soil evaporation using the proposed sourcing framework.

\subsection{Methodology: the proposed sourcing framework}

\subsubsection{Definitions}

\subsubsection{Definition of $\boldsymbol{E}_{g}$}

We define groundwater evaporation $\left(E_{g}\right)$ as the evaporative flux corresponding to the decrease of water stored in the saturated zone (groundwater) due to loss of water vapour at the soil surface. The result of $E_{g}$, in case of no external water inputs or outputs (i.e. a closed column), is a decline of water table, i.e. increase of $Z_{W T}$ in time: $d Z_{W T} / d t>0$; Figure 2.1. In case of bare soil $(T=0)$, with no water input from top boundary and no flow boundary condition at the bottom, groundwater evaporation $E_{g}$ is:

$E_{\mathrm{g}}=\left(\theta_{\text {sat }}-\theta_{\mathrm{r}}\right) \frac{\mathrm{d} Z_{\mathrm{WT}}}{\mathrm{d} t}$

where $\theta_{\text {sat }}$ is the water content at saturation, $\theta_{\mathrm{r}}$ is the residual water content (the assumption is that the water content in the soil is never below $\theta_{\mathrm{r}}$ value), $Z_{W T}$ is the water table depth ( $z$ is depth, which is zero at surface and positive downward) and $t$ is time; the $E_{g}$ is considered positive when the water table depth is increasing $\left(d Z_{W T} / d t>0\right)$ and negative when decreasing $\left(d Z_{W T} / d t<0\right)$.

In the closed column experiment, changes in water table depth are driven by $E_{g}$, so are related to the loss of free water content of the saturated zone, which is equal to the difference between saturation and residual water contents $\left(\theta_{\text {sat }}-\theta_{\mathrm{r}}\right)$. The term $\theta_{\mathrm{r}} \frac{\mathrm{d} z_{\mathrm{WT}}}{\mathrm{d} t}$ represents the residual water content left in the unsaturated zone after the evaporation process which is not evaporated and, hence, not counted in $E_{g}$. 


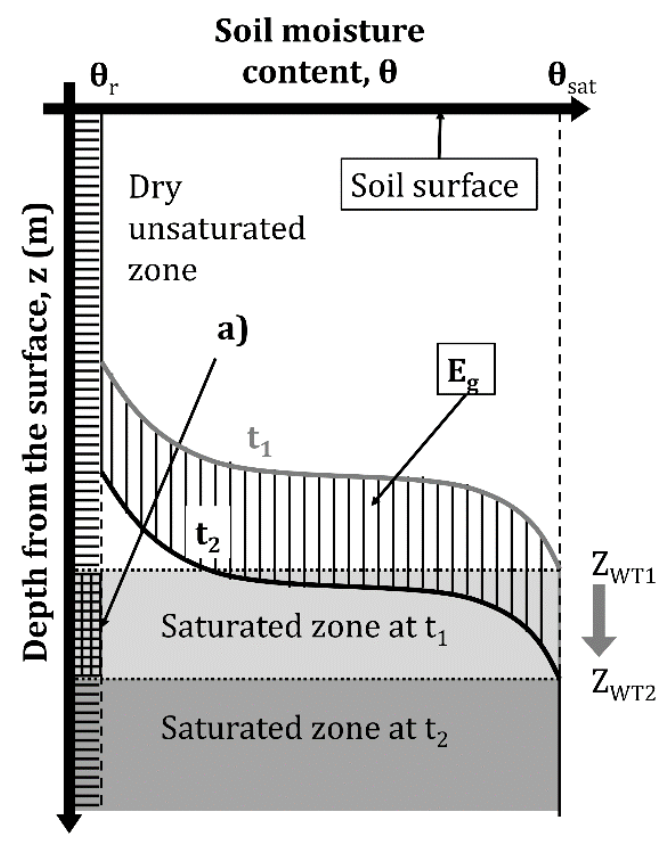

Figure 2.1: Graphic representation of $E_{g}$ in closed soil column with falling water table; $\theta_{\mathrm{r}}$ is residual water content; $\theta_{\mathrm{sat}}$ is saturation water content; the two curves represent two soil moisture profiles with depth, at the beginning $\left(t_{1}\right)$ and at the end $\left(t_{2}\right)$ of the groundwater evaporation $\left(E_{g}\right.$ - area between the two curves marked by vertical line shading) process, corresponding to water table decline from $Z_{W T 1}$ to $Z_{W T 2}$ respectively; a) is water converted to unsaturated zone water due to falling water table (squared grid).

\subsubsection{Definition of $E_{u}$}

We define unsaturated zone evaporation $\left(E_{u}\right)$ as the evaporative flux at the soil surface (Figure 2.2) corresponding to the decrease of water stored in the unsaturated zone. Assuming no infiltration events (no input of water from the upper boundary $Z_{\text {top }}$ ) and absent or very deep water table (no input of water from the bottom boundary), then:

$E_{u}=-\frac{\mathrm{d}}{\mathrm{d} t} \int_{Z_{\mathrm{top}}}^{Z_{\mathrm{WT}}} \theta \mathrm{d} z$

where $\theta$ is soil moisture. The $E_{u}$ term is considered a positive quantity when the amount of soil moisture in the soil is decreasing, hence the minus sign in the Equation 2.4.

If we want to take into account precipitation events, than we should include the infiltration term ( $I$, water entering the column from the top boundary) and the recharge term $(R$, water converted to saturated zone water); we obtain, then: 
A framework for sourcing of evaporation between saturated and unsaturated zone in bare soil condition

$E_{\mathrm{u}}=-\frac{\mathrm{d}}{\mathrm{d} t} \int_{Z_{\mathrm{top}}}^{Z_{\mathrm{WT}}} \theta \mathrm{d} Z-R+I$

Finally, if we want to include the presence of a water table in the soil profile, we must include the water converted from saturated zone to unsaturated zone water (and vice versa) when the water table is moving upward due to recharge $(R)$ or downward due to groundwater evaporation $\left(E_{g}\right)$. The resulting $E_{u}$ is then: $E_{\mathrm{u}} \Delta t=-\Delta S_{\text {unsat }}+\theta_{\text {sat }}\left(Z_{\mathrm{WT} 2}-Z_{\mathrm{WT} 1}\right)$

where $\Delta t=t_{2}-t_{1}, \Delta S_{\text {unsat }}$ is the change in water stored in the unsaturated zone and $Z_{W T 1}$ and $Z_{W T 2}$ are the vertical positions of the water table at time $t_{1}$ and $t_{2}$ respectively. The derivation of the Equation 2.6 is included in Appendix 2.6.1.

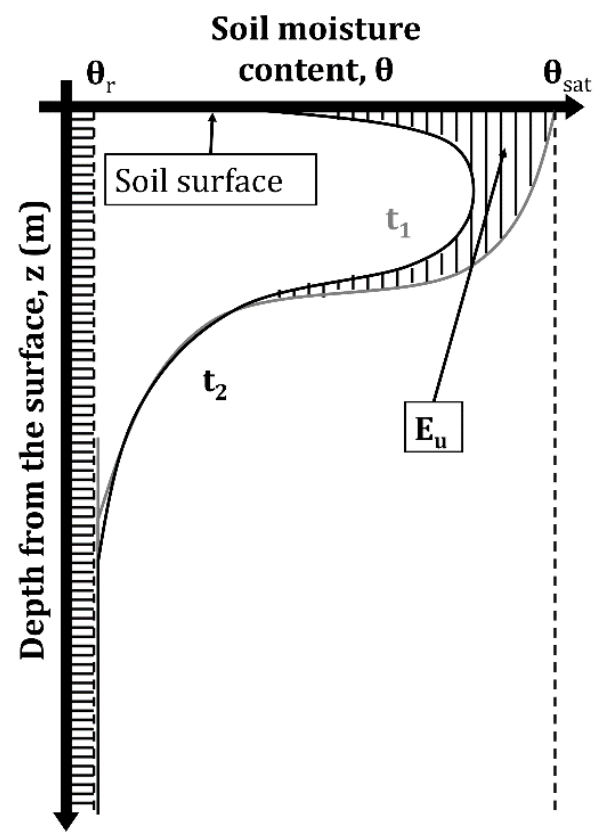

Figure 2.2: Graphic representation of $E_{u}$ under stable evaporative conditions and large $Z_{W T}$, i.e. absent saturated zone; $\theta_{\mathrm{r}}$ is residual water content; $\theta_{\text {sat }}$ is saturation water content; the two curves represent two soil moisture profiles with depth, at the beginning $\left(t_{1}\right)$ and at the end $\left(t_{2}\right)$ of the unsaturated zone evaporation ( $E_{u}$ - area between the two curves marked by vertical line shading) process. 


\subsubsection{Application to the conceptual models}

\subsubsection{Steady state condition}

If no changes in time in the soil moisture profile take place, then $E_{u}=0$. In such steady-state condition, the $E_{S S}=E_{g} \neq 0$ only if water is supplied continuously to the system, for example as lateral groundwater inflow $\left(G W_{i n}\right)$ with rate equal to $E_{g}\left(G W_{i n}=E_{g}\right)$, rate which can be calculated following Gardner and Fireman (1958):

$G W_{i n}=E_{\mathrm{g}}=E_{\mathrm{ss}}=\frac{a\left(\frac{\partial \Psi_{\mathrm{s}, 0}}{\partial x}-1\right)}{h_{\mathrm{s}}^{\mathrm{n}}+b}$

where $\Psi_{s, 0}$ is pressure head at the surface, and $a, b, n$ are empirical constants dependent on soil type. However, the Equation 2.7 does not take vapour flow into account.

If the water table is at large depth so that there is a dry soil layer (DSL) at the shallow subsurface with soil moisture at the residual state, then the evaporation takes place at the lower boundary of that soil layer, called "vaporization plane". In such case the water moves in vapour state from the vaporization plane to the soil surface and is not accounted for in the Equation 2.7. The solution for such transport (by Fick's diffusion) is given in Equation 2.8 (Gardner, 1958, Gowing et al., 2006).

$E_{\mathrm{g}}=E_{\mathrm{ss}}=Q_{\mathrm{v}}=D_{\text {soil }}^{v} \frac{\left(p_{s}-p_{w}\right)}{Z_{D S L}}$

where $Q_{\mathrm{v}}$ is vapour flow, $p_{w}$ is vapour pressure, $p_{s}$ is the saturated vapour pressure at atmospheric temperature, $D_{\text {soil }}^{v}$ is the diffusivity of water vapour through the soil (which is the limiting factor for $E_{S S}$, and may be calculated as in Rose, 1963) and $Z_{D S L}$ is the depth of the vaporization plane.

The highest steady-state evaporation rate is reached when water table is at the surface (depth $=0$ ) and the lowest when the water table is too deep to reach the surface by capillary flow so the water flow through the unsaturated zone depends entirely on the vapour flow.

\subsubsection{Quasi-steady state condition}

In a quasi-steady state condition of a saturated, closed soil column (no flow bottom boundary condition) which dries due to constant evaporative conditions at the top boundary, $E_{S S}=E_{g}+E_{u}$ and the definitions of $E_{g}$ and $E_{u}$ as in Equations 2.3 and 2.6 can be applied: the $E_{g}$ can be calculated from the drop of the water table, and the $E_{u}$ is equal to the change in soil moisture in the unsaturated zone in time, minus the amount of soil moisture converted from saturated zone water to unsaturated zone water:

$E_{\mathrm{Ss}}=E_{\mathrm{g}}+E_{\mathrm{u}}=\left(\theta_{\mathrm{sat}}-\theta_{\mathrm{r}}\right) \frac{\mathrm{d} Z_{\mathrm{WT}}}{\mathrm{d} t}-\Delta S_{\text {unsat }}+\theta_{\mathrm{sat}}\left(Z_{\mathrm{WT} 2}-Z_{\mathrm{WT} 1}\right)$

If $Z_{W T}$ is at the soil surface, no unsaturated zone exists, and Equation 2.9 simplifies to the steady-state conditions of Equation 2.7. When there is no liquid water connection between the saturated zone and the soil surface, $E_{g}$ depends on the flow of water vapour. In general this water vapour flow tends 
A framework for sourcing of evaporation between saturated and unsaturated zone in bare soil condition

to reach steady state (Equation 2.8) with time; this concept is in Walvoord, Phillips, et al. (2002) and in Walvoord, Plummer, et al. (2002), though it is referred there to as "long-time transient" state that "appears as a steady state"; i.e. the rates are so small that it seems that no change occurs.

Another case of quasi-steady state condition is that in which the top boundary condition allows $E_{p}$ to change in time while the water table depth remains constant due to the lateral groundwater inflow $\left(G W_{i n}\right)$ compensating evaporative loss the $E_{g}$. In this case, the $E_{s s}$ can be expressed as follows:

$E_{\mathrm{ss}}=E_{\mathrm{g}}+E_{\mathrm{u}}=\mathrm{GW}_{\mathrm{in}}-\frac{\mathrm{d}}{\mathrm{d} t} \int_{Z_{\mathrm{top}}}^{Z_{\mathrm{WT}}} \theta \mathrm{d} Z$

\subsubsection{Transient state condition}

A realistic soil evaporation is when transient conditions are taken into account, i.e. when all state variables change in time, along with the boundary conditions at the soil surface (the evaporative conditions) and at the bottom of the soil domain (i.e. water table changes in time due to evaporation, recharge and lateral flow from the aquifer). The $E_{u}$ and $E_{g}$ fluxes are calculated, then, as follows:

$E_{u} \Delta t=-\Delta S_{\text {unsat }}+R \Delta t-\Delta \theta_{\mathrm{f}-\mathrm{r}}$

$E_{\mathrm{g}} \Delta t=\theta_{\text {sat }}\left(Z_{\mathrm{WT} 2}-Z_{\mathrm{WT} 1}\right)-R+\left(\mathrm{GW}_{\mathrm{in}}-\mathrm{GW}_{\text {out }}\right) \Delta t+\Delta \theta_{\mathrm{f}-\mathrm{r}}$

where $\left(G W_{\text {in }}-G_{\text {out }}\right)$ is the term representing the net flow across the bottom of the soil profile; $\Delta \theta_{\mathrm{f}-\mathrm{r}}$ is the amount of water exchanged between saturated and unsaturated zone due to rising or falling of water table. The mathematical justification and derivation of the Equations 2.11 and 2.12 is included in Appendix 2.6.2.

Concluding, in order to source evaporation in transient conditions, it is necessary to:

- $\quad k n o w Z_{W T}$ for every time step;

- know the $\theta_{\text {sat }}$ and $\theta_{\mathrm{r}}$ of the soil material at every depth;

- know $E_{p}$ and quantity of water infiltrating at the top of the profile;

- calculate the soil moisture profile changes by calculating the coupled flows of heat, vapour and liquid water.

\subsubsection{The Hydrus1D model}

The proposed framework for evaporation sourcing has been implemented using a 1D model able to calculate the coupled flows of heat, vapour and liquid water depending on boundary conditions which are allowed to change in time. The Hydrus1D model (Simunek et al., 2009) has been selected because it permits the implementation of different physical processes listed in Section 2.1.2; it is widely used and tested and it is freely downloadable from the PC-PROGRESS webpage. The Hydrus1D version 4.14 solves either the liquid water flow only, or the coupled flows of heat, vapour and liquid water (Saito et al., 2006), see 
Appendix 2.6.3). The Hydrus1D gives as output the soil moisture content at any node of the model, and the total water balance of the simulated porous media (including evaporation). The output from Hydrus1D, hence, can be used to feed the equations of Sections 2.2.1 and 2.2.2; however, it does not directly source evaporation.

\subsubsection{The SOURCE package}

Hydrus1D output includes fluxes of liquid water and vapour calculated in each node of the soil profile (NOD\INF file), the output and input fluxes at the top and bottom boundaries for every time step and the total amount of water in the system ( $T \backslash L E V E L$ file). We developed and implemented a post-processing package, which we called "SOURCE", to calculate $E_{g}$ and $E_{u}$ using Hydrus1D simulation output. The SOURCE package is written in Python programming language (Ascher et al., 2001). It takes the ASCII output files of the Hydrus1D simulation as input and, depending on the particular boundary conditions chosen for the model, calculates the sourced evaporation fluxes, both for every time step and as an average over the period of the simulation. The result of the calculation is printed in an output file. In addition to these calculations, the model also provides a quality flag which defines differences between $E_{u}$ values calculated with two different, independent water balances, one using the node fluxes in the NOD\INF output from Hydrus1D, the other one using the calculation of $E_{g}$ from $E_{s s}$ from the TLLEVEL file, where the boundary fluxes are given; the flowchart explaining the functioning of the SOURCE package is presented in Figure 2.3.

The sourcing dependence on the bottom boundary conditions is as follow: (1) in case of quasi-steady state conditions with constant $Z_{W T}$, Equation 2.10 is applied, (2) in case of transient condition with changing $Z_{W T}$, knowing $Z_{W T 1}$ and $Z_{\text {WT2 }}$ for every time step, Equations 2.11 and 2.12 are applied, (3) in case of transient condition but in a soil profile isolated from the aquifer (no-flow boundary), Equation 2.6 is applied. In case of steady state, no sourcing is required since $E_{s s}=E_{g}$. 
A framework for sourcing of evaporation between saturated and unsaturated zone in bare soil condition

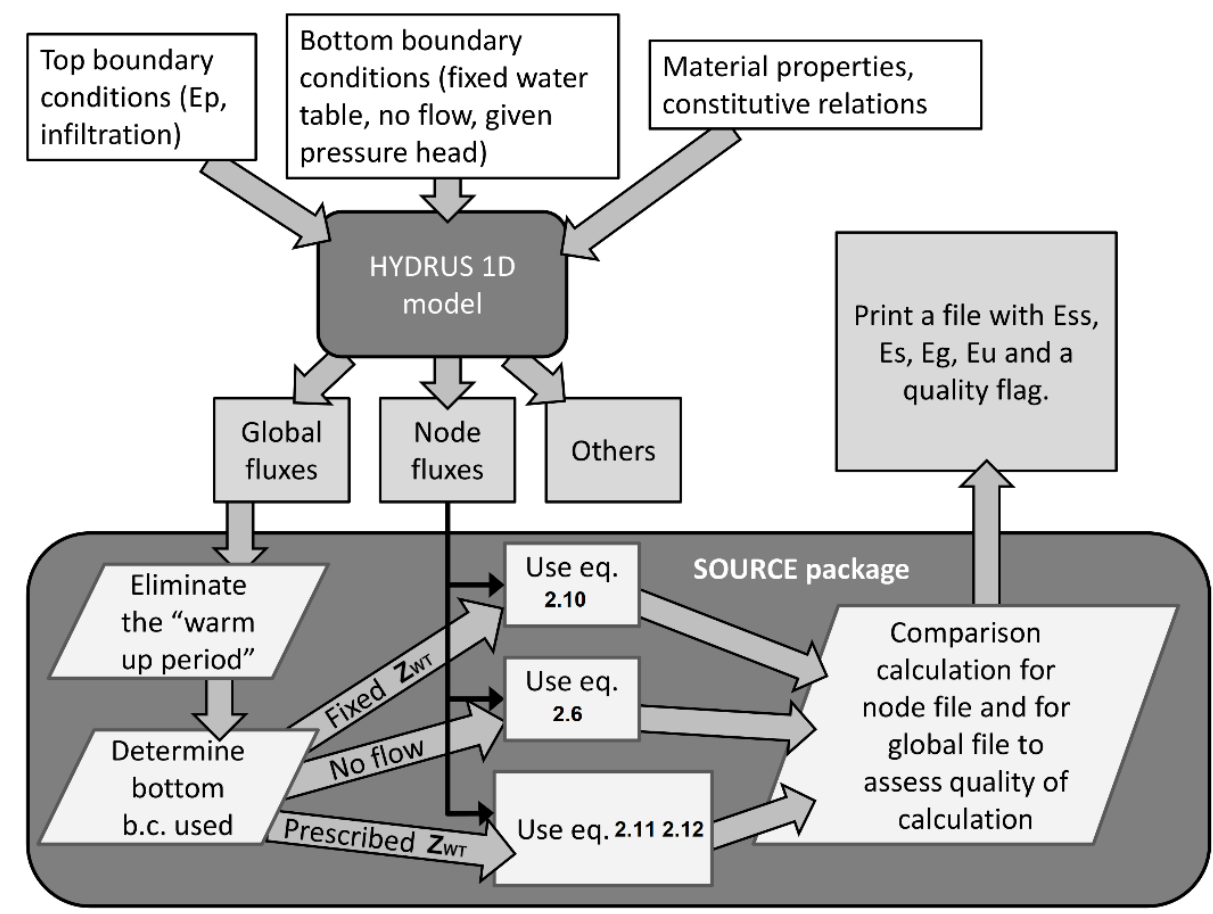

Figure 2.3: Flowchart showing the implementation of the proposed framework in the SOURCE package.

\subsubsection{Simulations}

To investigate the consequences of the application of the presented framework, the SOURCE package has been used to source the evaporation calculated by Hydrus1D in a series of simulations with the following two objectives: (a) to test the definitions of "shallow" and "deep" water table assumptions, using the quasi-steady state conditions, and to study how these assumptions hold with daily changes in the water fluxes; (b) to test the ability to source $E_{S S}$ of two measurement techniques such as: the water table fluctuation method (Gribovszki et al., 2010) and the "bucket method" (in the implementation by Wilson et al., 2001).

\subsubsection{Quasi-steady state: "shallow" and "deep" water table simulations}

We prepared two numerical experiments to check the definitions of: (i) "shallow water table assumption", where $E_{g} \sim E_{s S}$, and (ii) "deep water table assumption", where $E_{u}=E_{S S}$. We repeated both numerical experiments two times: first using Hydrus1D model with only liquid water flow, and then using Hydrus1D solving the coupled flows of heat, vapour and liquid water. 
The "shallow water table" numerical exercise aimed at determining the depth at which $E_{g} \sim E_{s s}$; the exercise was setup and modelled with Hydrus1D as follows: (a) shallow soil profile ( $1.0 \mathrm{~m}$ deep) with vertical discretization of 100 nodes per metre; (b) different homogeneous soils such as sand, silt and clay varied in between simulations applying standard Hydrus1D soil material properties; (c) different bottom boundary conditions of constant water table depth $\left(Z_{W T}\right)$ commonly referred as shallow (for example by Johnson et al. 2010) such as: $0.1,0.2,0.3,0.4,0.5,1.0 \mathrm{~m}$; (d) top boundary conditions setup as fluctuating evaporative conditions, using the dataset for day 27 July 2010 from semi-arid area Sardon, Spain and repeated for the whole simulation period of 30 days; in this data set, in the day 7 , a rain event was simulated to check if $E_{u}$ was still $\sim 0\left(2 \mathrm{~mm} \mathrm{~h}^{-1}\right.$ rain for a duration of $\left.5 \mathrm{~h}\right)$; run-off was not taken in to account; (e) initial conditions of hydraulic equilibrium.

The "deep water table" numerical exercise (aimed at determining the depth at which $E_{g} \sim 0$ ) was prepared as the "shallow water table" except that we used: (a) soil profile $4.0 \mathrm{~m}$ depth; (b) water table depths: $0.5,1.0,1.5,2.0,2.5$, $3.0,3.5 \mathrm{~m}$; (c) simulation period $=200 \mathrm{~d}$, without any rain event, in order to focus on the evaporation extinction depth.

\subsubsection{Water table fluctuation simulations}

The water table fluctuation method seems promising to obtain direct measurements of $E_{g}$ in the field conditions. We, hence, tested its performance with a numerical exercise (from here onwards referred as "water table fluctuation simulations", WTFS) aimed at observing water table fluctuation in the Hydrus1D model (coupled flows of heat, vapour and liquid water) and calculating the related $E_{g}$ using two methods: (i) the standard technique from Gribovszki et al. (2010), which from here onwards will be referred as "WTF" (water table fluctuation) method and (ii) the SOURCE package.

With Hydrus1D we executed a simulation with: (a) shallow soil profile (2.0 m deep) with vertical discretization of 100 nodes per metre; (b) two types of soil material hydraulic properties were considered: sandy loam standard material from Hydrus1D dataset (referred as "standard") and sandy loam material actually observed in the field (Sardon, Spain; material referred as "field"); the van Genuchten-Mualem $(1980,1984)$ parameters for the two soil materials are shown in Table 2.1); (c) no flow bottom boundary condition; (d) top boundary conditions setup as fluctuating evaporative conditions, using the dataset for day 27 July 2010 from semi-arid area Sardon, Spain, repeated for the whole simulation period of 30 days; in the day 7 , a rain event was simulated ( $2 \mathrm{~mm} \mathrm{~h}^{-1}$ rain for a duration of $5 \mathrm{~h}$ ) to check if $E_{u}$ was still $\sim 0$; runoff was not taken in to account; (e) initial conditions of hydraulic equilibrium with a water table depth of $0.5 \mathrm{~m}$ below the soil surface.

Table 2.1: Soil hydraulic parameters used for the "field" and "standard" sandy loam materials: $\theta_{r}$ is residual water content, $\theta_{\text {sat }}$ is saturated water content, 
A framework for sourcing of evaporation between saturated and unsaturated zone in bare soil condition

$\alpha_{G M}$ and $n_{G M}$ are parameters of the water retention function in the van Genuchten-Mualem model, $K_{S}$ is saturated hydraulic conductivity, $l$ is tortuosity parameter in the conductivity function in the van Genuchten-Mualem model, $S_{y}$ is specific yield (calculated using the other parameters by the van Genuchten-Mualem model).

\begin{tabular}{cccccccc}
\hline Material & $\theta_{\mathrm{r}}$ & $\theta_{\mathrm{s} a t}$ & $\begin{array}{c}\alpha_{G M} \\
\left(10^{-3} \mathrm{~m}^{-1}\right)\end{array}$ & $n_{G M}$ & $\begin{array}{c}K_{\mathrm{s}} \\
\left(\mathrm{m} \mathrm{d}^{-1}\right)\end{array}$ & $l$ & $S_{\mathrm{y}}$ \\
\hline "Field" & 0.02 & 0.33 & 0.3 & 1.5 & 2.9 & 0.5 & 0.15 \\
"Standard" & 0.06 & 0.41 & 0.75 & 1.9 & 1.06 & 0.5 & 0.27 \\
\hline
\end{tabular}

The calculation of daily $E_{g}$ using the method according to Gribovszki et al. (2010) was done as follows:

$E_{g}=S_{y}(24 r \pm s)$

where $S_{y}$ is the specific yield of the soil-aquifer system, $r$ is the slope of the tangential line drawn to the groundwater level curve in the analysed day, and $s$ is the difference in the observed groundwater levels over the $24 \mathrm{~h}$ period (Gribovszki et al., 2010).

\subsubsection{3 "Bucket" method simulations}

We tested the "bucket" method using the output dataset from the simulation of "deep water table" (see 2.5.1) with: (a) soil profile $4.0 \mathrm{~m}$ deep with vertical discretization of 100 nodes per metre; (b) "field" sandy loam soil properties; (c) bottom boundary conditions of constant water table depth $Z_{W T}=2.0 \mathrm{~m}$;

(d) top boundary conditions setup as fluctuating evaporative conditions, using the dataset for day 27 July 2010 from semi-arid area Sardon, Spain and repeated for the whole simulation period of 200 days; (e) initial conditions of hydraulic equilibrium. From this output we extracted the data to calculate $E_{u}$ with: (i) the SOURCE package and with the (ii) Wilson et al. (2001) "bucket" method; finally, we compared the results of the two methods. The "bucket" method was applied assuming the measurement of soil moisture at four depths in the soil profile $(0.25,0.50,1.00,1.50 \mathrm{~m})$ and the soil profile was divided into the following four layers: first, from 0.00 to $0.375 \mathrm{~m}$ depth; second, from 0.375 to $0.750 \mathrm{~m}$ depth; third, from 0.750 to $1.250 \mathrm{~m}$ depth; and fourth from 1.250 to $2.000 \mathrm{~m}$ depth. The SOURCE package was applied on the whole Hydrus1D output, hence the vertical discretization of the model (100 nodes per metre) was applied. 


\subsection{Results}

\subsubsection{Quasi-steady state: "shallow" and "deep" water table simulations}

The result of the Hydrus1D-SOURCE "shallow water table" numerical exercise described in Section 2.5.1 is presented in Table 2.2. It shows that with a water table at $0.2 \mathrm{~m}$ depth, the "shallow water table assumption" $E_{s s}=E_{g}$ holds very well in the case of sand materials and is only slightly worse for silt and clay materials, for which $E_{u}$ represents less than $5 \%$ of $E_{s s}$. When the water table is at $0.5 \mathrm{~m}$ depth, the $E_{g}$ is reduced at the expense of $E_{u}$ by $10-20 \%$ while at 1.0 $\mathrm{m}$ depth by more than $50 \%$. It is noteworthy that in sand, the $E_{g} / E_{s s}$ ratio for 'liquid-only' simulation (L), applying van Genuchten-Mualem (1980) soil hydraulic model (GM) is zero, i.e. $E_{s s}=E_{u}$, already at $0.5 \mathrm{~m}$ depth. This is due to the numerical approximation; in reality it is not zero, but a very low value $(\sim 0.01 \%)$. In the model experiment including vapour flow, i.e. in the coupled flows of heat, vapour and liquid water (Lv), with sand material and 50 and 100 $\mathrm{cm}$ depth, the simulations did not converge. For the same sand material simulations, but using Brooks and Corey (1964) soil hydraulic model (BC) different results were obtained; at $0.5 \mathrm{~m}$ depth, the $E_{g}$ represented $95-96 \%$ of $E_{s s}$ while at $1.0 \mathrm{~m}$ depth the $E_{g}$ was still $33-36 \%$ of $E_{s s}$ and the results of simulations with liquid water flow only $(\mathrm{L})$ or with the coupled flows of heat, vapour and liquid water (Lv) were similar (Table 2.2).

Table 2.2: Cumulative $E_{g} / E_{s s}$ (groundwater evaporation/subsurface evaporation) ratio for 30 days simulations with rainy event occurring at the day 7 of simulation, for three different water table depths $\left(Z_{W T}\right)$, with either liquid-only water flow (L) or liquid and vapour water flow (Lv) and using either van Genuchten-Mualem (GM) or Brooks and Correy (BC) soil hydraulic models; n.c. means not converged.

\begin{tabular}{ccccccccc}
\hline \multirow{2}{*}{$Z_{\mathrm{WT}}$} & Sand & Silt & Clay & Sand & Silt & Clay & Sand & Sand \\
\cline { 2 - 9 }$(\mathrm{m})$ & GM & GM & GM & GM & GM & GM & BC & BC \\
\cline { 2 - 9 } & L & L & L & Lv & Lv & Lv & L & Lv \\
\hline 0.2 & 0.99 & 0.95 & 0.96 & 0.99 & 0.95 & 0.96 & 1 & 1 \\
0.5 & 0 & 0.81 & 0.79 & n.c. & 0.82 & 0.79 & 0.95 & 0.96 \\
1 & 0 & 0.41 & 0.4 & n.c. & 0.42 & 0.4 & 0.36 & 0.33 \\
\hline
\end{tabular}

The result of the Hydrus1D-SOURCE "deep water table" numerical exercise described in Section 2.5.1 is presented in Figure 2.4. In that figure, the $E_{g} / E_{s s}$ ratio is presented as a function of water table depth $\left(Z_{W T}\right)$ for different types of soil in two simulation forms: with liquid-only water flow (L) and with the 
A framework for sourcing of evaporation between saturated and unsaturated zone in bare soil condition

coupled flows of heat, vapour and liquid water (Lv). It can be observed that in sand, the $E_{g}$ becomes negligible already at the depth of $40 \mathrm{~cm}$, in sandy loam at $1.5 \mathrm{~m}$ and in silt and clay at $\sim 4.0 \mathrm{~m}$. In sand material, the inclusion of the coupled flows of heat, vapour and liquid water results in a slightly larger (deeper) evaporation extinction depth, in sandy loam the evaporation extinction depth does not change, while in silt and clay, the evaporation extinction depth is shallower. It is interesting that in silt and clay at depth $>3.0$ $\mathrm{m}$, the $E_{g}$ appeared only after some simulation time and the starting time was dependent on the $Z_{W T}$ as well as on the vertical discretization of the profile (small $E_{g}$ rates did not appear with a coarser discretization than the one used in this study). For example, when $Z_{W T}$ was at $3.5 \mathrm{~m}, E_{g}$ started only after 150 d (i.e. 5 months).

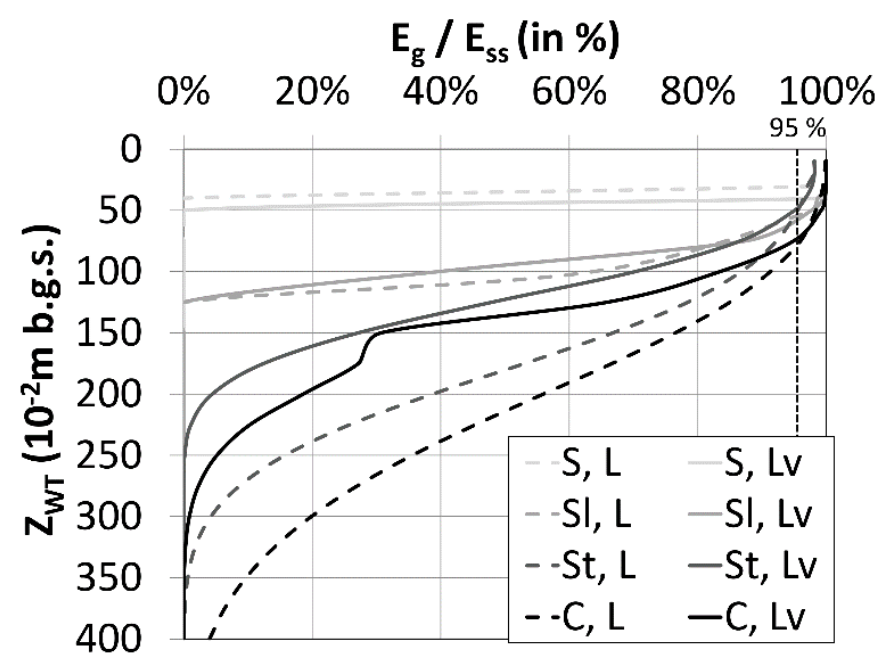

Figure 2.4: Relation between $E_{g} / E_{S S}$ (in\%) and $Z_{W T}$, calculated using van Genuchten-Mualem model. The $E_{g}$ refers to equilibrium rates, achieved at the end of the "deep water table" simulation (soil profile depth of $4.0 \mathrm{~m}$, fixed water table depth, daily fluctuating evaporative conditions with no rain events, initial conditions of hydraulic equilibrium; the result shown refer to day of simulation 200). S - sand; SI - sandy loam; St - silt; C - clay; L - "liquid water flow only"; Lv - "coupled flows of heat, vapour and liquid water".

The diurnal variability of $E_{s s}$ and its two components, $E_{g}$ and $E_{u}$, for $Z_{W T}=$ $0.5 \mathrm{~m}$ ("shallow water table" simulation) and for $Z_{W T}=2.0 \mathrm{~m}$ ("deep water table" simulation) is presented in Figure 2.5. In case of shallow water table simulation (Figure 2.5a), during early morning the $E_{S S}$ is zero or close to zero and it starts to increase through the morning when solar radiation increases so that the soil surface temperature also increases, reaching its maximum at 14:00 when the largest amount of water is transmitted through the soil to 
maintain the high evaporative rates (local time in Sardon is $2.5 \mathrm{~h}$ later than solar time, Figure 2.5a). Afterwards, the $E_{S S}$ rate decreases, due to the decrease of incoming solar radiation and soil temperature. The $E_{u}$ reaches its maximum approximately at 10:00 to decrease later and cease completely at 16:00 when the first layer of the profile is dried up. This is in agreement with the daily evaporation behaviour explained in Zeng et al., (2009b). In the case of deep water table $\left(Z_{W T}=2.0 \mathrm{~m}\right)$ simulation (Figure $2.5 \mathrm{~b}$ ), the $E_{S S}, E_{u}$ and $E_{g}$ increase in the morning, following the increase of evaporative condition and the increase of the soil surface temperature. That increase lasts only until $\sim 9: 00$ when $E_{u}$ and also $E_{s s}$ reach both their maxima at the same time (as $E_{g}$ is already stable and low) and then rapidly decrease. The initial increase of $E_{u}$ (and $E_{s s}$ ) is abruptly stopped when the top unsaturated zone dries up as $E_{s s}$ is limited to the rate at which groundwater can reach the soil surface from the deeper part of the profile. Therefore, during afternoon, the $E_{s s}$ is dominated by $E_{g}$ while $E_{u}$ declines nearly to zero as the unsaturated zone dries up completely.

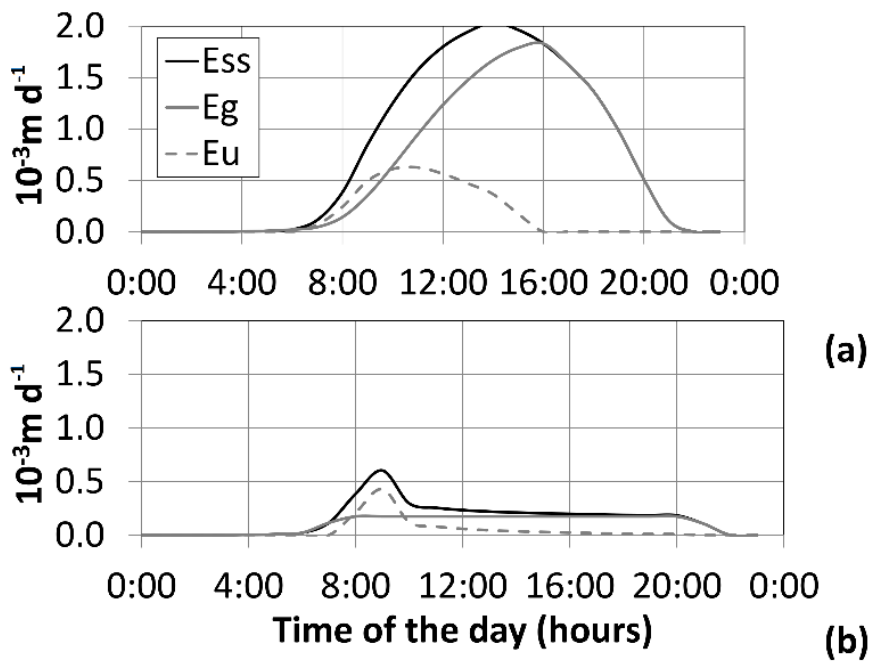

Figure 2.5: $E_{s s}, E_{u}$ and $E_{g}$ changes during the day, with $Z_{W T}$ at: (a) $0.5 \mathrm{~m}$ and (b) $2.0 \mathrm{~m}$ (no rain events, day of simulation, 200). Results from the "deep water table" simulations with the coupled flows of heat, vapour and liquid water, stable water table bottom boundary conditions, initial conditions of hydraulic equilibrium, "standard" sandy loam material described in Table 2.1.

Figure 2.6 shows $E_{s s}, E_{g}$ and $E_{u}$ as a function of depth at two time instances, one in the morning at 10:00 and the other in the afternoon at 15:00 for simulation day 200 of the "deep water table" simulation with the coupled flows of heat, vapour and liquid water and "standard" sandy loam material. The $E_{p}$ in the two time instances of the day was: $E_{p}=510^{-3} \mathrm{~m} \mathrm{~d}^{-1}$ at 10:00 and $E_{p}=$ $210^{-2} \mathrm{~m} \mathrm{~d}^{-1}$ at 15:00; the two time instances were selected as representatives 
A framework for sourcing of evaporation between saturated and unsaturated zone in bare soil condition

of the "early morning" and "daily peak" $E_{p}$ conditions, respectively. As expected, the evaporation rates are much higher in the "daily peak" conditions, but only for shallower water table depths (0.0 to $1.5 \mathrm{~m}$ depth), while below 1.5 $\mathrm{m}$ depth the evaporation rates are higher in the "early morning" conditions. In both "early morning" and "daily peak" conditions, the $E_{S S}$ remains at maximum rates $\left(E_{S S}=E_{p}\right)$ for shallower water table conditions, and at a certain $Z_{W T}$ start to decline $\left(Z_{W T}=2.5 \mathrm{~m}\right.$ for "early morning" condition and $Z_{W T}=1.0 \mathrm{~m}$ for "daily peak" condition, respectively). In both conditions, $E_{g}$ rates are higher for shallower $Z_{W T}$ and decrease with depth. The $E_{u}$ rates are low for shallower $Z_{W T}$ (when soil is completely saturated so there is no unsaturated zone) and increase with increasing $Z_{W T}$ reaching a maximum for a certain water table depth corresponding to the depth at which $E_{s S}$ starts to decline; below that water table depth, the $E_{u}$ starts to decline as well.

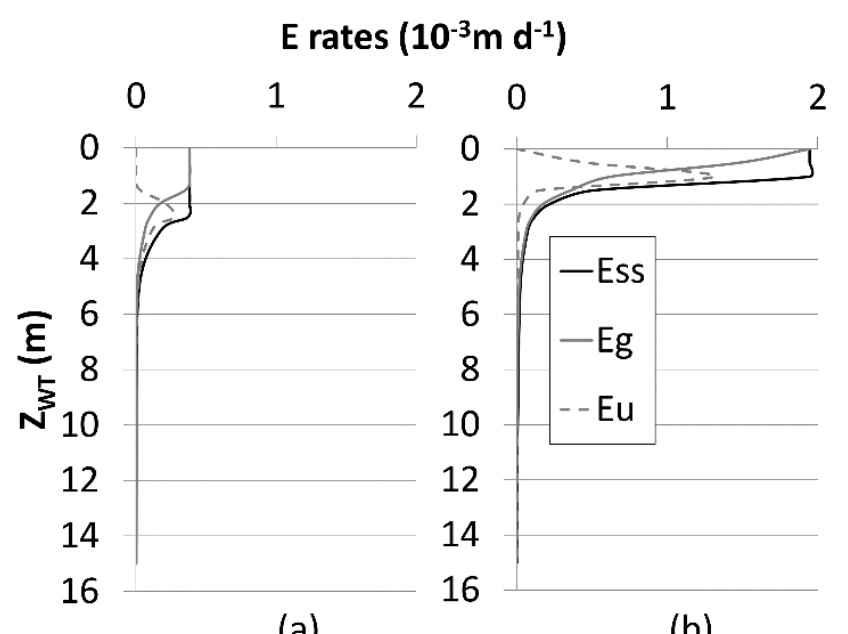

(a)

(b)

Figure 2.6: $E_{S S}, E_{u}$ and $E_{g}$ estimates as dependent on $Z_{W T}$ in two instances of the day differing by $E_{p}$, at: a) $10: 00\left(E_{\mathrm{p}}=510^{-3} \mathrm{~m} \mathrm{~d}^{-1}\right)$; b) 15:00 ( $E_{\mathrm{p}}=210^{-}$ $\left.2 \mathrm{~m} \mathrm{~d}^{-1}\right)$. Results from the "deep water table" simulations with the coupled flows of heat, vapour and liquid water, stable water table bottom boundary conditions, initial conditions of hydraulic equilibrium, "standard" sandy loam material described in Table 2.1.

\subsubsection{Water table fluctuation simulations}

The results of the two water table fluctuation simulations (WTFS), applying "field" and "standard" sandy loam material (Table 2.1) carried out as described in Section 2.5.2. are presented in Figure 2.7. The output of the "field" sandy loam simulation shows decline of pressure head with diurnal pressure head fluctuations at the bottom of the profile in the order of $\sim 0.04 \mathrm{~m}$ (that would 
be well detected by pressure transducer recorder) lasting 13 days and no fluctuations for the remaining days of the simulation, i.e. until day 84 . The output of the "standard" sandy loam simulation shows gentler decline of pressure head without fluctuations throughout the entire 84 days of simulation (Figure 2.7).

Applying the WTF method of data processing (Gribovszki et al., 2010), in the case of "field" sandy loam simulation (with $S_{y}=0.15$ assumed constant in depth), the $E_{g}$ daily rate in the period with water table fluctuations was $\sim 5.3$ $10^{-3} \mathrm{~m} \mathrm{~d}^{-1}$ while the total cumulative evaporation for the whole simulation period of $84 \mathrm{~d}$ was $\sim 7210^{-3} \mathrm{~m}$. Applying the same WTF method for the "standard" sandy loam simulation, the $E_{g}$ was zero.

Applying the SOURCE package of data processing, in the case of "field" sandy loam the average $E_{g}$ rate calculated for days 1-13 (when fluctuations are still visible) was $5.310^{-3} \mathrm{~m} \mathrm{~d}^{-1}$, i.e. the same as calculated by the WTF method. However, in contrast to the WTF method, the SOURCE package was able to estimate $E_{g}$ when water table fluctuations were not visible (or not detectable by pressure-transducer recorders); these $E_{g}$ values were in order of $1.510^{-3} \mathrm{~m} \mathrm{~d}^{-1}$ average for days $1-13$. Applying the SOURCE package, the average $E_{g}$ rate for the whole simulation period of $84 \mathrm{~d}$ for the "field" sandy loam was $3.210^{-3} \mathrm{~m} \mathrm{~d}^{-1}$ (total cumulative $22210^{-3} \mathrm{~m}$ ) while for the "standard" sandy loam $0.710^{-3} \mathrm{~m} \mathrm{~d}^{-1}$ (total cumulative $\sim 5610^{-3} \mathrm{~m}$ ).

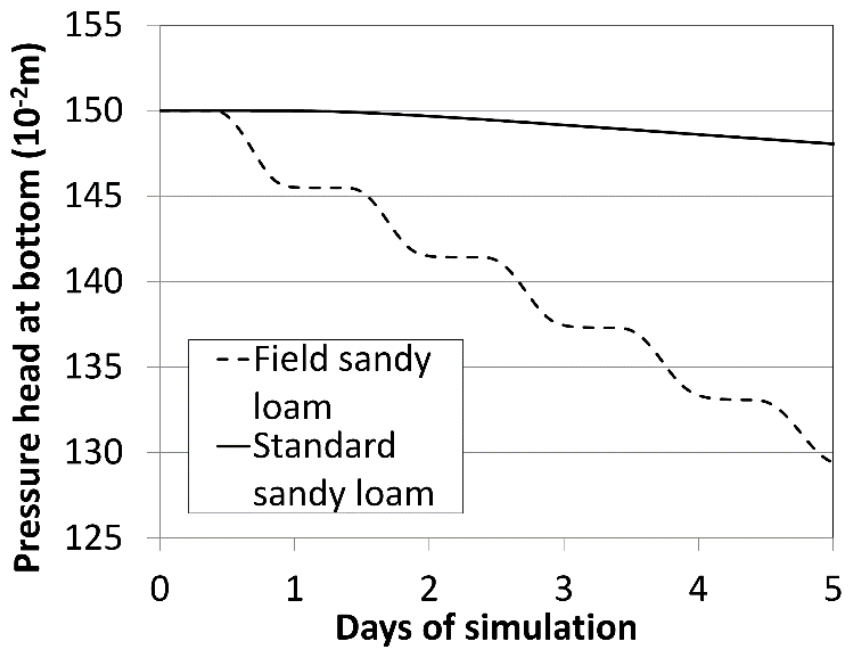

Figure 2.7: fluctuation of pressure head at bottom boundary due to diurnal fluctuation in evaporation, for the "standard" and "field" materials described in Table 2.1 as simulated by Hydrus1D with the coupled flows of heat, vapour and liquid water. 
A framework for sourcing of evaporation between saturated and unsaturated zone in bare soil condition

\subsection{3 "Bucket" method simulations}

The results of the two "bucket" method simulations comparing the sourcing performed using the SOURCE package with the sourcing performed with the method proposed by Wilson et al. (2001) are presented in Table 2.3. Both simulations were carried out with the "field" sandy loam material and "deep" water table $\left(Z_{W T}=2.0 \mathrm{~m}\right)$ as explained in Section 2.2.5.3. The results show that in the simulated semi-arid conditions, the Wilson et al. (2001) "bucket" method estimates of $E_{s S}, E_{u}$ and $E_{g}$ are substantially lower than those derived by the SOURCE package.

Table 2.3: Comparison of the sourcing of $E_{g}$ in "field" sandy loam soil with $Z_{W T}$ $=2.0 \mathrm{~m}$, performed by the "bucket" method used by Wilson et al., (2001) and the SOURCE package.

\begin{tabular}{cccc}
\hline $\begin{array}{c}\text { Sourcing } \\
\text { approach }\end{array}$ & $\begin{array}{c}E_{\mathrm{ss}} \\
\left(10^{-3} \mathrm{~m} \mathrm{~d}^{-1}\right)\end{array}$ & $\begin{array}{c}E_{\mathrm{u}} \\
\left(10^{-3} \mathrm{~m} \mathrm{~d}^{-1}\right)\end{array}$ & $\begin{array}{c}E_{\mathrm{g}} \\
\left(10^{-3} \mathrm{~m} \mathrm{~d}^{-1}\right)\end{array}$ \\
\hline "Bucket" method & 0.3 & 0.3 & 0 \\
SOURCE package & 1.5 & 0.7 & 0.8 \\
\hline
\end{tabular}

\subsection{Discussion}

\subsubsection{Quasi-steady state: "shallow" and "deep" water table simulations}

The $E_{g} / E_{s s}$ ratio presented in Table 2.2 shows a general decline with depth, with a decline of $E_{g}$ and an increase of $E_{u}$ contributions in the $E_{S S}$. At $Z_{W T}=0.2$ m condition, the $E_{g} / E_{s s} \geq 0.95$ which means that the $E_{u}$ contribution in $E_{s s}$ is $\leq 5 \%$. For deeper water table depth $(0.5 \mathrm{~m}$ and $1.0 \mathrm{~m})$, the $E_{g} / E_{s s}$ is smaller so the contribution of $E_{u}$ increases (although only to a certain depth, as seen in Figure 2.6). To remove common ambiguity in the term "shallow" groundwater, we propose to assume "shallow groundwater assumption" valid when $E_{g}>0.95$ $E_{S S}$. The advantage of that "shallow" water table depth definition is that it is not arbitrary and not referring to one, unique water table depth but is environmentally dependent, being defined by a quantitative sourcing constrain.

The relations between $E_{g}$ and $Z_{W T}$ (Figure 2.4) found in this study for various soil hydraulic properties using the coupled flows of heat, vapour and liquid water version of Hydrus1D model and the SOURCE package, are similar to the relations presented by Shah et al. (2007). However, their Hydrus1D model was run with liquid flow only, with total saturation as initial condition and no flow 
condition at the bottom boundary (in our study, initial conditions were of hydraulic equilibrium and fixed bottom boundary conditions). The differences in the setup of the simulations resulted in a slightly deeper evaporation extinction depth in Shah et al. (2007) calculations as compared to ours, presented in Figure 2.4 (few centimetres for sand and sandy loam, almost 1.0 $\mathrm{m}$ for silt and clay). In Figure 2.4 it is possible to see that the "shallow water table assumption" depth is between 0.4 and $0.75 \mathrm{~m}$ for all the four soil types. Below that depth, the $E_{g} / E_{s s}$ decreases sharply in the case of the sandy materials and slower for clay materials, until it reaches a point in which it is zero or close to zero, which is the evaporation extinction depth at which the "deep water table assumption" is true.

The use of the coupled Lv model instead of the $L$ model results in different changes in the evaporation extinction depth for different materials: it increases it for sand while it decreases it for silt and clay materials (there is no change in the evaporation extinction depth of sandy-loam material). Both the liquid water flow and the water vapour flow are modelled in the Hydrus1D model with coupled flows of heat, vapour and liquid water. The latter is driven by water vapour density and temperature gradients. In the case of a shallow water table there is an abundance of soil moisture in the upper profile, where the gradients of temperature and water vapour density result in an upward water vapour flow, increasing the $E_{g}$ evaporation extinction depth. In the case of a deep water table, the soil moisture is abundant in the deeper part of the profile, where the temperature and water vapour density gradients are smaller, and often reversed (Zeng et al., 2009b), resulting in a downward water vapour flow. In contrast with sand material, the evaporation extinction depth for silt and clay (St and C in Figure 2.4) is $>2.5 \mathrm{~m}$, i.e. in the deeper part of the profile, the downward water vapour flow imply that the evaporation extinction depth is decreased. The evaporation extinction depth for sandy-loam material results in water vapour fluxes being $\sim 0$.

The definition of "deep water table assumption" is also difficult because models sometimes require time to reach equilibrium for $E_{g}$ to start to be active, as described in Section 2.3.1. We observed that the time required to reach equilibrium depends on vertical model discretization (in order for the model to be able to calculate the small $E_{g}$ flux, high discretization is required) and on $Z_{W T}$ : for $E_{g}$ to start to be active, the simulated unsaturated zone must first reach equilibrium with the $E_{p}$ conditions at the top boundary and then remove free water from the unsaturated zone; the larger $Z_{W T}$ means a thicker unsaturated zone, hence, more time to reach equilibrium. When the water content in the unsaturated zone decreases (due to the $E_{u}$, which also declines in time), the $E_{g}$ gradually increases. For example, in Section 2.3.1 we explain that if the evaporation extinction depth of $E_{g}$ in silt and clay is $3.5 \mathrm{~m}$, the $E_{g}$ needs a period of 5 months with stable evaporative conditions without rain to become active. Therefore in the definition of "deep water table assumption", 
A framework for sourcing of evaporation between saturated and unsaturated zone in bare soil condition

time has to be included together with the evaporation threshold below which $E_{g}$ is neglected. The $Z_{W T}$ threshold below which $E_{g}=0$ also depends on soil hydraulic properties and on the expected total time without rain. An accurate knowledge of the soil hydraulic properties affecting water flow is, therefore, required to model $E_{g}$, especially when working with small magnitude fluxes, like in arid and semi-arid conditions.

The sourcing of $E_{S S}$ is a dynamic process, as can be observed in Figure 2.5 and 2.6. During a typical summer day, the first water to evaporate is the water in the upper profile of the soil (the upper part of unsaturated zone). The increase in potential evaporation conditions results in a peak of $E_{u}$ during the morning (Figure 2.5). The related decrease of water quantity in the top soil, triggers the decrease of $E_{u}$ and the increase of $E_{g}$, which reaches its maximum $E_{g}=E_{s s}$ when the top soil profile is dry $\left(E_{u}=0\right)$. This means that the maximum $E_{g}$ depends on the amount of soil moisture present in the top profile.

In Figure 2.6 we see that when $Z_{W T}$ is close to the surface, the $E_{g}$ is comparable with $E_{s S}$ which corresponds to "shallow water table assumption": the upward capillary flow of water from the saturated zone is sufficient to meet the $E_{p}$. With increasing $Z_{W T}, E_{g}$ decreases, while $E_{u}$ initially increases, reaching a maximum (in Figure 2.6a is at $\sim 2.5 \mathrm{~m}$ and in Figure $2.6 \mathrm{~b}$ at $\sim 1.0 \mathrm{~m}$ ), and then decreases again. The different patterns of the evaporation in the morning (Figure 2.6a) and in the afternoon (Figure 2.6b) are due to different $E_{p}$ conditions at the soil surface, which result in the $E_{u}$ peaks at different times of the day: the time at which a peak of $E_{u}$ happens depends on water table depth. In the morning (Figure 2.6a), the $E_{u}$ is more relevant than $E_{g}$ for all deeper $Z_{W T}$ $\left(Z_{W T}>1.5 \mathrm{~m}\right)$ due to the morning evaporation of soil moisture in the unsaturated zone (Figure 2.5) while in the afternoon (Figure 2.6b), the $E_{g}$ is the more relevant term at deeper $Z_{W T}\left(Z_{W T}>1.5 \mathrm{~m}\right)$.

The analysis of the "deep water table" simulations (Section 2.2.5.1, Figure 2.5 and Figure 2.6) shows that the relative relevance of $E_{g}$ and $E_{u}$ changes dynamically during a day, depending on the soil moisture stored in the unsaturated zone, and on the depth to groundwater. It can be noticed in Figure 2.6 that the depths at which $E_{u}>E_{g}, E_{u}=\max$, and $E_{g}=\max$, depend on the time of the day which makes the definition of concepts like "shallow water table assumption" and "deep water table assumption" difficult but not impossible. The proposed framework, as far as the authors know, is the first attempt at a precise definition of these terms frequently used in hydrogeology.

\subsubsection{Water table fluctuation simulations}

The $E_{g}$-related water table fluctuations are difficult to detect as they are usually low in magnitude and typically observed only for short period of few days: this makes it difficult to assess $E_{g}$ as a function of water table fluctuation, even in sites where such fluctuations are detectable. The amplitude of water table 
fluctuation induced by the diurnal variation of evaporative conditions and successive groundwater replenishment from the upstream areas depends to a large extent on the soil hydraulic properties and on the $Z_{W T}$, and it is often below the pressure transducer accuracy. In our WTFS simulations, the difference in soil material properties between "standard" and "field" sandy loams (Table 2.1), and more specifically in the $\alpha_{G M}$ parameter (reciprocal of the air entry pressure) of the van Genuchten-Mualem soil hydraulic model, with all other conditions held the same, resulted in visible fluctuations only for the "field" material.

The air entry pressure $\left(1 / \alpha_{G M}\right)$ is the value below which fluctuations in pressure head do not result in changes in soil moisture content. The changes in evaporative conditions at the top boundary of the profile result in changes in the pressure head in the top soil: the value of the $\alpha_{G M}$ parameter for the "field" sandy loam allows these changes to be transmitted through the profile and results in fluctuations of $Z_{W T}$ while the value of the $\alpha_{G M}$ parameter for the "standard" sandy loam does not. This means that the accurate determination of the spatial variability of the $\alpha_{G M}$ parameter is required in order to use properly the WTF method in the field conditions. Other difficulties in applying this technique to field conditions is the challenge in filtering out the $E_{g}$ signal affected not only by standard bias such as Earth tides, Moon tides, etc. but also by the influence of lateral groundwater flow and the impact of adjacent plants.

\subsection{3 "Bucket" method simulations}

In the "bucket" method of Wilson et al. (2001), the $E_{g}$ is disregarded due to the fact that $Z_{W T}=2.0 \mathrm{~m}$, i.e. the depth at which $E_{g}$ is usually neglected, while in the SOURCE package approach $E_{g}=54 \%$ of $E_{s s}$. In the Wilson et al. (2001) "bucket" method, also the $E_{u}=0.310^{-3} \mathrm{~m} \mathrm{~d}^{-1}$ is underestimated (Table 2.3) because of its lower vertical resolution of water content assuming only four soil layers with internally homogeneous water content estimates in each layer. Assuming more layers would yield a higher accuracy, but the number of layers is restricted by the amount of soil moisture monitoring probes it is technically possible to install in a profile without measurement interference. In the Wilson et al. (2001) "bucket" method, an error in the calculation of $E_{s s}$ is introduced by the assumptions that: (i) $E_{g}$ can be calculated using an analytical model (not used in our case because $Z_{W T}=2.0 \mathrm{~m}$ was the evaporation extinction depth, so that $E_{g}=0$ ), and (ii) soil moisture is internally homogenous in the soil layers where the soil moisture probes are installed. In semi-arid and arid areas, where water fluxes (liquid and vapour) are usually small, it is likely that the error introduced by these two assumptions is large as compared to the magnitude of $E_{s s}$ itself. All the problems of the "bucket" method, as well as the problems of the WTF technique, can be handled by the SOURCE package, which 
A framework for sourcing of evaporation between saturated and unsaturated zone in bare soil condition

is able to source $E_{g}$ and $E_{u}$ whenever the field soil evaporation conditions are well simulated using a calibrated and validated Hydrus1D model.

\subsection{Conclusions}

We propose a framework for sourcing of subsurface evaporation in bare soils focussing on two sources, the groundwater and the unsaturated zone moisture, in line with the sourcing equation $E_{s s}=E_{g}+E_{u}$. For each of the sourced components we defined its physical description in steady-state, quasi-steady state and transient conditions. The definitions proposed have been implemented in the novel "SOURCE" package, sourcing the $E_{S S}$ output from the Hydrus1D model into $E_{u}$ and $E_{g}$.

- The use of the SOURCE package over the Hydrus1D bare soil simulation allows sourcing of $E_{s s}$ into $E_{g}$ and $E_{u}$ components.

- The sourcing simulations indicated that $E_{g}$ is usually over-simplified in existing evaporation studies, especially in semi-arid and arid conditions where water fluxes are low but $E_{g}$ is typically a relevant component of groundwater balance.

- The application of the SOURCE package to the sourcing theories showed that small evaporative fluxes, especially evaporation from "deep" water table, can be easily miscalculated or ignored when applying standard hydrological methods.

- For the definition of "shallow water table assumption" we propose $E_{g}$ $\geq 95 \% E_{s S}$ evaporative condition. The specific depth corresponding with that condition changes depending on soil hydraulic properties, on climatic conditions and on the time scale considered; these factors should be mentioned whenever such definition is used. That depth should be calculated accounting for the coupled flows of heat, vapour and liquid water and considering specific hydraulic properties of the soil studied.

- For the definition of "deep water table assumption" we propose $E_{g}=0$ evaporative condition. The specific depth corresponding with that condition should always be mentioned, together with the time scale considered. That depth should be calculated accounting for the coupled flows of heat, vapour and liquid water and considering specific hydraulic properties of the soil studied.

- The "fluctuation method", used to determine evapotranspiration or transpiration only, has a limited use for the determination of $E_{g}$ in field studies, due to the difficulty in finding conditions (particular soil texture, high $E_{p}$ during the daytime, very shallow water table) where measurable water table depth fluctuations caused by soil evaporation occur and can be filtered out from the signal composite. 
- Whenever the "bucket" method is used to source $E_{S S}$ in the field, all the limitations and conclusions of this study should be carefully considered: incorrect spacing and frequency of data acquisition of the profile soil moisture probes can result in miscalculation of $E_{u}$, while the assumptions made on $E_{g}$ (e.g. depth at which it ceases) should be tested with a vadose zone water flow model simulation accounting for the coupled flows of heat, vapour and liquid water.

In order to proper source $E_{s s}$ with the SOURCE package in the field conditions, it is possible to either measure the soil water fluxes directly (which is problematic, as explained above) or calculate them using a vadose zone numerical model (e.g. Hydrus1D). The field measurements required, hence, will depend on the requirements of the vadose zone model; in the case of Hydrus1D, a good knowledge of the soil material properties, water table depth (for the bottom boundary conditions) and $E_{p}$ (for the top boundary conditions) are required for the preparation of such model. Additional measurements (for example soil moisture measurements, matric potential measurements, eddy tower measurements, etc.) are also important in order to calibrate and validate the Hydrus1D model. Once these conditions are met, the SOURCE package is able, in theory, to source the $E_{s s}$ : (a) even if no water table fluctuations are detectable, (b) with higher accuracy than the "bucket" method, (c) taking into account the contribution of the flow of water vapour in the soil. To improve the $E_{s S}$ sourcing framework proposed in this study and better simulate small water fluxes typical of semi-arid and arid areas, the SOURCE package should be tested on more accurate field condition data.

\subsection{Appendix}

\subsection{1 $E_{u}$ definition}

$E_{u}$ is defined as the decrease of water stored in the unsaturated zone due to evaporative fluxes at soil surface (Figure 2.2). Assuming no infiltration events (no input of water from the upper boundary) and absent or very deep water table (no influence of water table on the upper soil profile), then we obtain Equation 2.4.

In case of a shallow water table, the amount of water converted to saturated zone water (percolation or recharge) should be taken into account. If we assume a fixed water table condition at the bottom boundary, then the unsaturated zone water balance is:

$\frac{\mathrm{d}}{\mathrm{d} t} \int_{Z_{\mathrm{top}}}^{Z_{\mathrm{WT}}} \theta \mathrm{d} Z=-E_{\mathrm{u}}-R$ 
A framework for sourcing of evaporation between saturated and unsaturated zone in bare soil condition

where $Z_{\text {top }}$ and $Z_{\mathrm{WT}}$ are the vertical positions of the top of the soil profile and of the water table; recharge $(R)$ can be calculated as the unsaturated flow of water due to gravity only.

Both $E_{u}$ and $R$ are positive quantities. If we take into account infiltration of water from the top boundary $(I)$, then $E_{u}$ is obtained as in Equation 2.5, where $R$ must be taken into account in the water balance, in order not to overestimate $E_{u}$, as not all the loss of water from the unsaturated zone is due to evaporation but part of it can move to the saturated zone as well. In case there is evaporation from the soil profile $\left(E_{s s} \neq 0\right)$ but the moisture content of the unsaturated zone does not change due to upward fluxes from the saturated zone (so that the left member of Equation 2.14 is equal to zero), then $E_{s s}=E_{g}$ (in case that $R=0$ ).

If we assume a zero flux condition for the bottom boundary and a saturated zone at a depth where we can also assume $E_{g}=0$, then we should take into account the soil moisture converted from unsaturated zone to saturated zone water when water table rises (because of the recharge) from position at time $t_{1}\left(Z_{W T 1}\right)$ to position at time $t_{2}\left(Z_{W T 2}\right)$ :

$E_{\mathrm{u}} \Delta t=-\Delta S_{\text {unsat }}-R \Delta t-\Delta \theta_{\text {rise }}$

where $\Delta t=t_{2}-t_{1}, \Delta \theta_{\text {rise }}$ is the loss of soil moisture due to rise of water table and $\Delta S_{\text {unsat }}$ is the change in water stored in the unsaturated zone:

$\Delta S_{\text {unsat }}=\int_{Z_{\mathrm{top}}}^{Z_{\mathrm{WT} 2}} \theta_{\mathrm{t} 2} \mathrm{~d} Z-\int_{Z_{\mathrm{top}}}^{Z_{\mathrm{WT} 1}} \theta_{\mathrm{t} 1} \mathrm{~d} Z$

where $Z_{W T 1}$ and $Z_{W T 2}$ are the vertical positions of the water table at time $t_{1}$ and $t_{2}$ respectively (where $t_{2}>t_{1}$ and $Z_{W T 1}>Z_{W T 2}$, i.e., with a rising water table), and $\theta_{\mathrm{t} 1}$ and $\theta_{\mathrm{t} 2}$ are soil moisture profiles at time $t_{1}$ and $t_{2}$ respectively.

The loss/gain of water due to moving water table is the amount of water which is transferred from one zone to the other due to the movement of the water table. In the case of a falling water table, the water left behind is converted to unsaturated zone water: this amount should be taken out from the calculation because it is not evaporation (the water is not leaving the system). In case of water table falling due to $E_{g}$ the definition of the water loss/gain is given by Equation 2.3. In case of a rising water table due to an input of water from the unsaturated zone to the saturated zone (recharge $R$ ), the amount of water converted to saturated zone water is $-\theta_{\text {sat }} \frac{d Z_{w t}}{d t}=R+\Delta \theta_{\text {rise }}$, with $\frac{d Z_{w t}}{d t}$ being negative due to rising water table (water table depth decrease) and $R$ and $\Delta \theta_{\text {rise }}$ positive quantities, so we can write Equation 2.15 as: $E_{\mathrm{u}} \Delta t=-\Delta S_{\text {unsat }}+\theta_{\text {sat }}\left(Z_{\mathrm{WT} 2}-Z_{\mathrm{WT} 1}\right)$

\subsubsection{Transient state condition}

The water balance for the whole soil profile between time $t_{1}$ and $t_{2}$ is:

$\int_{Z_{\text {top }}}^{Z_{\text {tot }}} \theta_{\mathrm{t} 2} \mathrm{~d} Z-\int_{Z_{\text {top }}}^{Z_{\text {bot }}} \theta_{\mathrm{t} 1} \mathrm{~d} Z=\left(\mathrm{GW}_{\text {in }}-\mathrm{GW}_{\text {out }}-E_{\mathrm{ss}}\right) \Delta t$

where $\left(G W_{\text {in }}-\mathrm{GW}_{\text {out }}\right)$ is the term representing the flow at the bottom of the soil profile $\left(Z_{\text {bot }}\right)$, i.e. the lateral flow from the aquifer. 
The equation can be written as:

$$
\begin{gathered}
E_{\mathrm{ss}} \Delta t=\left(E_{\mathrm{u}}+E_{\mathrm{g}}\right) \Delta t=-\left(\int_{Z_{\mathrm{top}}}^{Z_{\mathrm{WT} 2}} \theta_{\mathrm{t} 2} \mathrm{~d} Z-\int_{Z_{\mathrm{top}}}^{Z_{\mathrm{WT} 1}} \theta_{\mathrm{t} 1} \mathrm{~d} Z\right)-\left(\int_{Z_{\mathrm{WT} 2}}^{Z_{\mathrm{bot}}} \theta_{\mathrm{t} 2} \mathrm{~d} Z-\int_{Z_{\mathrm{WT} 1}}^{Z_{\mathrm{bot}}} \theta_{\mathrm{t} 1} \mathrm{~d} Z\right) \Delta t= \\
=-\Delta S_{\text {unsat }}+\theta_{\text {sat }}\left(Z_{\mathrm{WT} 2}-Z_{\mathrm{WT} 1}\right)+\left(\mathrm{GW}_{\mathrm{in}}-\mathrm{GW}_{\text {out }}\right) \Delta t
\end{gathered}
$$

where $\Delta S_{\text {unsat }}$ is defined in Equation 2.16.

The amount of water exchanged between saturated and unsaturated zone due to recharge from the unsaturated zone (as shown in Equation 2.5) and due to the rising or falling of water table $\left(\Delta \theta_{\mathrm{f}-\mathrm{r}}\right.$, Equation 2.22$)$ should be taken out from the separate balance of the two zones because it is a loss (or gain) of water unrelated to evaporation:

$\Delta S_{\text {unsat }}=-\left(E_{\mathrm{u}}+R\right) \Delta t-\Delta \theta_{\mathrm{f}-\mathrm{r}}$

$-\theta_{\mathrm{sat}}\left(Z_{\mathrm{WT} 2}-Z_{\mathrm{WT} 1}\right)=-\left(E_{\mathrm{g}}-R+\mathrm{GW}_{\text {in }}-\mathrm{GW}_{\text {out }}\right) \Delta t+\Delta \theta_{\mathrm{f}-\mathrm{r}}$

so that the fluxes are calculated as:

$E_{\mathrm{u}} \Delta t=-\Delta S_{\text {unsat }}-R \Delta t-\Delta \theta_{\mathrm{f}-\mathrm{r}}$

$E_{\mathrm{g}} \Delta t=\theta_{\mathrm{sat}}\left(Z_{\mathrm{WT} 2}-Z_{\mathrm{WT} 1}\right)-R+\left(\mathrm{GW}_{\text {in }}-\mathrm{GW}_{\text {out }}\right) \Delta t+\Delta \theta_{\mathrm{f}-\mathrm{r}}$

The determination of the amount of water converted from saturated zone to unsaturated zone water due to a falling water table depends on the water retention curve of the material which depends on the soil hydraulic model used; e.g. van Genuchten model (1980), Brooks and Corey (1964), or others. Then, in case of a falling water table,

$\Delta \theta_{\mathrm{f}-\mathrm{r}}=\int_{Z_{\mathrm{WT} 1}}^{Z_{\mathrm{WT} 2}} \theta_{\mathrm{ret}} \mathrm{d} Z$

where $\theta_{\text {ret }}$ is the soil moisture content due to the capillary rise from the water table, which depends on the water retention curve. The water retention curve is a function of the sizes and volumes of the water-filled pores and of the amount of water adsorbed to the particles; hence it is a function of the matric potential (Hillel, 1998). It is usually determined by experiments, but can be also approximated by models.

The amount of water converted from unsaturated zone to saturated zone water due to a rising water table depends on the unsaturated zone soil moisture profile at time $t_{1}\left(\theta_{t 1}\right)$, on the properties of the material (which define $\left.\theta_{\text {ret }}\right)$ and on the net water flow at the bottom of the profile $\left(G W_{\text {in }}-G_{\text {out }}\right)$. In reality, however, the water flow at the bottom of the soil profile is rarely measured; the water table depth variation in time is a more common measurement. With this input, the Equation 2.21 has two unknowns: $E_{g} \Delta t$ and $\Delta \theta_{\mathrm{f}-\mathrm{r}}$. To discriminate between them we need to calculate the water flux at the bottom boundary for the "wet" conditions (with the measured soil moisture profile, Figure 2.8a) and for the "dry" conditions (Figure 2.8b; same $E_{p}$ as in the "wet" conditions but with no precipitation events). The water balance for the saturated zone in Figure 2.8a is:

$\theta_{\text {sat }}\left(Z_{\mathrm{WT} 2}-Z_{\mathrm{WT} 1}\right)=-\left(E_{\mathrm{g}}-R\right) \Delta t+\left(\mathrm{GW}_{\mathrm{in}}-\mathrm{GW}_{\text {out }}\right)_{\mathrm{wet}} \Delta t+\Delta \theta_{\mathrm{f}-\mathrm{r}}$ 
A framework for sourcing of evaporation between saturated and unsaturated zone in bare soil condition

while the water balance for the saturated zone in Figure $2.8 \mathrm{~b}$ is:

$\theta_{\text {sat }}\left(Z_{\mathrm{WT} 2}-Z_{\mathrm{WT} 1}\right)=-E_{\mathrm{g}} \Delta t+\left(\mathrm{GW}_{\text {in }}-\mathrm{GW}_{\text {out }}\right)_{\mathrm{dry}} \Delta t$

hence, the difference between the two bottom fluxes will be equal to $\Delta \theta_{\mathrm{fr}}$ :

$\Delta \theta_{\mathrm{f}-\mathrm{r}}=\left[\left(\mathrm{GW}_{\text {in }}-\mathrm{GW}_{\text {out }}\right)_{\mathrm{dry}}-\left(\mathrm{GW}_{\text {in }}-\mathrm{GW}_{\text {out }}\right)_{\text {wet }}\right] \Delta t$
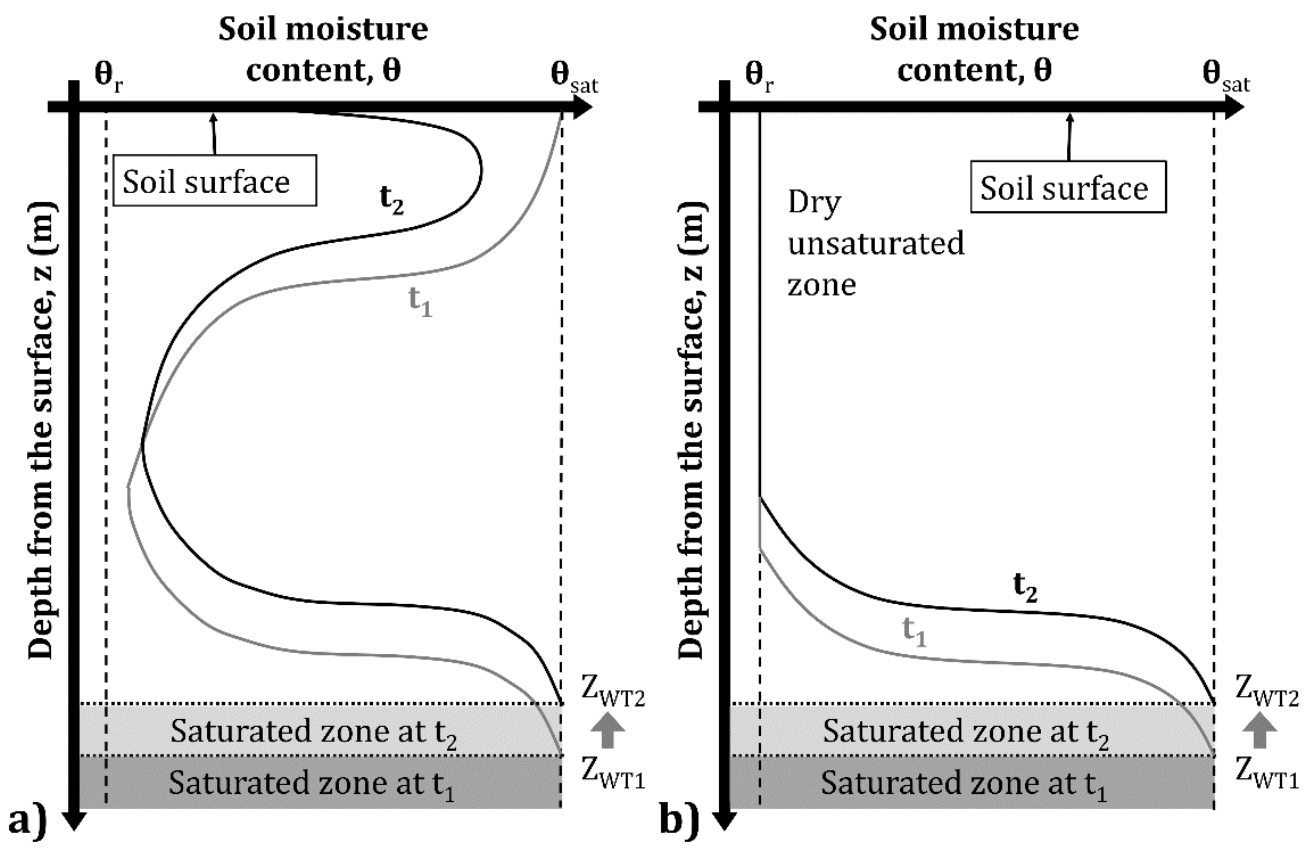

Figure 2.8: Graphic representation of: (a) "wet" and (b)"dry" unsaturated zone conditions for a rising water table; $\theta_{\mathrm{r}}$ is residual water content; $\theta_{\text {sat }}$ is saturation water content; the curves represent soil moisture profiles with depth, at the beginning $\left(t_{1}\right)$ and at the end $\left(t_{2}\right)$ of the evaporation process, corresponding to water table depths $Z_{W T 1}$ and $Z_{W T 2}$ respectively.

\subsubsection{The Hydrus1D model}

In this model, the mass conservation equation is written as in Saito et al. (2006):

$\frac{\partial \theta}{\partial t}=\frac{\partial q_{\mathrm{L}}}{\partial z}-\frac{\partial q_{\mathrm{V}}}{\partial z}$

where, $q_{\mathrm{L}}$ and $q_{\mathrm{v}}$ are the flux densities of liquid water and water vapour, respectively; $t$ is time; $z$ is the vertical axis, positive upward. The flux densities of liquid and water vapour are calculated in terms of their isothermal and thermal components:

$q_{\mathrm{L}}=q_{\mathrm{L} \Psi}+q_{\mathrm{LT}}=-K_{\mathrm{L} \Psi}\left(\frac{\partial \Psi}{\partial z}+1\right)-K_{\mathrm{LT}} \frac{\partial \mathrm{T}_{s}}{\partial z}$

$q_{\mathrm{v}}=q_{\mathrm{v} \Psi}+q_{\mathrm{vT}}=-K_{\mathrm{v} \Psi} \frac{\partial h}{\partial z}-K_{\mathrm{vT}} \frac{\partial \mathrm{T}_{s}}{\partial z}$ 
where, $q_{\mathrm{L} \psi}, q_{\mathrm{LT}}, q_{\mathrm{v} \psi}, q_{\mathrm{VT}}$ are respectively the isothermal and thermal liquid water flux densities, and the isothermal and thermal water vapour flux densities; $\Psi$ is the matric potential head; $\mathrm{T}_{S}$ is the soil temperature; and $K_{\mathrm{L} \psi}$, $K_{\mathrm{LT}}$ are the isothermal and thermal liquid water hydraulic conductivities, and $K_{\mathrm{v} \psi}$ and $K_{\mathrm{v} T}$ are the isothermal and thermal water vapour hydraulic conductivities, respectively. Combining Equations 2.26, 2.30 and 2.31, yields the governing liquid water and water vapour flow equation:

$$
\begin{aligned}
\frac{\partial \theta}{\partial t} & =\frac{\partial}{\partial z}\left[K_{\mathrm{L} \Psi}\left(\frac{\partial \Psi}{\partial z}+1\right)+K_{\mathrm{LT}} \frac{\partial \mathrm{T}}{\partial z}+K_{\mathrm{v} \Psi} \frac{\partial \Psi}{\partial z}+K_{\mathrm{VT}} \frac{\partial \mathrm{T}}{\partial z}\right]-S / S= \\
& =\frac{\partial q_{\mathrm{V}}}{\partial z}\left[K_{\Psi}\left(\frac{\partial \Psi}{\partial z}+1\right)+K_{\mathrm{T}} \frac{\partial \mathrm{T}}{\partial z}\right]-S / S
\end{aligned}
$$

where, $S / S$ is the source/sink term, $K_{\mathrm{h}}$ and $K_{\mathrm{T}}$ are, respectively, the isothermal and thermal total hydraulic conductivities, and

$K_{\Psi}=K_{\mathrm{L} \Psi}+K_{\mathrm{V} \Psi}$

$K_{\mathrm{T}}=K_{\mathrm{LT}}+K_{\mathrm{vT}}$

For a detailed description of the coupled version of Hydrus1D code, the reader is referred to Saito et al. (2006). The above mass balance equation has the same form as reported in Sophocleous (1979), which was criticized by Milly (1982) and reviewed in Prunty (2009), because adding the thermal term (KT) was not justified. However, in semi-arid and arid conditions, the thermal component of the liquid flow is usually negligible, and does not affect the reliability of the simulation, so the coupled version of the Hydrus1D code is used taking into account its limitations. 
A framework for sourcing of evaporation between saturated and unsaturated zone in bare soil condition 


\section{Chapter 3}

Groundwater and unsaturated zone evaporation and transpiration in a semi-arid open woodland 

woodland

\section{Abstract:}

Studies on evapotranspiration partitioning under eddy covariance (EC) towers rarely address the separate effects of transpiration and evaporation on groundwater resources. Such partitioning is important to accurately assess groundwater resources, especially in arid and semi-arid areas.

The main objective of this study was to partition (evaluate separately) the evaporation and transpiration components of evapotranspiration, originated either from saturated or unsaturated zone, and estimate their contributions in a semi-arid area characterized by relatively shallow groundwater Table ( $0-10$ $\mathrm{m}$ deep).

Evapotranspiration, tree transpiration and subsurface evaporation were estimated with EC tower, using sap flow methods and Hydrus1D model, respectively. To set up the Hydrus1D model, soil material properties, soil moisture, soil temperature, soil matric potential and water table depth were measured in the area. The tree transpiration was sourced into groundwater and unsaturated zone components $\left(0.017 \mathrm{~mm} \mathrm{~d}^{-1}\right.$ for both) and accounted for only $6 \%$ of the evapotranspiration measured by the EC tower $\left(0.565 \mathrm{~mm} \mathrm{~d}^{-1}\right)$, due to the low canopy coverage in the study area (7\%). The subsurface evaporation fluxes were also sourced into groundwater and unsaturated zone components using the SOURCE package, and their relative relevance in total evapotranspiration was assessed.

Subsurface evaporation was the main flux year-round $\left(0.526 \mathrm{~mm} \mathrm{~d}^{-1}\right)$. During late autumn, winter and early spring time, the unsaturated zone evaporation was dominant, while in dry summer the relevance of groundwater evaporation increased, reaching one third of evapotranspiration, although errors in the water balance closure point still at its possible underestimation. The results show that, in arid and semi-arid areas with sparse vegetation, the often neglected groundwater evaporation is a relevant contribution to evapotranspiration, and that water vapour flow should be taken into account in the calculation of extinction depth.

This Chapter is based on:

Balugani, E., Lubczynski, M. W., Reyes-Acosta, L., van der Tol, C., Frances, A. P., Metselaar, K., (2017), Groundwater and unsaturated zone evaporation and transpiration in a semi-arid open woodland. Journal of Hydrology, 547: 54-66. 


\subsection{Introduction}

In arid and semi-arid areas the scarce water resources are usually stored as groundwater. While the precipitation in the Mediterranean region is decreasing (Gualdi et al., 2013; Mariotti et al., 2015), the demand for the limited groundwater resources is increasing (Scanlon et al., 2006). In such conditions it is imperative to quantify the main water input constraining groundwater resources, i.e. the net groundwater recharge (Chenini and Ben Mammou, 2010). The evapotranspiration of groundwater resources is often underestimated, both because evaporation processes are not yet included in the theory (Zeng et al., 2011) and because transpiration from roots tapping the water table is not taken into account (Favreau et al., 2009; Miller et al., 2010a). The underestimation of groundwater evapotranspiration often results in the overestimation of the net recharge. Therefore it is critical to define accurately groundwater evapotranspiration which may represent a small but relevant reference percentage of total evapotranspiration.

There are various methods to estimate groundwater recharge, but it is difficult to know which one is the most reliable (Scanlon, Healy and Cook, 2002); for routine recharge estimation the best choice is a soil moisture recharge technique, provided all the important physical and physiological processes are represented adequately (Rushton et al., 2006). For example, water infiltrating in the soil after sparse rain events often evaporates completely before reaching the water table (Tweed et al., 2011); another example is that of the transpiration of water from trees, which can tap the water table with their roots (Favreau et al., 2009; Miller et al., 2010a). A good knowledge of evapotranspiration processes is, therefore, fundamental to sustainable agriculture and groundwater management, particularly in water scarce environments.

During dry seasons, mainly in arid and semi-arid locations, high evapotranspiration (ET) quickly depletes the unsaturated zone water, exposing the saturated zone to groundwater evapotranspiration $\left(E T_{g}\right)$ or, following the partitioning concept, to the processes of groundwater evaporation $\left(E_{g}\right)$ and groundwater transpiration $\left(T_{g}\right)$. The process of separating saturated from unsaturated zone fluxes is hereafter referred as sourcing. In this thsis we followed the terminology of Lubczynski and Gurwin (2005) discussed in Section 1.1.1, Equations 1.1 and 1.2. $E T_{u}$ is the unsaturated water evapotranspiration, $E_{u}$ and $T_{u}$ are the respective evaporation and transpiration components depleting the unsaturated zone (all in $L \mathrm{~T}^{1}$ units).

In recent years, interest in $E T_{S S}$ partitioning into $T_{S S}$ and $E_{S S}$ (Equations 2.1 and 2.2) has increased due to the development of new monitoring methods, which permit independent measurement of various water fluxes at different time scales and under different climatic conditions (Zhang et al., 2016). Both the Bowen ratio (only in wet conditions) and the eddy covariance (EC) methods (Perez et al., 1999) permit reliable measurement of latent heat flux (and 

woodland

therefore $E T$ ) but over relatively small areas and only in specific conditions (e.g. stable conditions for Bowen ratio). Thanks to so called footprint models, the area sampled by both Bowen ratio and EC methods can be determined with large spatial and temporal precision. Besides, it is possible nowadays to estimate $E_{S S}$ from models applying semi-continuous soil moisture and matric potential profile measurements (Kizito et al., 2008), while $E_{s}$ can be estimated from pan evaporation and measurement of tree interception using tipping buckets and gutters placed under a tree canopy (Ghimire et al., 2012; Hassan et al., 2017) and by interception models. Finally, in situ sap flow measurements (Granier, 1985) can be used to estimate tree transpiration $\left(T_{s S}\right)$ when using appropriate sampling, measuring and upscaling techniques (Granier, 1987; Reyes-Acosta and Lubczynski, 2013; Reyes-Acosta and Lubczynski, 2014). In this study we propose to combine all these techniques to determine the contributions of $E_{S}, E_{S S}$ and $T_{S S}$ to the total $E T$ for different land covers.

The partitioning of ET is particularly effective in landscapes where few plant species are present and individual tree canopies can be identified. In these landscapes $T_{S S}$ is restricted to trees and can be defined using sap flow measurements, while $E_{S S}$ is the only water output in the bare soil areas outside tree root influence. Tree root influence area is understood as the area where chemical and physical conditions (including water pressure head) are influenced by the presence of roots. Wallace (1997) presents an example of an ET partitioning study in such a landscape; ET was measured by means of EC over an area with a clear heterogeneity of land cover, i.e with patches of woodland and bare soil.

The sap flow technique does not work for grass. Whenever grass is present and active another technique is required to assess grass transpiration, either by modelling (Feddes et al., 1978) or by direct measuring, for example using a gas chamber (Yepez et al., 2005). Sometimes, however, in ET partitioning studies, grass transpiration is lumped together with subsurface evaporation and both regarded as the difference between the EC tower measurements of ET and the sap flow measurements of tree transpiration (Paço et al., 2009).

No groundwater influence on $E T$ rates has been a common assumption in partitioning studies, although groundwater evapotranspiration can be a substantial component of water balance, particularly in dry conditions, which, when not taken into account, can result in underestimation of total ET. In Wilson et al. (2001) the depth at which soil water was supposed to play a negligible role in total ET was set to $0.75 \mathrm{~m}$ below the ground surface (b.g.s.), probably due to the wet climate characteristic of the area studied. Baldocchi et al. (2004) showed the typical condition of a semi-arid, open woodland landscape: a poorly developed soil lying on top of a fractured granite bedrock regarded as non-evaporating (no information on water table depth was given in the article); in that case all subsurface evaporation was assumed to come from the unsaturated zone while the groundwater contained in the bedrock was assumed to be non-evaporating. Yaseef et al. (2010) defined bare soil $E_{s s}$ 
as $36 \%$ of $E T$ within a year in a semi-arid climate, assuming zero $E_{g}$ because of the $300 \mathrm{~m}$ b.g.s. groundwater table.

Williams et al. (2004) study was conducted in a periodically irrigated semiarid area olive orchard (400 trees ha ${ }^{1}$; water table depth, soil composition and type of bedrock are not provided). When the top soil layer was irrigated it was moist enough to meet the potential evapotranspiration demand $\left(E_{u}=E T_{p}\right)$ without affecting soil moisture in the deeper soil profile; in contrast, when the soil was dry long after irrigation, $E_{S S}$ was assumed to be negligible $\left(E T_{S S}=T_{S S}\right)$. The study used the isotopic method (Zhang et al., 2010) to partition the ET sources: water evaporated from the soil is depleted in the heavy isotopes compared to the water transpired from leaf surfaces; therefore the analysis of water vapour collected at the EC station gives indication of the individual contributions of $E_{s s}$ and $T_{s s}$. The tree sap flow measurements $\left(T_{s s}\right)$ underestimated the EC measured $E T_{S S}$ by $24 \%$ in the period before irrigation. The authors assumed that this was due to their sap flow method underestimating the total sap flow of the trees, based on the fact that the isotopic partitioning showed no soil evaporation for the period before irrigation. To overcome the mismatch, the $T_{S S}$ calculation from sap flow measurements was re-calibrated based on the EC measured ET.

The relevance of groundwater evapotranspiration, and hence the importance of sourcing, is supported by recent studies. For example, groundwater uptake from tree tap-roots was studied by Miller et al. (2010) using the water table fluctuation method (Loheide et al., 2005) in an oak savannah located in the western Sierra Nevada foothills. Tree canopy cover was $40 \%$ of the studied area and water table was at $8 \mathrm{~m}$ depth b.g.s. Their results showed that groundwater uptake contributed up to $90 \%$ of total $E T$ during the dry season. However, the water table fluctuation method applied by Miller et al. (2010) could not distinguish between root groundwater uptake $\left(T_{g}\right)$ and soil groundwater evaporation $\left(E_{g}\right)$. Hence they assumed that $E_{g}$ was negligible, attributing groundwater discharge entirely to $T_{g}$.

Recent studies demonstrated that our understanding of the processes of subsurface evaporation in dry conditions is still incomplete, as it is probably underestimated (Li et al., 2010; Smits et al., 2011; Soylu et al., 2011; Zeng et al., 2011a), mainly due to underestimation of groundwater evaporation (Chapter 2, Balugani et al., 2017). It is argued, for example, that vapour flow should be taken into account for a correct estimation of $E_{s S}$ (Saito et al., 2006; Bittelli et al., 2008; Zeng et al., 2009b). In partitioning studies, the kind of soil model typically used was a bucket model (Miller et al., 2010), but the evaporation extinction depth (the depth at which the evaporation from a water table becomes negligible) should be calculated using transient flow models, as argued by Shah et al. (2007). However, even the Hydrus1D model used by Shah et al. (2007) did not include heat and vapour flow. Vapour flow through the "almost dry" unsaturated zone can result in even deeper evaporation 

woodland

extinction depths than defined by Shah et al. (2007, see Section 2.3.1), meaning that $E_{g}$ fluxes could be greater than estimated so far. To our knowledge, no studies performed both partitioning and sourcing of ET to investigate the separate contributions of $E_{g}$ and $T_{g}$ in the overall water budget, taking into account the heat and water vapour flow in the calculation of subsurface evaporation.

The research questions of this study are: What is the contribution of $E_{g}$ and $T_{g}$ to the total $E T$ in the investigated semi-arid, open woodland area characterized by shallow water table? How does $E_{g}$ change in time? To answer these questions, the following objectives were defined:

1. experimentally partition ET measured with EC method into: (i) $E_{S S}$, modeled using Hydrus1D model applying heat and water vapour flow; and (ii) $T_{s S}$, estimated by upscaling of sap flow measurements;

2. source $E_{s s}$ into $E_{g}$ and $E_{u}$ and source $T_{s s}$ following the protocol of ReyesAcosta et al. (2015);

3. evaluate how the relative relevance of $E_{g}$ versus $E_{u}$ varies in time in a semi-arid open woodland with a shallow groundwater table (Chapter 2, Balugani et al. 2016).

These objectives provide the structural sub-headings used in the following Materials and Methods, Results and Discussion Sections.

\subsection{Materials and methods}

\subsubsection{Study area}

To study partitioning and sourcing of $E T$ in semi-arid conditions we selected a $2 \times 2 \mathrm{~km}$ study area, further referred as the maximum footprint area (MF, Figure 3.1 ), enclosing the maximum extent of all the footprints of the EC tower installed in the centre of that area. The MF is characterized by shallow water table and open woodland vegetation. The selected area is located in the northern part of the Sardon Catchment, described in section 1.4. The remote sensing (Quickbird and WorldView-II images) analysis of the MF area, executed following the protocol described in Reyes and Lubczynski (2013) for the whole Sardon catchment, showed that the canopy coverage in the MF study area was 7\%. The two Quercus spp. species had nearly equal canopy coverage; however, Quercus ilex species was predominant in the eastern, elevated part while Quercus pyrenaica in the western, lower part (the Sardon river valley, Figure 3.1). The study was conducted in the years 2009 and 2010 . It is formed by weathering of the underlying fractured granite rock. Extensive soil sampling was conducted in the study area to determine top soil water content, soil hydraulic properties, soil texture and depth to bedrock. Double ring infiltrometer tests were used to determine vertical hydraulic conductivity (Figure 3.1). 


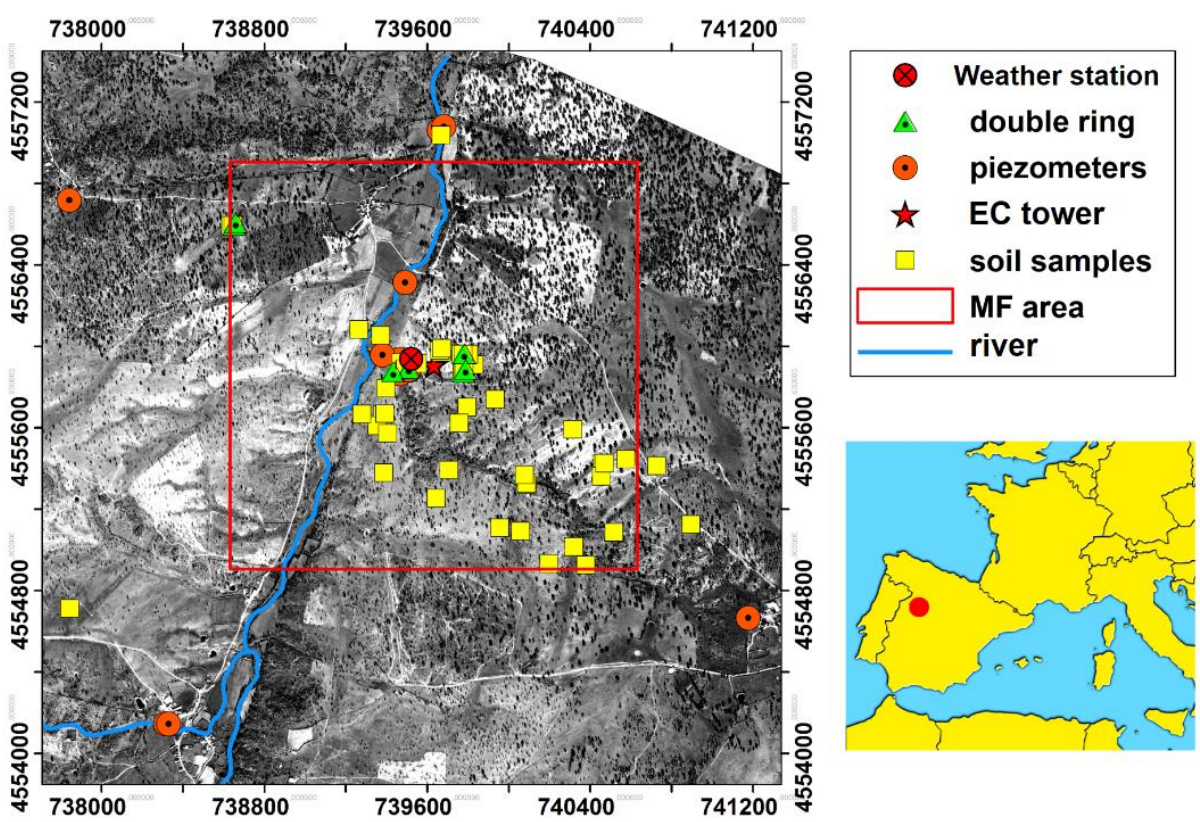

Figure 3.1: QuickBird image of the $22 \mathrm{~km}$ maximum footprint (MF) study area, showing the position of the eddy covariance $(E C)$ tower and of the piezometers close to the tower; the black dots are the tree canopies. The image is projected in WGS 84 - UTM zone 29N (metres).

\subsubsection{Partitioning and sourcing framework}

To partition and source ET, we: (i) installed an EC tower in the MF area to measure ET; (ii) measured sap flow in the trees to estimate $T_{s s}$; and (iii) monitored microclimatic conditions, soil moisture, matric potential and water table depth $\left(Z_{W T}\right)$ to setup, calibrate and validate a soil parameterization in the Hydrus1D model (Simunek et al., 2009). The ET measured by the EC tower is a point measurement (taken at the top of the tower); this measurement can be related to actual $E T$ at ground level by a probability density function, called the EC tower's footprint (Göckede et al., 2004). The footprint of an EC tower changes its size, position and shape in time, depending on wind strength and direction; an example of the EC tower footprint is shown in Figure 3.2.

In order to obtain and partition $E T_{s S}$, i.e. to estimate $E_{S S}$ and $T_{S S}$ separately and source each of them in the footprint area, we:

1. calculated the EC tower footprint every 30 min (Section 3.2.3.1);

2. determined the $2 \times 2 \mathrm{~km}$ MF study area (Figure 3.1);

3. divided the MF area into two categories (Figure 3.2): (i) the bare soil outside the ground projection of tree canopies where we assumed that only $E_{s s}$ was taking place, and (ii) the area corresponding to ground 

woodland

projection of tree canopies where we assumed that only $T_{S S}$ was taking place;

4. upscaled tree sap flow measurements to obtain maps of $T_{s s}^{M F}$ (estimated $T_{s S}$ in the MF area) every 30 min (Section 3.2.3.2, following the protocol described in Reyes-Acosta et al. 2015);

5. modelled $E_{S S}$ using the Hydrus1D model based on soil measuring profiles and water table measurement in the area and upscaled it to obtain maps of $E_{s s}^{M F}$ every $30 \mathrm{~min}$;

6. added $T_{s s}^{M F}$ and $E_{s S}^{M F}$ maps together to obtain $E T_{s s}^{M F}=E_{s S}^{M F}+T_{s S}^{M F}$ and multiplied them by the probability density function of the footprint to obtain an estimate of $E T_{S S}^{M F}$ in that particular footprint to be compared with EC tower evapotranspiration $\left(E T^{e c}\right)$.

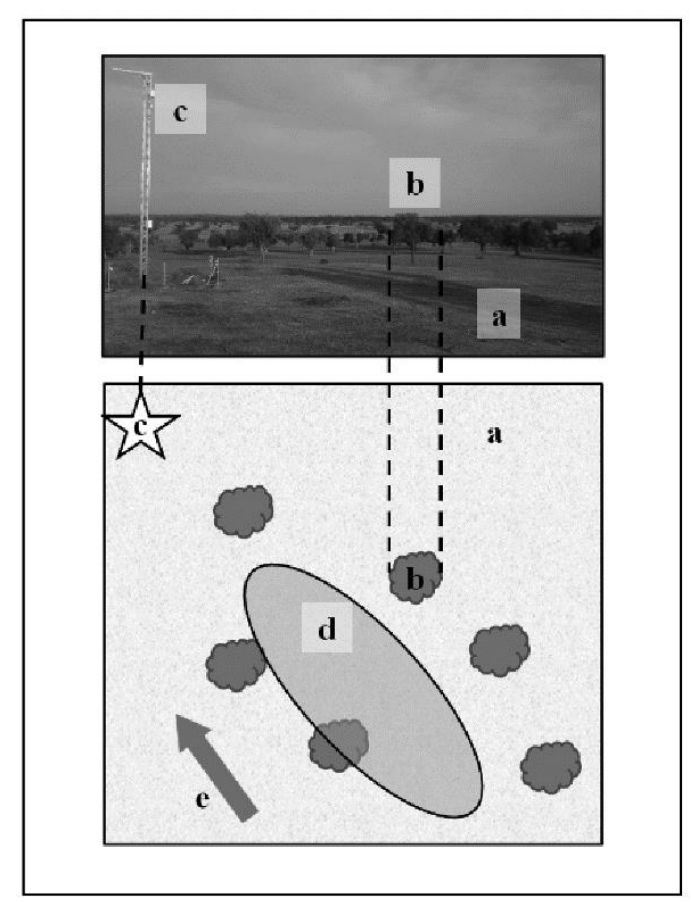

Figure 3.2: Picture of the eddy covariance (EC) tower (upper part) and schematic example of the subdivision for the upscaling procedure (lower part): (a) bare soil, where we assumed only subsurface evaporation $\left(E_{s S}\right)$ was present (no tree transpiration $T_{s s}$ ); (b) canopy areas, where we assumed only $T_{s s}$ was present (no $E_{s s}$ ); (c) EC tower position; (d) an example of EC tower footprint, (e) wind direction implying the presented footprint direction.

In order to source $E_{s s}$ and $T_{s s}$ to estimate $E_{g}, E_{u}, T_{g}$, and $T_{u}$ we:

1. used the SOURCE package (Chapter 2, Balugani et al. 2016) and upscaled it to obtain maps of $E_{g}$ and $E_{u}$ every 30 min (Section 3.2.3.3); and 
2. sourced $T_{s s}$ using $T_{g}$ and $T_{u}$ estimates by (Reyes-Acosta, Su and Lubczynski, 2015), to obtain $T_{g}$ and $T_{u}$ maps every $30 \mathrm{~min}$.

As in the partitioning part, the four maps of $E_{g}, E_{u}, T_{g}$, and $T_{u}$ were multiplied by the probability density function of the footprint, to obtain estimates of the individual sourced components and compare their sum with $E T^{e c}$. The whole process is shown as a flowchart in Figure 3.3.

The assumption that tree root water uptake is limited to the ground projection of the canopy area is based on the simplifying assumption that the tree roots are limited to that area (Reyes-Acosta and Lubczynski, 2013). That assumption was justified by direct observation while digging the area for soil sample collection and soil moisture profile preparation. As the tree canopy coverage in the study area was low and the experiment was carried out in dry summer seasons of 2009 and 2010 when grass was dormant and rains rare, the convenient assumption of negligible $E_{s}$, mainly due to interception, was justified. Also due to the very short vegetative period of the sparse grasses in the area (March-May, DOY 60-140), and continuous cattle grazing, the assumption of negligible grass interception and transpiration is justified.

\subsubsection{Techniques used}

\subsubsection{Evapotranspiration measured by EC tower}

We used an EC tower to measure $E T^{e c}$. We installed the EC system on the 10 $\mathrm{m}$ high tower located on an elevated point in the northern part of the Sardon catchment, within an oak open woodland landscape (Figure 3.1; trees average height is $4-5 \mathrm{~m}$ ). The system consisted of:

1. CNR1 four components net radiometer (Kipp and Zonen, Delft, The Netherlands).

2. CSAT3 sonic anemometer (Campbell Scientific Inc., Utah, USA).

3. LI7500 gas analyser (Licor Biosciences, Nebraska, USA).

4. WXT520 "multi weather sensor" for measurements of wind speed, direction, air temperature and humidity (Vaisala Oyj, Helsinki, Finland).

The tower was also equipped with two soil heat flux plates and 19 soil temperature sensors for the energy balance closure. The data were processed with the software AltEddy (www.climatexchange.nl/projects/alteddy/) of the Alterra Institute ( Wageningen University, The Netherlands; van der Tol, 2012). The footprint calculation was based on Hsieh et al. (2000) for the main wind direction and on Detto et al. (2006) for the crosswind direction. 


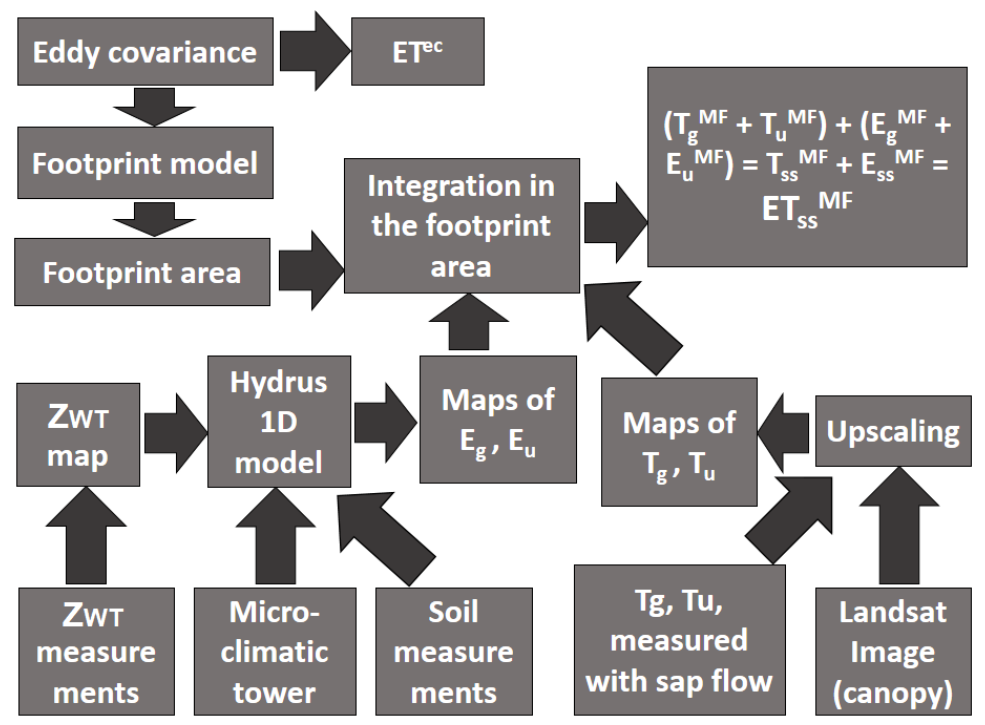

Figure 3.3: Flowchart of the partitioning framework. The Hydrus1D model was run for every $1 \mathrm{~m}^{-2}$ of the $Z_{W T}$ map within the maximum footprint (MF) study area.

When evaluating the peaks of evapotranspiration after rainfall, the question arises how reliable the EC data are during and shortly after rainfall, as heavy rainfall may affect the CSAT3 measurements when droplets block the sound transmission (Munger et al., 2012). According to the LI7500 manual, droplets on the infrared gas analyser may also hamper the gas concentration measurements.

(Heusinkveld et al., 2008) quantified the effects of dew on the LI7500 sensor by comparing measurements of two devices, one heated and one not heated, as in the case of our instrument. Although we took care to minimize the effects of droplets by mounting the LI7500 tilted, the applied quality filtering still resulted in missing evapotranspiration data in wet conditions. For our analysis it was important to assess whether such data gaps affected the estimate of the daily average ET. If failure of the EC technique coincided with a high evapotranspiration rate, then the daily average $E T^{e c}$ underestimated real $E T$. To verify whether this was the case, first we analysed the fraction of half-hourly data that was flagged as high quality versus the number of hours and days since last rainfall. This procedure showed how the quality of the data was correlated with sensor wetness. Second, we assessed how sensor wetness was correlated to $E T^{e c}$, by plotting $E T^{e c}$ versus hours since last rainfall. The two correlations together indicated how reliable daily $E T^{e c}$ were. 


\subsubsection{Tree transpiration estimated with sap flow}

To quantify the contribution of tree transpiration to $E T$, we took sap flow measurements during the months of August and September in 2009 and in 2010 using the optimization method described in Reyes-Acosta and Lubczynski (2014), which combines thermal dissipation probes (TDP) measurements (Granier, 1985) with heat field deformation (HFD) measurements (Nadezhdina et al., 1998; David et al., 2007). The optimization method consisted of three steps: (i) obtaining the TDP sap flow measurements using a standard TDP system (UP Gmbh, Germany) in cyclic switching power mode and correcting them using the cyclic heat dissipation (CHD) method (Lubczynski et al., 2012; Reyes-Acosta et al., 2012) to eliminate the natural thermal gradient (NTG) bias; (ii) correcting the TDP measurements for night flow using the HFD measurements (ICT international, Armidale, NSW, Australia); and (iii) correcting the sap flow data for radial and circumferential heterogeneity using multiple HFD measurements (Reyes-Acosta and Lubczynski, 2014).

To assess the sources of water transpired by trees $\left(T_{g}\right.$ or $\left.T_{u}\right)$, we applied the methodology described by Lubczynski (2009) to experimental data described in Reyes-Acosta et al. (2015). Constant doses of deuterated water were injected during $24 \mathrm{~h}$ into the groundwater using a network of piezometers drilled around the trees, following Brooks et al. (2002). This setup maximized the plume shape and the chemical dispersion through the soil. During and after the deuterated water injection, we used sap flow sensors to monitor $T_{s s}$ and collected xylem water, soil water and groundwater samples to assess the sources' contributions to $T_{s s}$ (Reyes-Acosta et al., 2015).

To upscale the transpiration estimates for the MF area we: (i) established the upscaling functions for each tree species using the procedure explained in Reyes and Lubczynski (2013) after digital mapping of the trees in the study area using a QuickBird image as reference; (ii) upscaled the 30 min sap flow measurements into whole-tree scale and to the investigated footprint area; (iii) extrapolated the results of the sap flow measurement campaign temporally into the whole dry summer period applying an artificial neural network model (Liu et al., 2009); and (iv) sourced sap flow $T_{s s}^{M F}$ into $T_{u}^{M F}$ and $T_{g}^{M F}$ using deuterium tracing experiments (Reyes-Acosta and Lubczynski, 2011; ReyesAcosta et al., 2015) for the whole dry summer period (according to the measurements, performed during dry summer campaigns of 2009 and 2010, Reyes-Acosta and Lubczynski, 2011).

\subsubsection{Evaporation modelled with Hydrus1D}

To model bare soil $E_{s s}$ we characterized spatially the soil properties, the water table depth and the soil moisture in the MF area from 2009 to 2015. 31 locations were sampled at multiple depths to characterize the soil texture variability. Also double infiltrometer tests were conducted in 7 locations to determine the vertical hydraulic conductivity in the MF area. To investigate the groundwater, we measured water table levels in 6 shallow piezometers 

woodland

installed within the MF area and 4 other piezometers outside the MF area but close to its borders (Figure 3.1; one of them penetrated the bedrock). To measure soil water content at three locations, multi-sensor Hydraprobes (Stevens Water Monitoring Systems, Inc.), were installed at four different depths $(25,50,75,100 \mathrm{~cm}$ b.g.s.). We also installed Decagon matric potential sensors at two different depths in each of the three above-mentioned profiles at 25 and $75 \mathrm{~cm}$ b.g.s. and polymer tensiometers (van der Ploeg et al., 2008) at $15 \mathrm{~cm}$ b.g.s. in two of the three profiles. In addition to the EC tower, a standard, $2 \mathrm{~m}$ high $E T_{p}$ weather station was available as a backup at distance of $100 \mathrm{~m}$ (Figure 3.1).

We modelled the soil water fluxes in the monitored profiles with the Hydrus1D code (Simunek et al., 2008) using the soil physical parameters, the measured water levels and the measurements from $E T_{p}$ weather station. We used the Hydrus1D version which solves the equation for the coupled flow of heat, liquid water and vapour water (Saito et al., 2006) in order to account for evaporation by water vapour flow to the surface. The use of a 1D model for the unsaturated zone is justified due to the low relevance of the lateral water flow along the small topographic gradients in the study area.

In each of the three Hydrus1D simulated soil moisture profiles, we set the measured $Z_{W T}$ as bottom boundary condition, the measurements from the weather station (net radiation, air humidity, air temperature, precipitation, wind speed, soil temperature) as top boundary condition and we applied the soil physical parameters as determined from the soil samples and from the infiltrometer tests. The model was calibrated against the soil temperature, soil matric potential and soil moisture monitored in the three profiles (for more information about the calibration, refer to Balugani et al. 2017). During the calibration period, the soil was completely bare (no grass present). Finally, in 2011 we validated the Hydrus1D model performing an infiltration experiment on one of the monitored profiles.

We then used the validated Hydrus1D parameters to model $E_{s S}^{M F}$ for the various water table depths and depths to bedrock in the area. First, we created maps of water table depth (bottom boundary condition for the model) and soil depth (depth of the modelled profile) with $1 \mathrm{~m}^{-2}$ precision. Soil hydraulic properties were found to be homogeneous in the MF area, so no map was created for them. Second, we grouped every pixel in the area with the same soil depth and $Z_{W T}$ in different sets and we ran Hydrus1D for each of these sets, using: (i) the measured evaporative conditions as upper boundary conditions for all the sets; (ii) the soil depth in that set for the model geometry; (iii) the same soil hydraulic properties for all the sets; and (iv) the $Z_{W T}$ maps from (Hassan et al., 2014) to determine the bottom boundary condition of each set.

$E_{s s}$ calculated by Hydrus1D was subsequently sourced into $E_{u}$ and $E_{g}$ using a post-processing package called SOURCE (for the algorithm used, refer to Balugani et al. 2016). The SOURCE package analyses the output files of 
Hydrus1D model containing information about soil moisture and water fluxes at all nodes in the modelled profile and fluxes at the model boundaries. This information is then used to make a water balance for the soil profile to determine $E_{g}$ and $E_{u}$. Therefore, the definitions of $E_{g}$ and $E_{u}$ in the SOURCE package are formulated from a water balance point of view: if $E_{S S}$ is a loss of water stored in the profile, then it is investigated which zone of the soil (the saturated or the unsaturated zone) was affected by that loss. In other words, $E_{g}$ is defined as "the evaporative flux corresponding to the decrease of water stored in the saturated zone (groundwater) due to loss of water vapour at ground surface" while $E_{u}$ is defined as "the evaporative flux at the ground surface corresponding to the decrease of water stored in the unsaturated zone" (Chapter 2, Balugani et al. 2016).

\subsection{Results}

\subsubsection{Partitioning of ET}

\subsubsection{Evapotranspiration, transpiration and evaporation estimates}

During the 2009-2010 study period we observed typical patterns of dry summer and winter rainfall and $E T_{p}$ as described in Section 3.2.1; the yearly precipitation for the two study years differed: $523 \mathrm{~mm} \mathrm{y}^{-1}$ in 2009 and $653 \mathrm{~mm}$ $\mathrm{y}^{-1}$ in 2010; referring to the hydrological years, the values are $310 \mathrm{~mm}$ from October 2008 to September 2009, and $702 \mathrm{~mm}$ from October 2009 to September 2010. In the dry summers the rainfall events were rare, but, if present, of high intensity (e.g. the two events at the end of the dry summer 2009 and 2010, both of $50 \mathrm{~mm} \mathrm{~d}^{1}$, Figure 3.4), while $E T_{p}$ was high, up to $7 \mathrm{~mm}$ $\mathrm{d}^{-1}$ at the peak of the dry summer 2010. During winter, the rainfall events were more frequent but less intense, while $E T_{p}$ conditions were low $\left(2 \mathrm{~mm} \mathrm{~d}^{-1}\right.$, Figure 3.4 ), due to low temperatures, low radiation and high relative humidity (not shown). 

woodland

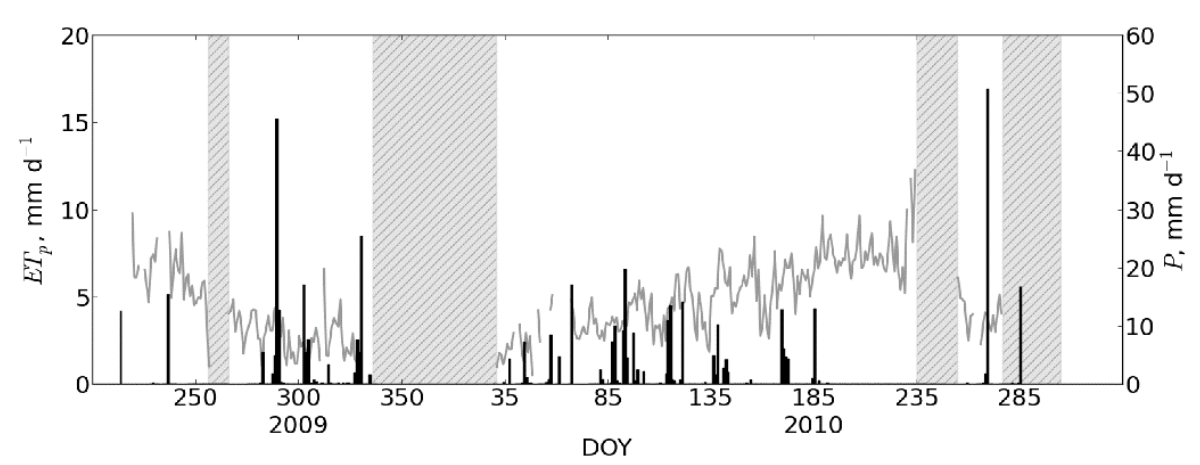

Figure 3.4: Precipitation ( $P$, black bars) and potential evapotranspiration $\left(E T_{p}\right.$, gray line) calculated with Penman-Monteith method. The measurements start on DOY 211 of year 2009 (30 July, 2009) and stop on DOY 310 of 2010 (27 December 2010).

The tree transpiration had the same magnitude in the two dry summers of 2009 and 2010 (Figure 3.5, also Reyes and Lubczynski, 2013) despite of differences in rainfall and $Z_{W T}$. The very low value of the upscaled, dry summer tree transpiration $\left(T_{s s}^{M F}=0.03 \mathrm{~mm} \mathrm{~d}^{1}\right.$ ) is due to the low tree density (canopy coverage $7 \%$ ). During dry summers, $E T_{p}$ was higher and the unsaturated zone was mostly dry, but the tree water demand was satisfied by groundwater uptake (Reyes-Acosta et al., 2015).

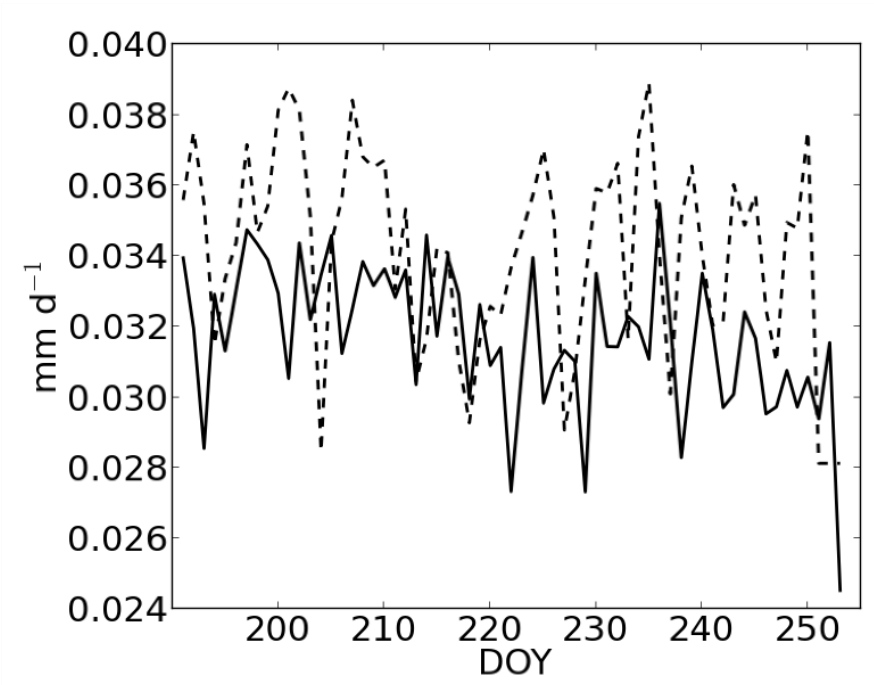

Figure 3.5: Upscaled $T_{s s}^{M F}$ for the maximum footprint MF study area, for the dry summers 2009 (dashed line) and 2010 (solid line), i.e. for the periods from DOY 190 (9 July) to DOY 255 (12 September). 
The soil moisture dataset from one of the three measured profiles is shown in Figure 3.6 together with the $Z_{W T}$ recorded in a piezometer placed at $3 \mathrm{~m}$ distance; all other datasets showed similar patterns. During the dry summer periods (DOY 200-300 of year 2009, 19 July to 27 October, and DOY 150-260 of year 2010, 30 May and 17 September) the soil moisture remained low, decreasing slowly while drying. At that time there was no recharge and the water table was slowly decreasing due to the combined effect of groundwater outflow to the stream and groundwater evapotranspiration $\left(E T_{g}\right)$. The first rain events started to moisten the soil profile already around DOY 280 (19 July) of year 2009 and DOY 260 (17 September) of year 2010, until moisture exceeded field capacity and groundwater recharge took place (DOY 357 of year 2009-23 December); at that time the soil moisture at 50, 75 and $100 \mathrm{~cm}$ b.g.s. reached a value close to saturation due to the high water table, while the soil moisture at $25 \mathrm{~cm}$ b.g.s. only occasionally showed an increase due to infiltrating rain.

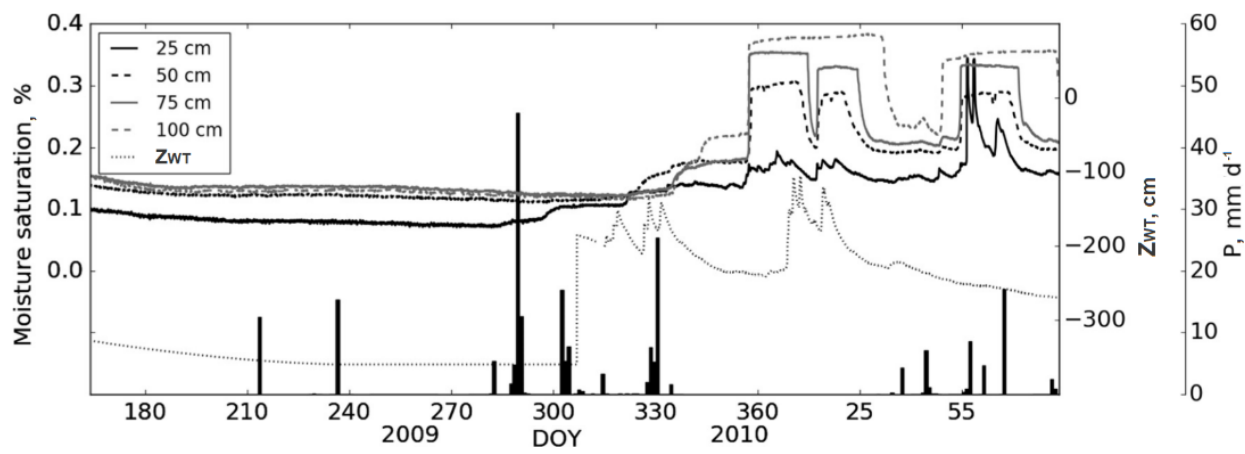

Figure 3.6: Water table depth $\left(Z_{W T}\right)$ plotted together with soil moisture saturation measured at four depths, starting at DOY 160 year 2009 (9 June) until DOY 85 year 2010 (26 March). In the period between DOY 290 and 345 (17 October and 11 December) for 2009 the piezometer was dry: in this period water table level was, hence, deeper than $3.6 \mathrm{~m}$. The few days gap in soil moisture data for dry summer 2010 was due to low battery. The bars represent the precipitation events $(P)$.

\subsubsection{Comparison of $E T^{e c}, E_{s s}^{M F}$ and $T_{s s}^{M F}$}

The time series of $E T^{e c}, E_{S S}^{M F}$ and $T_{s S}^{M F}$ for the year 2009 and 2010 are shown in Figures 3.5 and 3.7. Rainy days show poorer quality data and higher $E T^{e c}$ than dry days, but the problem of poor quality data was limited to the first $90 \mathrm{~min}$ after rainfall (for the procedure followed to check data quality, refer to Sections 3.2.3.1 and 3.4.2.1).

$E_{S S}^{M F}$ followed the trend of $E T^{e c}$ (Figure 3.7), especially in the winter period, so they are described together. In general, after $E T^{e c}$ and $E_{S S}^{M F}$ reached a maximum in April 2010 (DOY 110-120, 20-30 April, Figure 3.7), they started to decrease again in late spring, reaching values of less than $1 \mathrm{~mm} \mathrm{~d}^{-1}$ in the first week of September (DOY 240 - 250, diamond symbols in Figure 3.7), 

woodland

while $E T_{p}$ continued to increase significantly up to 23 August 2010 (DOY 235, Figure 3.4). In $2010 E T^{e c}$ and $E_{S S}^{M F}$ started to increase again with the first rain events during the end of the dry summer (see Figure 3.7 for DOY 260-270, 17 - 27 September 2010).

Both $E T^{e c}$ and $E_{S S}^{M F}$ followed the pattern described by Hillel (1998), i.e. just after a rain event the soil was wet and $E T^{e c}$ and $E_{S S}$ rates were determined by $E T_{p}$ conditions (S1 stage evaporation, Hillel 1998), e.g. in Figure 3.7 after the frequent rain events in the period between DOY 30 and 1102010 (30 January - 20 April); later on, the first centimetres of soil became dry and evaporation dropped steadily (S2 stage evaporation, again in Figure 3.7 DOY 90 and 190 2010 or 31 March - 9 July). During late spring and summer (May-October, DOY 130-280), when the rain events were sparse and of high intensity, the $E T^{e c}$ and $E_{S S}^{M F}$ differed: (i) during the first stage evaporation $E_{S S}^{M F}$ was higher than $E T^{e c}$ (e.g. in Figure 3.7, the period between DOY 150 and 180 in 2010, 30 May and 29 June); and (ii) in the late, asymptotic part of the second stage of evaporation in dry summer, when the long periods without precipitation events allowed the soil to dry up, resulting in low and almost steady evaporation rates (Figure 3.7, period between DOY 90 and 200 of 2010, 31 May and 19 July, during this period $E_{S S}^{M F}$ was lower than $E T^{e c}$ ).

$T_{S S}^{M F}$ values were very low with respect to overall $E T^{e c}$ (Figure 3.7, the thick dashed line at the bottom of the plots). As explained before, this was due to the low tree canopy coverage in the MF area. $T_{s S}^{M F}$ estimated for the late springsummer period was at its maximum because of large moisture availability and maximum $E T_{p}$ in that period, allowing both tree species, $Q$. ilex and $Q$. pyrenaica, to transpire at the potential rate.

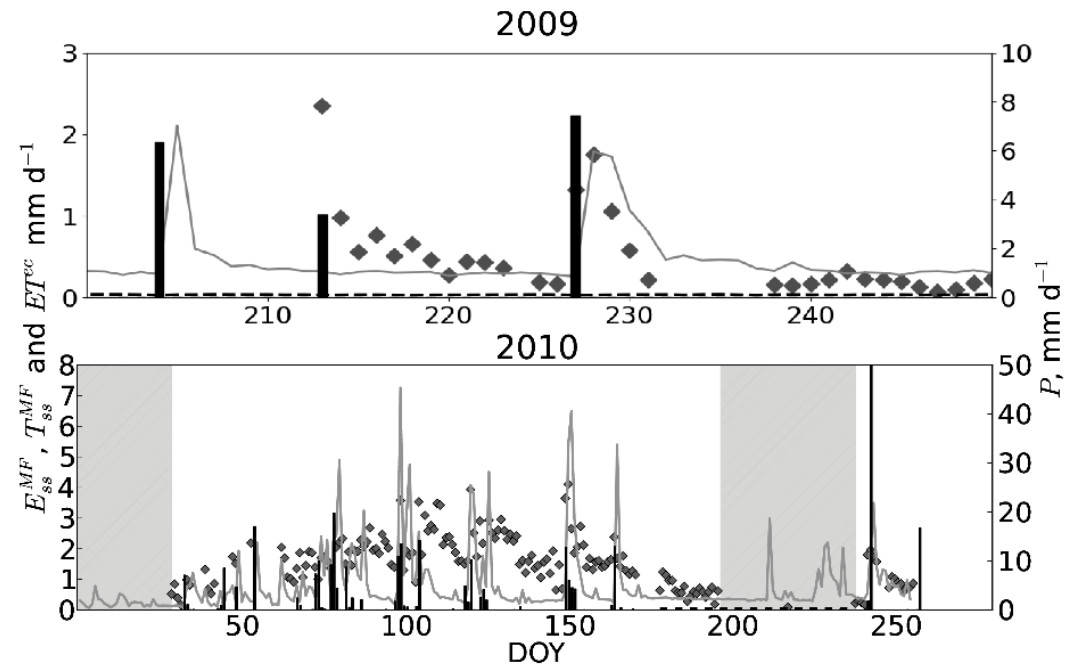

Figure 3.7: EC tower evapotranspiration measurements ( $E T^{e c}$, diamonds) and precipitation ( $P$, black bars) compared to subsurface evaporation ( $E_{S S}^{M F}$, gray 
solid line) and subsurface transpiration ( $T_{s S}^{M F}$, shaded black line at the bottom) defined for the maximum footprint area (MF) for the dry summer 2009, DOY 200-250 (from 19 July to 7 September when sap flow measurements were available) and for the year 2010, DOY 0-280 (from 1 January to 7 October). The shaded areas represent periods when the EC tower data was unavailable or incomplete.

\subsubsection{Sourcing of $E_{s s}^{M F}$ into $E_{g}$ and $E_{u}$}

The time series of the sourced components of $E_{s s}^{M F}$ show (Figure 3.8, 2009) that: the $E_{g}$ was above the $E_{u}$ during the long period of drought in between the two rain events, when the groundwater table continuously declined (Figure $3.6)$; the $E_{g}$ was below the $E_{u}$ during rain events and shortly after because water that infiltrated in the top soil started to evaporate quickly before reaching the extinction depth (the depth at which infiltrating water moves downward faster than it evaporates, (Zeng et al., 2009a). Hence, the water infiltrated after the dry summer rain events did not recharge the water table. During the wet winter and spring of 2010, when the soil moisture was above field capacity due to frequent rains, even low rate precipitation events resulted in recharge, so the $E_{g}$ was negligible (Figure $3.8,2010$ ) compared to the dry summer periods of both 2009 and 2010. 

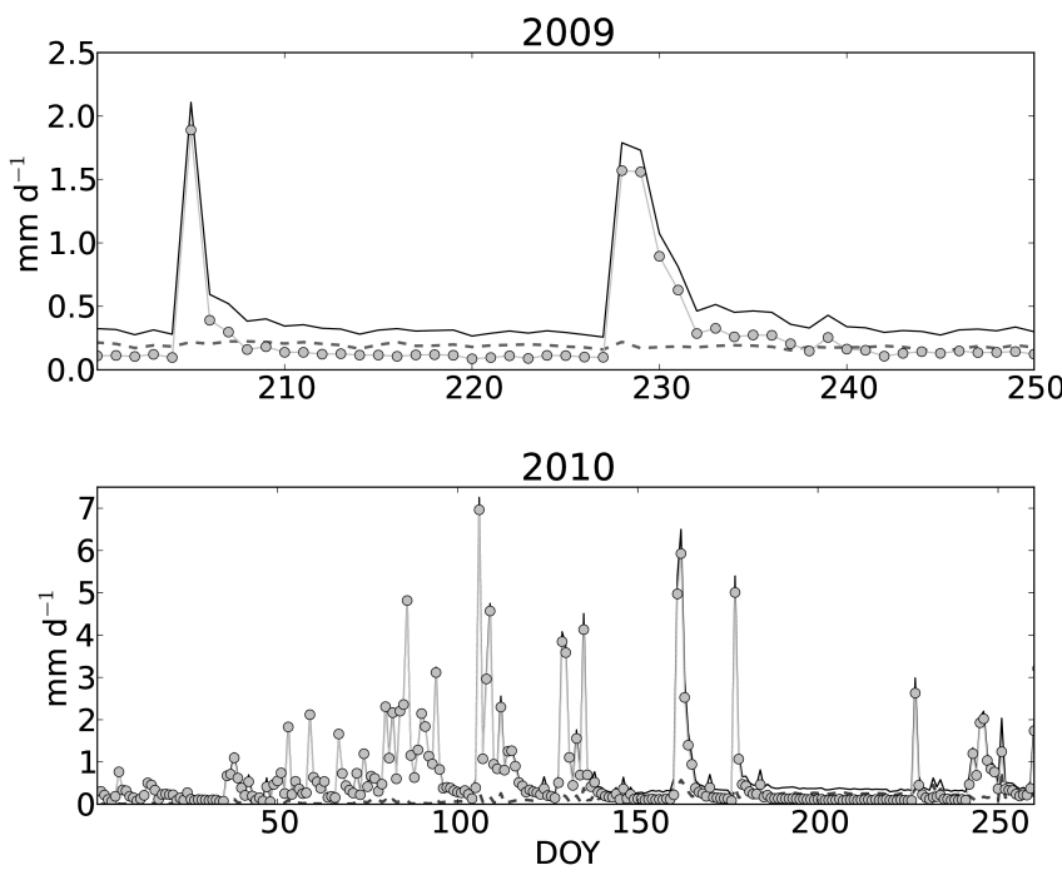

Figure 3.8: Sourcing of subsurface evaporation $\left(E_{s s}^{M F}\right)$ in the maximum footprint (MF) study area, for: the dry summer 2009 (from 19 July to 7 September) and the year 2010 (from 1 January to 17 September). The $E_{s s}^{M F}$ is represented by black line, groundwater evaporation $\left(E_{g}^{M F}\right)$ by dashed line and unsaturated zone evaporation $\left(E_{u}^{M F}\right)$ by gray line with circles.

\subsubsection{Relative relevance of sourced components}

The comparison of the sourced and upscaled $E_{S S}^{M F}$ and $T_{S S}^{M F}$ with $E T^{e c}$ for dry summers 2009 and 2010 is presented in Table 3.1. In the dry summer 2009 (the "very dry year"; $37 \mathrm{~mm}$ rainfall between June to September), the agreement between $E T_{s S}^{M F}\left(E T_{s S}^{M F}=E_{s S}^{M F}+T_{s S}^{M F}\right)$ and $E T^{e c}$ was very good with only $1 \%$ difference. The $E_{u}^{M F}$ was the main contributor to $E T^{e c}(69 \%)$ while the $E_{g}^{M F}=$ $E_{u}^{M F}$ ratio was 0.35 and the $T_{g}^{M F}=T_{u}^{M F}$ ratio was 1 . The tree transpiration was a minor contributor to $E T^{e c}, 6 \%$. In the dry summer 2010 (the "wet year" with rainfall of $106 \mathrm{~mm} \mathrm{y}^{-1}$ from June to September), $E T_{s s}^{M F}$ was higher than $E T^{e c}$ ( $0.685 \mathrm{~mm} \mathrm{~d}^{-1}$ and $0.518 \mathrm{~mm} \mathrm{~d}^{-1}$ rainfall, respectively). $E_{u}^{M F}$ was, again, the main contributor to $E T^{e c}(93 \%)$ while the evaporation and transpiration sourcing ratios were the same as in 2009; the tree transpiration was similar (6\% of $E T^{e c}$ ) as well.

In a similar analysis carried out between 30 January (DOY 30) and 7 October (DOY 280) 2010 (Table 3.1), we excluded the tree transpiration due to the lack of sap flow measurements in winter and spring periods and also the 
days when the quality of the EC measurements was low. The results show: generally higher absolute values of evaporative fluxes than in dry summer; the $E_{S S}^{M F}$ lower than $E T^{e c}$ by $24 \%$; and an $E_{g}^{M F}=E_{u}^{M F}$ ratio (0.22) significantly lower than comparable ratios in the dry summer, emphasizing lower $E_{g}^{M F}$ contributions to $E T_{s s}^{M F}$.

Table 3.1: Partitioning and sourcing of estimated subsurface evapotranspiration $\left(E T_{S S}^{M F}\right)$ vs evapotranspiration measured by the EC tower $\left(E T^{e c}\right)$ for: the dry summer (period from 29 July to 7 September, DOY $210-$ 250) 2009; the dry summer 2010; and for the period between DOY 30 and 280 of the year 2010 (from 30 January to 7 October).

\begin{tabular}{|c|c|c|c|c|c|c|}
\hline \multirow[t]{3}{*}{ Period } & \multirow{2}{*}{\multicolumn{2}{|c|}{$\begin{array}{l}\text { HYDRUS 1D } \\
E_{S S}^{M F}\left(\mathrm{~mm} \mathrm{~d}^{-1}\right)\end{array}$}} & \multirow{2}{*}{\multicolumn{2}{|c|}{$\begin{array}{l}\text { sap flow } \\
M S \\
S S\end{array}$}} & \multirow{3}{*}{$\begin{array}{l}\text { SUM } \\
E T_{S S}^{M F} \\
\left(\mathrm{~mm} \mathrm{~d}^{-1}\right)\end{array}$} & \multirow{3}{*}{$\begin{array}{l}\text { EC tower } \\
E T^{e c} \\
\left(\mathrm{~mm} \mathrm{~d}^{-1}\right)\end{array}$} \\
\hline & & & & & & \\
\hline & $E_{g}^{M F}$ & $E_{u}^{M F}$ & $T_{g}^{M F}$ & $T_{u}^{M F}$ & & \\
\hline Dry summer & 0.137 & 0.389 & 0.017 & 0.017 & 0.56 & 0.565 \\
\hline 2009 & $24 \%$ & $69 \%$ & $3 \%$ & $3 \%$ & $99 \%$ & $100 \%$ \\
\hline Dry summer & 0.17 & 0.483 & 0.016 & 0.016 & 0.685 & 0.518 \\
\hline 2010 & $33 \%$ & $93 \%$ & $3 \%$ & $3 \%$ & $132 \%$ & $100 \%$ \\
\hline DOY $30-280$ & 0.226 & 1.018 & & & 1.257 & 1.649 \\
\hline 2010 & $4 \%$ & $62 \%$ & & & $76 \%$ & $100 \%$ \\
\hline
\end{tabular}

The uncertainty associated with $T_{s S}^{M F}$ and $E_{S S}^{M F}$ are $16 \%$ of $E T_{S S}^{M F}$. Error in $T_{S S}^{M F}$ was less than $1 \%$ (Reyes and Lubczynski, 2013) while for the evaporation estimates, the uncertainty in $Z_{W T}$ and soil hydraulic properties resulted in an error of $15 \%$ of the total measurement. This value was calculated using the standard deviation of the mean values for the soil hydraulic properties (which are calculated using all the samples taken in the area) and the uncertainty in the water table level calculated by the distributed model of Hassan et al. (2014): the Hydrus1D model was run for all possible soil hydraulic properties and $Z_{W T}$ combinations (e.g. maximum hydraulic conductivity, lower $Z_{W T}$ ) and we used the results to establish the uncertainty of the $E_{s s}^{M F}$ calculation.

\subsection{Discussion}

\subsubsection{ET partitioning in semi-arid areas}

In arid or semi-arid areas, especially those covered by open woodlands, the tree $T_{S S}$ component of $E T$, next to climatic and water availability constraints, is highly dependent on tree species type, density, and size of canopy area, i.e. tree characteristics detectable from space (Lubczynski, 2009; Reyes and Lubczynski, 2013). As "open woodland" can have a canopy coverage ranging from $5 \%$ to even $80 \%$ (Anderson et al., 1999), the $T_{s S}$ component of $E T$ can 

woodland

vary substantially between different land covers. However, in an open woodland, trees never get "crowded", and are limited in their growth by water or nutrient availability and competition between different individuals.

In the MF study area, with canopy coverage of $7 \%$, and with a "shallow" water table, $T_{s s}^{M F}$ accounted for only $6 \%$ of $E T^{e c}$. For comparison, the Table 3.2 presents a summary of the results of various partitioning studies performed in open woodlands with climate similar to the MF study area, but with different canopy coverages. Yaseef et al. (2010), who directly measured $E_{s s}$ and $T_{s s}$ in an area with Mediterranean climate (Israel) with 60\% canopy coverage, found yearly values for $E_{s s}$ and $T_{s s}$ of $33.8 \%$ and $42.3 \%$ of total $E T$, respectively. In an olive field in Morocco with high tree density (400 stems ha-1, no information on canopy coverage), Williams et al. (2004) estimated $T_{u}$ after irrigation as high as $20-30 \%$ of $E T^{e c}$ and $T_{s s}$ as $80-70 \%$ ( $E_{g}$ was assumed negligible). In these two examples, a higher tree density and canopy coverage compared to our study resulted in a larger contribution of $T_{S S}$ to $E T$ (although $E_{S S}$ still represented $1 / 3$ of $E T$ ), suggesting $T_{S S}$ dependence on canopy coverage.

However, there are studies that seem to contradict the relationship between $T_{S S}$ and canopy coverage. For example, Paço et al. (2009), with a canopy coverage of $21 \%$, found $T_{S S}=100 \%$ of $E T$ (and $E_{S S}=0$ ) during a dry summer period with a setup similar to the one presented in this study (the area studied was the maximum footprint area for a $28 \mathrm{~m}$ high EC tower). Their finding of $E_{s S}=0$ might have been due to experimental design. They measured $E T$ with an EC system and estimated $T_{s s}$ with sap flow measurements while $E_{s s}$ was assumed to be $E_{s s}=-T_{S s}$. To estimate $T_{s s}$ they used the Granier sap flow measurement method (Granier, 1985) which, in sparse tree environments, is highly vulnerable to overestimation errors if the analysis does not account for: (i) natural temperature gradient (Lubczynski et al., 2012; Reyes-Acosta et al., 2012); and (ii) radial variability of the sap flow as discussed by Reyes-Acosta and Lubczynski (2014). Paço et al. (2009) did not explain whether they dealt with these potential problems. The overestimation of $T_{s s}$ could explain the underestimation of $E_{S S}$. 
Table 3.2: Summary of the partitioning studies conducted in arid and semiarid areas for comparison with this study. The symbol 'n.r.' means 'not reported'.

\begin{tabular}{|c|c|c|c|c|c|}
\hline Study & Methods & Location & $\begin{array}{l}\text { Canopy } \\
\text { coverage }\end{array}$ & Results & $\begin{array}{l}\mathrm{Z}_{\mathrm{WT}} \\
(\mathrm{m} \text { b. } \\
\text { g.l. })\end{array}$ \\
\hline $\begin{array}{l}\text { Baldocchi } \\
\text { et al. } \\
\text { (2004) }\end{array}$ & $\begin{array}{l}\text { Two EC towers (at } 23 \mathrm{~m} \text { and } 2 \mathrm{~m} \text { above ground), } \\
\text { bucket soil model }\end{array}$ & $\begin{array}{l}\text { Semi-arid, mediterranean } \\
\text { (California) open woodland (oak) }\end{array}$ & $40 \%$ & $\begin{array}{l}\text { understory (soil + } \\
\text { grass) } E T=40-60 \% \\
\text { of overstory } E T \text { in } \\
\text { winter and } 10 \% \text { in } \\
\text { dry summer }\end{array}$ & n.r. \\
\hline $\begin{array}{l}\text { Williams et } \\
\text { al. (2004) }\end{array}$ & $\begin{array}{l}\text { EC tower, isotopic partitioning, sap flow (heat } \\
\text { ratio method), bucket soil model }\end{array}$ & $\begin{array}{l}\text { Mediterranean climate } \\
\text { (Morocco), olive orchard } \\
\text { plantation }\end{array}$ & $\begin{array}{l}\text { Tree density } \\
=400 \text { ha }^{-1}\end{array}$ & $\begin{array}{l}\text { after correction, } E_{u} \\
=20-30 \% E T^{e c}, E_{g} \\
=0\end{array}$ & n.r. \\
\hline $\begin{array}{l}\text { Paço et al. } \\
\text { (2009) }\end{array}$ & $\begin{array}{l}\text { EC tower, heat dissipation sap flow method, } \\
\text { GWD monitoring, interception measurements }\end{array}$ & $\begin{array}{l}\text { Mediterranean climate } \\
\text { (Portugal), open oak woodland }\end{array}$ & $21 \%$ & $\begin{array}{l}E_{s s}+\operatorname{grass} T= \\
44 \%\end{array}$ & $3.5-6$ \\
\hline $\begin{array}{l}\text { Miller et al. } \\
\text { (2010) }\end{array}$ & $\begin{array}{l}\text { Same as Baldocchi et al. (2004), plus sap flow (heat } \\
\text { ratio) and GWD fluctuation for } T_{g}\end{array}$ & Same as Baldocchi et al. (2004) & $40 \%$ & $\begin{array}{l}\text { during dry periods, } \\
T_{g}=90 \% \text { of } E T^{e c}\end{array}$ & $\sim 8$ \\
\hline $\begin{array}{l}\text { Yaseef et } \\
\text { al. (2010) }\end{array}$ & $\begin{array}{l}\text { Microclimatic station, sap flow (heat pulse } \\
\text { velocity and heat dissipation methods), soil } \mathrm{CO}_{2} \\
\text { flux chamber }\end{array}$ & $\begin{array}{l}\text { Mediterranean climate (Negev } \\
\text { desert), open woodland of } \\
\text { Aleppo Pine }\end{array}$ & $60 \%$ & $\begin{array}{l}E_{g}=0 \%, E_{u}= \\
30 \%, T_{s s}=40 \%\end{array}$ & 300 \\
\hline This study & $\begin{array}{l}\text { EC tower, microclimatic station, soil transient } \\
\text { flow model, thermal dissipation and heat field } \\
\text { deformation sap flow methods, WTD } \\
\text { measurements }\end{array}$ & $\begin{array}{l}\text { Semi-arid climate (Spain), open } \\
\text { woodland (oak) }\end{array}$ & $7 \%$ & $\begin{array}{l}E_{g}=20-30 \%, E_{u}= \\
60 \%, T_{g}=T_{u}=7 \%\end{array}$ & $3-10$ \\
\hline
\end{tabular}

It's interesting to compare the contributions of dry summer $E_{S S}$ and $T_{S S}$ fluxes, i.e. normalized $E_{s s}\left(E_{s s, n}\right)$ and normalized tree transpiration $\left(T_{s s, n}\right.$, i.e. tree water uptake divided by corresponding canopy area) respectively. The $E_{S s, n}$ was, on average (taking both years), $0.6 \mathrm{~mm} \mathrm{~d}^{1}$, while $T_{s s, n}$ of $Q$. ilex and $Q$. pyrenaica were $0.83 \mathrm{~mm} \mathrm{~d}^{-1}$ and $1.19 \mathrm{~mm} \mathrm{~d}^{-1}$ respectively, as measured by Reyes and Lubczynski (2013). $T_{s s, n}$ was higher than $E_{s s, n}$, however, as the MF area covered by bare soil (93\%) was much larger than the canopy coverage area. This resulted in much higher overall $E_{s s}$ than $T_{s s}$.

\subsubsection{Sourcing of $E_{s s}^{M F}$ and $T_{s s}^{M F}$ into groundwater and unsaturated zone components}

In the two dry summers of the years 2009 and 2010, trees used the same amount of water from the shallow root system $\left(T_{u}\right)$ and from the roots tapping the water table $\left(T_{g}\right)$. The tree transpiration $\left(T_{s s}\right)$ did not change much during the late spring-summer period, even when the soil dried up and the water table dropped considerably (more than $1 \mathrm{~m}$ ). Also Miller et al. (2010) showed that groundwater uptake by oak trees, measured using WTF technique (Section 2.2.5.2), did not change much between May-Nov 2008, while the water table dropped $1 \mathrm{~m}$. The low values of $T_{g}^{M F}$ and $T_{u}^{M F}$, both $0.016 \mathrm{~mm} \mathrm{~d}^{-1}$ were due to very low tree density, so it did not affect the water budget significantly. The decline of water table observed typically from June to September (DOY 150- 

woodland

270 , Figure 3.6) was due to lateral groundwater outflow and $E_{g}$, while $T_{g}$ had negligible impact.

In the MF area, grass had a negligible contribution to ET. The grass was present only shortly in early spring (March-May, DOY 60-140), i.e. when $E T_{p}$ was low, and died quickly during late spring, when the soil dried up. Besides, the grass in the study area was sparse, probably due to the poor development of the soil (regolith or entisoils) and to intensive cattle grazing. For all these reasons, we assumed a negligible effect of grass transpiration on yearly $E_{s S}^{M F}$ (Table 3.1) and no effect on dry summer $E T_{s s}$. The $E_{s s}$ in the area under the trees was assumed negligible due to the tree shade effect on soil surface temperature and net incoming radiation.

The diffusion of water vapour increased $E_{s s}^{M F}$, especially during the dry summer period. In the dry summer of 2009 and 2010, the dryness of the top unsaturated zone thermally insulates the groundwater from changes in temperature at the ground surface, creating high temperature gradients in the top unsaturated zone. In the MF study area, for a clear-sky summer day at midday, the dry top soil temperature difference between the surface and 15 $\mathrm{cm}$ b.g.s. was $10^{\circ} \mathrm{C}$, and $18^{\circ} \mathrm{C}$ between the surface and $25 \mathrm{~cm}$ b.g.s., reaching stability below $1 \mathrm{~m}$ b.g.s. (the temperature at $1 \mathrm{~m}$ changed only seasonally, but not daily). The high temperature gradient is a driving factor for water vapour flow and influences the flow of water in the unsaturated zone (Zeng et al., 2009a); in this study, the vapour flow by diffusion enhanced the overall evaporation of both infiltrating water and groundwater.

When taking into account the whole year (DOY 30-280 for year 2010, Table 3.1), $E_{u}$ is the most relevant source of $E_{s s}^{M F}$. This is because the rain input was concentrated in the wet, cold part of the year (from October-November to April, DOY 290-100), when the $E T_{p}$ was low and water input high, so that the unsaturated zone was moist enough to meet the potential evapotranspiration demand $\left(E_{u}=E T_{p}\right)$. The absolute amount of water evaporated this way $\left(E_{u}=\right.$ $E T_{p}$ ) during the wet part of the year is higher than the absolute amount of water evaporated as $E_{g}$ during the dry summer.

\subsubsection{Problems estimating $S 1$ and late $S 2$ stages of evaporation}

The larger Hydrus1D estimates of S1 as compared to $E T^{e c}$ ( $E_{s s}^{M F}$ right after rain, Section 3.3.1.2 and Figure 3.7) can be either due to the low quality data collected by the tower in the first 90 min after rain event (Section 3.3.1.2) or by the Hydrus1D model setup. In relation to the EC tower measurements, the quality of the data collected during these $90 \mathrm{~min}$ has been analysed following Foken et al. (2005). The analysis shows that $84 \%$ of the data collected in the first 90 min after rainfall is to be considered "good" quality and $60 \%$ of "very good" quality (categories 1-6 and 1-3 in Foken et al., 2005). This means that the problem of droplets on the gas analyser had only a small effect on the daily 
evaporation rate calculated from the EC data, because the duration of the instrument failure was always shorter than the sampling time.

If the EC measurements taken after rain events are correct (Figure 3.7), then the problem should be in the Hydrus1D simulations. One possibility could be the frequency we selected for atmospheric variables: we passed hourly data to the Hydrus1D model (we could not use smaller time steps for the rainfall input because the acquired field measurements had an hourly frequency), and this means that the water reaching the soil was averaged over the whole hour. If all the rain fell in few minutes of an hour, as it is often the case during dry summer in the MF area, this would result in a precipitation rate higher than soil infiltration capacity and, so, in some run-off, implying that not all rain could infiltrate in the subsurface and evaporate from there.

The substantially lower $E_{S S}^{M F}$ than $E T^{e c}$ in the late S2 (that is, in "dry" periods, Section 3.1.2 and Figure 7) is more difficult to interpret. Possible explanations are: (i) underestimation of the hydraulic conductivity of the soil; or (ii) wrong prediction of spatially distributed $Z_{W T}$ applied to the upscaling of $E_{S S}^{M F}$. Out of these two, the first is unlikely due to the large amount of hydraulic conductivity measurements taken and relatively low variability of these measurements, while the second is analysed below.

To investigate the $E_{s S}^{M F}$ uncertainty resulted by eventually incorrect definition of the $Z_{W T}$, we compared several averaged $Z_{W T}$ values to fit the EC tower observation (with the assumption of negligible $T_{s S}^{M F}$ ). We simulated $E_{S S}^{M F}$ with Hydrus1D in four sub-periods corresponding to the months of year 2010 in which groundwater level was recessing (DOY 90-120; 120-150; 150-180, 180-210 or 31 March-30 April; 30 April-30 May; 30 May-29June; 29 June-29 July), using as fixed bottom boundary conditions different $Z_{W T}$ values (Figure 3.9), e.g. for sub-period one, we ran the Hydrus1D model with $Z_{W T}$ fixed at 1.0 $\mathrm{m}, 1.5 \mathrm{~m}, 2.0 \mathrm{~m}, 2.5 \mathrm{~m}, 3 \mathrm{~m}$ and $5 \mathrm{~m}$; we repeated the procedure for subperiod two and so on. We then compared the medians of $E_{s S}^{M F}$ (for various $Z_{W T}$ values) and the median of $E T^{e c}$ (Figure 3.9 and Table 3.3) as an indicator of the fit between Hydrus1D simulation and the EC tower measurements; we used the median because it is a robust statistic and gives a general idea of the late S2 evaporation rate, avoiding the overestimation of the peaks. The median values are also shown in Table 3.3.

In the first sub-period (DOY 90-120, corresponding to April 2010) the median value of $E T^{e c}$ is very similar to the median value of $E_{s s}^{M F}$ for an averaged $Z_{W T}$ of $3 \mathrm{~m}$ b.g.s. (Table 3.3 and Figure 3.9). In the second sub-period (DOY 120-150 May), the $E T^{e c}$ median value is close to the $E_{S S}^{M F}$ median value for the $2 \mathrm{~m}$ b.g.s. $Z_{W T}$. In the third sub-period (DOY 150-180 June) the $E T^{e c}$ has a median value also close to the $E_{S S}^{M F}$ median for the $2 \mathrm{~m}$ b.g.s. $Z_{W T}$, while in the fourth sub-period (DOY 180-210 July) the $E T^{e c}$ is closer to the $E_{S S}^{M F}$ median value the $3 \mathrm{~m}$ b.g.s. $Z_{W T}$. However, our measurement-based estimates for the averaged water table in the MF area, based on the observation taken from the piezometers and on the prediction from an independent hydrogeological model 

woodland

of the catchment area of which the MF area is a subset (Frances et al., 2015; Section 3.2.1), were deeper, i.e. $3.9 \mathrm{~m}$ depth on DOY 180 (year 2010) and 5.1 $\mathrm{m}$ depth on DOY 233 (year 2010). The difference between the $Z_{W T}$ required to be fed to Hydrus1D to match the EC tower measurements and the $Z_{W T}$ actually observed in the area is so large that the problem of disagreement between Hydrus1D and EC tower estimates (Figure 3.7) could not be explained by uncertainty of the $Z_{W T}$ used as an input to Hydrus1D. The reason of the low estimates of the late second stage evaporation is discussed in further detail in Section 3.4.3.

The low S2 evaporation estimates from our Hydrus1D model is the reason for the $24 \%$ mismatch between $E_{S S}^{M F}$ and $E T^{e c}$ for the extended period (DOY 30280 ) in year 2010 (Table 3.1). However, the mismatch between $E T_{s S}^{M F}$ and $E T^{e c}$ in the dry summer 2010 (Table 3.1) is likely also due to the small amount of the EC collected data in this period. The absence of sap flow measurements to estimate $T_{S S}$ outside of dry summer (Table 3.1) is not critical because $T_{S S}$ is negligible anyway.

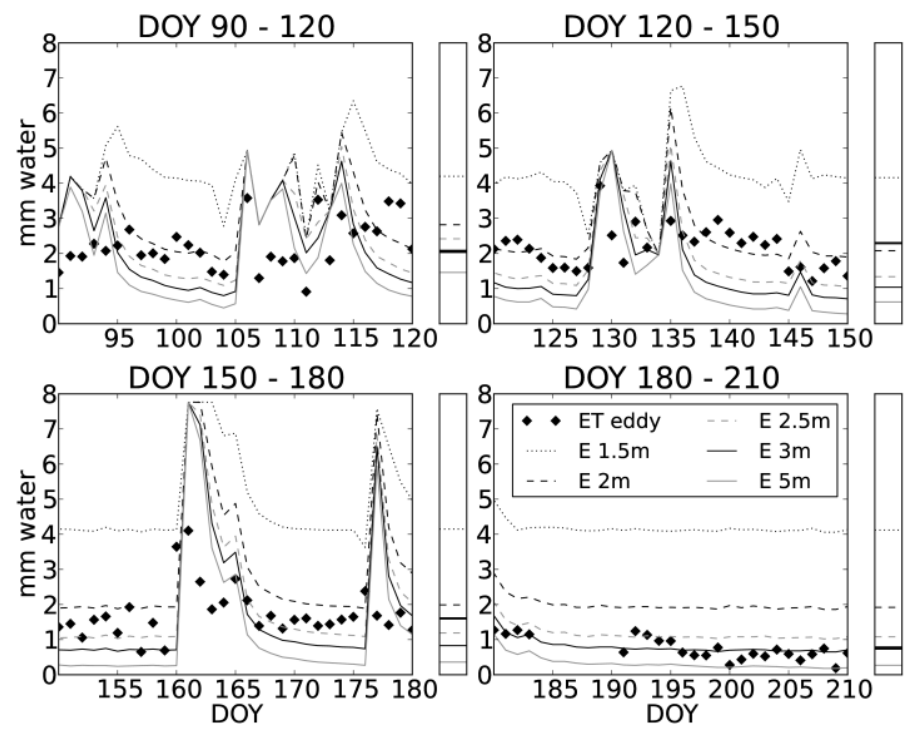

Figure 3.9: Evapotranspiration measurements from the EC tower $\left(E T^{e c}\right)$ and subsurface evaporation $\left(E_{S S}^{M F}\right)$ for five different averaged water table depths in the maximum footprint (MF) study area. The dataset is shown for 4 periods of year 2010. The period before DOY 90 is not shown because model results are not dependent on water table depth due to very moist top soil. The bars aside the graphs show the median values of the time series of $E T^{e c}$ and $E_{S S}^{M F}$ for each period. 
Table 3.3: Median evaporation rates: median values of evaporation estimates (in $\mathrm{mm} \mathrm{d}^{-1}$ ) for different water table depths, corresponding to the time series shown in Figure 3.9.

\begin{tabular}{|c|c|c|c|c|c|c|}
\hline $\begin{array}{l}\text { Period } \\
\text { (DOY) }\end{array}$ & $E T^{e c}$ & $1.5 \mathrm{~m}$ & $2 \mathrm{~m}$ & $\begin{array}{l}M F \\
2.5 \mathrm{~m}\end{array}$ & $3 \mathrm{~m}$ & $5 \mathrm{~m}$ \\
\hline $90-120$ & 2.07 & 4.2 & 2.82 & 2.42 & 2.03 & 1.46 \\
\hline $120-150$ & 2.29 & 4.16 & 2.08 & 1.34 & 1.04 & 0.62 \\
\hline $150-180$ & 1.6 & 4.15 & 1.99 & 1.19 & 0.83 & 0.36 \\
\hline $180-210$ & 0.77 & 4.12 & 1.92 & 1.08 & 0.73 & 0.27 \\
\hline
\end{tabular}

\subsubsection{The relevance of $E_{g}$ in semi-arid climate}

In semi-arid areas, particularly during dry seasons, $E_{g}$ can be an important water loss for an aquifer (Lubczynski, 2000, 2009, 2011). However, the $E_{g}$ can be easily overlooked due to the relatively small rates as compared to rainfall, and difficulties in predicting its dependence on $Z_{W T}$. Our findings indicate that, in dry summers in the MF area, $30 \%$ of ET originated from groundwater $\left(E T_{g}\right)$, especially from $E_{g}$, even when the average $Z_{W T}$ was at 5,8 $\mathrm{m}$ b.g.s. When the unsaturated zone was dry, there was little liquid contact between saturated zone and ground surface, so that capillary flow, even if present, was very small. However, the temperature gradients explained in Section 3.4.2.1 were high enough to trigger $E_{g}$, not only by liquid fluxes but also by water vapour flow, reaching its maximum in late dry summer (Figure 3.8 2009, see also Zeng et al., 2009a; Zeng et al., 2011a).

Even while taking into account capillary flow and only diffusive water vapour flow in the Hydrus1D model, the simulated $E_{S S}^{M F}$ underestimated $E_{g}$. That underestimation, mainly in the late second stage $E_{S S}^{M F}$, seems to be due to an evaporation process not accounted for by Hydrus1D. The correct estimate of the whole water vapour flow is very important for $E_{s s}$ estimates in the dry summer because of much higher permeability of a very dry porous media to gas flow as compared to a wet porous media (Saito et al., 2006; Shokri et al., 2008). The temperature gradients (Section 3.4.2.1) and their daily variations ( $40{ }^{\circ} \mathrm{C}$ at the ground surface, $8^{\circ} \mathrm{C}$ at $15 \mathrm{~cm}$ b.g.s. and $6^{\circ} \mathrm{C}$ at $25 \mathrm{~cm}$ b.g.s.) are driving factors strong enough to sustain vapour flow in the soil (Zeng et al., 2009a). However, in the current version of the Hydrus1D model, the only mechanism for water vapour flow through the soil is diffusion, while the other gas flow processes in the soil, not accounted for in this study, can also be relevant in the overall vapour flow between groundwater and ground surface, such as dispersion (Grifoll et al., 2005; Grifoll, 2011) or advection (Zeng et al., 2011a). The presence of these unaccounted gas flow processes could explain the underestimation of $\mathrm{S} 2 E_{S S}$ as a consequence of underestimation of $E_{g}$. However, to solve that problem, a more focussed study on identifying different 

woodland

gas flow processes considering the relation between $E T^{e c}$ and specific water table depths is required.

\subsection{Conclusions}

Areas with sparse vegetation, abundance of bare soil, "shallow groundwater" and dry climatic conditions are prone to substantial groundwater evaporation $\left(E_{g}\right)$, particularly during long dry seasons typical for arid and semi-arid areas. The inclusion of water vapour in the determination of $E_{g}$ extinction depth should be carefully considered to avoid strong underestimation of $E_{S S}$, e.g. due to incorrect soil modelling, which could eventually cover possible errors in the sap flow estimates of $T_{s s}$. A wrong estimation of $E_{g}$ can lead, for example, to incorrect water vapour input to the atmosphere in climatic models of semi-arid and arid areas around the globe and to incorrect calibration of aquifer saturated hydraulic conductivity in groundwater modelling, resulting in underestimation of total water loss from an aquifer and related overestimation of groundwater resources. The low estimates of $E_{g}$ obtained in the simulations with Hydrus1D highlight the need for an improvement of the knowledge related to gas flow processes and implementation of that knowledge in the subsurface hydrological models to improve accuracy of $E_{g}$ estimates, particularly in dry conditions by defining the relationship between $E_{g}$ and $Z_{W T}$ in different hydrogeological conditions. 
Chapter 4

Testing three approaches to estimate soil evaporation through a dry soil layer in a semiarid area 


\section{Abstract:}

Bare soils and grasslands in arid and semi-arid conditions constitute a large portion of the earth surface. Evaporation, which is the main component of the water balance in these conditions, often takes place through a dry soil layer (DSL). There is no scientific agreement yet on the DSL effects on evaporation rates.

The implementations of three conceptual models of DSL-evaporation were tested for the simulation of evaporation rates in a semi-arid study area in Central Spain: (i) the daily-average model, based on the assumption that the daily average vapour transport in a DSL can be represented in analogy to isothermal liquid flow; (ii) the numerical model solving the Richards equation, in this case Hydrus1D was used; and (iii) the pore-scale model, based on soil column experiments in laboratory conditions. The evaporation rates estimated by the three conceptual models for semi-arid field conditions were compared with the evaporation rates measured by an eddy covariance tower in the same area.

The results indicate that the daily-average conceptual model assumption, in which the DSL has no effects on evaporation, does not hold in very dry conditions. The numerical model solving the Richards equation was not able to simulate the effects of the DSL on evaporation rates. The evaporation estimates obtained by the pore-scale conceptual model were closest to the eddy covariance measurements during the dry season, however this model was applicable only to the relatively steady evaporation conditions during afternoons and only assuming spatially constant DSL thickness.

This Chapter is based on:

Balugani, E., Lubczynski, M. W., van der Tol, C., Metselaar, K., (2018), Testing three approaches to estimate soil evaporation through a dry soil layer in a semi-arid area. Journal of Hydrology, 567(September): 405-419. 


\subsection{Introduction}

Evaporation from bare soils and grasslands is the most important component of the hydrological balance in semi-arid and arid areas (Lawrence et al., 2006; Wang, 2015). Such areas cover a significant part of the earth surface and can be found in all continents (Peel et al., 2007). They are particularly vulnerable to desertification processes, following changes in their hydrological balances (Badreldin et al., 2017). The grass in these areas typically transpires only during the rainy seasons, while in the dry season become dormant, senesce or die, converting to bare soil. Therefore evaporation from the bare soil becomes the main water flux in the water budget in semi-arid and arid areas (Brutsaert, 2014a). In this study, the soil is defined as the porous, unconsolidated material covering an underlying bedrock, regardless of its water content.

The soil evaporation process is strongly dependent on the hydraulic connection between the soil surface and the saturated zone (Good et al., 2015; Maxwell and Condon, 2016). Gardner and Fireman (1958) studied the steadystate evaporation from a water table in soil columns' laboratory experiments, calculating the upward liquid flow with the Buckingham-Darcy law. They found that the bare soil evaporation shows an exponential decay with increasing water table depth. Shah et al. (2007) simulated the steady-state evaporation from a bare soil as dependent on water table depth using a variable saturation, one-dimensional flow model (Hydrus1D) based on the numerical solution of the Richards' equation (Simunek, et al. 2005). This type of model requires a continuous liquid connection between the saturated zone and the soil surface, which is a valid assumption for a shallow water table with mild evaporative conditions (Lehmann et al., 2008), but questionable for arid and semi-arid conditions and/or a deep water table. At a certain water table depth $\left(Z_{W T}\right)$ the gravity forces become stronger than the capillary forces, and liquid continuity is disrupted (Shokri and Salvucci, 2011).

The evaporation rates from bare soils drop significantly when a DSL develops, i.e. between S1 and S2 stages of evaporation (see Section 1.1.2 of this thesis, Or et al. 2013), with S2 rates so small that they are usually neglected in field studies (Chapter 3, Balugani et al. 2017). The transition between S1 and S2 depends on soil material properties and also on soil temperature, as found by Neriah et al. (2014). Laboratory experiments show that S2 evaporation rates are independent from S1 rates and do not vary much over a wide range of soil materials and boundary conditions (Or et al., 2013). This means that $\mathrm{S} 2$ rates are mostly similar in different evaporative conditions. The small $\mathrm{S} 2$ rates $\left(<1 \mathrm{~mm} \mathrm{~d}^{-1}\right.$ ) are often neglected in field studies, when either the soil surface is dry or the water table is considered to be deep enough (Shah et al., 2007). For example, Miller et al. (2010) neglected groundwater evaporation in an area with $Z_{W T}$ between 7-12 $\mathrm{m}$ b.g.s. (below ground surface), 
while Paço et al. (2009) neglected soil evaporation when pasture was dry with a $Z_{W T}$ between 4-6 $\mathrm{m}$ b.g.s. However, the bare soil evaporation can be an important component in a hydrological balance in both dry deserted lands (Wang, 2015) and during dry seasons in Mediterranean climates, as confirmed in Chapter 3 and Balugani et al. (2017), for a study area characterized by an open woodland ecosystem, and $Z_{W T}$ between 1-10 m b.g.s. Moreover evaporation in arid conditions was documented even at $Z_{W T}>100 \mathrm{~m}$ b.g.s. by Li et al. (2014), Scanlon (2000), Walvoord et al. (2002a; 2002b).

The presence of a DSL has been attested both in laboratory and field studies, but its effects on bare soil evaporation are controversial. The DSL observed in laboratory conditions consists of an air-dry layer between the soil surface and the vaporization plane (Figure $1.2 a$ and $b$ ): water in the DSL is present only in vapour form. The soil is completely saturated by the gaseous phase that has, therefore, higher mobility than in the remaining part of unsaturated zone. The thickness of the observed DSL ( $\left.Z_{D S L}\right)$ goes from few $\mathrm{mm}$ (Deol et al., 2014) to more than $50 \mathrm{~cm}$ (Sun et al., 2016). In laboratory experiments, typically under steady state conditions, water transport from the vaporization plane to the soil surface can be explained by vapour diffusion alone, and the formation of a DSL results in a strong decrease of evaporation rates (Or et al., 2013). In field studies, however, the DSL is more dynamic, due to daily changes in evaporative condition: (i) $Z_{D S L}$ can change due to redistribution of soil moisture when the driving solar radiation is absent during night (Idso et al., 1979), water vapour can condense in the DSL due to temperature profile changes, and evaporate from it in the morning (Assouline et al., 2013; Deol et al., 2014); (ii) air turbulence in the atmosphere can enhance the vapour transport in the first $2-4 \mathrm{~cm}$ of the DSL (Ishihara et al., 1992). These processes can greatly increase the transport of water vapour through the DSL, which can be as high as the upward flow of liquid water from the deeper soil to the vaporization plane (Brutsaert, 2014a).

The three main approaches to modelling the evaporation from a soil with a DSL are to: (i) assume that the DSL has no real effect on the daily cumulative soil evaporation; (ii) assume that the DSL can be modelled as if the liquid water continuity through the profile is maintained; (iii) use the DSL model developed from laboratory experiments observations. We call these three conceptual models, respectively: (i) the daily-average (DA) conceptual model; (ii) the numerical solution to the Richards' equation (NSRE) conceptual model; and (iii) the pore-scale (PS) conceptual model. Table 4.1 shows a collection of studies about soil evaporation in the presence of a DSL, the conceptual models used and the type of experiment (field, laboratory, and numeric). For more studies of DSL soil evaporation, see Wang (2015).

Table 4.1: Literature review table of studies of soil evaporation where a DSL was present, all conducted in sandy soils unless otherwise stated; all have found the model to properly fit the measurements unless otherwise stated. 
Mod. stands for "modified version of the NSRE model". For more literature about DSL effects on evaporation reported in studies, see Wang (2015).

\begin{tabular}{|c|c|c|c|c|}
\hline Study & Conceptual model used & $\begin{array}{l}\text { Type of } \\
\text { experiment }\end{array}$ & Climatic conditions & Notes: \\
\hline Brutsaert (2014) & DA & Field & $\sim 6 \mathrm{~mm} \mathrm{~d}^{-1}$ & \\
\hline $\begin{array}{l}\text { Lehmann et al. } \\
(2008)\end{array}$ & PS & Laboratory & $\sim 6 \mathrm{~mm} \mathrm{~d}^{-1}$ & $9 \mathrm{~cm} Z_{D S L}$ (at onset of S2) \\
\hline $\begin{array}{l}\text { Shokri \& Salvucci } \\
\text { (2011) }\end{array}$ & PS & Laboratory & $15 \mathrm{~mm} \mathrm{~d}^{-1}$ & $E$ strongly reduced with $Z_{\mathrm{DSL}}=12 \mathrm{~cm}$ \\
\hline Sakai et al. (2011) & NSRE (mod.) & Numerical & $12 \mathrm{~mm} \mathrm{~d}^{-1}$ & $3 \mathrm{~cm} Z_{D S L}$ \\
\hline Deol et al. (2014) & NSRE & Field & $8 \mathrm{~mm} \mathrm{~d}^{-1}$ & $\begin{array}{l}\text { Microlysimeter } Z_{D S L}=6 \mathrm{~mm} \\
\text { Measurements only during the day (10-18 hours) }\end{array}$ \\
\hline Li et al. (2014) & $\begin{array}{l}\text { No modelling, only } \\
\text { measurements }\end{array}$ & Field & Very arid conditions $\left(\sim 15 \mathrm{~mm} \mathrm{~d}^{-1}\right)$ & $\begin{array}{l}\text { WTD }>200 \mathrm{~m} ; Z_{D S L} \text { not reported, but hardly any soil } \\
\text { moisture in the first } 60 \mathrm{~cm} \text { of soil. }\end{array}$ \\
\hline $\begin{array}{l}\text { Assouline et al. } \\
\text { (2013) }\end{array}$ & NSRE & Field & $5 \mathrm{~mm} \mathrm{~d}^{-1}$ & Lysimeter; $Z_{D S L} 1-5 \mathrm{~cm}$ \\
\hline Zeng et al. (2011a) & NSRE (mod) & Field & $\sim 10 \mathrm{~mm} \mathrm{~d}^{-1}$ & DSL not taken into account \\
\hline $\begin{array}{l}\text { Aminzadeh \& Or } \\
\text { (2014) }\end{array}$ & PS & Laboratory & $5-9 \mathrm{~mm} \mathrm{~d}^{-1}$ & $\begin{array}{l}\text { No indication about DSL, but the model can } \\
\text { reproduce E in S2. }\end{array}$ \\
\hline Neriah et al. (2014) & PS & Laboratory & Various, from 5 to $30 \mathrm{~mm} \mathrm{~d}^{-1}$ & $\begin{array}{l}\text { Dependence of the porous media hydraulic properties } \\
\text { on } \mathrm{T} \text {. } \\
\text { E rates at } \mathrm{S} 2 \text { are similar at all the different evaporative } \\
\text { conditions. }\end{array}$ \\
\hline $\begin{array}{l}\text { Dijkema et al. } \\
(2017)\end{array}$ & NSRE (mod) & Field & $\mathrm{ET}_{\mathrm{p}}>15 \mathrm{~mm} \mathrm{~d}^{-1}$ & $\begin{array}{l}\text { Lysimeter; the study shows the limitations of } \\
\text { HYDRUS1D in simulating both a DSL and } \\
\text { evaporation in very dry conditions. }\end{array}$ \\
\hline Sun et al. (2016) & $\begin{array}{l}\text { No modelling, only } \\
\text { measurements }\end{array}$ & Field & Super-arid, $19 \mathrm{~mm} \mathrm{~d}^{-1}$ & $\begin{array}{l}\text { Lysimeter, } Z_{D S L}=50 \mathrm{~cm} \text {, DSL has effects on } \\
\text { infiltration-evaporation cycles. }\end{array}$ \\
\hline This study & NSRE, DA, PS & Field & $\begin{array}{l}\text { During dry season, mean PET } 3.5 \mathrm{~mm} \\
\mathrm{~d}^{-1} \text { (15 mm d } 1 \text { in the afternoon). }\end{array}$ & $\begin{array}{l}Z_{D S L} \sim 25 \mathrm{~cm} \text {, DSL effect on evaporation rate } \\
\text { changes depending on overall dryness of the system, } \\
\text { cannot be properly modelled by NSRE, the afternoon } \\
\text { evaporation is underestimated by the PS conceptual } \\
\text { model. }\end{array}$ \\
\hline
\end{tabular}

The DA conceptual model is based on the assumption that the limiting factor for the daily averaged soil evaporation during $\mathrm{S} 2$ is the upward isothermal flow of liquid water to the vaporization plane. In other words, the complex vapour transport processes in the DSL can be simplified when integrated through a daily cycle, resulting in a negligible effect of the DSL on the daily soil evaporation rates. Therefore, the soil evaporation can be calculated as isothermal liquid water flow to the soil surface, with an exponential evaporation decay behaviour (Brutsaert, 2014a). However, the exponential behaviour seems dependent on climatic conditions as well as on soil material (McColl et al., 2017a).

The NSRE conceptual model is based on the assumption that the numerical solution to Richards' equation can properly model evaporation from a soil, even in the presence of a DSL. However, the NSRE conceptual model cannot properly model an air-dry DSL, because it does not permit discontinuity in the liquid phase (Dijkema et al., 2017); instead, a "pseudo-DSL" can be modelled, defined as a soil layer where soil moisture is almost at residual state, and water vapour flow is larger than liquid water flow. The idea is that the "pseudo-DSL" can properly model the soil evaporation rates, albeit not the soil moisture profile (Assouline et al., 2013). However, recent publications have shown that this approach leads to wrong evaporation rates estimates, especially in arid 
and semi-arid conditions (Dijkema et al., 2017; Fetzer et al., 2017), probably due to the imperfect modelling of the evaporation process in the DSL.

The PS conceptual model is based on the laboratory observations reviewed in Or et al. (2013). This conceptual model first predicts the depth of the drying front at the end of S1 as dependent on soil material properties, then calculates S2 water vapour flow using Fick's equation. An analytical solution for bare soil evaporation under steady-state conditions, with a DSL layer in which water can move only by vapour diffusion, has been elaborated by Sadeghi et al. (2012). A limitation of this approach is that it assumes hydrostatic equilibrium above the drying front and stable evaporative conditions. Neither of these conditions are met in the field. Moreover, several field studies reported water vapour flow larger than estimated by vapour diffusion alone and the cause is still debated (Webb and Ho, 1998; Zeng et al., 2011b; Assouline et al., 2013).

The main objectives of this study are to test, in a semi-arid area with a reported $0.25 \mathrm{~m}$ thick $\mathrm{DSL}$ :

- the assumption of the DA conceptual model that the DSL has a negligible effect on soil evaporation;

- the assumption of the NSRE conceptual model that it is possible to predict the soil evaporation rates by modelling a "pseudo-DSL";

- the ability of the PS conceptual model to explain the observed evaporation rates in the area.

These objectives provide the structural sub-headings used in the following Methods, Results and Discussion Sections.

\subsection{Study area and materials}

\subsubsection{Study area}

The selected study site is a $2 \times 2 \mathrm{~km}$ area, the same described in sections 1.4 and 3.2.1. The average elevation of the area is $790 \mathrm{~m}$ a.s.l., the elevation difference between the river and the highest point in the east is $\sim 30 \mathrm{~m}$. Figure 4.1 shows a close up of the study area. The position of the Eddy Covariance station and the soil altitude are shown in the map in the centre, and the depth of the groundwater table in the map on the right. 

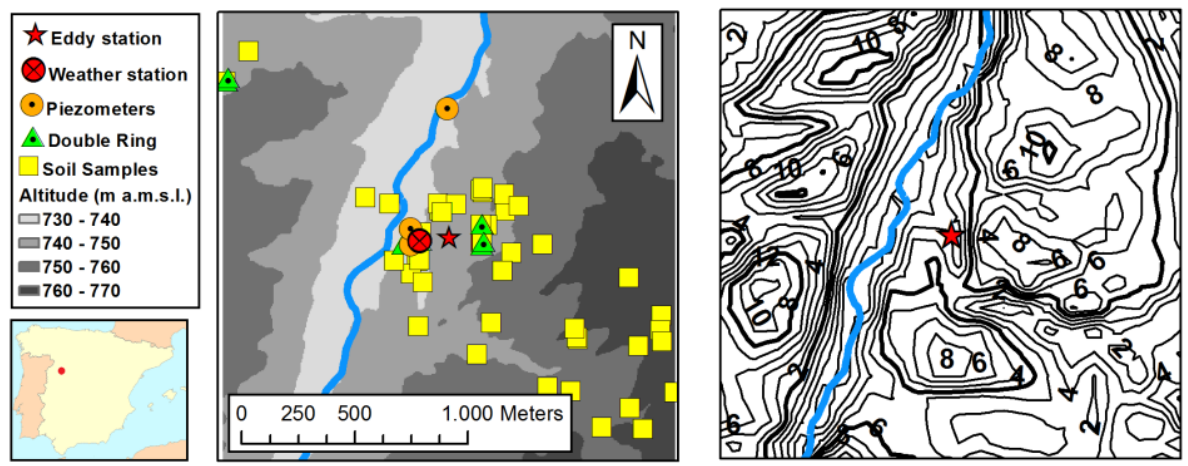

Figure 4.1: Study area $(2 \times 2 \mathrm{~km})$ : the left map shows the measurements taken in the study area around the eddy covariance station and the altitude; the right map shows the depth of the groundwater table (in m b.g.s.) on August 21, 2010, after Frances et al. (2015). Both soil moisture and matric potential profiles are so close to the weather station that the symbols would superimpose.

\subsubsection{Groundwater measurement and modelling}

The shallow groundwater shows a change of $Z_{W T}$ ranging from $\sim 0.5 \mathrm{~m}$ b.g.s. in the west, close to the river to $\sim 10 \mathrm{~m}$ b.g.s. in the east in the higher terrain (Figures 4.1 and 4.2). We installed several piezometers in the western part in the sloping terrain (recording $Z_{W T}$ every hour), while in the eastern part the presence of shallow granite prevented the installation of piezometers. However, we monitored a deep well further east, just outside of the study area. The typical yearly changes of the $Z_{W T}$ range from the shallowest at the end of spring (March-April) to the deepest at the end of summer (October) with amplitude of $\sim 2 \mathrm{~m}$. The spatio-temporal water table dynamics for the years 2009-2010 were modelled by Frances et al. (2015). 


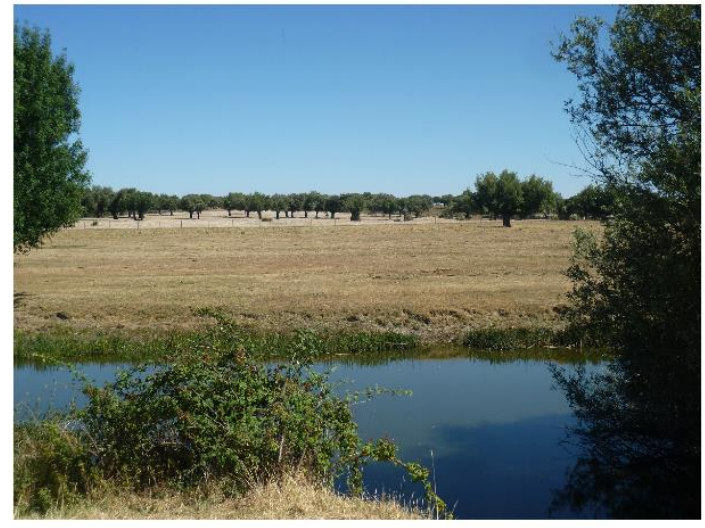

Figure 4.2: La Mata catchment during dry season: Sardon River in the foreground, then bare soil and further away scattered trees; all in the gentlysloping landscape.

\subsubsection{Micrometeorological measurements}

An EC tower was installed in the study area to measure the actual evapotranspiration ( $E T^{e c}$ ) every 30 minutes (Chapter 3, Balugani et al. 2017). The $10 \mathrm{~m}$ high tower (average trees height is 4-5 m) was equipped with a CNR1 four components radiometer (Kipp and Zonen, Delft, The Netherlands), a CSAT3 sonic anemometer (Campbell Scientific Inc., Utah, USA), a LI7500 gas analyser (Licor Biosciences, Nebraska, USA), and a WXT520 "multi weather sensor" for measurements of wind speed, direction, air temperature and air humidity (Vaisala Oyj, Helsinki, Finland). The EC tower was positioned on a gently sloping terrain about $300 \mathrm{~m}$ from the river (Figure 4.2). Additional equipment consisted of two soil heat flux plates (Hukseflux) and 19 temperature sensors, placed on a vertical profile from below to above the soil surface, used for the assessment of the energy balance. The data, collected for a total duration of 2 years (2009-2010), was then processed with the software AltEddy (Wageningen University and Research, The Netherlands). The footprint of the EC tower was calculated using the analytical model by Hsieh et al. (2000) for the main wind direction with the modification by Detto et al. (2006) for the inclusion of the lateral dispersion. A $2 \mathrm{~m}$ high weather station was also available in the area, at $\sim 100 \mathrm{~m}$ from the EC tower, which measured continuously wind speed, relative humidity, air temperature, incoming and outgoing solar radiation, precipitation, and soil heat flux every hour. 


\subsubsection{Calculation of $E T^{e c}$}

To differentiate (partition) between soil evaporation and tree transpiration, the study area was divided into bare soil area and tree canopy area, the latter assumed as equal to ground projection of tree canopy area (Figure 3.2). The EC tower footprint shape and position was calculated for each 30 minute time interval, so that it was known when the tree canopies were measured by the EC tower. The tree transpiration was estimated by upscaling sap flow measurements following the methodology proposed by Reyes and Lubczynski (2013). This allowed the authors to estimate the total tree transpiration (6\% of the total evapotranspiration measured by EC tower) and to eliminate it from the evapotranspiration dataset, obtaining an estimate of bare soil evaporation measured by the EC tower $\left(E^{e c}\right)$. Additional information on the evapotranspiration partitioning can be found in Chapter 3.

\subsubsection{Soil measurements}

To design and calibrate the NSRE conceptual model and investigate the water potentials and temperatures of the DSL, we set up three monitoring soil profiles in the study area. The profiles were equipped with soil moisture and temperature sensors (Hydraprobe, Stevens, USA) at four depths (25, 50, 75 and $100 \mathrm{~cm}$ b.g.s.) and matric potential sensors (Decagon MPS1, USA, measuring range 0 to $-0.5 \mathrm{MPa}$ ) at three depths $(15,25$ and $75 \mathrm{~cm}$ b.g.s.). Due to the very dry conditions of the top soil, two polymer tensiometers (POTs, Bakker et al. 2007, measuring range 0 to $-1.6 \mathrm{MPa}$ ) were also installed, both at $15 \mathrm{~cm}$ b.g.s. at the two different locations, next to two soil moisture profiles. All soil measurements were recorded every hour by a Campbell CR1000 data logger (Campbell Scientific, USA). The POTs sensors have wider measuring range than most tensiometers and were used to determine the formation and presence of the DSL, in conjunction with manual measurements performed with soil ring sampling and a WP4 dew point potentiometer (Decagon Devices, USA). In the context of this study, the DSL is defined as a soil layer with matric potential <-1.5 MPa (the lowest measurable with the POT sensor). Moreover, when taking the soil samples (locations shown in Figure 4.2), we measured soil moisture manually in the soil at different depth using a portable Theta Probe (Delta-T Devices, UK). These manual measurements were taken in September 2011. A ponding experiment was performed on one of the three soil profiles in order to inverse-calibrate the Hydrus1D model. 


\subsection{Conceptual models and methods:}

\subsubsection{Testing DA conceptual model assumption}

The main assumptions of the DA conceptual model are that: (1) even if the evaporation through a DSL is a complex vapour flow phenomenon, when averaged over a day it can be calculated as the upward, isothermal liquid water flow driven by pressure gradients, with negligible effect of gravity; (2) the evaporation process affects only the water in the topmost layer (above the zero-flux plane) of the soil (Figure 1.2b; Brutsaert, 2014a). The assumption (1) is based on the idea that most processes in a daily evaporation cycle either cancel each other (e.g. thermally driven fluxes, Zeng et al. 2009a; night-time wetting from below, Idso et al. 1979) or enhance water vapour transport through the DSL to equal the liquid water transport up to the vaporization plane (e.g. atmospheric turbulence, Ishihara et al. 1992). When these processes are taken into account in the dynamic nature of the $\mathrm{DSL}$, the water vapour transport through this dry layer is significantly larger than expected when assuming only Fick's diffusion (as found, for example, by Parlange et al. 1998). Due to an abundant evidence from field-studies (reviewed in Brutsaert, 2014a), the DSL effect as an evaporation rate-limiting factor is considered relatively small (again, when averaged over a day), and the main factor controlling the evaporation rate is the capillary rise of liquid water to the vaporization plane. The assumption (2) is that a zero-flux plane exists below the vaporization plane (Figure 1.2b), at a fixed depth $d$ where capillary and gravity forces acting on liquid water are at equilibrium: above the zero-flux plane water moves upward due to hydraulic head gradients, while below, water moves downward by gravity forces (Jackson et al., 1973; Payne et al., 1990; Villegas and Morris, 1990; Daamen et al., 1993; Tsujimura et al., 2001; Khalil et al., 2003). Therefore, only water above the depth $d$ evaporates.

The solution of the linearized Richards' equation leads to two possible equations: one for short-term evaporation $(E)$, where $E\left[\mathrm{~L} \mathrm{~T}^{-1}\right]$ decreases with the square root inverse of time, $t^{-1 / 2}$; and the other for long-term evaporation, where $E$ decreases following an exponential decay formulation. The assumptions for the linearization and solution of the Richards' equation are that: (i) the initial volumetric water content is uniform throughout the soil profile $\left(\theta_{i}\right.$, dimensionless); (ii) as soon as the evaporation process starts, the volumetric water content at the soil surface is air-dry ( $\theta_{0}$, dimensionless); (iii) the zero-flux plane depth $d$ [L] (calculated as in Equation 9 of Brutsaert, 2014a) is constant. The evaporative flux at the surface following Brutsaert (2014a) is:

$E_{d}=E_{0} \sum_{n=1,2, \ldots}^{\infty} \exp \left(-\frac{(2 n-1)^{2} t}{\kappa}\right)$

where:

$E_{0}=2 \bar{D}\left(\theta_{i}-\theta_{0}\right) / d$

$\kappa=4 d^{2} / \pi^{2} \bar{D}$ 
where $E_{0}$ is in [ $\mathrm{L} \mathrm{T}^{-1}, \mathrm{~mm} \mathrm{~d}^{-1}$ in this study], $\bar{D}$ is the liquid-saturation weightedmean diffusivity of air in soil $\left[\mathrm{L}^{2} \mathrm{~T}^{-1}, \mathrm{~mm}^{2} \mathrm{~d}^{-1}\right.$ in this study] (dependent on soil saturation, see Brutsaert 2014a, Equation 4), $t$ is time [T] and $\kappa$ is the characteristic timescale of soil drying (Brutsaert 2014a, Appendix 4.7.1); all defined in Equation 4 to 6 of Brutsaert (2014a). For large $t$, the series in Equation 4.1 converges to (Brutsaert, 2014a):

$E_{d}=E_{0} \exp (-t / \kappa)$

while the limiting case for small $t$ is $=\frac{1}{2} D e_{0} t^{-1 / 2}$, where $D e_{0}$ is the desorptivity (defined in equation 12 of Brutsaert 2014a).

We identified all the drying periods after precipitation in summers 2009 and 2010 and split these periods into two subsets: a calibration-set, when a DSL was not yet formed in the soil (mid-April to July) and a validation-set, when a DSL was reported (August-September); then we used the first subset to calibrate the model (i.e. fit Equation 4.4) and the second to validate the model. We are interested in the long-term solution (Equation 4.4) to calculate the evaporation values for a long drying event after a precipitation, when a DSL is usually formed. Brutsaert (2014a) shows a practical method to determine $E_{0}$ and $\kappa$ directly from evaporation data: this can be done by fitting a linear function to a semi-log plot of evaporation values in time. We fitted Equation 4.4 to the semi-log plots of evapotranspiration during the drying events of the first half of the dry season (calibration) to determine $E_{0}$ and $\kappa$, and then we compared the predicted evaporation rates with the measured ones for the validation dataset. Note that, due to the second assumption of this conceptual model, the soil moisture below the zero-flux plane is not relevant in the evaporation process, so the $Z_{W T}$ has no impact on the estimated evaporation.

\subsubsection{Testing NSRE conceptual model assumption}

The main assumption of the NSRE conceptual model is that a proper modelling of the liquid phase discontinuity in the DSL is not needed to estimate the evaporation rates from a dry soil. The NSRE cannot model liquid phase discontinuity in the soil profile phase (Dijkema et al., 2017); with this assumption, however, it can be used even when such discontinuity is clearly reported in the field (Assouline et al., 2013). The water vapour diffusion is taken into account: the DSL is approximated as a "pseudo-DSL", a soil layer where the water vapour diffusion is larger than the liquid water flow, even if the liquid water continuity is not lost.

We applied the NSRE conceptual model in the study area by simulating the bare soil evaporation using the Hydrus1D numerical model (version 4.14) with coupled heat, liquid and water vapour flow, described in Simunek et al. (2005) and Saito et al. (2006). The model simulates the liquid flow of water through a porous media by Darcian flow, while water vapour is simulated by the diffusion flow only. We used the van Genuchten (1980) expression for the water retention curve (WRC). A 1D model was chosen because: (i) the focus 
was only on the evaporation process; (ii) the model is widely used in the literature for similar studies; (iii) the topographical gradients involved are relatively small. Hydrus1D has been already shown to be able to model evaporation of water from a soil with a $5 \mathrm{~cm}$ thick DSL, even with the van Genuchten (1980) WRC (Assouline et al., 2013).

We used field and laboratory measurements to determine the boundary conditions and the soil hydraulic properties of the Hydrus1D model. The soil hydraulic properties were estimated by laboratory analysis of the soil samples collected in the area together with the data from the double ring infiltrometer tests conducted at 7 locations; these were used as a starting point for inverse calibration using the data of the ponding experiment performed at the end of September 2011 (see Section 4.2.2). The micrometeorological measurements collected every 30 minutes were used as the top model boundary condition. The bottom boundary was set as the $Z_{W T}$, extracted from the groundwater model of Frances et al. (2015) for years 2009 and 2010.

The Hydrus1D model was calibrated using the dataset collected in the three soil monitoring profiles (Figure 4.2, Chapter 3,; the depth of soil profiles was $\sim 2 \mathrm{~m}$ b.g.s.). The temperature at the soil surface was monitored by an infrared radiometer (IR100 from Campbell Scientific) and the $Z_{W T}$ in piezometers by 3 water level recorders (Keller DCX-22, Switzerland) and by manual measurements. Uniform temperature and soil moisture at field capacity over the whole profile were set as the initial condition of the 2 years simulation. The simulation started 2 months before the setup and initialization of the EC tower measurements $\left(Z_{W T}\right.$ and meteorological measurements from the $2 \mathrm{~m}$ high weather station are available for that period).

To compare the Hydrus1D model evaporation with the EC tower measurements, the Hydrus1D evaporation was upscaled over the whole bare soil area using maps of $Z_{W T}$ obtained from Frances et al. (2015) and compared to $E^{e c}$ using the EC tower footprint calculation. For that purpose the study area was divided into pixels of $1 \mathrm{~m}^{2}$. In every pixel representing bare soil, the Hydrus1D models were run with known $Z_{W T}$ obtained from Frances et al. (2015). In this way, we obtained Hydrus1D modelled evaporation at 30-minute temporal and $1 \mathrm{~m}^{2}$ spatial resolution. We then multiplied these maps of Hydrus1D evaporation by the EC tower footprint (a probability density map) in order to calculate the evaporation modelled by Hydrus1D in the footprint sampled by the EC tower. We call this Hydrus1D-simulated footprint evaporation $E_{f}$. This upscaling method is described in more detail in Balugani et al. $(2016,2017)$.

\subsubsection{Testing the applicability of the PS conceptual model}

The PS conceptual model is based on laboratory experiments of soil evaporation, where an air-dry DSL develops at the beginning of S2 with $Z_{D S L}$ determined by the soil hydraulic properties of the soil. The formation of an air- 
dry DSL was observed in numerous laboratory experiments where initially saturated soils were left to evaporate under stable evaporative conditions (Lehmann et al. 2008; Or et al. 2013; Shokri and Salvucci 2011). The saturation conditions as observed in the laboratory studies in the soil profile during S2 is schematically shown in Figure 1.2a (Yiotis et al., 2003; Shokri, Lehmann and Or, 2009). The soil profile consists of three zones: a saturated zone, an intermediary unsaturated zone (called "film" region by Lehmann et al. 2008) where water moves upward by capillary flow, and an upper DSL zone where liquid water continuity is lost and water moves only as vapour. Lehmann et al. (2008) define the thickness of the intermediary zone by a characteristic length $(L c)$, which is the height of the hydraulically connected region between the receding drying front (the saturated zone) and the vaporization plane (Figure 1.2a). If the evaporation rates are low, which is often the case during $\mathrm{S} 2$, the liquid phase above the drying front is close to hydrostatic equilibrium. In the case of hydrostatic equilibrium the $L c$ can be calculated by linearization of the water retention curve for the soil material (Figure 1.2a, Shokri and Salvucci 2011; Or et al. 2013), which implies that the depth of the drying front at the onset of S2 depends only on the hydraulic properties of the soil.

We implemented the PS conceptual model based on the theoretical model presented in Shokri and Salvucci (2011) and Or et al. (2013), using an approach similar to that of Assouline et al. (2013). The main elements of the PS conceptual model for S2 from soil columns are: (a) evaporation rate through a DSL layer is restricted to Fick's water vapour diffusion rate, so no liquid water flow takes place; and (b) $L c$, determined by the soil material properties only, represents the maximum height of continuity in the liquid water above the saturated zone. Assouline et al. (2013) applied that PS conceptual model to calculate the evaporation flow from a lysimeter with a reported air-dry soil layer at the top. This was done by assuming only Fick's diffusion flow for water vapour in the $\sim 0.04 \mathrm{~m}$ thick top DSL, and using soil moisture content and temperature information at the top and bottom of the DSL as boundary conditions to calculate the diffusion. We followed the method of Assouline et al. (2013); the equation for the water vapour diffusion $\left(E_{\text {diff }}\right)$ becomes, then:

$E_{\text {diff }}=D_{\text {soil }}^{v} \frac{\Delta C_{v}}{Z_{D S L}}$

where $D_{\text {soil }}^{v}$ is the diffusion coefficient for water vapour in the soil, defined as in Millington and Quirk (1960), and $\Delta C_{v}$ is the difference between vapour concentration at the vaporization plane and at the soil surface. Both quantities $\left(D_{\text {soil }}^{v}\right.$ and $\Delta C_{v}$ ) are dependent on soil and atmospheric concentrations as detailed in Assouline et al. (2013).

The identification of the initial $Z_{D S L}$ as equal to the characteristic length $L c$ is applicable in laboratory conditions and with initially saturated bare soils, but it is problematic in field conditions, where random precipitation events, changing $Z_{W T}$ conditions and variable evaporative conditions result in a more complex soil moisture profile. When the original concept of $L c$ is taken into 
account, $Z_{D S L}$ depends on $Z_{W T}$ (e.g. Figure $1.2 \mathrm{a}$ ), as $Z_{D S L}=Z_{D S L}-L c$, with $L c$ calculated by linearization of the van Genuchten WRC. This differs from the field observations, where a mostly constant $Z_{D S L}(\sim 0.25 \mathrm{~m}$ b.g.s.) was observed (through direct measurements and POT dataloggers, Section 4.2.5) over the whole area despite different $Z_{W T}$. Therefore, we implemented two versions of the PS model: (i) the first, called $E_{V Z}$ model, incorporating the $L c$ concept, with a $Z_{D S L}$ dependent on both $Z_{W T}$ and $L c$ (determined by soil material properties) and (ii) the second, called $E_{C Z}$ model, more representative of field observations with a spatially and temporally constant $Z_{D S L}=0.25 \mathrm{~m}$ over the whole area (with a set up similar to the soil profile in Figure 1.2b).

The PS model was developed to explain stable evaporation in laboratory experiments, so its applicability to field studies, where evaporative conditions can change dramatically at different time scales, can be problematic. In Shokri and Salvucci, (2011) the PS conceptual model was tested in laboratory experiments with potential evaporation rates of $\sim 10 \mathrm{~mm} \mathrm{~d}^{-1}$ and initially saturated soil columns of $60 \mathrm{~cm}$ height. In our study area evaporation rates were $\sim 3 \mathrm{~mm} \mathrm{~d}^{-1}$ during the afternoon, the $Z_{W T}$ was $10 \mathrm{~m}$ b.g.s. in the higher elevated parts of the catchment, and changes in evaporative conditions between day and night were large, ranging from $20 \mathrm{~mm} \mathrm{~d}^{-1}$ during a day to condensation during a night. Fick's diffusion flow was calculated as in Assouline et al. (2013), knowing the air relative humidity, the soil relative humidity, the temperature at the vaporization plane and using Millington and Quirk (1960) for the diffusion coefficient.

In order to meet the assumptions and to apply the PS conceptual model in our study, we limited the analysis to afternoon periods of the day when the evaporative conditions were the most stable. We used three criteria to select assessment days from the available time series: (i) a DSL was observed by the POT measurements, (ii) withered grasses occurred in the whole area (i.e. only bare soil present), (iii) no precipitation was recorded in the preceding week and in analysed days. The decision to calculate the bare soil evaporation only during the afternoon, from 14:00 to 19:00 local time (appr. 11:30-16:30 solar time) was taken to exclude the possible evaporation of condensation water in the DSL in the morning and because the temperature gradient in the soil, the air temperature, the relative humidity and the net radiation did not change much during that period of the day. In this way the calculations were performed for relatively stable evaporative conditions, when the presence and dryness of the DSL was confirmed, and the soil moisture profile below the vaporization plane was relatively close to equilibrium. The analysis for the PS conceptual model was carried out for the following days: 11 August and 26 September of 2009; 29 June, 13 and 14 July, 21 August and 26 September of 2010. 


\subsubsection{Comparison of the three conceptual models}

We evaluated the three conceptual models based on their ability to estimate the $E^{e c}$ measurements. The three conceptual models estimate soil evaporation at different time frames: (i) the DA conceptual model estimates the daily cumulative evaporation; (ii) the NSRE estimates the evaporation rate for each time step, in this case every 30 minutes; (iii) the PS model estimates the soil evaporation every hour during the stable-conditions period of the day (14:00 to 19:00 local time, see Section 4.3.3). The $E^{e c}$ measurements are taken every 30 minutes. We compared the daily values of evaporation measured by the EC tower with those estimated by the DA and by the NSRE conceptual models by integrating the $E^{e c}$ and NSRE evaporation over a day. Then, we compared the PS evaporation estimates with the $E^{e c}$ and NSRE evaporation for the same period of the day. Finally, we calculated the cumulative water vapour diffusion through the DSL over a whole day to obtain daily values. However, this is a stretch of the PS model assumptions, and it is possible that water transport processes are missed in doing so.

\subsection{Results}

\subsubsection{Field measurements}

The results of the EC measuring campaign, together with the corresponding rainfall data, are presented in Figure 4.3. The acquired data show that the hydrological year going from October 2008 to September 2009 ( 310 mm y${ }^{-1}$, early 2009 not shown) was much drier than that going from October 2009 to September 2010 ( 702 $\mathrm{mm} \mathrm{y}^{-1}$ ). Consequently, water table was deeper and soil moisture was lower at the beginning of the dry season in 2009 than in the same period of 2010. During the wet winter of 2009-2010, with low potential evapotranspiration and frequent rain events, the $E^{e c}$ did not show drying trends, but increased steadily until April (mid-spring). After April weather conditions started to change, with fewer rain events (every $\sim 2$ weeks) and higher potential evaporation, and some drying spells appeared marked by daily decreases of $E^{e c}$ between one precipitation event and another. The $E^{e c}$ was the largest at the beginning of the dry season of the wetter year $2010(3.5 \mathrm{~mm} \mathrm{~d}$ 1 in June 2010), when $E T_{p}$ and soil moisture were high and then steadily declined throughout the dry season, down to $\sim 2 \mathrm{~mm} \mathrm{~d}^{-1}$ in September 2010; the lowest $E^{e c}<1 \mathrm{~mm} \mathrm{~d}^{-1}$, were recorded at the end of the dry season in the drier year 2009. The $E^{e c}$ in June 2010 was three times larger than in September 2009. For more details see Balugani et al. (2017). 


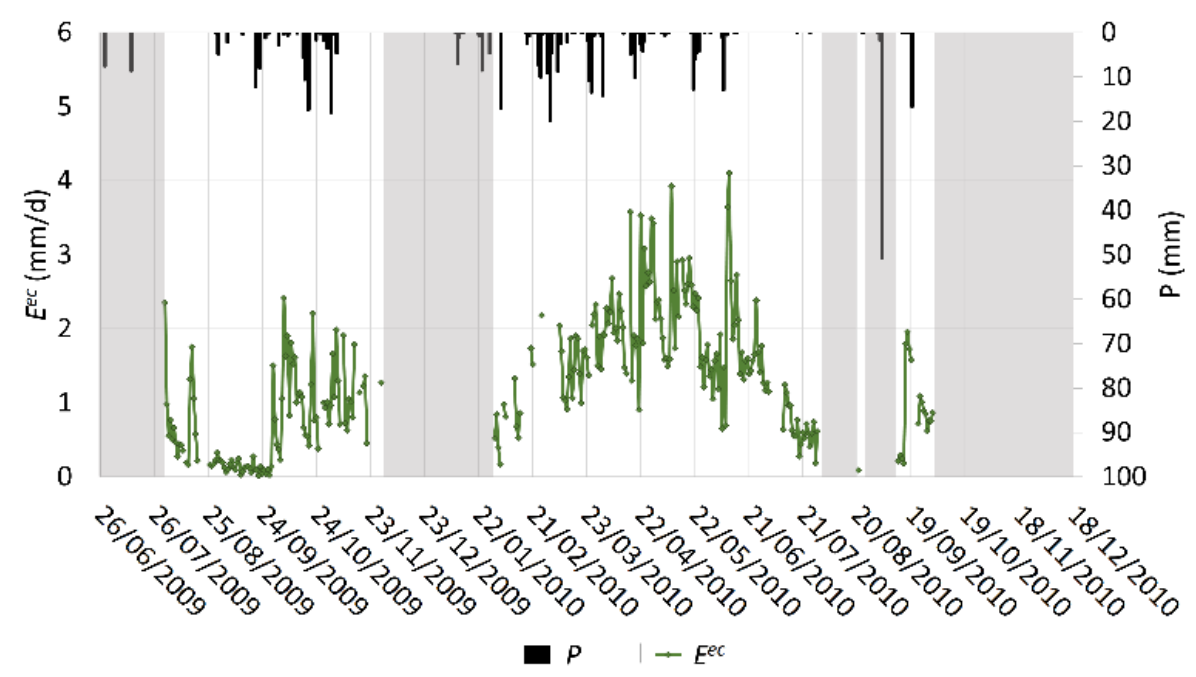

Figure 4.3: Daily evaporation measured by the eddy covariance tower $\left(E^{e c}\right)$ and daily rainfall data. Periods in which the EC tower had data gaps are shown with grey shade.

The $E^{e c}$ magnitude in the study area as analysed by different EC-tower footprint orientations shows no $E^{e c}$ dependence on wind direction during the dry season despite large differences in $Z_{W T}$ ranging from $<0.5 \mathrm{~m}$ b.g.s. along Sardon valley to $\sim 10 \mathrm{~m}$ at the eastern side of the study area (see Appendix 4.7.1). This is to be expected when a DSL develops in the whole area: Or et al. (2013) and Neriah et al. (2014) show that S2 rates are very similar even if boundary conditions vary.

During the dry season (summer): (i) the water in the river (Figure 4.1) stops flowing and the river itself breaks up into many elongated ponds hydraulically linked with groundwater (Figure 4.2); (ii) the grasses wither and are eaten by the cattle (already during May, Figure 4.2); and (iii) a DSL, enhanced by the large vapour pressure deficit (VPD) and transpiration of grasses, quickly forms up to a depth exceeding the root depth of the grass. Weather measurements taken at $2 \mathrm{~m}$ height show that the relative humidity drops below $20 \%$ during a day in dry season, while the air temperature may vary from $12{ }^{\circ} \mathrm{C}$ during night to $37^{\circ} \mathrm{C}$ during the day. The soil surface temperature ranges from 8 to $50^{\circ} \mathrm{C}$ and the precipitation events are short and rare. The POT measurements (Figure 4.4), the direct observation during the soil sampling, and the presence of withered grass prove that a DSL $\sim 0.25 \mathrm{~m}$ thick was present in the investigated area during most of the drying season, particularly after grass senescence (May) to the first heavy precipitation events (around mid-September). 


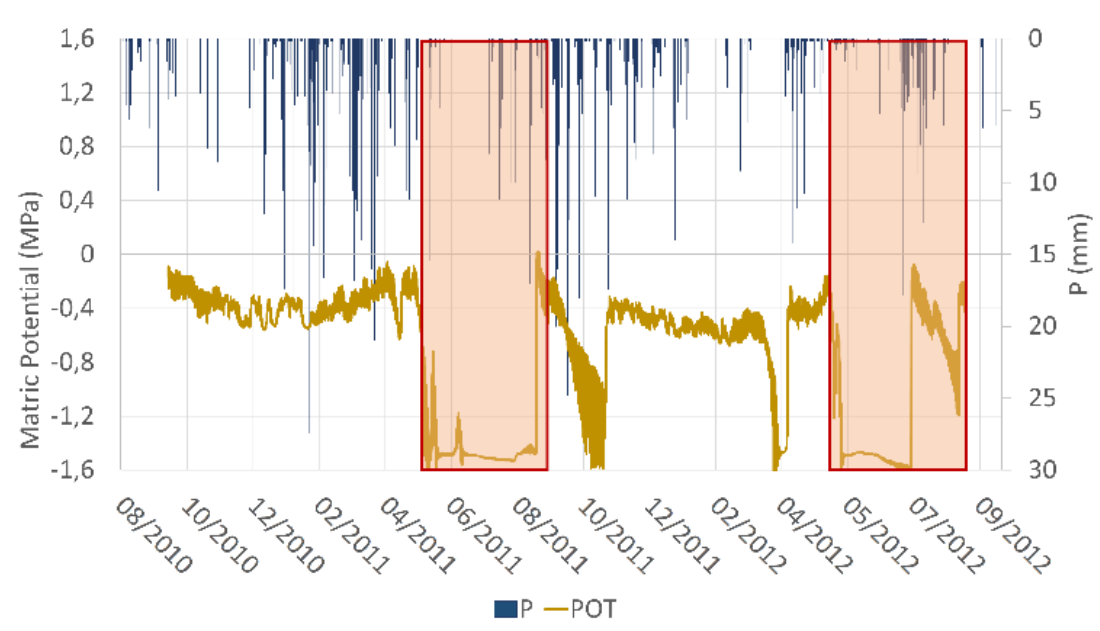

Figure 4.4: POT (polymer tensiometer) and daily rainfall measurements near the weather station, Figure 4.2. The dry seasons (from grass senescence to first heavy rains) are coloured.

\subsubsection{Testing DA conceptual model assumption}

The DA model calibrated using the drying events from the first half of the dry summer 2010 shows a consistent error when validated on the drying events from the second half of the dry summer (not shown). We first identified all the drying events in the dataset, beginning from the last day of rain and recording duration (in days) and cumulative daily $E^{e c}$ until the next rain. Then, looking at soil moisture data, we divided it into two subsets: the drying events relative to moister soils (beginning of the dry summer, May-June 2010) and drying events relative to soils with a DSL (end of summer, July-September 2009 and 2010; Figure 4.6). We used the first subset to calibrate the DA model by linear regression of $\ln \left(E_{E C}\right)$ against duration $t$ (days); in this way, we obtained the two parameters $E_{0}=2.88 \mathrm{~mm} \mathrm{~d}^{-1}$ and $\kappa=26.9$ days, with a $\mathrm{R}^{2}=0.76$, RMSE $=0.36 \mathrm{~mm} \mathrm{~d}^{-1}$. However, when applied to the validation dataset, the DA model predicted daily evaporation rates with a RMSE $=1.04 \mathrm{~mm} \mathrm{~d}^{-1}$.

The consistent error in the evaporation rate predictions is due to the fact that the drying events in the three periods analysed (Figure 4.5) are described by significantly different sets of $E_{0}$ and $\kappa$ parameters. Looking at the semilog plot in Figure 4.5, it seems reasonable to infer that the calibration dataset and the validation dataset have different sets of parameters for Equation 4.4. This means that the linear model fitted to the calibration data is significantly different from the linear model fitted to the validation dataset. To test this hypothesis we: (i) divided the validation dataset further into the second half of summer 2009 and the second half of summer 2010; (ii) fitted a linear model 
to each of the three subsets (second half of dry summer 2009, first half of dry summer 2010 and second half of dry summer 2010, referred from here on as sh2009, fh2010 and sh2010); (iii) tested the hypothesis that the linear models are the same with an ANOVA test. The test showed that all the linear models are significantly different, with very low $p$ values for the comparisons between sh2009 and fh2010 model and sh2010 and fh2010 models, and $p=0.028$ for the comparison between sh2009 and sh 2010 models. The $E_{0}$ and $\kappa$ parameters for the models fitted to the subsets are, respectively: $0.64 \mathrm{~mm} \mathrm{~d}^{-1}$ and 17.0 days for the sh2009 model, and $1.81 \mathrm{~mm} \mathrm{~d}^{-1}$ and 14.7 days for the sh2010 model.

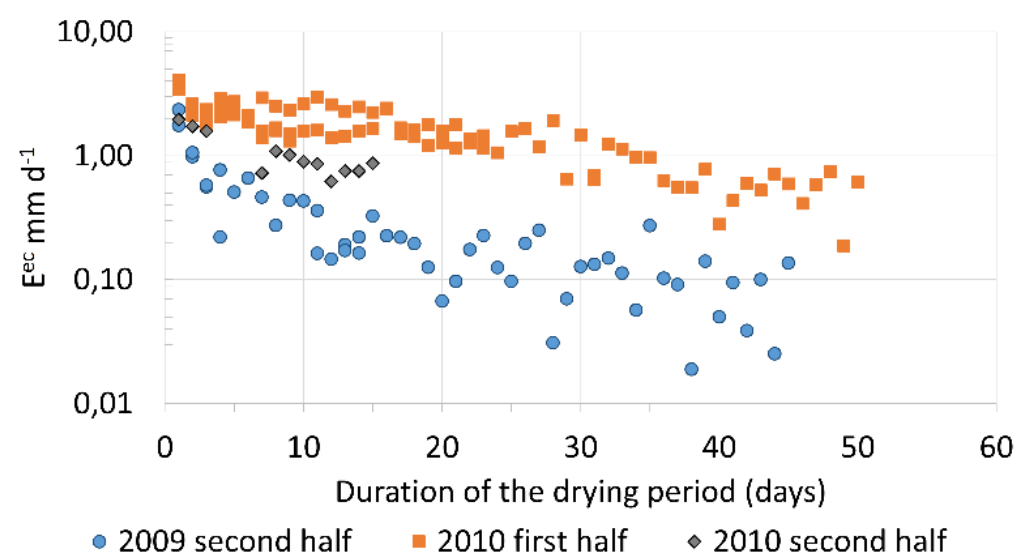

Figure 4.5: Semi-log plot of $E^{e c}$ versus time. The $E^{e c}$ dataset was divided into three subsets with different dry conditions each starting at different Julian date of the drying periods: DOY 211 (30 July 2009, orange dots), DOY 119 (29 April 2010, blue squares), DOY 161 (10 June 2010, grey diamonds).

\subsubsection{Testing NSRE conceptual model assumption}

The evaporation estimated by Hydrus1D for the EC tower footprint $\left(E_{f}\right)$ differs from the $E^{e c}$ in daily averages (Figure 4.6, Chapter 3 ) and in 30-minute estimates (Figure 4.6); these differences are mainly due to the winddependent footprint position influencing Hydrus1D estimates as explained in Section 4.2.3. Hydrus1D modelled the formation of a very thin pseudo-DSL 1$3 \mathrm{~cm}$ thick only during the driest period. The Hydrus1D estimates for the daily evaporation rates are presented and discussed in detail in Chapter 3 . Here it is important to note that, although during wet periods (autumn to mid-spring) $E_{f}$ is a good estimate of $E^{e c}$, during late spring and dry season $E_{f}$ is larger than $E^{e c}$ right after a precipitation event; later on $E_{f}$ drops quickly to nearly steadystate while the $E^{e c}$ shows a continuous, slow decline (Figure 4.6). $E_{f}$ strongly 
depends on the footprint position: it predicts high $E_{f}$ rates for shallow water tables (close to the Sardon river, $Z_{W T}$ 0.5-2 $\mathrm{m}$ b.g.s.) and low for the higher terrain where $Z_{W T}$ is deeper (7-10 m b.g.s.). $E^{e c}$, instead, shows no dependence on the wind-speed and wind-direction dependent footprint position (see Section 4.3.1 and Appendix 4.7.1), so there is no significant difference in $E^{e c}$ between the river valley and the higher terrain footprints. Therefore, the error of the evaporation prediction from Hydrus1D is related to the $Z_{W T}$, and therefore to the footprint position as affected by wind direction. The absolute (and relative) errors in the north, east, south and west quadrants are, respectively: $-0.01 \mathrm{~mm} \mathrm{~d}^{-1}(0.21),-0.05 \mathrm{~mm} \mathrm{~d}^{-1}(1.00), 0.008 \mathrm{~mm} \mathrm{~d}^{-1}(0.16)$ and $0.11 \mathrm{~mm} \mathrm{~d}^{-1}(2.20)$; where the absolute error is $E_{f}-E^{e c}$ and the relative error is the ratio of the absolute error to the average $E^{e c}$. Figure 4.7 shows the absolute error depending on wind direction (EC footprint position). When the results are averaged for the whole area, the relative error becomes $1.16 \mathrm{~mm}$ $\mathrm{d}^{-1}$.
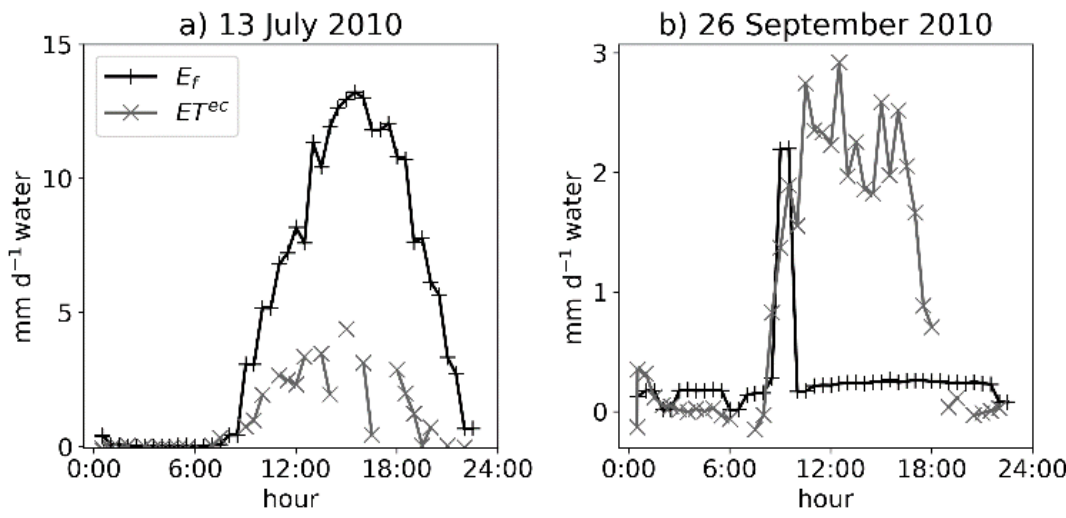

Figure 4.6: Comparison between $E_{f}$ and $E^{e c}$ for: a) 13 July 2010, with predominant wind coming from west, i.e. from the river valley, with shallow $Z_{W T}$ (0.5-2 m b.g.s.); b) 26 September 2010, with predominant wind coming from the south, i.e. from the higher terrain, with deep $Z_{W T}$ (7-10 m b.g.s.); the spike of $E_{f}$ in 26 September 2010 at 10:00 is due to the wind temporarily coming from the river valley. 


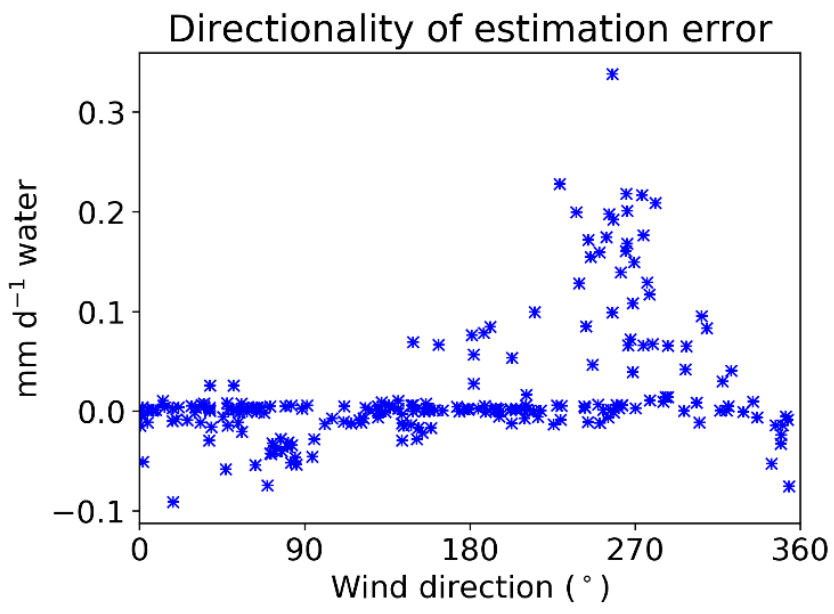

Figure 4.7: Difference between $E_{f}$ and $E^{e c}\left(E_{f}-E^{e c}\right.$, in $\mathrm{mm}$ per half hour) plotted against various wind directions; $\mathrm{N}$ is north, $\mathrm{E}$ is east, $\mathrm{S}$ is south and $\mathrm{W}$ is west. Positive values found in the west, i.e. towards the valley with shallow water table $\left(200-300^{\circ}\right)$ mean that $E_{f}>E^{e c}$, while negative values found in the east, i.e. towards the higher elevated area with deep water table $\left(50-100^{\circ}\right)$ mean that $E_{f}<E^{e c}$.

\subsubsection{Testing the applicability of the PS conceptual model}

The evaporation fluxes calculated applying the pore scale conceptual model with a constant $Z_{D S L}\left(E_{C Z}\right)$ and with a variable $Z_{D S L}\left(E_{V Z}\right.$, calculated as $Z_{D S L}=$ $\left.Z_{W T}-L c\right)$, during the stable-conditions period and for the whole day, are reported in Table 4.2. $E_{C Z}$ calculated for the stable part of the day show the same order of magnitude as the $E^{e c}$ measurements; however, the relative error $\left(E_{C Z}-E_{E C}\right) / E_{E C}$ fluctuates between $889 \%$ and $6 \%$ (average 1.19) with the highest relative error reported in Augusts of both years. $E_{V Z}$ has the same order of magnitude as $E_{C Z}$, but it tends to underestimate $E^{e c}$, with an average relative error of -0.82 . The daily values of $E_{C Z}$ and $E_{V Z}$ have also the same order of magnitude of the daily $E^{e c}$, with an average associated relative error of 0.85 and -0.91 , respectively. The daily estimates of $E_{V Z}$ always underestimate the measured $E^{e c}$.

Table 4.2: Comparison of the $E^{e c}$ values with the evaporation calculated using the pore-scale conceptual model for the same time of the day, with a fixed DSL 
$\left(E_{C Z}\right)$ and with a $Z_{D S L}$ determined by $Z_{W T}$ and $L c\left(E_{V Z}\right)$; in $\mathrm{mm} \mathrm{d}^{-1}$. Subscript err stands for relative error.

\begin{tabular}{|c|c|c|c|c|c|c|c|}
\hline & 11/Aug/2009 & 26-Sep-09 & 29-Jun-10 & 13-Jul-10 & 14-Jul-10 & 21/Aug/2010 & 26-Sep-10 \\
\hline \multicolumn{8}{|c|}{ Stable-conditions period $(14: 00-18: 00)$} \\
\hline$E^{E C}$ & 0.36 & 0.91 & 1.27 & 0.96 & 0.96 & 0.09 & 0.89 \\
\hline$E_{C Z}$ & 0.9 & 0.16 & 0.9 & 0.9 & 0.9 & 0.89 & 0.16 \\
\hline$E_{V Z}$ & 0.13 & 0.01 & 0.05 & 0.03 & 0.03 & 0.07 & 0 \\
\hline$E_{C Z \text { err }}$ & 1.5 & -0.82 & -0.29 & -0.06 & -0.06 & 8.89 & -0.82 \\
\hline$E_{V Z \text { err }}$ & -0.64 & -0.99 & -0.96 & -0.97 & -0.97 & -0.24 & -0.99 \\
\hline \multicolumn{8}{|c|}{ Daily values } \\
\hline$E^{E C}$ & $8.00 \mathrm{E}-02$ & $7.80 \mathrm{E}-02$ & $2.74 \mathrm{E}-02$ & $2.15 \mathrm{E}-02$ & $2.18 \mathrm{E}-02$ & 1.99E-02 & $1.99 \mathrm{E}-02$ \\
\hline$E_{C Z}$ & $3.58 \mathrm{E}-02$ & $3.12 \mathrm{E}-03$ & $3.06 \mathrm{E}-02$ & $9.39 \mathrm{E}-02$ & $7.80 \mathrm{E}-02$ & $6.65 \mathrm{E}-02$ & $8.73 \mathrm{E}-04$ \\
\hline$E_{V Z}$ & $5.13 \mathrm{E}-03$ & $1.72 \mathrm{E}-04$ & $1.61 \mathrm{E}-03$ & $3.48 \mathrm{E}-03$ & $2.24 \mathrm{E}-03$ & $5.12 \mathrm{E}-03$ & 2.61E-05 \\
\hline$E_{C Z \text { err }}$ & -0.55 & -0.96 & 0.12 & 3.37 & 2.58 & 2.34 & -0.96 \\
\hline$E_{V Z \text { err }}$ & -0.94 & -1 & -0.94 & -0.84 & -0.9 & -0.74 & -1 \\
\hline
\end{tabular}

\subsubsection{Comparison of the three conceptual models}

The conceptual model with the lowest overall relative error is the NSRE model for the whole period (dry summers 2009-2010) and for the daily values; however, the pore-scale model has the lowest relative error during the stableconditions period. The average relative error for the daily-average model for the validation period (dry summer 2010) is 1.44; the average relative error for the same period for the NSRE model is 0.53 . The average relative error for the daily values of the pore-scale models are 0.85 and -0.91 for the $E_{C Z}$ and $E_{V Z}$, respectively; the average relative error for the same period for the NSRE model is 0.67 . The average relative error for the stable-conditions period of the pore scale models are 1.19 and -0.82 for the $E_{C Z}$ and $E_{V Z}$, respectively; the average relative error for the same period for the NSRE model is 2.3.

\subsection{Discussion}

\subsubsection{Testing daily-average conceptual model assumption}

The differences in $E_{0}$ between the three daily-average fitted models $(2.88 \mathrm{~mm}$ $\mathrm{d}^{-1}, 0.64 \mathrm{~mm} \mathrm{~d}^{-1}$ and $1.81 \mathrm{~mm} \mathrm{~d}^{-1}$ for fh2010, sh2009 and sh2010 models respectively) are probably due to the presence of a DSL. Equation 4.2 shows that $E_{0}$ depends on two things: the initial soil saturation (from soil surface to depth $d$ ) and the soil diffusivity, itself dependent on soil saturation. The assumption of a quick redistribution of infiltrated water after a precipitation event can be invalid when a DSL is present in the topsoil: if the precipitation event is relatively short, it infiltrates only the first centimetres of soil and then evaporates completely, with no effect on the lower, dry topsoil (as in Sun et al. 2016 in Table 4.1). A typical dry-summer rain event in the Sardon study area ( 5 to $18 \mathrm{~mm}$ in $\sim 1 \mathrm{~h}$ ) infiltrates only the first centimetres of soil, with no 
effect on soil dryness at a depth of $15 \mathrm{~cm}$ (see Figure 4.4). This means that the assumption of initially homogeneous soil moisture (Brutsaert, 2014a) after a precipitation event, is not correct whenever the depth of water infiltration from such event is smaller than $Z_{D S L}$ (typically $\sim 5 \mathrm{~cm}$ ). This behaviour have been reported in other arid and semi-arid areas (see the precipitation events in Zeng et al., 2011b and Sun et al. 2016, Table 4.1) and confirms the finding by Wang (2015, Table 4.1).

The different values for the characteristic timescale of soil drying $(\kappa ; 26.9$, 17.0 and 14.7 days for fh2010, sh2009 and sh2010 models respectively) show that this parameter is also affected by the dryness of the system. $\kappa$ depends on the depth of the zero-flux plane and on the soil diffusivity (Equation 4.3). As seen before, the fact that the soil diffusivity depends itself on soil moisture saturation is problematic whenever a DSL is present in the topsoil. Moreover, Neriah et al. (2014, table 4.1) reported that the effect of temperature on the soil material hydraulic properties has a significant effect on the transition between S1 and S2, especially on $L c$, which decreases linearly with temperature. $L c$ and $d$ (depth of the zero-flux plane) are similar, as both depend on the balance between the capillary, viscous and gravity forces, so potentially $d$ is also affected by soil temperature during S2. Finally, using satellite data of soil moisture (NASA SMAP) for the whole Earth, McColl et al. (2017b) showed recently that $\kappa$ depends on climatic conditions: in fact $\kappa$ decreases not only due to an increase in soil sand fraction but also with an increase in the aridity index.

\subsubsection{Testing NSRE conceptual model assumption}

The proper way to use the Richards' equation to model water transport in dry soils is a controversial topic. Numerous field studies showed that, in dry-soil field conditions, water vapour diffusion alone cannot explain the observed evaporation rates, usually larger than the predicted ones. To model such water transport, different approaches have been proposed: the inclusion of an enhancement factor (Philip and de Vries, 1957, analysed in Webb and Ho 1998), the effects of air advection in the soil (Rose, 1968a, 1968b; Zeng et al., 2011b), the night-time condensation of water in the DSL (Wang 2015, Table 1 ), the daily cycle of soil water redistribution (Idso et al. 1979), the effects of atmospheric turbulence on the first $\mathrm{cm}$ of soil (Ishihara et al., 1992), the proper simulation of the soil water distributed as thin films covering the soil grains (Tuller and Or, 2001). However, there is no agreement yet on which of these approaches is the right one.

Even the assumption that an approximation of the DSL is enough to estimate soil evaporation rates is problematic and different levels of approximation of the DSL conditions can be found in literature. Assouline et al. (2013, Table 4.1) obtained good evaporation estimates using the standard van Genuchten (1980) WRC for $Z_{D S L}$ between $1-5 \mathrm{~cm}$. Sakai et al. (2009) used a 
modified WRC for low water contents (Fayer and Simmons, 1995) for $Z_{D S L} \sim 3$ $\mathrm{cm}$ (Sakai et al. 2011, Table 4.1). Dijkema et al. (2017, Table 4.1) pointed out that the best option is to enable liquid-phase discontinuities in the soil profile, so they used the bimodal Durner WRC (Durner, 1994) with Hydrus1D to model a lysimeter experiment in Las Vegas, NV, USA; there was no direct observation of an air-dry DSL, but the measurements showed very dry soil conditions from soil surface to a depth of $\sim 0.25 \mathrm{~m}$. Interestingly, Dijkema et al. (2017) showed that the model was not able to simulate the very low soil moisture in the topsoil (Figure 6 of that article) and had trouble simulating evaporation in drying conditions with a dry soil surface.

The differences between $E_{f}$ and $E^{e c}$ (Figure 4.7) are due to the difficulty of the NSRE conceptual model to properly approximate the effects of a DSL. As a consequence the $E_{f}$ estimates are reliable only when a DSL is absent, i.e. in the wet seasons, but are unreliable in dry seasons when the DSL thickness is substantial. The presence of a DSL in an area, such as observed in this study, would limit the $E_{f}$ rates even with a shallow water table, making the $E_{f}$ rates almost independent from $Z_{W T}$. The fact that $E_{f}$ is smaller than $E^{e c}$ in higher terrain (Figure 4.6, 4.7, between 50 and $100^{\circ}$ ) cannot be due to the Hydrus1D difficulty in simulating a DSL; in fact, the proper simulation of a diffusion-only layer would result in even smaller $E_{f}$ rates. A possible explanation for the $E^{e c}>E_{f}$ in higher terrain is beyond the scope of this study, and it is discussed in Section 4.5.5.

\subsubsection{Testing the applicability of the pore-scale conceptual model}

The main reason for the difference between $E_{C Z}$ and $E_{V Z}$ values is in the calculation of the distance the water vapour must travel from the vaporization plane to the soil surface, i.e. $Z_{D S L}$. The two implementations of the pore-scale conceptual model show completely different values and patterns among each other, showing the importance of the definition of $Z_{D S L}$ in determining the calculation of the vapour fluxes. In the $E_{C Z}$ implementation, a constant $Z_{D S L}$ results in evaporation rates dependent only on evaporative conditions. In the case of $E_{V Z}$, instead, the evaporation rates depend mostly on changes in $Z_{W T}$. These two different patterns remain the same in the calculation of the daily values. From here on, only the calculation for the stable-conditions period is discussed, the results for the daily calculations are discussed in Section 4.5.4. A spatially constant $Z_{D S L}$ is to be expected in Sardon study area during summer, due to spatially homogeneous soil properties and the presence of grass that depletes the soil water in the root zone up to wilting point before senesce at the beginning of the dry season. The $E_{C Z}$ implementation is, therefore, even if not perfect, a better representation of the conditions observed in the field than the $E_{V Z}$ method, as it assumes a spatially constant DSL thickness around the EC tower (as corroborated by field observations, Sections 4.2.5 and 4.3.3). 
$E_{C Z}$ shows a different behaviour than $E^{e c}$ : it changes depending mostly on the temperature at the bottom of the DSL, which has the highest daily variation between mid-August to mid-September (see support material). The $E_{C Z}$ depends only on the difference in water vapour concentration between the soil surface and the bottom of the DSL. The water vapour concentration at the soil surface, due to very high temperatures and low relative humidity during the day as considered in this analysis, is usually very low and does not change much. The water vapour concentration at the bottom of the DSL, instead, given that the soil moisture content at that depth is mostly constant, varies with soil temperature. Therefore, a change in soil temperature at the bottom boundary of the DSL (0.25 m b.g.s.) can result in a change of $E_{C Z}$ of an order of magnitude. $E_{C Z}$ shows larger negative relative errors in September of both years due to a combination of relatively low air temperature $\left(\sim 21^{\circ} \mathrm{C}\right)$ and high relative humidity $(\sim 46 \%)$, resulting in a $E_{C Z}$ lower than the measured $E^{e c}$. The reason for the overestimation of $E_{C Z}$ in August, instead, is not apparent.

In this study, defining the $Z_{D S L}=Z_{W T}-L c$ resulted in very thick DSLs for the $E_{V Z}$ calculations, so thick that the water vapour flow through them was one to two order of magnitude smaller than the $E^{e c}$. The $L c$ calculated by linearization of the van Genuchten retention curve based on the field measured soil material properties is $L c=0.12 \mathrm{~m}$. This means that, in the $E_{V Z}$ method, the DSL thickness can go from $0.12 \mathrm{~m}$ in the river valley, where water table is $\sim 0.5 \mathrm{~m}$ b.g.s., to $9.75 \mathrm{~m}$ in the higher terrain, where $Z_{W T}$ reaches $10 \mathrm{~m}$ b.g.s. The $E_{V Z}$ rates are inversely proportional to DSL thickness, so to $Z_{W T}$; this means that the assumption of $Z_{D S L}=Z_{W T}-L c$ is not valid, at least in the case studied where the $E^{e c}$ shows no clear relation to $Z_{W T}$. This was expected, as the definition of $L c$ is based on controlled experiments with initially saturated soil columns which continuously and homogeneously dries over constant evaporative conditions. In the field the soil is exposed to a variety of evaporative conditions, presence of grass and cyclical rewetting due to precipitation events.

\subsubsection{Comparison of the three conceptual models}

The two main sources of errors in the soil evaporation estimates when applying the three conceptual models are: (i) how soil evaporation is related to $Z_{W T}$, and (ii) how the changes in soil moisture content of the topsoil in $\mathrm{S} 2$ evaporation are modelled. The performances of the conceptual models in predicting evaporation rates in this study are mainly related to how sensitive they are to $Z_{W T}$, while the $E^{e c}$ measurements show little relationship with $Z_{W T}$ or wind direction (Appendix 4.7.1). Note that the effects of topography on EC measurements are discussed in Appendix 4.7.2, whereas the quality of the $E T^{e c}$ measurements in Appendix 4.7.3. It appears that the best predicting conceptual models are those in which the sensitivity of evaporation to $Z_{W T}$ is small, at least at the same $Z_{D S L}$ conditions. These are the DA conceptual model and the $E_{C Z}$ implementation of the PS conceptual model. However, the rigidity 
of their DSL-related assumptions is problematic in semi-arid areas, due to the high inter and intra-annual variation in atmospheric conditions (wet and dry years, wet and dry seasons).

The main source of error in the Hydrus1D estimates of evaporation comes from the WRC used to model the soil hydraulic properties. The WRC has an effect on both the properties of the developed pseudo-DSL (residual water content, soil-vapour diffusion coefficient, $Z_{D S L}$ ) and on the relation between evaporation rates and $Z_{W T}$. This is especially true for sandy materials, which have a steeper WRC resulting in larger matric potential gradients in the soil profile. The relative error of the Hydrus1D model is low when averaged over the whole area due to the balance between overestimation of evaporation in shallow $Z_{W T}$ conditions and underestimation in deep $Z_{W T}$ conditions. The mean root square relative error is, in fact, three times the evaporation estimates, and Figure 4.6 shows how different the NSRE evaporation estimates can be with respect to $E^{e c}$.

The pore-scale conceptual model, when applied to the stable conditions period, shows low relative errors for the $E_{C Z}$ implementation. However, the relative errors are much larger when the model is applied to a whole day, due to the obvious limitations related to unstable evaporative conditions throughout a day. This makes the pore-scale conceptual model impractical for field studies, especially in semi-arid areas, where evaporative conditions change widely within a day and within a year. For example, in the Sardon study area, only $\sim 12 \%$ of the total precipitation takes place during the dry summer, while the $E T_{p}$ is 10 times larger during summer than during winter; also, soil surface temperature and relative humidity, in the dry summer, can change from $8{ }^{\circ} \mathrm{C}$ and $100 \%$ during the early morning to $50{ }^{\circ} \mathrm{C}$ and $20 \%$ during the afternoon.

Brutsaert (2014a, Table 4.1) disregards $Z_{W T}$ in his daily-average conceptual model for evaporation in dry conditions as a consequence of the assumption that the evaporation process affects only water above a zero-flux plane; the latter, according to literature, remains in the first few tens $\mathrm{cm}$ of soil. The DA conceptual model also allows another interesting observation: the effect of the DSL on the evaporation process seems related to the history and the conditions of a specific dry spell. These conditions are related to the soil moisture content in the soil at the beginning of the dry spell considered, to the strength of the evaporative conditions, and to the presence of grasses that quickly deplete the soil moisture from a certain soil layer. A possible indicator of the history of the system is the $Z_{D S L}$ thickness at the beginning of the drying spell. Assouline et al. (2013, Table 4.1), for example, applied the PS and the NSRE conceptual models to the lysimeter data from their study and found that the $\sim 4 \mathrm{~cm}$ thick DSL had a negligible effect on the evaporation rates. Similarly, Wang (2015, Table 4.1) shows that, in semi-arid and arid conditions and with sandy soils, the effects of a DSL on the soil evaporation become large when $Z_{D S L}>5 \mathrm{~cm}$. Therefore, it is important to find a way to quantify the dryness of a system, for 
example through the DSL thickness, which largely constrains the evaporation process.

\subsubsection{Potential causes of $E_{f}<E^{e c}$ in elevated terrain with deep water table}

According to Shah et al. (2007), for the soil material considered in this study the extinction depth (the $Z_{W T}$ at which evaporation by liquid flow ceases) is $4.75 \mathrm{~m}$. With the water table deeper than $4.75 \mathrm{~m}$ and sandy loam soil material, the Hydrus1D $E_{f}$ was very low $\left(\sim 0.2 \mathrm{~mm} \mathrm{~d}^{-1}\right)$, in contrast to $E^{e c}$ that was large $>2 \mathrm{~mm} \mathrm{~d}^{-1}$ (Figure 4.7b).

A number of possible processes not included in Hydrus1D might be relevant, resulting in underestimation of $E_{f}$ from a $Z_{W T}>4.75 \mathrm{~m}$. These processes could be:

- mechanical dispersion;

- air advection in the dry unsaturated zone;

- natural convection in a sloping, dry unsaturated zone;

- preferential evaporation flow;

- abrupt pressure and temperature changes because of strong eddies formation on the soil surface;

- a constitutive liquid hydraulic conductivity function which is incorrect in dry conditions.

First, the mechanical dispersion process of water vapour in the unsaturated zone has been studied by Grifoll et al. (2005) who found (Grifoll, 2011) that the dispersivity mechanism can be relevant only in case of a Stefan flow (flow induced by the production or removal of a chemical species at a certain interface). The lack of Stefan flow in the case studied means that the process of mechanical dispersion is likely not relevant in our case.

Second, the air advection has been already analysed by Liu et al. (2005) for highland marshes and Zeng et al. (2011a) for drier conditions. When the gas pressure gradients in the unsaturated zone are strong enough, and the pores filled with gas are well connected (as in the case of a dry unsaturated zone), then the gas can move by advection flow. Zeng et al. (2011a) found that advection of air does play a role, albeit small, in the evaporation process for a very dry top unsaturated zone. The presence of a dry unsaturated zone layer, where water moves only as water vapour by advection flow, may explain a rate of soil evaporation independent of $Z_{W T}$, as measured by the EC tower: with a deep $Z_{W T}$ the advection flow could result in direct water vapour transport from the saturated zone to the soil surface. This process, not included in Hydrus1D, can be present in our case, and could be a cause of the Hydrus1D underestimation of $E_{f}$.

Third, natural convection, according to Schery and Petschek, (1983) usually does not take place in the unsaturated zone. It occurs when the Rayleigh 
dimensionless number associated to the free convection flow exceeds a critical value, i.e. when the heat transfer for the fluid switches from conduction to convection. The Rayleigh number calculated for very permeable materials, high temperature gradients and big length scales is below the critical value: the loss of air's heat in the unsaturated zone by conduction is faster than by convection to colder areas of the profile. Rose and Guo (1995), however, show how taking into account temperature inversion in a sloping soil profile results in a higher Rayleigh number, potentially leading to convection processes during the night (because of the inverse temperature gradient in the soil). The convection of air in sloping porous material was also observed by Antoine et al. (2009). It is important to note that even if convection of air in sloping soil took place during night, this would not be measured by the EC method, which does not work in such stable conditions (Fisher et al., 2007) when flux occurs below the measurement height and does not reach the sensor. This means that, although this process might be relevant for the calculation of the overall modelling of evaporation from bare soil, it cannot be the cause of the mismatch between the evaporation calculated by Hydrus1D and the EC tower measurements as both did not account for it.

Fourth, Papafotiou et al. (2010) studied the effect of preferential evaporation patterns in porous material with both numerical modelling and laboratory experiments. Preferential evaporation in soils originates from heterogeneities in the soil texture, structure and compaction. The soil in the study area is fairly homogeneous in texture and structure, the only possible source of heterogeneity could have been originated by animal trampling resulting in soil compaction. This was not observed in the field as animals graze everywhere, with some preference for the area close to the river.

Fifth, the bare soil, as already explained, experiences large diurnal changes in temperature, with very high temperatures in the afternoon. These conditions lead to the formation of air turbulences, in the form of eddies and even dust devils (observed) resulting in abrupt changes in the pressure and temperature at the soil surface, which can trigger advective flows of vapour in the dry unsaturated zone. This possibility was studied for gas exchanges between unsaturated zone and atmosphere in the work by Poulsen and Møldrup (2006). They concluded that higher amplitudes and frequencies of pressure variations result in higher values of diffusion-dispersion coefficients and also in a larger $E$ contribution. Maier et al. (2011) arrived at a similar conclusion for forest soils. This process is not accounted for in Hydrus1D but it would influence the $E^{e c}$ measurements, therefore it could contribute to the mismatch between the Hydrus1D $E_{f}$ and $E^{e c}$.

Sixth, the majority of the constitutive relationships for the hydraulic properties of the soil materials, also in Hydrus1D, are optimized for relatively wet conditions. Therefore, the same properties may be poorly characterized in the very dry conditions observed in the top unsaturated zone during this study. 
This problem cannot be eliminated a priori as a possible cause of the Hydrus1D simulation errors.

The amount of (possibly) unaccounted processes, the amount of variables playing a role in the field conditions and the small magnitudes of the fluxes in summertime semi-arid and arid conditions, make it difficult to point out the cause of the mismatch between $E_{f}$ and $E^{e c}$; the only way to identify the unaccounted process or processes is to systematically analyse them using both laboratory and field experiments. This can be done dividing the possible "suspects" into categories depending on the possibility to eliminate them: the advection flow cannot be eliminated (only reduced); the turbulence is related to specific conditions at the soil surface and can be controlled in laboratory; the other factors depend on soil materials and geometry and can be controlled in the field. Designing a series of lab- and field-experiments, slowly adding complexity at each step, should allow to find which is the process (or processes) overlooked in the Hydrus1D assessment of groundwater evaporation in very dry conditions with relatively deep water table with welldeveloped DSL.

\subsection{Conclusions}

The present study tested the performance of three different conceptual models (the daily-average, the NSRE and the pore-scale) for modelling soil evaporation in the presence of a DSL, in a semi-arid area during two dry seasons, 2009 (drier) and 2010 (wetter).

The results suggest that:

- Among the three conceptual models tested, the daily-average conceptual model is the most practical for field conditions, as it is designed based on field studies with few input data available; however, its assumption of negligible DSL effect on the evaporation process seems not appropriate for very dry conditions, when the DSL thickness increases in time and the initial soil moisture profile after a precipitation event is not uniform. Under such conditions, the assumption of area-specific $E_{0}$ and $\kappa$ parameters is problematic. The performance of this conceptual model, therefore, needs to be corrected for the history of the drying area, related to soil moisture contents and evaporative conditions.

- The NSRE conceptual model, represented by Hydrus1D, had the lowest overall relative error when averaged over the whole area and in the whole period. However, this masks the overestimation of evaporation rates during drying periods, especially for shallow water tables, and underestimation of evaporation rates from deep water table conditions. Also, it could not properly simulate a DSL, which confirms the findings of Assouline et al. (2013) and Dijkema et al. (2017). This seems not to seriously affect the evaporation flux calculation when the DSL is thin, e.g. 
$\sim 3 \mathrm{~cm}$ as in Assouline et al. (2013), even if the soil moisture profile simulated departs considerably from the observed one. However, when the topsoil is drier, the simulation of drying events is more problematic (Dijkema et al., 2017). In this study, where the DSL thickness is $\sim 0.25$ $\mathrm{m}$, the Hydrus1D model using the van Genuchten soil moisture-water pressure relationship could not properly simulate the evaporation rates.

- The pore-scale conceptual model, modified in order to adapt it to field conditions, performed well in the prediction of evaporative rates (both the $E_{V Z}$ and $E_{C Z}$ method), at least for the part of the day with more stable evaporative conditions (mid-day to late afternoon). The model shows a strong dependence on temperature at the bottom of the DSL, which is not evident in the $E^{e c}$ dataset. Due to the assumption of stable evaporative conditions, the model was not able to properly estimate the daily evaporation rates; because of this, the model is no applicable to field conditions.

This study indicates possible future directions for the improvement of modelling of soil evaporation in very dry conditions, i.e. arid and semi-arid areas, during dry season, when a DSL affects evaporation. It is still unclear, for example, when exactly a DSL starts to affect the evaporation process in field conditions. This could depend on the thickness of the DSL, which, in turn, depends on soil characteristics and duration of the drying event, and/or on the drying history of the system. Another research direction could be to adapt the pore-scale model to arid and semi-arid field conditions. This would help understanding the physical processes influencing the movement of water in a DSL under field conditions (e.g. atmospheric turbulence, variation in the temperature, pressure and vapour concentration gradients).

\subsection{Appendix}

\subsubsection{ET ${ }^{e c}$ dependence on wind direction}

We tested the hypothesis that there is a relation between wind direction and $E T^{e c}$ magnitude, and more specifically, that in our study area the higher $E T^{e c}$ is associated with the wind from the western side with shallow $Z_{W T}$ than the wind from the eastern side where $Z_{W T}$ is deeper. Before analysing $E T^{e c}$ directly, we analysed the directionality of the surface roughness, which influences $E T^{e c}$ readings. In order to do so we first analysed roughness length $\left(z_{0}\right)$ in all cardinal directions around the flux tower from the measurements of the wind speed and friction velocity of the sonic anemometer (installed at $10 \mathrm{~m}$ height), then analysed the changes of roughness length for momentum $\left(z_{0 m}\right)$ with respect to wind direction following van der Tol et al. (2003). We grouped the EC data into classes of wind direction of $30^{\circ}$, rejecting data with an absolute 
difference between wind direction measured by CSAT3 and the Vaisala $>25^{\circ}$. For each of these $30^{\circ}$ classes of wind direction, $z_{0 m}$ was calculated from friction velocity $u^{*}$ and wind speed $u$, both estimated from measurements of the 3D sonic anemometer. A logarithmic wind profile was assumed as:

$u=\frac{u^{*}}{k_{K}} \ln \left(\frac{z}{z_{0 m}}\right)-\Xi_{m}$

where $k_{K}=0.41$ is von Kármán constant and $\Xi_{m}$ is a correction for stability. We used the equation of Paulson (1970) for stable and unstable conditions to calculate $\Xi_{m}$ per half hour. The parameter $z_{0 m}$ was estimated by minimizing the root square difference between measured and modeled (Equation 4.6) wind speed.

The roughness length for heat $\left(z_{0 h}\right)$ can only be calculated if a surface temperature is defined. We used the radiometrically derived surface temperature $T_{r a d}$ calculated from the longwave radiation measured at the station, to estimate the roughness length for heat in a similar way to the roughness length for momentum:

$T_{a}-T_{\text {rad }}=\frac{T^{*}}{k_{K}} \ln \left(\frac{z}{z_{0 h}}\right)-\Xi_{h}$

where $T^{*}=-H /\left(\rho_{a} c_{p} u^{*}\right), H$ is sensible heat flux derived from the sonic anemometer data directly, $\rho_{a}$ is the specific mass of the air $\left(\mathrm{kg} \mathrm{m}^{-3}\right), c_{p}$ the heat capacity $(\mathrm{J} \mathrm{kg}), T_{a}$ the air temperature measured at the station. The parameter $z_{0 h}$ was estimated by minimizing the root square difference between measured and modelled $T_{\text {rad }}$. This resulted in a value of $z_{0 h}$ as low as $2.410^{-4}$ $\mathrm{m}$. Similar values have been reported before in dry, sparsely vegetated areas (Verhoef et al., 1997; Gökmen et al., 2012). $\Xi_{h}$ is calculated: (i) for unstable conditions with the formulation of Paulson (1970); (ii) considered zero for stable and neutral conditions. See also Equation B13 in Van Der Tol et al. (2009).

We found that the ratio of friction velocity over wind speed (and thus $z_{0 m}$ ) was rather constant over cardinal directions except for the $z_{0 m}$ of $\sim 0.9 \mathrm{~m}$ in north-east direction vs. $\sim 0.2 \mathrm{~m}$ in other directions. The different values in the north and east directions was due to the position of the sonic anemometer (with the tower and the gas analyser blocking the wind coming from northeast) and not due to differences in soil roughness; therefore, we decided to assign a constant value to $z_{0 m}(\sim 0.2 \mathrm{~m})$ for all directions, i.e. we found no directionality for the soil roughness.

To analyse the directionality of the evapotranspiration measured by the eddy covariance tower, we could not use the actual values of $E T^{e c}$ given wind direction, because both wind and $E T^{e c}$ might have been related to other climatic processes, e.g. if wind after rainfall is frequently coming from the west, then the west will show a higher evapotranspiration value (which does not strictly depend on $Z_{W T}$ difference with respect to the eastern part). Indeed, the wind direction was unevenly distributed both over the daytime and the seasons, which means that simply correlating wind direction and $E T^{e c}$ would be meaningless. However, both diurnal and seasonal periodicity can be removed 
by normalizing $E T^{e c}$ with the Priestley-Taylor potential evapotranspiration $\left(E T_{0}\right)$ as:

$E T_{\text {norm }}=\frac{E T^{e c}}{E T_{0}}$

where $E T_{\text {norm }}$ is the normalised evapotranspiration, $E T^{e c}$ is the evapotranspiration measured by the EC tower (with a frequency of 30 minutes), all with the same, synchronized frequency of 30 minutes.

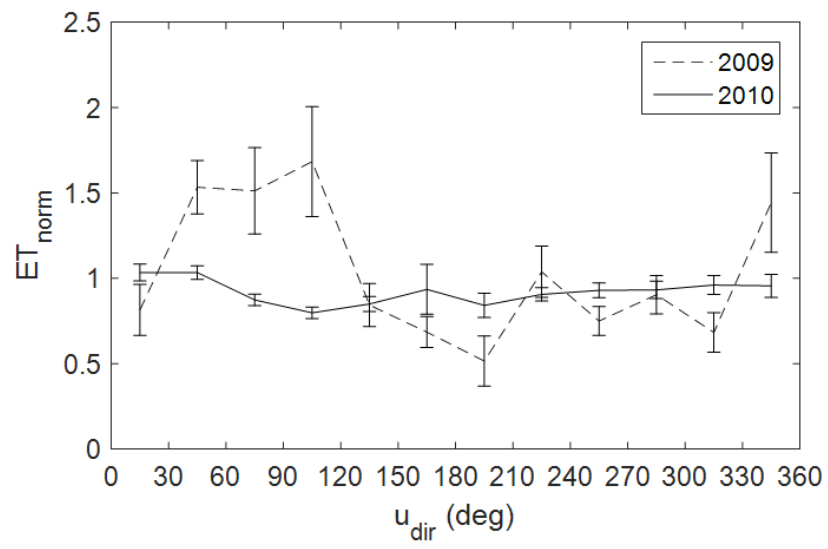

Figure 4.8: $E T_{\text {norm }}$ from Equation 4.8 plotted against wind direction for the whole half hourly dataset (the bars indicate the standard error, i.e. a measure of the variation within the class). A wind direction $0^{\circ}$ means wind from the north, $90^{\circ}$ from the east, $180^{\circ}$ from the south and $270^{\circ}$ from the west.

The analysis of the $E T_{\text {norm }}$ dependence upon wind direction is presented in Figure 4.8 together with associated standard error bars. For the year 2010, $E T_{\text {norm }}$ does not show any significant relation to wind direction. For the year $2009 E T_{\text {norm }}$ shows some variation depending on wind direction, but the low amount of data results in wide error bars. The higher $E T_{\text {norm }}$ measured in year 2009 are recorded when wind is coming from the higher terrain area where water table is deep (wind direction $30-120^{\circ}$, north-east). Therefore, no clear relationships between $E T_{\text {norm }}$ and wind direction is apparent.

\subsubsection{ET ${ }^{e c}$ dependence on topography}

A question arises regarding the validity of the $E T^{e c}$ measurements in a terrain not completely flat (as with the gentle hills in Sardon study area). For clarity, we separate the discussion of the effects of the complexity of the terrain upon the accuracy of the $E T^{e c}$ measurements into two parts: (i) the effects on the wind field and the fluxes; and (ii) the suitability of the measurement technique. 
Raupach and Finnigan (1997) reviewed topographical effects on the meteorology. They distinguished direct effects of topography on irradiance and the wind field from indirect effects related to variation in soil and vegetation that correlate with topography. With a wind tunnel experiment, they showed that hills modify the direction of the wind (creating revers flow and wakes) in a way that affects the EC measurements resulting in changes in the order of $40 \%$ of the Stanton number (Raupach and Finnigan, 1997) near the hill top. In our study area, the effect of the rugged terrain on wind could have some effects on the representativeness of the measurements and the validity of the footprint model. However, the obstacles in our study area are very gentle, as their height to length ratio of $1 / 50$ is five times lower than the lower of the two hills studied by Raupach and Finnigan (1997). Moreover, the eddy covariance tower is not located near the top or the foot of a hill. For these reasons we do not expect significant direct effects of the topography on the turbulence.

The topography clearly affects the soils and the vegetation in our dry study area. There is a large contrast in surface temperature and in roughness between the patches of trees and bare soil. However, the footprint model holds for a surface with a spatially constant roughness length (as in our case, see Appendix 4.7.1) although it has not been designed for sparse vegetation areas. More complicated footprint models are not necessarily better, unless sufficient data are available for parameterization and validation. In our study, we know that the wind direction is correct, and we assessed the sensitivity of the footprint shape upon the surface roughness in order to get an idea of the uncertainty of the footprint.

In order to test whether the rugged terrain and the distribution of the trees affected the wind field, we analysed the tilt of the average wind field, i.e. the roll and pitch of the wind vector from different directions. This analysis was carried out with the software AltEddy (version 3.71) as well as "manually" using Matlab, for a 10 days in row period of 2010 when the $E T^{e c}$ was about $2 \mathrm{~mm}$ d1. It appeared that, depending on the wind direction, there was a mild roll of between 0 and $5 \%$ and a pitch between 0 and $6 \%$ of the wind vector. The tilt of the wind field was not larger than at other flux sites.

We carried out several other tests on the EC data to check the suitability of the measurement technique for our study area conditions. A potential problem was the strong buoyancy in the area that might cause strong vertical winds. van der Molen et al. (2004) evaluated the effect of the angle of attack on the measurement accuracy of the wind speed for two brands of sonic anemometers (both similar in design to the one used by us) and found a correction method for it. We followed that method and plotted on a histogram the ratio of the vertical and the horizontal wind speed (not shown) and found that the absolute value of this ratio was smaller than 0.5 in $95.4 \%$ of the cases, indicating that correction for angle attack was not necessary. 


\subsection{3 $\mathrm{ET}^{\mathrm{ec}}$ measurements quality and related error.}

Out of the four components of the energy balance, the $E T^{e c}$ probably had the largest relative error, as being the smallest of the fluxes during the dry period and as derived from two sensors: a sonic anemometer and a gas analyser. The values of $E T^{e c}$ were between $0.04 \mathrm{~mm} \mathrm{~d}^{-1}$ and $4.00 \mathrm{~mm} \mathrm{~d}^{-1}$ (the value of 0.04 $\mathrm{mm} \mathrm{d}^{-1}$ was extremely low, and only occurred for 12, 22, 26 and 28 September 2009).

It is widely accepted that the error in $E T^{e c}$ is around $20 \%$ (e.g. Goulden et al. 1996), but it can be even higher when the gas fluxes are low as in very dry conditions. However, that accuracy can be improved by comparing $E T^{e c}$ to water balance estimates as found by Scott (2010) for savannah landscape. We found that, in the very dry periods, the VPD was $\sim 10 \mathrm{hPa}$ and the standard deviation of the $10 \mathrm{~Hz}$ vapour pressure measurements was about half of the one during the wet period. Because the fluctuations in VPD and vertical wind speed are of the same order of magnitude in both the wet and dry season, we assume that the error associated with the $E T^{e c}$ measurements is also similar in the wet and the dry season (approximately 20\%). As such there is no reason to assume that the accuracy of the measurements of gas concentrations and of wind speed changed between dry and wet period in absolute sense.

Physical limitations of the instruments, such as the separation of the responses of the anemometer and of the gas analyser, the size of the eddies that can be sampled, and the terrain effects (non-horizontal mean wind at the tower height), play a role in our case. We investigated this by means of a sensitivity analysis of AltEddy by switching on and off corrections (type of axis rotation, spectral fitting) and deliberately entering a smaller or larger distance between anemometer and gas analyser (i.e. changing the planar fit method), which resulted in changes in $E T^{e c}$ of only a few percent. The effects of changing the planar fit method were in absolute sense smaller than in the wet period $\left(0.5 \mathrm{~W} \mathrm{~m}^{-2}\right.$ in the dry period versus $0.7 \mathrm{~W} \mathrm{~m}^{-2}$ in a wet period), but larger in relative sense. 
Chapter 5

Evaporation through a Dry Soil Layer: Column Experiments 


\begin{abstract}
:
Modelling of water vapour transport through a dry soil layer (DSL), typically formed in arid and semi-arid top soils during dry seasons, is still problematic. Previous laboratory experiments in controlled environments showed that the only vapour transport process through the DSL is by Fick's law of diffusion. However, field experiments exhibited consistently higher evaporation rates than predicted by diffusion flow only. Some proposed reasons for the mismatch were: (i) daily cycles of condensation and evaporation in the DSL due to changes in solar radiation; (ii) wind effects on air movement in the DSL; (iii) atmospheric pressure fluctuations; (iv) non-linear influence of the DSL thickness on the evaporation process. To link the laboratory experiments with field observations, we performed soil column experiments in the laboratory with thick (>50 cm) DSL, and with different wind speeds, two radiative lamp schedule (continuous and $12 \mathrm{~h}$ daily cycles) and different thicknesses of DSL. Atmospheric pressure, air temperature and humidity were measured continuously. The results show that the evaporation rates observed are larger than those predicted by diffusion flow only. We found that it was possible to model the evaporation rates as a function of atmospheric pressure fluctuations. In conclusion, atmospheric pressure fluctuations can induce evaporation rates in DSL larger than estimated by diffusion flow only, possibly explaining the discrepancy between laboratory and field experiment DSL evaporation rates.
\end{abstract}

This Chapter is based on:

Balugani, E., Lubczynski, M.W. and Metselaar, K., A framework for sourcing of evaporation between saturated and unsaturated zone in bare soil condition. Accepted by Water Resources Research, awaiting publication. 


\subsection{Introduction}

Evaporation is one of the main components of the hydrologic cycle in semi-arid and arid areas, where topsoil (the first few decimetres of soil material) is often very dry, especially during dry season (Wang, 2015). Such areas, sometimes referred as water limited environments (Parsons and Abrahams, 1994), are characterized by low precipitation and high potential evaporation; the precipitation events are mostly concentrated in few months (wet season), but rare during the rest of a year, when long periods of droughts are common (dry season).

When a drought is long enough for evaporation to deplete soil moisture in the topsoil, a dry soil layer (DSL) forms, where water moves only as vapour (Brutsaert, 2014b, Or et al., 2013). Vapour transport is often not included in standard capillary flow models (but it has been introduced in some of them, e.g. Saito et al., 2006). Droughts typically occur in semi-arid and arid regions but can also be temporally present in other climates (e.g. subtropical, moderate etc.) particularly because of climate change enhancement (Schlaepfer et al., 2017; Mukherjee et al., 2018; Xu et al., 2019). Droughts negatively impact water resources and agricultural production; moreover, a better understanding of evaporation through DSLs could potentially increase the accuracy of global circulation models for climate change predictions (Scholes, 2020).

The evaporation process from an initially saturated soil material (e.g. by flooding) is thought to occur in two (Or et al., 2013a) or three (Hillel, 2004) stages; here the two stages evaporation description is adopted, as described in Section 1.1.2 and Figure 1.2a. In S2, after the formation of a DSL, water evaporates at the vaporization plane and is transported as water vapour through the DSL to the ground surface (Shokri et al., 2009). The depth of the newly formed vaporization plane is determined by the pore size distribution and temperature of the soil (Figure 1.2a, Lehmann et al., 2008; Neriah et al., 2014). The thickness of the capillary-driven zone, called $L_{c}$ (excluding the capillary fringe, Figure 1.2a), is also determined by the pore size distribution of the soil material.

Observations of DSLs' development in laboratory evaporation experiments showed that the water vapour flow through a DSL can be modelled assuming Fick diffusion flow only (Or et al., 2013). Most of such experiments were performed on initially saturated sandy soil columns of 5-60 centimetres height under controlled, stable evaporative conditions and with a bottom boundary conditions of either no-flow (Lehmann et al., 2008), or a fixed matric potential head (Nima et al., 2011). Or et al. (2013) review of laboratory studies summarized the related research in the following observations: (i) evaporation rates during $\mathrm{S} 2$ were independent from the rates of $\mathrm{S} 1$; (ii) the evaporation in $\mathrm{S} 2$ did not change much (remained lower than $1 \mathrm{~mm} \mathrm{~d}^{-1}$ ) over a wide range of boundary conditions and soil textures; and (iii) the evaporation rates observed 
during S2 could be described using Fick's law of diffusion (from here on referred to simply as diffusion).

In the field studies, in contrast to the laboratory column experiments, the evaporation through a DSL showed rates substantially higher than the rates predicted using diffusion only (Assouline et al., 2013; Deol et al., 2014; Dijkema et al., 2017; Sun et al., 2016). The DSL thickness ( $\left.Z_{D S L}\right)$ varied from a few millimetres in a humid sub-tropical climate (Deol et al., 2014), to more than $50 \mathrm{~cm}$ in a desert climate (Sun et al., 2016). There seems to be no agreement yet on the process(es) involved in the transport of water through the DSL, with the most probable candidates being: daily cycles of wetting and drying of the DSL; advection driven by wind; and advection and dispersion driven by fluctuations in barometric (atmospheric) pressure (Chapter 4, Balugani et al. 2018).

In most field studies where the reported $Z_{D S L}$ was $<5 \mathrm{~cm}$, it was possible to simulate the observed evaporation rates using models that ignored the liquid water discontinuity, i.e. ignoring the DSL, or even ignoring (diffusion) vapour flow altogether (Assouline et al., 2013, Brutsaert, 2014a). Direct field observations showed daily changes of $Z_{D S L}$ in the order of few centimetres, attributed by Assouline et al. (2013) to condensation and evaporation at the vaporization plane; they also suggested that these changes increase the water vapour diffusion through the DSL by: (a) decreasing the diffusion path length; and (b) storing a certain amount of liquid water close to the soil surface, available for evaporation in the early morning (Brutsaert, 2014a; Idso et al., 1979). However, the effect of daily cycles on water vapour transport through a DSL is expected to decrease with increasing $Z_{D S L}$.

Soil evaporation studies, mainly conducted in dry sandy soils in semi-arid and arid conditions (Balugani et al., 2018; Dijkema et al., 2017; Wang, 2015), showed evaporation rates higher than the rates predicted using only diffusion flow, and that the DSL impact on evaporation rates increases linearly for $Z_{D S L}$ $<5 \mathrm{~cm}$, and logarithmically for $Z_{\mathrm{DSL}}>5 \mathrm{~cm}$. McColl et al. (2017a) showed that the characteristic time-scale of soil drying depends on both soil material properties and aridity index (the latter defined in McColl et al., 2017b, as the ratio between mean daily net radiation and latent heat of vaporization). Dijkema et al. (2017) and the work presented in Chapter 4 (Balugani et al. 2018) show that the underestimation of evaporation rates by a numerical model based on Richard's equation is due to difficulties in modelling the liquid water flow in the dry conditions at the topsoil $\left(Z_{D S L} \sim 25 \mathrm{~cm}\right)$. Hence, the evaporation rates observed in the presence of a thick DSL are neither those estimated by diffusion only nor by liquid water flow only.

A possible mechanism of water vapour transport through a (thick) DSL is air advection, which can be induced in the soil material by changes of air pressure at the surface, due to wind or to barometric pressure variations. Davarzani et al. (2014) conducted soil column evaporation experiments in a 
wind tunnel and showed that warm, dry wind with fluctuating speeds had no effect on S2 evaporation.

Another possible mechanism of water vapour transport through a (thick) DSL is barometric pumping, which has two modes of transport in the gas phase: direct advection up and down due to periodic changes in gas phase pressure, and mechanical dispersion resulting from such pumping, as described in Auer et al. (1996). The periodic changes in barometric pressure result in air being pumped in and out of the soil (Kuang et al., 2013). Grifoll (2013) used a numerical model to study the effects of three causes of mechanical dispersion on evaporation through a thin ( $\sim 1 \mathrm{~cm}$ only) DSL: (i) temperature variations, which, since water vapour pressure is dependent on temperature, create a thermally induced flow (Zeng et al., 2009b), (ii) barometric pumping, that had a negligible effect, and (iii) Stefan flow, i.e. flow induced by the production or removal of a chemical species at a certain interface (Lampinen et al., 2001), which had magnitude similar to the flow due to vapour diffusion. Sánchez-Cañete et al. (2013) showed the relevance of barometric pumping in the transport of $\mathrm{CO}_{2}$ through dry soils, however there are no studies assessing the impact of this process on the transport of water vapour through a DSL.

The aim of this study was to investigate which process was mainly responsible for the transport of water vapour through a thick, sandy, DSL, imposing controlled laboratory conditions as close as possible to those observed in the field in semi-arid areas. The specific objectives of this study were to test:

1. the commonly used assumption that the water transport through a thick DSL is by diffusion only;

2. the effects on evaporation rates through a DSL of:

a) daily cycles in solar radiation (implying changes in temperature and vapour density at soil surface as well);

b) different wind speeds (air turbulence);

c) barometric pressure changes and the related barometric pumping and air advection effects.

\subsection{Materials and methods}

\subsubsection{Soil columns' design}

For the experiment, two PVC columns with different heights and diameters were used, from here on referred to as short and long column, respectively (Figure 5.1). Both columns were equipped with soil moisture, matric potential and temperature sensors (Decagon, USA, Figure 5.1). The sensors were connected to a Campbell CR1000 data logger (Campbell Scientific, USA) recording data every 5 minutes. The bottoms of the columns were covered with $5 \mathrm{~cm}$ of gravel ( $5 \mathrm{~mm}$ size) separated from the overlying soil material by 
perforated aluminium plates (with $3 \mathrm{~mm}$ holes). The columns were wrapped in glass wool to insulate their walls and slow down lateral heat loss.

A valve connected each column to a Mariotte bottle in order to maintain a fixed water table depth $\left(Z_{W T}\right)$ inside the columns. The Mariotte bottles were continuously weighed with digital balances $(0.01 \mathrm{~g}$ accuracy). Since the water in the columns was in equilibrium with the water in the Mariotte bottles, and the only possible output of the water from the Mariotte bottle-column system was as water vapour through the column top, the change in weight of the Mariotte bottle must have been related to water evaporation from the column.

The columns were filled with quartz sand sieved to fraction 0.1 to $0.25 \mathrm{~mm}$ particle size. The sand was packed in the columns $1 \mathrm{~cm}$ at a time until the columns were completely filled. The final porosity of the sand was 0.40 (material density of $\sim 1.06 \mathrm{~g} \mathrm{~cm}^{-3}$ ). The water retention curve for the sand material was determined using a Decagon WP4 dew point potentiometer (Decagon Devices, Pullman, WA, USA).

The $Z_{\mathrm{DSL}}$ was calculated as $Z_{D S L}=Z_{W T}-\left(h_{b}+L_{c}\right)$, where $h_{b}$ is the air entry value (Shokri and Salvucci, 2011). $L_{c}$ can be calculated by linearization of the water retention curve determined for the soil material, as explained in Lehmann and Or, 2009. In this study, for the material used, the $L_{c}$ was estimated to be $10 \mathrm{~cm}$ and confirmed by direct observation using destructive sampling at the end of the experiment.

The top boundary conditions were set up using a radiative lamp (800 W maximum power), with a timer switch and a fan. The atmospheric pressure, continuously measured in the nearby ( $1500 \mathrm{~m}$ distance) weather station at the University, was representative for the atmospheric pressure inside the laboratory (not pressurized). The target evaporative conditions were typical for semi-arid conditions: maximum net radiation of $70 \mathrm{MJ} \mathrm{m}^{-2} \mathrm{~d}^{-1}$; maximum top soil temperature $\sim 75{ }^{\circ} \mathrm{C}$ (with fan off); relative humidity of $20 \%$ at $10 \mathrm{~cm}$ above soil surface; all together representing evaporative conditions of $20 \mathrm{~mm}$ $\mathrm{d}^{-1}$. 


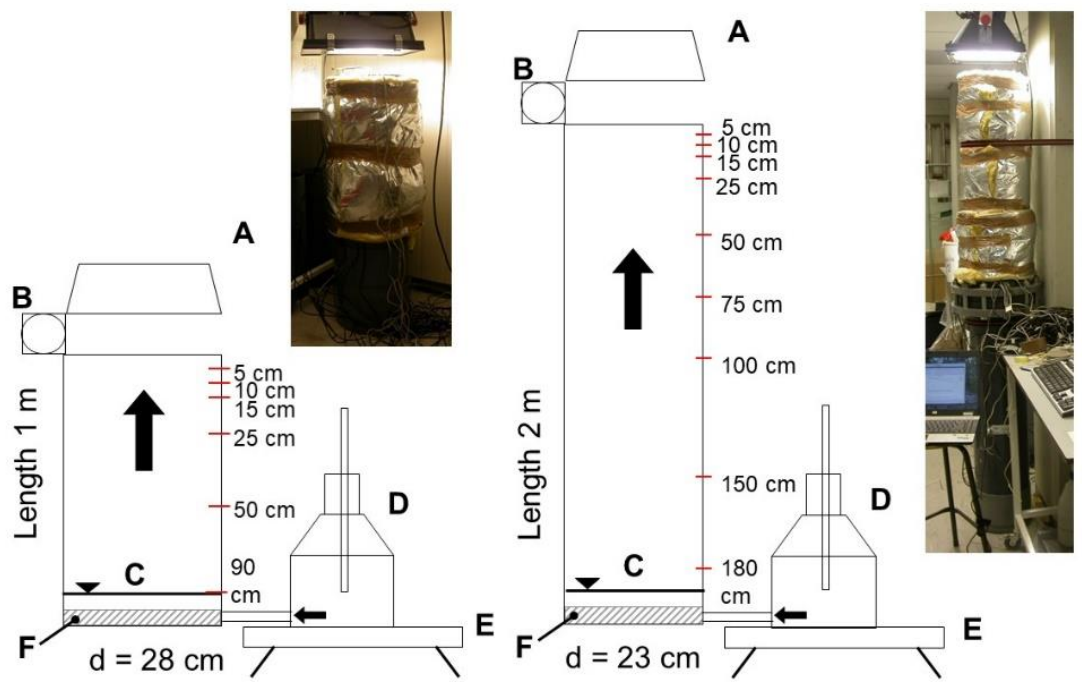

Figure 5.1: Geometry and experimental setup of the short $(1 \mathrm{~m})$ and long (2 m) columns: A - radiative lamp, B - fan, C - water table, D - Mariotte bottle, E - digital balance, $\mathrm{F}$ - gravel layer ( $5 \mathrm{~cm}$ thick) and $\mathrm{d}$ - diameter of a column; the numbers at the right sides of the columns represent depths of installation of the temperature and soil moisture/matric potential sensors. The arrows in the Mariotte bottles indicate the direction of the water flow from the bottles to the columns.

\subsubsection{Diffusion flow in a thick DSL}

To test the hypothesis that the only transport mechanism of water vapour through a thick DSL $\left(Z_{D S L}>50 \mathrm{~cm}\right.$ ) is by diffusion (objective 1 ), the observed evaporation rates from the columns were compared with the corresponding theoretical rates of diffusion, calculated as in Assouline et al. (2013). This was done for different $Z_{D S L}$ : if the hypothesis that there is a proportionally inverse relation between diffusion flow and $Z_{D S L}$ (Equation 5.1) was true, this relation should appear in the measured evaporation rates. The different evaporation rates were determined for three different $Z_{W T}: 90,80,70 \mathrm{~cm}$ in the short column and 190,180, $170 \mathrm{~cm}$ in the long column.

Assuming that only water vapour diffusion takes place between the vaporization plane and the column surface (see Figure 1.2a), the evaporation rate from a column filled with porous material can be calculated with Fick's law (Shokri et al., 2009) as:

$E_{\text {diff }}=D_{\text {pm }}^{v} \frac{C_{\text {sat }}-C_{\text {air }}}{Z_{D S L}}$

where $C_{\text {sat }}$ and $C_{\text {air }}[\mathrm{mol} / \mathrm{mol}]$ are the vapour densities in soil pores at the vaporization plane (both depend on soil temperature) and in the air above the 
column surface respectively, and $D_{\text {soil }}^{v}\left[\mathrm{~m}^{2} \mathrm{~s}^{-1}\right]$ is the diffusion coefficient for water vapour in the soil material, calculated as in Moldrup et al. (2000):

$D_{\text {soil }}^{v}=\frac{S_{g}^{2.5}}{\phi} D_{v}^{\text {air }}$

where $S_{g}$ is the volumetric gas phase content in the soil material (equal to porosity in the DSL, both dimensionless), $\phi$ is the porosity, and $D_{v}^{\text {air }}$ is the temperature dependent diffusion coefficient of water vapour in free air $\left[\mathrm{m}^{2} \mathrm{~s}\right.$ $\left.{ }^{1}\right]$, corrected for the absolute mean temperature of the dry layer $T[\mathrm{~K}]$, as $D_{v}^{\text {air }}=0.22(T / 273)^{1.75}$.

\subsubsection{Radiative Cycles and Stable Wind Effects on Vapour Transport through a DSL}

To test the effects on evaporation rates due to changes in radiation input and with different wind speed applied on the soil surface (objectives $2 a$ and $2 b$ ) upon evaporation rates, evaporative conditions were changed and evaporation rates were measured at equilibrium conditions. The experimental setup involved different tests denoted as T1 to T8 (Table 5.1) performed on both columns, with the three variables, $Z_{W T}$, wind speed and radiative lamp schedule, changed one at a time. When the water table height above the column's bottom (WTH) was changed, the columns were left to equilibrate for $\sim 5$ days.

Table 5.1: Sequence of experimental tests and their description. WTH - water table height measured from the bottom of the column, $\mathrm{U}$ - wind speed. Every time the WTH was raised, the first 5 days of the Mariotte bottle weight datasets were considered as the equilibration period, so were not used in the evaporative rate calculations.

\begin{tabular}{ccccccc}
\hline Test & Start & End & $\begin{array}{c}\text { WTH } \\
{[\mathbf{c m}]}\end{array}$ & $\begin{array}{c}\text { U } \\
{\left[\mathbf{m ~ s}^{-1}\right]}\end{array}$ & $\begin{array}{c}\text { Lamp } \\
\text { schedule }\end{array}$ & Notes \\
\hline T1 & 14 Oct 2011 & 18 Nov 2011 & 10 & 0 & on 24 h & $\begin{array}{c}\text { column's } \\
\text { equilibration }\end{array}$ \\
\hline T2 & 19 Nov 2011 & 04 Dec 2011 & 10 & 0 & on 24 h & at equilibrium \\
\hline T3 & 05 Dec 2011 & 11 Dec 2011 & 10 & 1.8 & on 24 h & fan turned on \\
\hline T4 & 12 Dec 2011 & 19 Dec 2011 & 20 & 1.8 & on 24 h & WTH raised \\
\hline T5 & 20 Dec 2011 & 22 Dec 2011 & 20 & 1.8 & on 24 h & bottle test \\
\hline T6 & 23 Dec 2011 & 12 Jan 2012 & 20 & 1.8 & on/off 12 h & lamp 12 h cycle \\
\hline T7 & 13 Jan 2012 & 08 Feb 2012 & 30 & 1.8 & on/off 12 h & WTH raised \\
\hline T8 & 09 Feb 2012 & 19 Feb 2012 & 30 & 0.3 & on/off 12 h & slower wind \\
speed
\end{tabular}

In T1, water kept entering the two columns under constant evaporative condition (fan turned off, radiative lamp continuously on) until steady-state 
equilibrium was reached with $W T H=10 \mathrm{~cm}$ in both columns, i.e. $Z_{W T} 90 \mathrm{~cm}$ and $190 \mathrm{~cm}$ and $Z_{\text {DSL }} 80 \mathrm{~cm}$ and $180 \mathrm{~cm}$ for the short and long columns, respectively. In $\mathrm{T} 2$, the evaporation rates were measured after equilibrium was reached, with the same evaporative conditions as in T1. In T3, the fan was turned on, creating wind speed of $1.8 \mathrm{~m} \mathrm{~s}^{-1}$. In T4, the WTH rose to $20 \mathrm{~cm}$ implying $Z_{D S L} 70 \mathrm{~cm}$ and $170 \mathrm{~cm}$, for the short and long columns, respectively. In T5, the connections between the Mariotte bottles and the columns were closed to test the experimental column design for possible leakages. In T6, the radiative lamp schedule was changed to $12 \mathrm{~h}$ on/off cycles. In T7, the WTH rose to $30 \mathrm{~cm}$ implying $Z_{D S L} 60 \mathrm{~cm}$ and $160 \mathrm{~cm}$ for the short and long columns, respectively. In T8, the wind speed was decreased to $0.3 \mathrm{~m} \mathrm{~s}^{-1}$.

The ANOVA test was used to determine the statistical significance of the differences between evaporation rates measured in all the tests, while the Tukey post hoc test was used to assess which group of data differed from the others.

\subsubsection{Barometric pressure fluctuation effects on vapour transport through a DSL}

To test the hypothesis that the water vapour transport through a thick DSL is a combination of diffusion and barometric pressure changes (objective 2c), as described by Auer et al. (1996), the observed evaporation rates were compared with the calculated sum of the diffusion and barometric pumping (advection) flows. Barometric pressure changes and wind speed changes were studied separately due to the lack of direct observation of air pressure through the columns' profiles.

\subsubsection{Direct barometric pumping}

Assuming that the barometric pressure fluctuations can be represented by a few low frequency Fourier components, each is characterized by amplitude of pressure change $\Delta p_{a t m}$ [kPa] (calculated as the difference between barometric pressure at the start of a monotonic change and at the end), the maximum depth of the soil gas phase layer (containing water vapour) mixed with air above the soil (i.e. affected by direct barometric pumping) is:

$2 \Delta L_{\text {pump }} \cong 2 \frac{\Delta p_{a t m}}{p_{0}} Z_{D S L}$

where $p_{0}$ is the average surface pressure [kPa] (for the full derivation of Equation 5.3, see Auer et al., 1996). Therefore, the actual distance travelled by water vapour by diffusion $(L)$ is equal to the depth between the vaporization plane and the layer directly mixed by barometric pumping, i.e. $L=Z_{D S L}-$ $2 \Delta L_{\text {pump }}$. 


\subsubsection{Dispersion due to barometric pressure fluctuations}

The mechanical dispersion, combined with water vapour diffusion ( $E_{\text {diff }+ \text { disp }}$ in $\mathrm{mm} \mathrm{d}^{-1}$ ), can be expressed as follows (Bear, 1972; Auer et al., 1996):

$E_{\text {diff }+ \text { disp }}=\left(D_{\text {soil }}^{v}+\alpha|V|\right) \frac{C_{\text {sat }}-C_{\text {air }}}{L}$

$V \cong-\frac{\Delta p_{a t m}}{p_{0}}(L-z) \omega \sin (\omega t)$

where $\alpha$ is the dispersivity coefficient [m], $|V|$ is the positive measure of the pore scale velocity of the gas phase $V\left[\mathrm{~m} \mathrm{~s}^{-1}\right], z$ is depth from the soil surface $[\mathrm{m}], \omega$ is the angular frequency $[\mathrm{Hz}]$, and $t$ is time [s]. The term $\alpha$ depends on soil material properties at the scale of interest, so it depends on soil type, water vapour transport distance, and lateral scale of the experiment (Vanderborght and Vereecken, 2007). An estimate for $\alpha$, which usually varies by less than one order of magnitude, can be obtained from the dataset of Vanderborght and Vereecken (2007).

The combination of Equations 5.4 and 5.5 can be simplified as $E_{\text {disp }}=f(|V|)$ and $V \cong g\left(\Delta p_{a t m}\right)$. Combining the two equations results in $E_{\text {disp }}=f \circ g\left(\Delta p_{a t m}\right)=$ $h\left(\left|\Delta p_{a t m}\right|\right)$, where the two functions, $f$ and $g$, can be replaced by $h$. Therefore, the hypothesis that there is significant correlation (using a moving average with a window of 5 days) between changes in barometric pressure $\left(\Delta p_{\text {atm }}[\mathrm{kPa}\right.$ $\left.\left.\mathrm{d}^{-1}\right]\right)$ and corresponding evaporation rates $\left(E\left[\mathrm{~mm} \mathrm{~d}^{-1}\right]\right)$ was tested, i.e. that $E=h\left(\left|\Delta p_{a t m}\right|\right)$ for all the tests boundary conditions. This was done without any assumption regarding $\alpha$ values nor distance travelled by water vapour. The correlations between the measured evaporation rates and the parameters such as amplitude and frequency characterizing the barometric pressure fluctuations were tested.

Simplifying Equation 5.4 by assuming constant diffusion flow and a constant vertical water vapour concentration gradient, it is possible to calculate total evaporation rate as:

$$
\begin{gathered}
E_{\text {diff }+ \text { disp }}=\left(D_{\text {soil }}^{v}+\alpha|V|\right) \frac{d C_{v}}{d z}=D_{\text {diff }} \frac{d C_{v}}{d z}+\alpha|V| \frac{d C_{v}}{d z}= \\
\quad=\frac{d C_{v}}{d z} \alpha\left|-\frac{\Delta p_{\text {atm }}}{p_{0}}(\mathrm{~L}-\mathrm{z}) \omega \sin (\omega t)\right|+D_{\text {soil }}^{v} \frac{d C_{v}}{d z}
\end{gathered}
$$

where $d C_{v}=C_{s a t}-C_{\text {air }}$. Equation 5.6 can be simplified as:

$E_{\text {diff }+ \text { disp }} \cong\left|\Delta p_{\text {atm }} \cdot k_{1}\right|+k_{2}$

where: $k_{1}=\frac{d c}{d z} \alpha \frac{1}{p_{0}}(\mathrm{~L}-\mathrm{z}) \omega \sin (\omega t) ; k_{2}=\left(D_{p m}^{v} \frac{d c}{d z}\right)$. Equation 5.7 suggests that evaporation rates should be correlated with $\left|\Delta p_{a t m}\right|$. To calibrate and validate the model, the short column evaporation dataset was split into two sets: calibration (T2, T3 and T4) and validation (T6, T7 and T9). The model parameters were calibrated using half of the short column dataset, and validated against the other half of the short column dataset. Moreover, the model was validated by modelling the long column evaporation and comparing the simulated with measured data. 


\subsection{Results}

\subsubsection{Soil column measurements}

Figure 5.2 shows the cumulative evaporation of six (T2-4 and T6-T8) experimental Tests at short and long columns as explained in Table 5.1. All the conducted Tests resulted in the continuous decrease of water from the Mariotte bottles as a result of outflow due to evaporation from water table through the columns. The evaporation rates were relatively small (average evaporation was $0.27 \mathrm{~mm} \mathrm{~d}^{-1}$ with standard deviation $0.26 \mathrm{~mm} \mathrm{~d}^{-1}$ ) and varied among the Tests, as indicated by different slopes. The Tests had also periodic fluctuations due to different evaporative conditions.

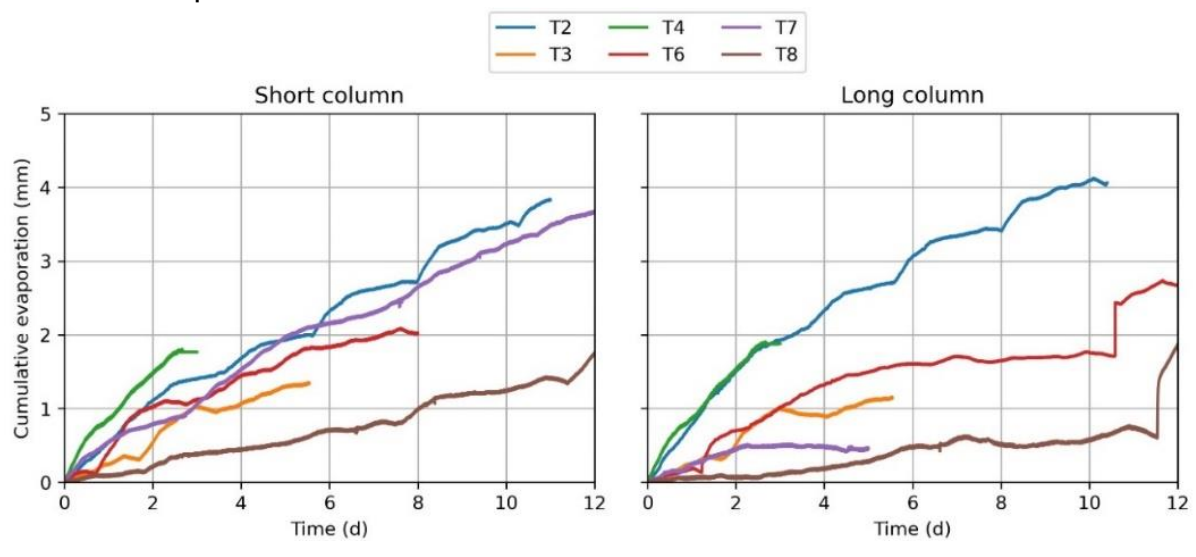

Figure 5.2: Cumulative evaporation [mm] for experimental Tests T2-4 and T68 in short and long columns as explained in Table 5.1.

\subsubsection{Evaluation of diffusion, wind speed, and daily cycles effects on vapour transport through a DSL}

The measured evaporation rates at the two columns are shown in boxplots in Figure 5.3. The Tests T3, T6, T7 and T8 (Table 5.1) showed similar evaporation rates, slightly smaller in the long column (with larger $Z_{D S L}$ ) than in the short, while the Tests T2 and T4 indicated the opposite relation.

The difference between the mean evaporation rates of the two columns (all Tests) were not statistically significant (ANOVA, 95\%, $n=7000$ ). The paired differences between mean evaporation rates of the same Test type but at different columns, were statistically significant at $95 \%$ confidence interval for all the Tests, except for T2 and T6. The paired differences between mean evaporation rates of different Test types at the same column, were statistically significant at $99.9 \%$ confidence interval. It should be noted that the changes in evaporative conditions were cumulative, so, for example, the first 
evaporative Test (T2, with wind speed $0 \mathrm{~m} \mathrm{~s}^{-1}$ ) was significantly different from the following evaporative Test T3 (wind applied with speed $1.8 \mathrm{~m} \mathrm{~s}^{-1}$, all other conditions kept as in T2). This means that the different slopes of the evaporation curves for T2 and T3 were statistically significant, i.e. not random.

The Tukey tests confirmed that the evaporation differences between Tests at different columns were significant, except for T3, T6 and T7 (where water table depth was changed). Since the evaporative conditions were changed systematically, the interpretation of these statistics should be done as per Table 5.1 and looking at Figure 5.2. For the details of the statistical analysis refer to appendix 5.6.1 and Table 5.3.

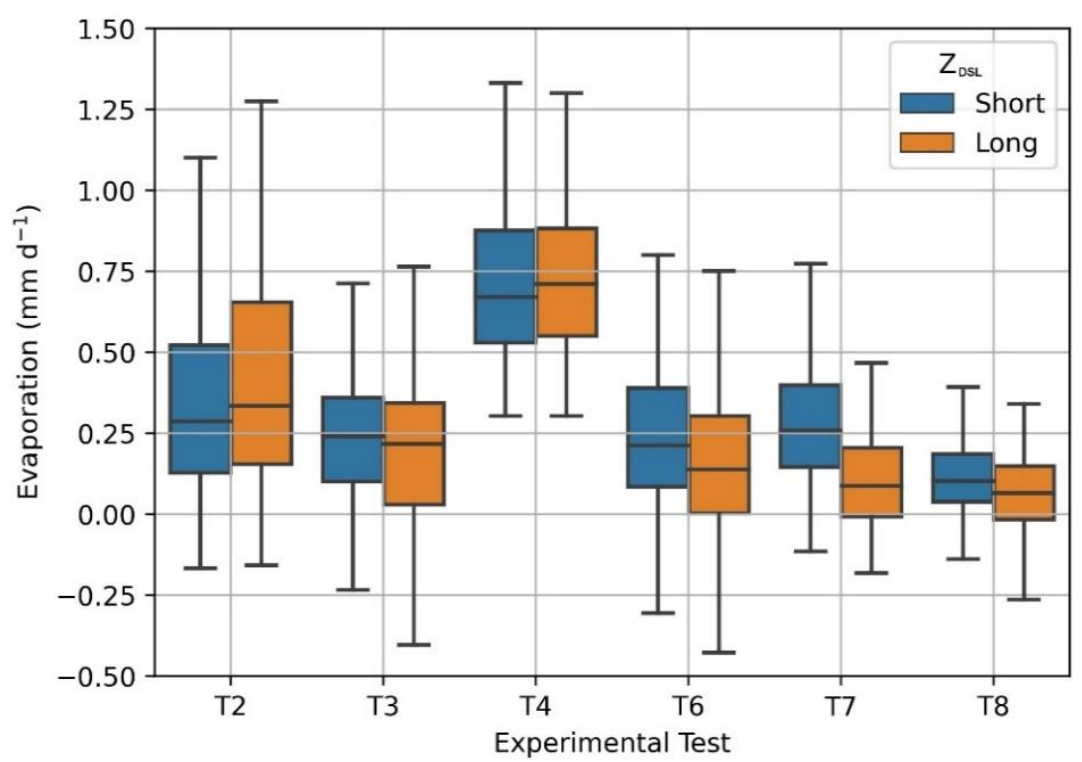

Figure 5.3: Boxplot of the evaporation rates for experimental Tests as per Table 5.1 .

\subsubsection{Barometric pressure fluctuations effects on vapour transport through a DSL}

\subsubsection{Diffusion and direct barometric pumping effect}

Both diffusion related evaporation estimates (Table 5.2), i.e. one with diffusion only (Equation 5.1) and the other with diffusion and direct barometric pumping (Equation 5.3), underestimated the experimental evaporation rates and none could properly model the evaporation patterns measured in the column experiments. The evaporation estimated with only diffusion was 2 to 3 orders of magnitude smaller than the evaporation measured, and did not follow the pattern of increases and decreases in evaporation rates between different 
Tests. When the direct barometric pumping effect was added to the diffusion, it only marginally increased the total evaporation flux.

Table 5.2: Comparison of measured (experimental) average daily evaporation rates as in the Tests (Table 5.1), with evaporation rates calculated using: (i) diffusion only (Equation 5.1); (ii) the sum of diffusion and direct barometric pumping effect (substituting $Z_{D S L}$ of the Equation 5.3 in the Equation 5.1); (iii) the sum of diffusion flow and effect of barometric pressure fluctuation calculated using Equation 5.9, calibrated using the short column dataset (results are the same for both columns). All evaporations are in $\mathrm{mm} \mathrm{d}^{-1}$. The $Z_{D S L}$ for every experimental Test is also shown for completeness.

\begin{tabular}{|c|c|c|c|c|c|c|c|}
\hline Evaporation $\left[\mathrm{mm} \mathrm{d}^{-1}\right]$ & Column & $\mathrm{T} 2$ & $\mathrm{~T} 3$ & $\mathrm{~T} 4$ & T6 & $\mathrm{T} 7$ & $\mathrm{~T} 8$ \\
\hline \multirow{2}{*}{ Experimental } & Short & 0.350 & 0.240 & 0.728 & 0.277 & 0.286 & 0.127 \\
\hline & Long & 0.408 & 0.207 & 0.755 & 0.241 & 0.118 & 0.066 \\
\hline \multirow{2}{*}{ Diffusion only } & Short & 0.061 & 0.004 & 0.005 & 0.001 & 0.000 & 0.000 \\
\hline & Long & 0.029 & 0.002 & 0.002 & 0.003 & 0.004 & 0.002 \\
\hline \multirow{2}{*}{$\begin{array}{c}\text { Diffusion with direct } \\
\text { barometric pumping } \\
\text { effect }\end{array}$} & Short & 0.077 & 0.008 & 0.008 & 0.004 & 0.002 & 0.005 \\
\hline & Long & 0.043 & 0.011 & 0.011 & 0.009 & 0.009 & 0.010 \\
\hline $\begin{array}{l}\text { Diffusion and barometric } \\
\text { pressure fluctuation effect }\end{array}$ & $\begin{array}{l}\text { Calibrated on } \\
\text { Short }\end{array}$ & 0.265 & 0.328 & 0.344 & 0.344 & 0.256 & 0.226 \\
\hline \multirow{2}{*}{$\mathrm{Z}_{\mathrm{DSL}}(\mathrm{cm})$} & Short & 80 & 80 & 70 & 70 & 60 & 60 \\
\hline & Long & 180 & 180 & 170 & 170 & 160 & 160 \\
\hline
\end{tabular}

\subsubsection{Dispersion due to barometric pressure fluctuations}

In Figure 5.4 the hourly evaporation rates $\left(E_{h}\right)$, expressed in daily rates, are plotted against the corresponding hourly barometric pressure changes $\left(\Delta p_{h}\right)$. There was a significant correlation (average Pearson coefficient $\sim 0.7$ ) between evaporation rates and both amplitude and frequency of the barometric pressure fluctuations. This indicated a relation between evaporation and barometric pressure changes: faster barometric fluctuations with larger amplitude corresponded to larger evaporation rates.

Figure 5.4 shows that there are three different relations between $E_{h}$ and $\Delta p_{h}$ : (a) a positive relation between positive $\Delta p_{h}$ and positive $E_{h} ;$ (b) a negative relation between negative values of $\Delta p_{h}$ (i.e. when barometric pressure decreases) and positive $E_{h}$, which held for negative $E_{h}$ and positive $\Delta p_{h}$; and (c) a negative relation between positive $\Delta p_{h}$ and negative $E_{h}$. When the dataset was divided into quadrants (indicated by the red lines in Figure 5.4, e.g. 
negative $E_{h}$ and negative $\Delta p_{h}$, positive $E_{h}$ and negative $\Delta p_{h}$, and so on) it was possible to fit to each a linear model with statistically significant correlation $\left(R^{2} \sim 0.6\right.$ and $\left.p<0.01\right)$. Note that the point at which the positive relation starts does not correspond to the Cartesian system origin (point 0,0 in Figure 5.4).

Looking at Equations 5.4 and 5.5 the velocity of the gas $V$, which depends on $\Delta p_{h}$, enters the evaporation calculation as absolute value. Therefore, a mirroring effect (as in Figure 5.4) was expected (a change from a positive to a negative relation with respect to an axis of symmetry). However, the decreasing relation in Figure 5.4 is also observed for positive values of $\Delta P_{h}$; in our case, an increase in atmospheric pressure results in an increase of water pushed from the columns into the Mariotte bottles (a "negative evaporation" rate, $E<0$ ) and vice versa. Note that the point at which the positive relation starts does not correspond to the Cartesian system origin (point 0,0 in Figure $5)$, and it is not shifted only with respect to the $y$ axis.

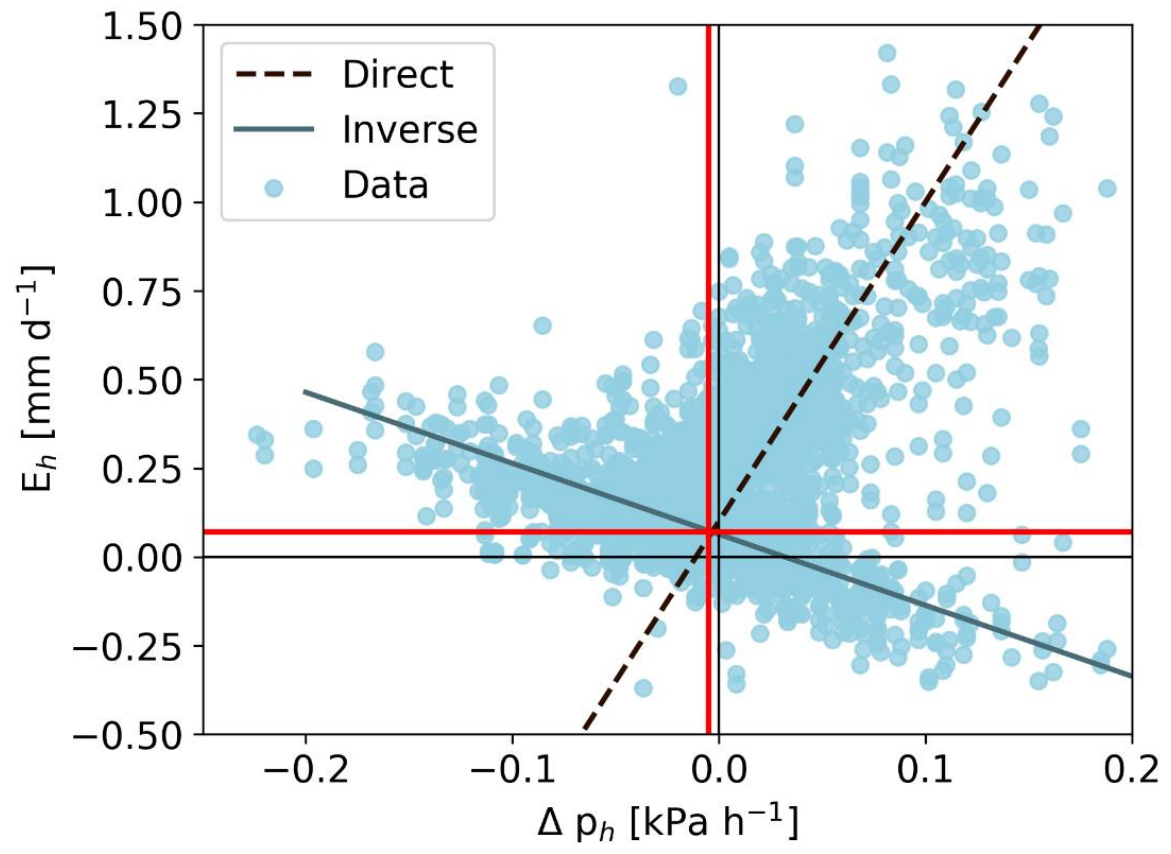

Figure 5.4: Scatterplot of the hourly evaporation rates $\left(E_{h}\right)$ expressed in daily rates, versus the hourly changes in barometric pressure $\left(\Delta p_{h}\right)$ for both columns and the best linear fits for the positive and negative relations. The red lines show the intersection point between the two relations, and the designated quadrants to determine them. 


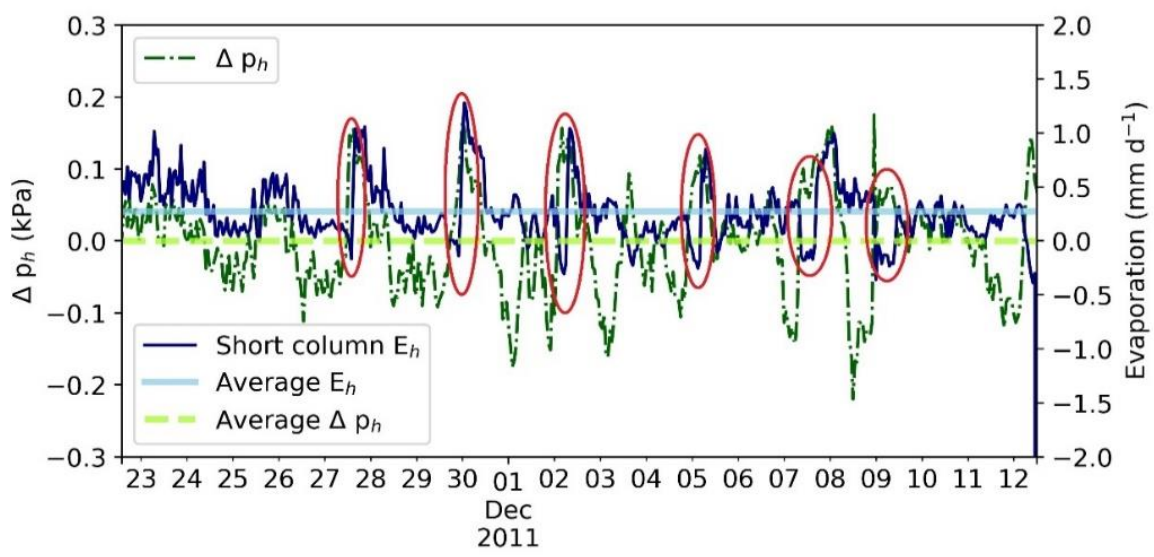

Figure 5.5: Hourly time series of the evaporation rates $\left(E_{h}\right)$ and barometric pressure changes $\left(\Delta p_{h}\right)$ for the short column T6 Test; the red circles correspond to the rare cases of positive $\Delta P_{h}$ and negative $E_{h}$. Note that: (i) $\Delta p_{h}$ had zero mean; and (ii) the average $E_{h}$ was positive and $E_{h}$ behavior was symmetrical to $\Delta p_{h}$ whenever the latter had negative values.

The evaporation calculated using the model presented in Equation 5.6 and calibrated using the short column dataset $(\mathrm{T} 2, \mathrm{~T} 3, \mathrm{~T} 4)$, fitted the evaporation rates and pattern of the short column validation dataset (T6, T7, T8), as well as the long column whole dataset (Figure 5.6 and 5.7). The model based on equation (5.8), calibrated by fitting linear models for the inverse and direct relationships for the short column T2, T3 and T4 datasets, is different from equation (5.7), since we: (i) had to add a constant term inside the module function $\left(k_{3}\right)$ in order to explain the shift with respect to the $\mathrm{x}$ axis, that is not expected by looking at equation (7); and (ii) we found two different multiplying coefficients (which, in the model, included both $k_{1}$ and $k_{3}$ as well), $k_{1}^{\text {positive }}$ and $k_{1}^{\text {negative }}$, for the positive and negative relations between $E_{h}$ and $\Delta P_{h}$, respectively:

$E_{\text {tot }}=f(\Delta P)=\left\{\begin{array}{l}\left|k_{1}^{\text {positive }}\left(\Delta p_{\text {atm }}+k_{3}\right)\right|+k_{2}, \Delta p_{a t m}+k_{3}<0 \\ \left|k_{1}^{\text {negative }}\left(\Delta p_{\text {atm }}+k_{3}\right)\right|+k_{2}, \Delta p_{\text {atm }}+k_{3} \geq 0\end{array}\right.$

where $k_{1}^{\text {positive }}=4.91\left[\mathrm{~mm} \mathrm{kPa}^{-1}\right], k_{1}^{\text {negative }}=-2\left[\mathrm{~mm} \mathrm{kPa}^{-1}\right], k_{2}=0.07[\mathrm{~mm} \mathrm{~d}$ $\left.{ }^{1}\right]$, and $k_{3}=0.003\left[\mathrm{kPa} \mathrm{h}^{-1}\right]$. It should be noted here that the $k_{3}$ parameter fitted on the data had very low statistical significance, due to the wide spread of the data on the $\mathrm{x}$ axis at $E_{t o t}=k_{2}$. A further statistical analysis could not reject the null hypothesis that $k_{3}=0$; hence, this parameter was neglected in the following analysis. The differences between equations (5.8) and (5.7), and their applicability, is discussed in section 4.2. 


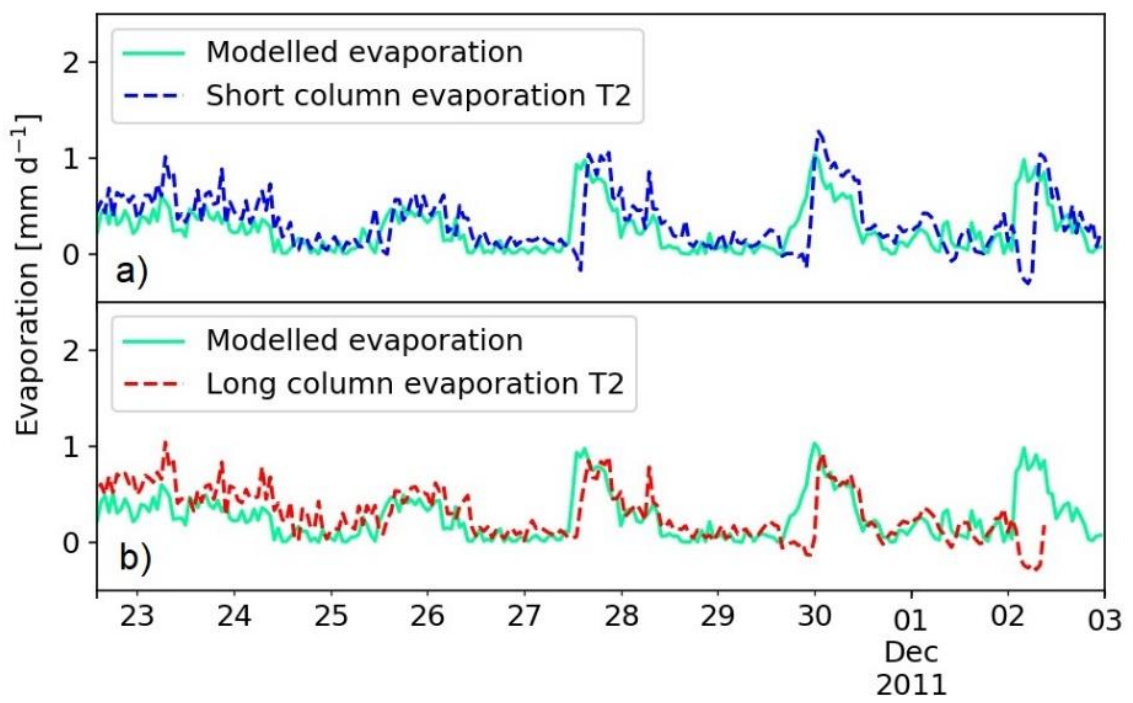

Figure 5.6: Hourly evaporation rates, measured and modelled using Equation 5.8, calibrated using short column T2, T3 and T4 evaporation dataset. The evaporation is presented for the T2 Test in the calibration period, 22 November - 3 December 2011 for the: a) short column (e.g. calibration dataset); b) long column (e.g. validation dataset).

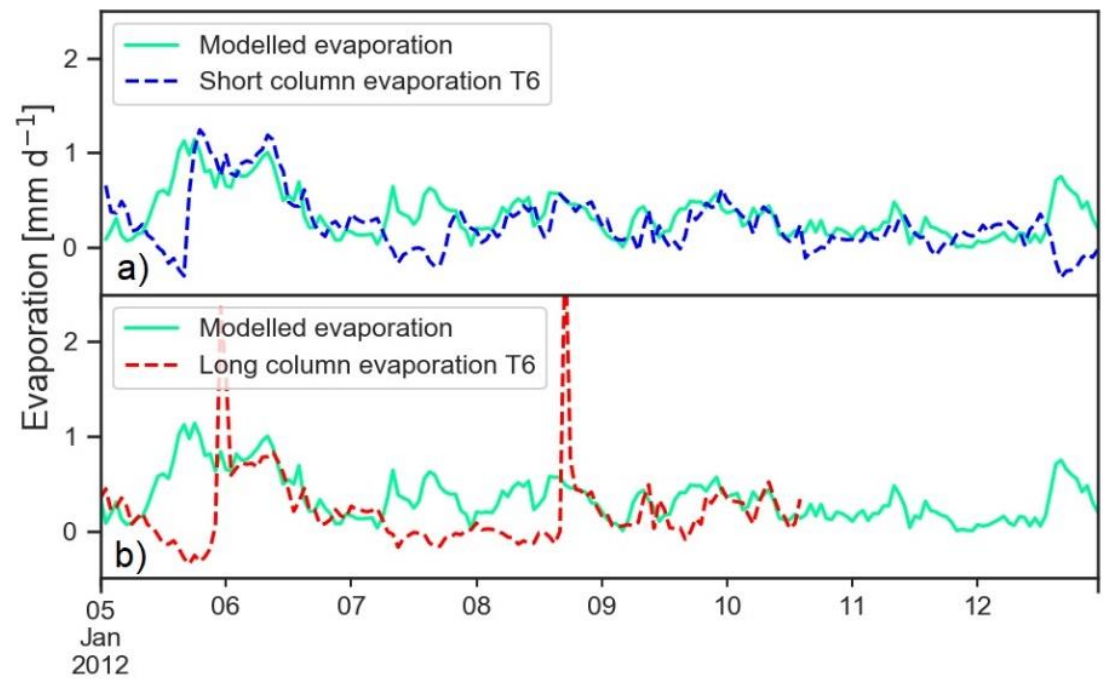

Figure 5.7: Hourly evaporation rates, measured and modelled using Equation 5.8, calibrated using short column T2, T3 and T4 evaporation dataset. The evaporation is presented for the T6 Test in the validation period, 5 January 13 January 2012, for the: a) short column; b) long column. 


\subsection{Discussion}

\subsubsection{Water vapour transport through the DSL}

\subsubsection{Diffusion}

The assumption that the main water vapour transport mechanism is diffusion did not hold, even for constant evaporative conditions. This result was not affected by the uncertain value of the diffusion coefficient, as demonstrated by the lack of a clear relationship between evaporation rates and by water vapour concentration differences and $Z_{D S L}$, predicted by Fick's law. Since the $Z_{D S L}$ is in the denominator in equation (5.1), an inverse relation between evaporation rates and $Z_{D S L}$ would be expected if water vapour transport through the DSL was mainly due to diffusion flow. However, even though the mean experimental evaporation rates are lower in the long column than in the short column (Table 2), that difference is not statistically significant (Section 3.2) and not true for all Tests (i.e. it is not verified in Tests T2 and T4). The results, however, do not prove that DSL evaporation rates are always independent of $Z_{D S L}$, but rather that, when $Z_{D S L}$ is $>50 \mathrm{~cm}$, the effect of $Z_{D S L}$ on evaporation rates is minimal, and the evaporation rates are mainly dependent on other transport processes than diffusion.

The findings of this study showed that diffusion alone cannot explain the evaporation rates obtained in this study. This was unexpected, since previous laboratory experiments found that the diffusion flow could explain the evaporation rates measured in soil columns under stable evaporative conditions (Shokri et al., 2008; Shokri et al., 2009; Shokri and Salvucci, 2011). The discrepancy between this and previous studies could be due to the much larger $Z_{\mathrm{DSL}}(>50 \mathrm{~cm})$ applied in this study; the large distance travelled by water vapour decreases the diffusion flow considerably, and enhances other processes, which otherwise, with shorter $Z_{D S L}$, are less relevant (like the barometric pressure fluctuations effect, see below).

\subsubsection{Radiative daily cycles}

Measured evaporation rates generally decreased between the Tests with $24 \mathrm{~h}$ continuous lamp schedule (T2, T3, T4) and the Tests with 12/12 on/off lamp schedule $(T 6, T 7, T 8)$ as can be seen in Table 5.2 and Figure 5.3. The paired differences between the Tests with different lamp schedules, however, were not always statistically significant: $\mathrm{T} 2-\mathrm{T} 6, \mathrm{~T} 2-\mathrm{T} 7, \mathrm{~T} 2-\mathrm{T} 8, \mathrm{~T} 4-\mathrm{T} 6, \mathrm{~T} 4-\mathrm{T} 7$, and T4T8 showed significantly different evaporation rates, while T3-T6, T3-T7 and T3T8 did not (Tables 5.1 and 5.2). Therefore, it was not possible to identify a clear statistical relationship between lamp schedule, i.e. duration of radiations supplied and evaporation rates through a thick DSL.

The effect of changing the radiative lamp schedule from continuous to cyclic resulted in a significant reduction of evaporation rates between T4 and T6 only (Figure 5.3; Table 5.1). Effects of condensation and evaporation were not 
apparent in the columns since there was no observed change in the measured soil moisture. Therefore, the change in the lamp schedule had an effect on evaporation rates but not on soil moisture in the topsoil. Note that the lamp schedule affected the top boundary temperature, as discussed further in Section 5.4.1.3, with the temperature decreasing from $\sim 32{ }^{\circ} \mathrm{C}$ (T4) to $\sim 23^{\circ} \mathrm{C}$ (T6).

\subsubsection{Wind speed}

The effect of stable wind, with different velocities, on evaporation through a thick DSL was statistically significant. The wind effect on evaporation rates was best analysed by comparing the Tests (Table 5.1) where the wind speed was the only variable changed, i.e. T2 with T3 (0 and $1.8 \mathrm{~m} \mathrm{~s}^{-1}$, respectively) and T7 with T8 (1.8 and $\left.0.3 \mathrm{~m} \mathrm{~s}^{-1}\right)$. The evaporation rates associated with different wind speeds were significantly different ( $p$-value $<0.05$ ) in both columns. However, it is remarkable that the increase in wind speed between tests T2 and T3 was associated with a decrease in evaporation rate, in contrast to the 'expected' decrease in evaporation rates between Tests T7 and T8 when wind speed decreased (Table 5.1, Figure 5.3).

Wind speed increase has three effects on evaporation rates: it increases evaporation through advection in the gas phase in the DSL, affects the water vapour density at the soil surface by its direct removal, and it decreases evaporation by cooling of the soil surface. The unexpected decrease of evaporation with increased wind speed between Tests T2 and T3 can be explained by the cooling effect of the wind speed on the top boundary temperature. Increase in wind speed, thus, resulted in a dramatic drop of the top boundary temperature from $\sim 72{ }^{\circ} \mathrm{C}$ in $\mathrm{T} 2$ to $\sim 35^{\circ} \mathrm{C}$ in $\mathrm{T} 3$, so also in the decrease of the DSL temperature gradient in T3. In contrast, in the T7-T8 transition, the reduction of the wind speed resulted in a rise in the top boundary temperature of only $6^{\circ} \mathrm{C}$, with a minimal effect on the DSL temperature profile.

The temperature gradient in the DSL and, as such, the gradient of vapour densities in soil pores, are a function of the top boundary temperature, which depends on both the radiative lamp schedule and the wind speed. The Equation 5.1 suggests a correlation between the diffusion flow of water vapour in the DSL and the surface temperature. A direct relation between top boundary temperature and evaporation rates would be expected if evaporation from the columns was only due to diffusion flow. However, no clear relation was observed (see also appendix 5.6.3); therefore, it appears that other processes are involved in the transport of water vapour through the DSL.

\subsubsection{Barometric pressure fluctuations}

The direct barometric pumping of air in and out of the topmost soil, which reduced the thickness of the layer travelled by the water vapour (Auer et al., 1996), was shown to have small relevance in this study (Table 5.2) as it was at least one order of magnitude smaller than the measured evaporation rates. 
The process mainly responsible for the transport of water vapour through the DSL with $Z_{D S L}>50 \mathrm{~cm}$ was the dispersion due to barometric pressure fluctuations, as indicated by the correlation between frequency and amplitude of the barometric pressure fluctuations and the measured evaporation rates (Figures 5.4 and 5.5). Moreover, the estimate for the $k_{2}$ parameter of equation (5.8) is the same magnitude $(0.07 \mathrm{~mm} \mathrm{~d}-1)$ as the diffusion flow predicted in Table 5.2 .

The Equation 5.8 allowed to model the behaviour of the measured evaporation time series in both the validation dataset of the short column (T6, T7 and T9) and in the validation dataset in the long column, as shown in Figures 5.6 and 5.7. Given these results, the model appears to be robust, at least considering the soil properties and the $Z_{D S L}$ applied in this study.

\subsubsection{DSL thickness effect for $Z_{D S L}>50 \mathrm{~cm}$}

Many factors that increase evaporation rates for small $Z_{D S L}($ e.g. $<5 \mathrm{~cm})$ can have negligible or even opposite effects on evaporation rates of $Z_{D S L}$ larger than $15 \mathrm{~cm}$. For example, wind can increase evaporation rates by actively removing water vapour from the first few $\mathrm{cm}$ of soil (Davarzani et al., 2014; Mosthaf et al., 2014). However, when $Z_{D S L}$ is larger than the maximum depth of wind turbulence effect, wind can only remove air from the soil pores close to the soil surface, which have a small concentration of water vapour. However, wind can also cool the soil surface, decreasing the temperature gradient and, hence, decreasing the evaporation rates.

Another factor that affects evaporation in different ways depending on $\mathrm{Z}_{\mathrm{DSL}}$ is the pumping out of water vapour from the first centimetres of the soil profile, caused by changes in barometric pressure: if $Z_{D S L}$ is comparable to the depth of the soil layer affected by this process (which, in this study, corresponded to $\sim 2.5$ and $\sim 5 \mathrm{~cm}$ for the short and long column, respectively), the direct barometric pumping increases evaporation rates, but otherwise, when $Z_{D S L}$ is substantially larger, it has no effect on evaporation rates (Auer et al., 1996).

The effect of daily fluctuations of evaporative conditions on evaporation rates is probably also affected by $Z_{D S L}$. The soil temperature profile changes daily due to changes in evaporative conditions at the surface, with daily variations in soil temperature decreasing with increasing depth. If $Z_{D S L}$ is shallow enough, soil temperature variations can influence the bottom of the DSL where liquid water is in equilibrium with the air saturated with water vapour. Therefore, an increase of evaporation because of direct transport of water vapour through condensation and evaporation cycles is expected (Assouline et al., 2013).

However, if the $Z_{D S L}$ is deep enough, the change in temperature at the bottom of the DSL is negligible. This is what happened in this study: the depth of temperature fluctuation was already negligible at $50 \mathrm{~cm}$, which was less not only than the $Z_{D S L}$ of the long column, but also less than the shortest $Z_{D S L}$ of 
the short column, resulting in a negligible effect of daily changes of evaporative conditions on evaporation rates in all $Z_{D S L}$ tested (see Table 5.2).

\subsubsection{Possible limitations of the study}

An alternative explanation for the fluctuations in the evaporation rates observed in Figure 5.3 could be the heterogeneity of the soil column material packing, or random errors. As these fluctuations appeared to have the same behaviour in both short and long column, however, the effect of soil heterogeneity and of randomness can be ruled out, pointing at the impact of barometric pressure fluctuations instead.

One reported effect of barometric pressure fluctuations on groundwater is that they directly affect the water pressure in the column, resulting in fluctuations in the water levels. This effect probably plays a role in the interchanging, positive and negative relations between $E_{h}$ and $\Delta p_{h}$ shown in Figure 5.5. However, the hypothesis that the effect of barometric pressure fluctuations was limited to fluctuations in the water level in the columns can be ruled out, since this would result in fluctuations without long term trend due to evaporation. Moreover, this hypothesis is disproved by the fact that the measured Mariotte bottle's weight changes were larger than those predicted using the equation for water table fluctuations by Rojstaczer and Riley (1990). In field conditions, such fluctuations would have an effect on evaporation rates only at the shallow water table depth conditions, due to the changes in $Z_{D S L}$.

The main difference between physically based Equation 5.7 and the calibrated empirical Equation 5.8 is that in Equation 5.8 there are two empirical coefficients ( $k_{1}^{\text {positive }}$ and $k_{1}^{\text {negative }}$ ) instead of only one $\left(k_{1}\right)$ in Equation 5.7. Note, the empirical coefficients $k_{1}^{\text {positive }}$ and $k_{1}^{\text {negative }}$ represent the efficiency with which the barometric fluctuation extracts the water vapour from the column (a combination of $\alpha$ and other soil material properties), and they switch from one to the other when either the air above the column is pushed inside the column, or the air in the column is pulled out of the column. This overall gas transport in soils, with compression and expansion behaviour, was observed for $\mathrm{CO}_{2}$ flow in similar conditions (sandy soil, semi-arid climate, dry topsoil; Fig. 6 in Sánchez-Cañete et al. 2013).

It is possible to explain the need for two different coefficients ( $k_{1}^{\text {positive }}$ and $k_{1}^{\text {negative }}$ ) for the dependence of $E_{h}$ on $\Delta p_{h}$ by looking at equation (5.6), where the terms $\frac{d C}{d z} \alpha \frac{1}{p_{0}}(\mathrm{~L}-\mathrm{z}) \omega \sin (\omega t)$ are simplified into the empirical parameter $k_{1}$. This simplification is based on the assumption that all the terms simplified are independent on the sign of $\Delta p_{h}$, i.e. they do not change their values between a compression or an expansion cycle. However, this may not hold true for the term $\frac{d c}{d z}$ : during a compression cycle $\left(\Delta p_{h}>0\right)$, air from above the soil is pumped inside the soil column, and hence the concentration gradient between 
the saturation value at vaporization plane and atmospheric value at soil surface gets compressed by a distance $2 \Delta L_{\text {pump }}$. In the same way, during an expansion cycle $\left(\Delta p_{h}<0\right)$ the air inside the soil column is pumped out into the atmosphere, and the gradient is extended equally by a distance $2 \Delta L_{\text {pump }}$. Therefore, it should be expected that $\frac{d C}{d z}$ has a larger value when $\Delta p_{h}>0$ and a smaller value when $\Delta p_{h}<0$, that is exactly what happens to $k_{1}$ in this case.

\subsection{Conclusions}

This study shows that the main process of water vapour transport through a thick DSL was not diffusion but barometric pressure fluctuations. More in detail, the findings of this study are that:

- The assumption of only diffusion flow with thick $Z_{D S L}$ did not hold even for the experiment with constant evaporative conditions.

- The evaporation conditions such as wind effect and daily radiation cycles had only very small effect on the evaporation rates with a $Z_{D S L}>50 \mathrm{~cm}$.

- The predicted diffusion flow, mechanical dispersion flow, and direct barometric pumping effect could not model the time series of evaporation rates measured in the experiments (Table 5.1).

- The model based on the Equation 5.8 was able to simulate the measured soil evaporation rates and their trends (Figures 5.6 and 5.7).

- The evaporation measured was found to be mainly dependent on barometric pressure fluctuations effect on the water vapour in the DSL, with two dominant processes of water vapour flow mechanism: dispersion due to barometric pressure fluctuation and direct barometric pumping.

The findings of this study indicate that the relevant processes of water vapour transport in thick DSLs are different from the processes in thin DSLs, with thick and thin defined by the depth at which these transport processes change their magnitude. The results of this study are relevant because: (i) DSL with comparable thickness have been reported in field conditions in semi-arid and arid areas; (ii) the measured water vapour transport is the basis to understand how $Z_{D S L}$ influences evaporation rates in the presence of a DSL (Balugani et al., 2017; McColl et al., 2017b); (iii) the evaporation rates measured in the presence of thick DSL confirmed that assuming only diffusion flow as transport mechanism in the DSL is likely incorrect, particularly for $Z_{D S L}$ $>50 \mathrm{~cm}$. The evaporation estimated under the assumption of diffusion flow only is substantially smaller than the experimentally measured evaporation.

Further studies should try to: (a) define how the relevant processes of water vapour transport through a DSL (barometric fluctuations, diffusion, daily cycles of evaporation/condensation, wind) change with increasing $Z_{D S L}$, testing different evaporative conditions on soil columns with different imposed $Z_{\mathrm{DSL}}$; 
and (b) test the results of the laboratory experiments as presented in this study under field conditions.

\subsection{Appendix}

\subsubsection{Experiment preparation}

Before starting the experiment, we: (i) tested the thermal insulation of the column walls; (ii) estimated the thermal properties of the soil filling the columns; (iii) let the water enter the columns and equilibrate for 1 month; and (iv) checked the Mariotte bottles connection with the columns for leaks. After the end of the experiment, we ( $v$ ) performed a ponding experiment on both columns for calibration of the hydraulic properties of the packed sand.

To test (i), we inserted 4 thermistors in the first $1 \mathrm{~cm}$ of the soil at various distances from the column centre $(0,5,10 \mathrm{~cm}$ and at the walls) and measured the soil temperature with the radiative lamp on, with and without glass wool covering the column walls. To calibrate the thermal properties of the columns (ii), the changes in the temperature profile in the dry columns were measured after turning on the radiative lamp until equilibrium was reached and also while changing the radiative lamp schedule to $12 \mathrm{~h}$ on/off schedule (to simulate the day-night cycle). When the temperature profiles of the columns were stable, water was let enter the columns bottom until it reached a height of $10 \mathrm{~cm}$ from the bottom (Figure 5.1), and then the columns were left to equilibrate (iii) for a period of 1 month to reach hydrostatic equilibrium. Successively, the connection between the Mariotte bottles and the columns was closed for 3 days to investigate possible water losses due to evaporation from the bottles or by leakage (bottle test, iv). During the equilibration period and the leakage check, the top evaporative conditions were kept constant at $20 \mathrm{~mm} \mathrm{~d}^{-1}$, i.e. the radiative lamps were left on all the time, while the fans were turned off. Finally, after the end of the experiments, a constant head infiltration experiment of the duration of 30 minutes was carried out ( 3 litres for every column) with the radiative lamps and fans both off. The radiative lamps were turned on after all the water infiltrated into the soil to maintain stable evaporative conditions at the top boundaries. The soil moisture and matric potential data from the constant head infiltration experiment were used to calibrate the soil moisture properties of the packed material.

During the equilibration period ( $T 1$, Table 1$)$, the water entered from the bottom of the columns, stabilizing in both columns at WTH $=10 \mathrm{~cm}$, i.e. at 90 and $190 \mathrm{~cm}$ depth from the surface in short and long column, respectively. The temperature difference between column centre and walls was minimal ( $\sim 0.1$ ${ }^{\circ} \mathrm{C}$ ) after the installation of the glass wool; therefore, the heat flow could be described as only vertical. At the beginning of the test water entered the columns quickly, but after $\sim 4$ days a small, stable (equilibrium) water loss rate 
was reached with stable soil temperatures $\sim 70,60,50$, and $36^{\circ} \mathrm{C}$ at 5,10 , $15,25 \mathrm{~cm}$ depths respectively.

There was no water leakage from the columns, which means that the outflow of the water from the columns was passing only through the upper boundary as water vapour. When the connection between the Mariotte bottles and the columns were closed (T5, Table 1), no changes in weight was measured by the balances (Figure 5.2), confirming that all the water from the Mariotte bottles was moving into the columns. The long equilibration period of the main tests (T2-4 and T6-8) allowed the two columns to reach steady state before starting the experiment, i.e. the loss of water from the Mariotte bottles was not due to water wetting the soil material but exclusively to the evaporation of water from the columns.

\subsubsection{Tukey Test results}

The Tukey test (Table 5.3) shows that the average rates of evaporation of the experiment tests fall into one of two categories: (i) no significant difference; (ii) significantly different at a probability $<0.05$. In order to test the differences between different treatments for the two columns, the Tukey test was applied to the experimental treatments with: (a) data from both columns combined; (b) only data from the short column; and (c) only data from the long column. When taking into account the data for both columns, all tests were statistically different, except for the tests comparison T3-T6, T3-T7, T6-T7, which were not significantly different. The tests comparisons for the single columns (only short and only long column) show that T8-T3 and T8-T7 were also not statistically different for the long column.

Table 5.3: Tukey test results of the comparison between: different tests in the two columns; different tests in the short column; and different tests in the long column. The difference between evaporation rates of any pair of two 
experimental tests is considered statistically significant (in bold) if $p$ value $<0.05$.

\begin{tabular}{|c|c|c|c|}
\hline \multirow{2}{*}{ Comparison } & \multicolumn{3}{|c|}{ Tukey test $p$ value } \\
\hline & Both columns & Only Short & Only Long \\
\hline$T_{2}-T_{3}$ & $2.3410-5$ & $8.8310-5$ & $9.9410-3$ \\
\hline$T_{2}-T_{4}$ & 0.00 & 0.00 & $1.5210-3$ \\
\hline T2-T6 & $2.0710-5$ & $2.0010-2$ & $3.2410-3$ \\
\hline $\mathrm{T}_{2}-\mathrm{T}_{7}$ & $8.5310-5$ & $1.2410-2$ & $3.2210-4$ \\
\hline $\mathrm{T} 2-\mathrm{T} 8$ & 0.00 & 0.00 & 0.00 \\
\hline$T_{3}-T_{4}$ & 0.00 & 0.00 & $110-7$ \\
\hline$T_{3}-T_{6}$ & $9.5310-1$ & $7.1610-1$ & $9.9010-1$ \\
\hline $\mathrm{T}_{3}-\mathrm{T}_{7}$ & $9.75^{10-1}$ & $3.4110-1$ & $8.3610-1$ \\
\hline$T_{3}-T_{8}$ & $9.2210-4$ & $3.4810-5$ & $1.5310-1$ \\
\hline $\mathrm{T}_{4}-\mathrm{T} 6$ & 0.00 & 0.00 & 0.00 \\
\hline $\mathrm{T}_{4}-\mathrm{T}_{7}$ & 0.00 & 0.00 & 0.00 \\
\hline $\mathrm{T}_{4}-\mathrm{T} 8$ & 0.00 & 0.00 & 0.00 \\
\hline T6-T7 & $110-1$ & 9.99 10-1 & $3.8710-1$ \\
\hline T6-T8 & 0.00 & 0.00 & $1.15_{10-3}$ \\
\hline T7-T8 & $1.1010-6$ & 0.00 & $9.73^{10-1}$ \\
\hline
\end{tabular}

\subsubsection{Evaporation rates and top-soil temperature relationship}

Figure 5.8 shows the scatterplot of temperature measured at $5 \mathrm{~cm}$ depth in the soil in relation with the measured evaporation rates, both averaged over a whole Test (see Table 5.3). The objective is to test the assumption that the main effect of wind speed and daily cycles of radiation would impact evaporation rates by changing the soil temperatures in the DSL. The scatterplot shows that there is some relationship between evaporation rates and temperatures at $5 \mathrm{~cm}$ depth; however, the relationship is not clear (and was not found statistically significant). Soil temperatures are expected to have a role in the water vapour transport process through diffusion, so if that was the only transport mechanism, we would expect to see a clear relationship in Figure 5.8. The weak relationship shown in Figure 5.8 points to the fact that diffusion is only one of the transport mechanisms. 


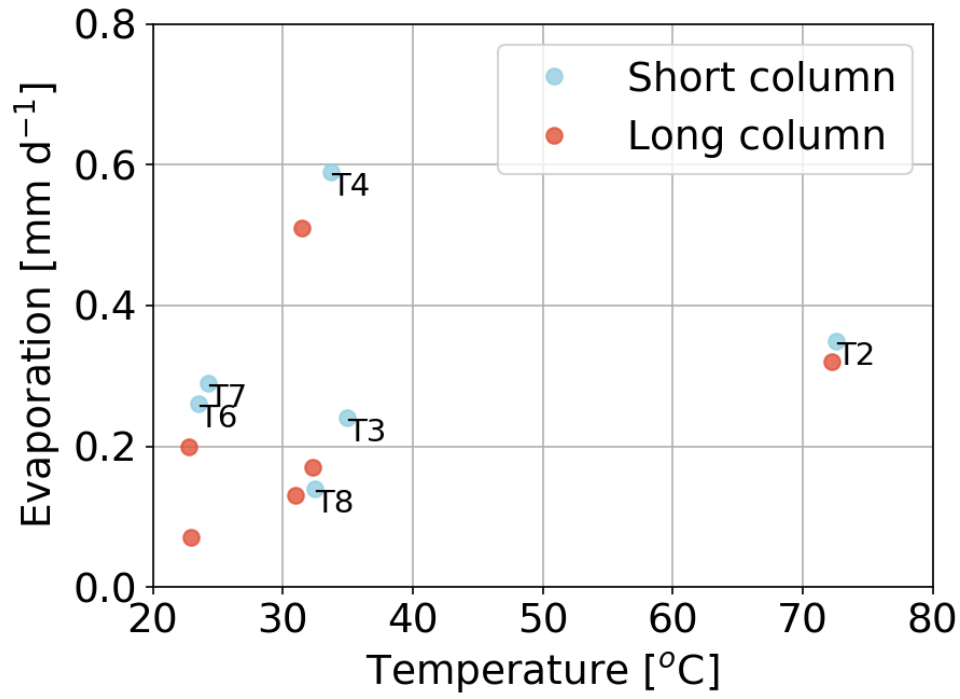

Figure 5.8: Scatterplot of the top boundary temperatures and related evaporation rates for the different experimental tests for both short and long column. The experimental test name is indicated for the short column data. 
Chapter 6

Lysimeter and In-situ Field Experiments to Study Soil Evaporation through a Dry Soil Layer under Semi-Arid Climate 


\begin{abstract}
:
Soil evaporation during droughts is often constrained by water vapour transport through the air-dry soil layer (DSL) formed at the top soil. Often, the only process considered in such transport is diffusion; however, field studies conducted in arid and semi-arid field conditions showed that other transport processes can be also relevant, providing measured evaporation rates much higher than those predicted by diffusion. To understand the driving process of evaporation through a DSL, the same lysimeter setup as earlier applied in a laboratory experiment in the Netherlands, with $70 \mathrm{~cm}$ thick DSL, was installed in the field in Spain, next to in-situ soil profile measurements, and the correlations between possible drivers of the vapour transport processes and the evaporation measured in the lysimeter were evaluated. Moreover, the evaporation process in both the lysimeter and in-situ soil was also modelled with Hydrus1D (and SOURCE package) for comparison. With the DSL thickness of $70 \mathrm{~cm}$ in 2012 and $12 \mathrm{~cm}$ in 2015, the lysimeter recorded similar evaporation rates ( $1.25 \mathrm{~mm} \mathrm{~d}^{-1}$ and $1.05 \mathrm{~mm} \mathrm{~d}^{-1}$, respectively). These evaporation rates were different than the laboratory estimates in the Netherlands in Chapter 5 $\left(0.3 \mathrm{~mm} \mathrm{~d}^{-1}\right)$ and different than the Hydrus1D estimates $(0.17$ and $0.78 \mathrm{~mm}$ $\mathrm{d}^{-1}$ for the lysimeter and the in-situ soil in 2012 , and 0.36 and $2.06 \mathrm{~mm} \mathrm{~d}^{-1}$ for the lysimeter and the in-situ soil in 2015, respectively). The main driver of the field lysimeter evaporation was the change in the soil temperature profile, which concealed other less important drivers, i.e. atmospheric pressure fluctuation and diffusion. A model to estimate evaporation is proposed, based on the changes in soil temperature profile and barometric effect. The model yielded good estimates, comparable with experimental, cumulative lysimeter measurements of evaporation in both 2012 and 2015.
\end{abstract}

This Chapter is based on:

Balugani, E., Lubczynski, M.W. and Metselaar, K., Lysimeter and In-situ Field Experiments to Study Soil Evaporation through a Dry Soil Layer under Semi-Arid Climate. In preparation. 


\subsection{Introduction}

Soil evaporation in dry environmental conditions is a complex process that is difficult to quantify (Brutsaert, 2014a; Vanderborght et al., 2017). Dry environmental conditions happen any time there is a prolonged period without precipitation, resulting in soil moisture being progressively depleted by plant transpiration and soil evaporation. Droughts or dry spells occur in every climate, but are the norm in arid and semi-arid areas, during specific periods of a year (dry seasons). Long term droughts happen also in other climates (subtropical, Mediterranean) and their frequency is increasing due to climate change (Mukherjee et al., 2018; Schlaepfer et al., 2017; Xu et al., 2019). Long term droughts deplete water resources, but also negatively affect agricultural productivity. Therefore, the understanding of evaporation processes and their quantification in dry conditions is especially important for water management and agriculture practices.

In a bare soil, during prolonged dry conditions, a soil starts to dry from the surface downward, forming a dry soil layer (DSL, Figure 1.2), in which water is transported as vapour to the soil surface (Balugani et al., 2017; Brutsaert, 2014a; Or et al., 2013). A soil can also be covered by grass during part of a year and become bare during the dry season; when grass is exposed to drought, soil matric potential in the root zone may reach the wilting point, so it withers and either dies or becomes dormant. The grass can also be eliminated by fire, wind, grazing animals, or humans, leaving behind, in the dry season, a bare soil with a well-developed DSL. The grass roots left behind usually wither and remain in the soil, with expected little effect on the vapour transport in the dry soil. The formation of a DSL can occur in bare lands or grasslands but also in the soils of open woodlands characterized by scattered trees or shrubs, and of other savannah type areas with a sparse woody vegetation.

A description of the evaporation process during a drought is presented in Section 1.1.2, and shown in Figure 1.2a and 1.2b for the case of a shallow and a deep water table, respectively. In both cases, when the drying front reaches a certain depth, equal to a critical length $\left(L_{c}\right)$ at which capillary forces are too small to sustain hydraulic continuity, a layer with no hydraulic connection with the soil surface, the DSL, develops. Water moves upward through the DSL from the capillary-driven zone after evaporation, which takes place at a specific plane, called "vaporization plane" (Or et al., 2013). Continued evaporation results in the movement of the vaporization plane downward in the soil profile, leaving behind a DSL. In the case of a deep water table, after a precipitation event, precipitation infiltrates into the soil and then moves downward in the profile, eventually reaching the deeper soil (Figure 1.2b). However, at the zero flux plane water tends to accumulate, since the downward force of gravity and the upward capillarity forces are at equilibrium (Daamen et al., 1993; Jackson et al., 1973; Khalil et al., 2003; Tsujimura et al., 2001; Zeng et al., 2011a). 
Liquid water below the zero flux plane moves downward due to gravity; liquid water above the zero flux plane moves upward due to capillary forces and reaches the vaporization plane; above the vaporization plane water moves only as water vapour (Brutsaert, 2014a). In a prolonged drought or long dryseason, the liquid water stored in the capillary-driven zone may deplete, and the profile transitions to the situation represented in Figure 1.2a.

The formation of DSLs in bare soils has been observed in laboratory and field conditions. Laboratory short column experiments (Lehmann et al., 2008; Lehmann and Or, 2009; Or et al., 2013; Shokri and Salvucci, 2011) consider usually: (a) short and narrow soil columns (a few decimetres long, a few centimetres in diameter); (b) initially saturated conditions; (c) a bare soil surface (no plant activity); and (d) stable (artificially imposed) evaporative conditions. Laboratory lysimeter (long column) experiments (Balugani et al., 2018; Chapters 4 and 5) are characterized by: (a) columns with length $\sim 1-2$ $\mathrm{m}$ and diameter $\sim 1 \mathrm{~m}$; (b) various initial conditions; (c) a bare soil surface; and (d) stable (artificially imposed) evaporative conditions. Field lysimeter experiments (Assouline et al., 2013; Dijkema et al., 2017; Ma et al., 2019) use: (a) longer and wider soil columns than laboratory conditions (few meters long, 1 to 2 meters in diameter); (b) initial conditions dependent on weather conditions; (c) soil surface bare or covered by grass; (d) evaporative conditions determined by the weather. In published laboratory column experiments on bare soils, the thickness of a newly formed DSL $\left(Z_{D S L}\right)$ was in the order of $\sim 3-$ $14 \mathrm{~mm}$ (Or et al., 2013), while in lysimeters applied in laboratory and field observations $Z_{D S L}$ was $\sim 5$ to $50 \mathrm{~cm}$ (Chapter 4, Wang, 2015; Balugani et al., 2018).

Whereas it seems accepted that water is transported through the DSL as vapour, the main transport mechanism through the DSL is not clear yet (Brutsaert, 2014a; Vanderborght et al., 2017), as different studies suggest different governing processes. It is also not yet clear which processes contribute, and in which order of importance and magnitude. Laboratory experiments (Or et al., 2013) suggest that the water vapour transport in the DSL can be explained by Fick diffusion only (from hereafter referred as diffusion). Lysimeter experiments, however, often measure evaporation rates larger than those predicted by independently parameterized diffusion; this has been attributed to the temporally varying environmental conditions mainly affecting advective water fluxes, for example due to wind speed (Davarzani et al., 2014; Fetzer et al., 2017; Scotter and Raats, 1969), thermal gradients (Saito et al., 2006; Zeng et al., 2007), daily cycles of soil moisture condensation and related evaporation at the vaporization plane, changing $Z_{D S L}$ (Assouline et al., 2013; Deol et al., 2014), the effect of atmospheric pressure fluctuations (Chapter 5), and the controversial enhanced vapour transport mechanism (Philip and de Vries, 1957; Webb and Ho, 1998). In field experiments, other processes possibly contribute to the evaporation rate, e.g. heterogeneous soil conditions leading to preferential evaporative fluxes (Or et 
al., 2013; Vanderborght et al., 2014), and natural convection in sloping dry soils (Rose and Guo, 1995).

The difficulty in determining the dominant transport process(es) taking place in the DSL is due to: (a) technical limitations in monitoring the transport of water vapour in the soil; and (b) large variability in soil properties (e.g. pore geometry, water retention curve in dry conditions, diffusion coefficient) and in environmental conditions in field studies, resulting in uncertain parameterization of transport models. Given the difficulty in practice-oriented applications, this often leads to either neglecting the effect of the DSL on the evaporation process, or to its parameterization as a "resistance term" (Vanderborght et al., 2017). The underlying assumption is that the transport processes in the DSL can be simplified when integrated over a whole day. This implicitly assumes that the driving forces of evaporation are the same with or without a DSL. However, the simplification of the DSL as a resistance term determined only by porous medium properties is problematic, since studies by McColl et al. (2017b) and Balugani et al. (2018) reported that such resistance term depends on the dryness of a system, i.e. on air humidity above the soil and on soil moisture in the soil profile.

The transport of water vapour in a DSL is similar to that of $\mathrm{CO}_{2}$ (soil respiration, Brændholt et al., 2017). The transport of $\mathrm{CO}_{2}$ through the soil, as measured in field experiments, is often larger than that predicted using diffusion (Maier et al., 2010). Various studies found correlation between the transport of $\mathrm{CO}_{2}$ and various forcing factors: wind speed (Farrell et al., 1966; Massmann and Farrier, 1992), barometric (atmospheric) pressure changes (Clements and Wilkening, 1974; Elberling et al., 1998), soil temperature profile changes (Roland et al., 2015), and Earth and sea tides-induced groundwater fluctuations (Jiao and Li, 2004; Kuang et al., 2013). To assess the relevance of different gas phase transport processes in such studies, the correlation between the measured soil respiration and the measured environmental forcing factors, e.g. wind speed, air temperature, and atmospheric pressure, is usually studied statistically (Bowling et al., 2015; Roland et al., 2015; Sánchez-Cañete et al., 2013). Different forcing factors were identified in various field conditions setups: correlation with net solar radiation indicating thermal convection in the soil (Austrian Central Alps, Roland et al., 2015; Negev Desert, Israel, Ganot et al., 2014); correlation with daily changes in air temperature and synoptic changes in atmospheric pressure (southeast Spain, Sánchez-Cañete et al., 2013); daily changes in atmospheric pressure and wind speed (southwest Germany, Maier et al., 2010).

In the previous field studies presented here (Chapters 3 and 4 ), the authors analysed the evapotranspiration fluxes in a semi-arid site (Sardon) and found that the evaporation from bare soils was much larger than predicted when assuming vapour diffusion flow only (Chapter 3, Balugani et al., 2017). The authors also observed a DSL of $\sim 50 \mathrm{~cm}$ in the dry season, after grasses withered and became dormant. The simulation of the soil water fluxes in the 
bare soil using the Hydrus1D model overestimated the evaporation rates and was not able to simulate the formation of a DSL. Afterwards, laboratory lysimeter experiments were executed (Chapter 5 ) to determine the relevance of possible transport processes through a DSL with a thickness $Z_{D S L}>50 \mathrm{~cm}$. The laboratory results showed that the main process determining vapour flow was atmospheric pressure fluctuation.

In the study presented in this Chapter, to compare the laboratory with the field evaporation processes, the laboratory lysimeter experimental setup proposed in Chapter 5, was adapted in the semi-arid field conditions of the Sardon site previously studied in Chapters 3 and 4, (Balugani et al., 2017; Balugani et al., 2018). The relevance of environmental factors such as relative humidity, air temperature, or solar radiation, as forcing factors of water vapour transport through a DSL, was assessed using both lysimeter and field monitoring, with a method based on $\mathrm{CO}_{2}$ soil respiration studies. Moreover, a nearby soil profile was also monitored to compare the lysimeter conditions with the actual soil conditions at the site. The objectives of this study were:

- To use the laboratory-tested lysimeter setup in field conditions, in order to measure evaporation rates through a thick DSL;

- To identify the forcing factors of vapour transport in a soil with a DSL in field conditions;

- To test if the model developed in laboratory conditions, where the vapour transport in the DSL is driven by atmospheric pressure changes, also holds in field conditions;

- To compare the model obtained for the relevant forcing factors with the evaporation estimates predicted assuming liquid water flow and water vapour diffusion in the soil profile using the Hydrus1D model.

\subsection{Materials and methods}

\subsubsection{Field lysimeter and in-situ measurements}

The lysimeter experiment (2012-2015) was setup in May 2012, in Trabadillo site at the Sardon Catchment, Spain (section 1.4; Fig. 6.1d; latitude: $41.1172^{\circ}$, longitude: $-6.1471^{\circ}$ ). The lysimeter installed in the field had the same setup as in an earlier laboratory experiment (described in Chapter 5), adapted given local constraints. The field lysimeter consisted of a PVC column of $1 \mathrm{~m}$ height and a diameter of $0.28 \mathrm{~m}$, wrapped in glass wool to insulate the walls from heat loss and connected with a 2 litre Mariotte bottle at the bottom, to keep a fixed water table depth at $80 \mathrm{~cm}$ below the lysimeter top of the column. The Mariotte bottle was positioned on top of the lysimeter base so that the lysimeter weight included the weight of the Mariotte bottle. The lysimeter was filled to the top of the column with the same material as in the laboratory experiment: well-sorted, oven-dried sand of $0.10-0.25 \mathrm{~mm}$ particle size, added $1 \mathrm{~cm}$ at a time and carefully packed to avoid introducing heterogeneity in the 
porous medium. The final porosity of the sand was 0.40 . The lysimeter was open at the top to allow evaporation but closed at the bottom.

a)

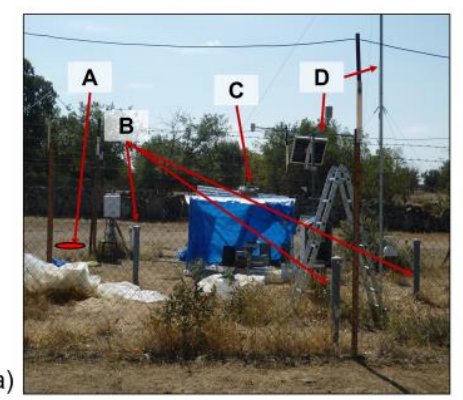

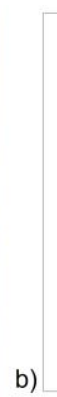

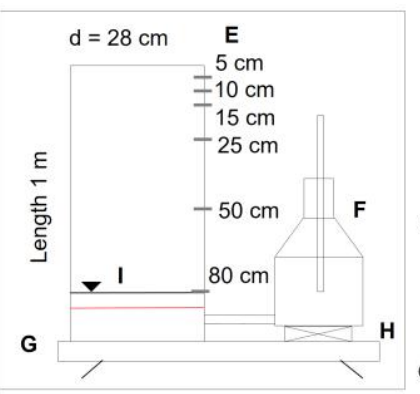

d)

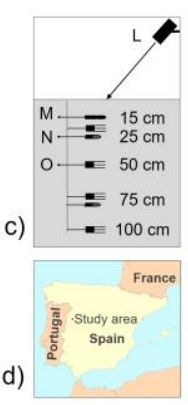

Figure 6.1: Monitoring setup: a) Sardon study site (A - in-situ soil monitoring profile; B - piezometers; C - lysimeter); D - weather station.); b) schema of the lysimeter column ( $\mathrm{E}$ - depth markers of matric potential and temperature sensors; F - Mariotte bottle; G - lysimeter weighing device; $\mathrm{H}$ - Mariotte bottle weighing device; I - water table inside the column) ; c) schema of the in-situ soil monitoring profile ( $L$-infrared radiometer; $M$ - POT matric potential sensor; N - MPS1 matric potential sensors; and O - Hydraprobe soil moisture and temperature sensor); d) location of the Sardon catchment in Spain.

The lysimeter was equipped with six matric potential $\left(\Psi_{L, \text { depth }}\right)$ and temperature $\left(T_{L, \text { depth }}\right)$ sensors (MPS1, Decagon, USA; range -10 to $-500 \mathrm{kPa}$ ) installed as shown in Figure $6.1 \mathrm{~b}$. The weight of the Mariotte bottle, representing the amount of water entering or leaving the lower boundary of the soil column, was measured every 5 minutes using a load cell (SM100, Interface, USA $)$ installed in a device with accuracy $0.01 \mathrm{~g}\left(10^{-4} \mathrm{~mm}\right.$ of water evaporated in the column). The accuracy of the lysimeter $(\sim 300 \mathrm{~kg})$, designed and constructed at the laboratory of the University of Twente (the Netherlands), was $30 \mathrm{~g}$, corresponding to 0.03 litre of water, or $\sim 0.5 \mathrm{~mm}$ of water in the lysimeter column. Using the terms presented in Section 1.1.1, the water evaporating from the saturated zone, in this case measured by the change in weight of the Mariotte bottle, is called groundwater evaporation $\left(E_{g}\right)$; the evaporation resulting in a decrease in weight of the whole column is the total evaporation $(E)$. Hence, the difference $E-E_{g}$ is the evaporation from the soil not affecting the saturated zone, and is referred to as unsaturated zone evaporation $\left(E_{u}\right)$.

The setup required the construction of a levelled concrete basement inside a fence (to protect it from animals); then, the lysimeter was assembled and lubricated to minimize friction. The soil material was oven-dried prior to insertion in the lysimeter column, and gently packed throughout insertion. The connection between the Mariotte bottle and the column bottom was opened on 13 May 2012, and the lysimeter was left to equilibrate with atmospheric 
conditions for five days, allowing the water table to rise and stabilize at $20 \mathrm{~cm}$ above the column bottom. During this 5 days, the sensors were tested, rearranged, and another test was performed from 19 to 22 May 2012. Finally, the experiment was started and left on the field unattended (supervised from the Netherlands); the data was collected on 10 September 2012 and it was found that the 2 litres Mariotte bottle drained after only 19 days, much faster than expected. The lysimeter was, then, left in the field until 2016; the Mariotte bottle remained empty until the first rains in October 2012, when the precipitation events infiltrated in the lysimeter column and recharged the Mariotte bottle. In July 2015 the first $25 \mathrm{~cm}$ of lysimeter soil were removed to determine the presence of a DSL and the experimental length of the $L_{c}(10 \mathrm{~cm}$; see Section 6.3.1). The matric potential sensors (MPS1) in the in-situ soil profile and in the lysimeter did not work properly between 2012 to June 2013.

The soil in the study area is spatially homogeneous, with a texture between sandy-loam and loamy-sand, similar on average to the sand used to fill the lysimeter, but less well-sorted (Frances et al., 2014), and has a depth $\sim 1 \mathrm{~m}$ b.g.s. The in-situ soil monitoring profile is equipped with four soil moisture and temperature sensors (Hydraprobe, Stevens, USA, at 25, 50, 75 and $100 \mathrm{~cm}$ b.g.s.), two matric potential sensors (Decagon MPS1 sensors at 25 and $75 \mathrm{~cm}$ b.g.s.) and another, more accurate matric potential sensor (POT, Bakker et al., 2007; range 0 to $-1.5 \mathrm{MPa}$, at $15 \mathrm{~cm}$ b.g.s.), with a sampling time of 30 minutes. The following depth-dependent variables were measured, soil moisture $\left(\theta_{\text {depth }}\right)$, soil temperature $\left(T_{s, \text { depth }}\right)$ and matric potential $\left(\Psi_{s, \text { depth }}\right)$. Besides, a temperature radiometer measured the temperature of the soil surface every 5 minutes $\left(T_{s, 0}\right)$. The weather station provided also hourly data of relative humidity $(R H)$, air temperature $\left(T_{a}\right)$, net short wave radiation $\left(S_{n}\right)$, wind speed $(u)$, atmospheric pressure $\left(p_{a t m}\right)$, rainfall $(P)$, and water table depth $\left(Z_{W T}\right)$ from a nearby piezometer.

\subsubsection{Theoretical framework}

The two physical mechanisms of water vapour transport in a porous medium through a DSL (evaporation) are as follow: dispersion (disp., concentration driven diffusion and mechanical dispersion) and advection (adv., pressure driven). The forcing factors driving vapour fluxes considered in this study are: (a) isothermal liquid water flow (adv.); (b) diffusion (disp.); (c) soil temperature profile gradients (adv.); (d) wind speed (adv., also enhances disp.); (e) daily cycles of condensation and evaporation through the DSL (adv. and disp.); and (f) atmospheric pressure fluctuation (adv. and disp.). Since the mechanism of enhanced vapour transport is based on the condensation and evaporation on two different sides of liquid water islands in the porous medium (Ho and Webb, 1996, 2006; Webb and Ho, 1998), and a DSL is nearly air-dry, the liquid water islands are likely rare in the DSL; therefore, the enhanced vapour transport process was not analysed in the present study. 


\subsubsection{Isothermal liquid water flow}

There are two reasons to consider isothermal liquid water flow as a forcing factor in the presence of a DSL. First, studies by Fayer and Simmons (1995), Webb (2000), Khlosi et al. (2008), and Lu et al. (2008) analysed the possibility that the actual evaporation flow could be miscalculated, because of the use of retention curves not suitable for air-dry soil conditions (as is the case of the Brooks and Corey and Van Genuchten water retention curves, as per Vanderborght et al., 2017). By using a retention curve adapted to allow very high matric potentials, they were able to model isothermal liquid water flow in soils below the residual soil moisture level, while other retention curves (Khlosi et al., 2008, Lu et al., 2008), usually predict very low hydraulic conductivities. Second, Assouline et al. (2013) and Brutsaert (2014a) were able to model daily evaporation estimates in the presence of a thin $(<5 \mathrm{~cm})$ DSL by using isothermal liquid water flow only. Because of such thin DSL, they were able to neglect its presence, adding the DSL as a resistance term for liquid water flow. In the case of isothermal liquid water flow being the main process limiting evaporation rates, the evaporation rates from the column $(E)$ should be correlated with the potential evaporative conditions $\left(E_{p}\right)$ at the soil surface; hence the hypothesis $E=f\left(E_{p}\right)$ was tested, where $E_{p}$ was calculated using Penman-Monteith (Monteith, 1980).

\subsubsection{Diffusion}

Various laboratory experiments determined that diffusion is the main process describing transport of water vapour through a DSL (Or et al., 2013; Shahraeeni and Or, 2012; Shokri et al., 2009; Shokri and Or, 2011). Evaporation by diffusion flow based on Fick's law is calculated as:

$E=D_{\text {soil }}^{v} \frac{\Delta_{z} C_{v}}{Z_{D S L}}$

where $D_{\text {soil }}^{v}$ is the diffusion coefficient for water vapour in the soil defined as in Millington and Quirk (1960), $\Delta_{z} C_{v}$ is the difference between water vapour concentration $\left(C_{v}\right)$ at the vaporization plane and at the soil surface $\left(\Delta_{z}\right.$ indicates the vertical differential) and $C_{v}$ is the product of soil temperature and relative humidity (Assouline et al., 2013). If we assume that water vapour is at saturation at the vaporization plane, then the evaporation rate is determined by changes in time in vapour pressure above the soil surface $\left(p_{w}\right)$, so $E$ should be correlated with $p_{w}$; hence the hypothesis $E=f\left(p_{w}\right)$ was tested, where $p_{w}$ is calculated using both $R H$ and $T_{a}$ measurements (at $2 \mathrm{~m}$ height) as:

$p_{w}=p_{s} R H$

where the saturated vapour pressure $p_{s}$ was calculated using Buck equation (Buck, 1981) as:

$p_{s}=0.61121 \exp \left(\left(18.678-\frac{T_{a}}{234.5}\right)\left(\frac{T_{a}}{257.14+T_{a}}\right)\right)$ 


\subsubsection{Soil temperature profile}

Thermal fluxes of water vapour have an effect on the evaporation process in field conditions, especially in the DSL (Du et al., 2018; Saito et al., 2006; Zeng et al., 2011a; Zeng et al., 2009a). The water thermal fluxes usually move through the soil from high temperature layers towards low temperature layers, meaning that the fluxes are downward during most of the day, with possible upward fluxes only in the night. Since the thermal fluxes are driven by differences in temperature in the DSL profile, if they are the main process determining the evaporation rate, than changes in $E$ should be correlated with the changes in the soil temperature profile. In semi-arid areas the temperature of the bare soil surface can reach very large values at midday and very low values during the night, while air temperature may not change that much. This can lead to abrupt changes in air pressure close to the soil surface, which would not be observed by the weather station sensors, placed at $2 \mathrm{~m}$ height. To account for this process, the difference in temperature between $T_{s, 0}$ and $T_{a}$ was included in this analysis as well. Therefore, two hypotheses were tested here: (1) one based only on soil temperatures is $\Delta_{t} E=f\left(\Delta_{t}\left(T_{s, v a p}-T_{s, 0}\right)\right)$, where $\Delta_{t}$ indicates the time differential of a variable, where $T_{s, v a p}$ is the soil temperature at vaporization plane and $T_{s, 0}$ is the soil temperature at the surface; and (2) another which includes air temperature variations as well, as $\Delta_{t} E=f\left(\Delta_{t}\left(T_{s, v a p}-\right.\right.$ $\left.T_{s, 0}-T_{a}\right)$ ).

\subsubsection{Wind speed}

Wind speed $(u)$, together with air temperature and relative humidity, can influence evaporation by decreasing the height of the viscous sub-layer with the formation of small eddies (Haghighi and Or, 2013, Figure 1.2) and by inducing advection in the first centimetres of soil (Haghighi and Or, 2013; Haghighi and Kirchner, 2017; Mosthaf et al., 2014). Davarzani et al. (2014) conducted soil column evaporation experiments in a wind tunnel that showed that $u$ influenced non-linearly the evaporation, which depended also on $T_{a}, R H$ and the porosity of the porous medium. The impact of $u$ upon the evaporation through a DSL (referred as "second stage evaporation" S2 in Davarzani et al., 2014), was found by them not to be significant, but the soil in their experiments was initially saturated, in contrast to this study. Brændholt et al. (2017), instead, showed that $u$ had some effects on the $\mathrm{CO}_{2}$ soil respiration flux. Therefore, the correlation between $E$ and $u$ was analysed in this study, and the hypothesis $E=f(u)$ was tested.

\subsubsection{Daily cycles of condensation and evaporation of soil moisture}

The detection of the effects of daily cycles of condensation and evaporation of soil moisture in the DSL on evaporation rates, requires accurate measurements of the matric potential profile in the lysimeter. The measured matric potential gradients should, then, correlate with the evaporation rates. Assouline et al. 
(2013), who observed daily cycles of condensation and evaporation in the field, assumed an accumulation process for water vapour (with some condensation) in the soil near the surface during the night, and the evaporation of the accumulated water during the morning, with the mass transfer calculated as in Brutsaert (2005), i.e. $E=C_{e} \rho_{a} \overline{\bar{u}}_{i}\left(C_{\text {sat }}-C_{\text {air }}\right)$, where $C_{e}$ is water vapour transport coefficient, $\rho_{a}$ is air density, $\overline{\bar{u}}_{i}$ is the low pass filtered wind speed (see Section 6.2.4), $C_{s a t}$ and $C_{\text {air }}$ are water vapour concentrations at the saturation and in the air, respectively. Therefore, evaporation rates should be correlated with the same drivers as in the diffusion equation, but also with the daily average wind speed $(\bar{u})$; hence the hypothesis $E=f\left(p_{w}, \bar{u}\right)$ was tested.

\subsubsection{Barometric effects due to $p_{\text {atm }}$ fluctuations}

Changes in the barometric pressure can influence the evaporation process by direct pumping out the gas phase (with water vapour) from a soil (direct barometric pumping), thus increasing air circulation in the first centimetres of the top soil and causing advection and mechanical dispersion in the DSL (Auer et al., 1996, Chapter 5). These processes, all driven by changes in atmospheric pressure, will be referred collectively as "barometric effects". The formulation of the barometric effects given in Auer et al. (1996), after simplification as in Chapter 5, is:

$E \cong\left|\Delta p_{a t m} k_{1}\right|+k_{2}$

where $k_{1}$, and $k_{2}$ are empirically determined coefficients and the empirical model formulated in Section 5.3.3, Equation 5.8 is:

$E=f\left(\Delta p_{a t m}\right)=\left\{\begin{array}{l}\left|k_{1}^{\text {inverse }}\left(\Delta p_{\text {atm }}\right)\right|+k_{2}, \Delta p_{\text {atm }}<0 \\ \left|k_{1}^{\text {direct }}\left(\Delta p_{\text {atm }}\right)\right|+k_{2}, \Delta p_{\text {atm }} \geq 0\end{array}\right.$

where $k_{1}^{\text {inverse }}$ and $k_{1}^{\text {direct }}$ are empirical coefficients, while inverse and direct refer to the type of correlation between evaporation rate and atmospheric pressure fluctuations. Therefore, evaporation caused by barometric effects should correlate with the time differential of atmospheric pressure, hence the hypothesis $E=f\left(\left|\Delta_{t} p_{a t m}\right|\right)$ was tested.

\subsubsection{Data analysis}

Data analysis focussed on determining the correlation between the potential forcing factors driving vapour fluxes listed in Section 6.2.3 and evaporation rates $\left(E_{g}\right.$ and $E$ ) obtained from the lysimeter experiment. In the context of a broader analysis, the correlation with all the environmental variables directly measured by the weather station was also considered. The present study does not have corresponding eddy covariance measurement of evaporation rates; such measurement was available in the Sardon study area only in years 20092010 (Chapters 3 and 4).

Weather conditions show variability at different time scales, typically seasonal, synoptic ( $\sim 7$ days) and diurnal time scales. Field observations show 
that the DSL in the Sardon study area forms in the late spring and lasts to late summer, so the correlations are studied only for the period May to September. All measurements were normalized and standardized as:

$X_{N}=\frac{(X-\bar{X})}{\sigma}$

where $X_{N}$ is the standardized variable, $X$ is the variable measurement, $\bar{X}$ is the average of the variable over the period considered, $\sigma$ is the standard deviation of the variable in the same period. The normalization procedure is necessary to compare variables otherwise affected by extreme yearly variations in both means and variances.

Then, in order to study the correlations only on certain time scales, high and low pass filters were applied. A high pass filter extracts from time series only the variations occurring below a certain time scale, so for example a daily high pass filter, filters out the overall trend and all variations with periods longer than a day. A low pass filter does the opposite: it filters out all variations shorter than the considered time scale, so for example a daily low pass filter, filters out all variations shorter than a day, while keeping the variations longer than a day and the overall trend. This allows the study of the correlation of evaporation rates with forcing factors at defined time scales, increasing the significance of the correlation test. The high pass filter $\left(X_{i}\right)$ used, was that proposed by Wilks (2006) for meteorological variables:

$X_{i}=\frac{\left(X-\overline{X_{l}}\right)}{\sigma_{i}}$

where $X_{i}$ is the high pass filtered standardized value for a moving time window of width $i, \bar{X}_{l}$ is the running mean, and $\sigma_{i}$ is the standard deviation in the same window. The time window determines the time scale filtered; the values of $i$ considered in this study were $i=0.5 \mathrm{~d}$ for daily and $i=3 \mathrm{~d}$ for synoptic time scales, following Sánchez-Cañete et al. (2013). The low pass filter $\left(\overline{\bar{X}}_{i}\right)$ is defined as the opposite of the high pass filter, so as the running mean itself; to be consistent with Equation 6.7, it was formulated as:

$\overline{\bar{X}}_{i}=\frac{\left(\overline{X_{l}}-\bar{X}\right)}{\sigma}$

To fit a linear model to the $E$ rates, multivariate regression analyses were conducted on all possible combinations of explanatory variables. The explanatory variables were also ranked depending on their Pearson linear correlation with $E$. The Spearman correlation coefficient was considered as well, to account for possible monotonic, but not linear, correlations. The correlations and the regressions between the forcing factors and evaporation rates were calculated both for: the standardized forcing factors, the filtered and standardized forcing factors, and the time differentials of forcing factors, since the driver of the gas transport process could be the time derivative of the forcing factor instead of the magnitude of the forcing factor itself. The assumption of linear correlation is used in order to avoid additional uncertainty related to non-linear regression fitting. This assumption seems acceptable since the forcing factors for the transport processes are already linearized. 
Finally, the multiple linear models obtained were evaluated using the NashSutcliffe efficiency coefficient (NSE), defined as:

$N S E=1-\frac{\sum_{t=1}^{n}\left(X_{0}^{t}-X_{m}^{t}\right)^{2}}{\sum_{t=1}^{n}\left(X_{0}^{t}-\overline{X_{0}}\right)^{2}}$

where $X_{0}^{t}$ and $X_{m}^{t}$ are the observed and modelled values at time $t$, respectively; $\overline{X_{0}}$ is the mean of the observed values; and $n$ is the number of samples. The $N S E$ can go from $-\infty$ to 1 , with 1 indicating a perfect match, 0 that the model predictions are not better than the mean, and $N S E<0$ that the observed mean is a better predictor than the model (Du et al., 2018). Another way to evaluate the quality of a statistical model is to adjust the $R^{2}$ by the number of explanatory variables used in the predictive model:

$\bar{R}^{2}=1-\left(1-R^{2}\right) \frac{n-1}{n-p-1}$

where $p$ is the number of explanatory variables.

\subsubsection{Simulation of the lysimeter and in-situ soil evaporation with Hydrus1D and SOURCE package}

The applied Hydrus1D model (version 4.xx) accounted for coupled flow of heat, isothermal and thermal liquid water flow, and water vapour flow by diffusion (Saito et al., 2006). The model was used to estimate the evaporation rates from both the lysimeter experiment and the in-situ soil profile. The model input consisted of: (i) the environmental variables measured in the weather station as upper boundary conditions; (ii) the soil parameters determined by laboratory experiment for the lysimeter soil (Chapter 5) and the in-situ soil (Chapter 3); (iii) the in-situ and lysimeter soil matric potentials and soil temperatures measured, for the initial conditions and for the calibration purposes. The lower boundary conditions were set as: no flux boundary for the lysimeter; prescribed groundwater table depth for the in-situ soil profile, measured hourly in a piezometer close to the in-situ soil profile. The evaporation flux simulated with Hydrus1D was sourced into its groundwater and unsaturated zone components ( $E_{g}$ and $E_{u}$, respectively) using the SOURCE package (Chapter 2).

We, then, compared the evaporation rates estimated by Hydrus1D-SOURCE for the lysimeter with the evaporation rates observed experimentally. Moreover, the resulting soil matric potential simulated by Hydrus1D was compared with lysimeter and in-situ soil measurements, to test if Hydrus1D was able to simulate the formation of a DSL. Finally, the evaporation estimates obtained with the multivariate regression model (explained in section 6.2.4) was tested against the estimates from Hydrus1D for both the lysimeter and the in-situ soil in 2012 and in 2015. 


\subsection{Results}

The experiment was carried out during 4-years, between 2012-2015, focussing on dry hydrological years October 2011-September 2012 and October 2014September 2015 with only 312 and $322 \mathrm{~mm}$ of rain respectively, while the hydrological years October 2012-September 2013 and October 2013September 2014 were wet, with yearly rainfalls $631,682 \mathrm{~mm}$ respectively (Figure 1.4 in Chapter 1 ).

\subsubsection{Field measurements}

Figure 6.2 shows the measurements recorded by the weather station, the soil profile and the lysimeter in the dry season 2012 as of 23 May, considered as the start of the experiment, after stabilization and some testing of the material, until the 2 litres Mariotte bottle dried up on 11 June.

2012 was a very dry year $(337 \mathrm{~mm})$, with no rain events during the period considered, and large diurnal fluctuation of $T_{a}$ and $R H\left(22{ }^{\circ} \mathrm{C}\right.$ and $75 \%$ changes, respectively) implying also large diurnal fluctuation of $E_{p}$ (Figure 1.4). The amplitude of diurnal soil temperature variations at the ground surface were even larger $\left(>30^{\circ} \mathrm{C}\right)$, but decreased rapidly with depth from $\sim 5^{\circ} \mathrm{C}$ at $25 \mathrm{~cm}$ to $<1{ }^{\circ} \mathrm{C}$ at $50 \mathrm{~cm}$ depth (Figure $6.2 \mathrm{~d}$ ). The lysimeter $T_{L, \text { depth }}$ showed similar behaviour as the in-situ $T_{s, \text { depth }}$. The in-situ soil was drying up already at the beginning of the experiment, and after 3 weeks dried down to $50 \mathrm{~cm}$ (Figure 6.2d). The POT sensor in-situ reached its minimum matric potential value (1.5 MPa, wilting point) already in 26 May 2012. In contrast, the lysimeter soil was dry at the start of the experiment $\left(Z_{D S L}=70 \mathrm{~cm}\right)$ but, despite that, since the beginning of the experiment, the Mariotte bottle continuously kept decreasing its weight due to $E_{g}$ and emptied already on 11 June, much earlier than expected. The average groundwater evaporation rate measured by the Mariotte bottle weighing device during the period 23 May to 11 June 2012 was $1.25 \mathrm{~mm} \mathrm{~d}^{-1}$. 


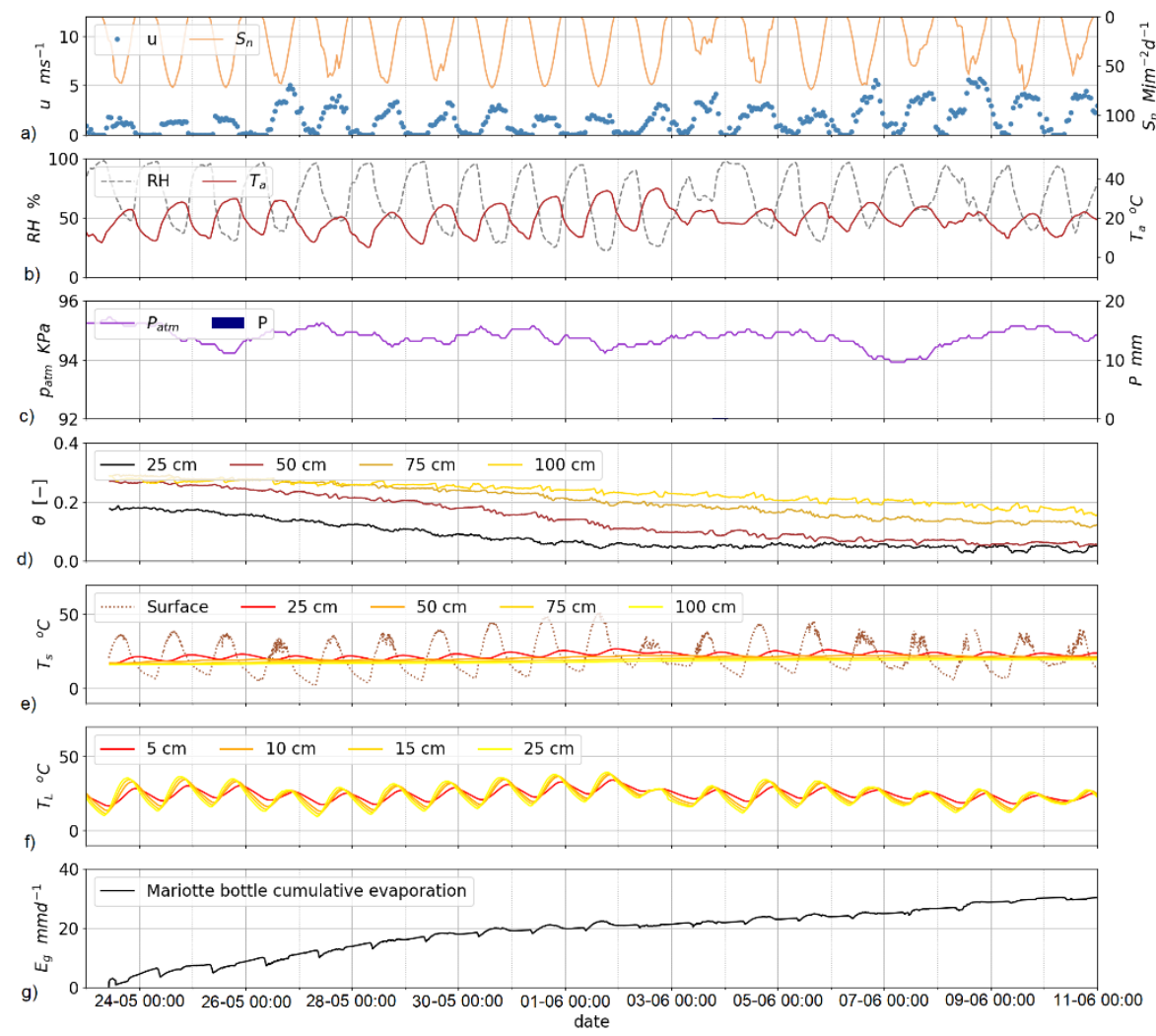

Figure 6.2: The dataset collected during dry season 2012 (23 May to 11 June): a) wind speed $(u)$ and net short wave radiation $\left(S_{n}\right)$; b) relative humidity $(R H)$ and air temperature $\left.\left(T_{a}\right) ; c\right)$ atmospheric pressure $\left(p_{a t m}\right)$ and precipitation $(P)$; d) in-situ soil moisture $\left(\theta_{\text {depth }}\right) ;$ e) in-situ soil temperature $\left(T_{s}\right.$, depth $) ;$ f) lysimeter soil temperature $\left.\left(T_{L, d e p t h}\right) ; \mathrm{g}\right)$ cumulative lysimeter groundwater evaporation $\left(E_{g}\right)$ measured by the Mariotte bottle.

The Mariotte bottle was filled with water by rain in November 2012 and remained full of water till the end of the experiment in 2015; therefore, due to the high water table in the lysimeter, it did not provide any meaningful data on evaporation. In contrast, the in-situ soil profile dried up every summer, with the $15 \mathrm{~cm}$ deep POT showing wilting point values in all years (2013, 2014, $2015)$, and the $25 \mathrm{~cm}$ deep MPS1 sensor in the in-situ soil profile reaching their minimum value $(-500 \mathrm{kPa})$ at the beginning of June in years 2014 and 2015 . In the lysimeter, some drying was recorded only by the $5 \mathrm{~cm}$ deep matric potential sensor during summer 2013 and 2014, showing that the soil reached field capacity. During the spring 2015, the matric potential sensors in the 
lysimeter, at depths 5,10 and $15 \mathrm{~cm}$, showed continuous drying down to maximum measurable dryness. In 2015 precipitation events stopped at the beginning of May, and the in-situ profile and the lysimeter column soil moisture contents started to decrease.

In July 2015, during lysimeter maintenance, the first $25 \mathrm{~cm}$ of the lysimeter soil were removed for cleaning, which also allowed the observation of a $12 \mathrm{~cm}$ thick DSL. Afterwards, the soil material was placed back in the lysimeter, exactly as positioned before and the experiment was continued. In July 2015 the lysimeter was saturated up to $78 \mathrm{~cm}$ above the lysimeter bottom, i.e. 22 $\mathrm{cm}$ depth, with the Mariotte bottle completely filled by water due to flooding of the column in the previous years 2013 and 2014. The amount of water in the lysimeter was not affected by the maintenance, hence the lysimeter was still saturated up to $78 \mathrm{~cm}$ when the experiment was started again.

Figure 6.3 shows the measurements taken in the dry season 2015 for 19 days, to be comparable with the measurements shown in Figure 6.2; both periods were representative of typical dry condition with large vapour pressure deficit (large $E_{p}$ ). The lysimeter 2015 measurements showed weight changes similar to those recorded in the summer 2012, but with much thinner DSL (12 $\mathrm{cm}$ in 2015 and $70 \mathrm{~cm}$ in 2012). The average evaporation rate measured by the lysimeter between 9 and 28 August 2015 was $1.05 \mathrm{~mm} \mathrm{~d}^{-1}$. Unfortunately, the lysimeter measurement sensitivity was not sufficient to detect daily fluctuations in weight, only the main evaporation trend was detected. Due to the ideal conditions, the measurements taken in the periods shown in Figures 6.2 and 6.3 were acquired and used to calibrate (2012) and validate (2015) the statistical models presented in the Section 6.3.3.

Since the Mariotte bottle remained full of water after summer 2012, the only measurements of evaporation $(E)$ available afterwards, were those from the lysimeter weight. The comparison between 2012 Mariotte bottle weight and 2015 lysimeter weight measurements, however, was still possible, since both weight measurements were done during dry periods, when DSLs were developed as in Figure 1.2a, so in both cases the measured evaporation represented groundwater evaporation $\left(E \approx E_{g}\right)$. The small water input from rare rain events did not infiltrate more than few centimetres (no increase in the matric potential at $5 \mathrm{~cm}$ depth was observed) and evaporated quickly, with negligible effects on the lysimeter experiment. Hence, the $E_{g}$ for 2015 was calculated as $E$ minus $P$. 


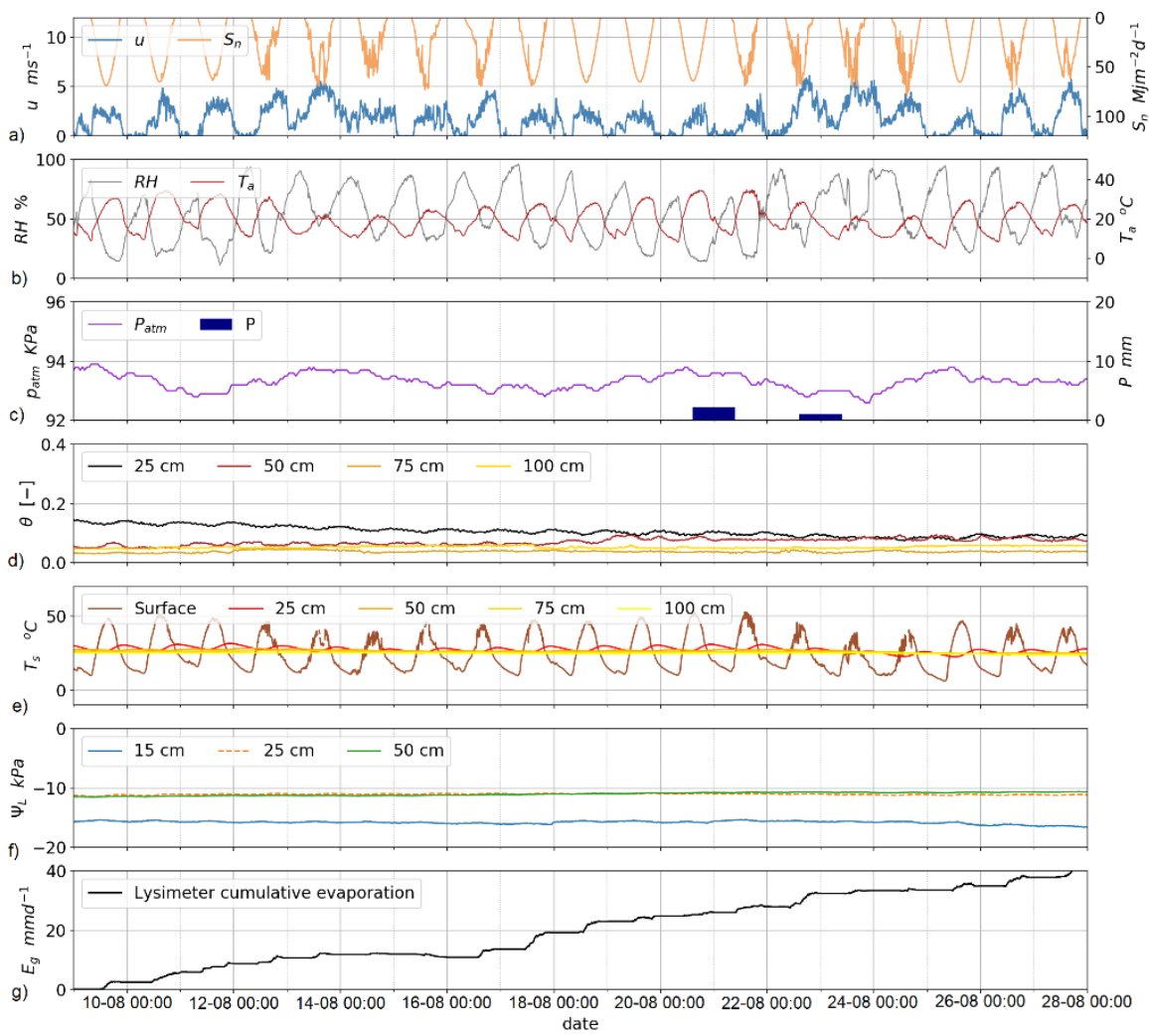

Figure 6.3: Dataset collected during dry season 2015 (9 to 28 August 2015): a) wind speed $(u)$ and net short wave radiation $\left(S_{n}\right) ;$ b) relative humidity $(R H)$ and air temperature $\left.\left(T_{a}\right) ; c\right)$ atmospheric pressure $\left(p_{a t m}\right)$ and precipitation $(P)$; d) in-situ soil moisture $(\theta)$; e) in-situ soil temperature $\left(T_{s}\right)$; f) lysimeter soil matric potential ( $\Psi_{L}$; sensors at depths 10 and $5 \mathrm{~cm}$ not shown because too negative); g) lysimeter cumulative evaporation measurement.

\subsubsection{Correlation between environmental variables}

The standardized values of $T_{a}, T_{s, 0}, S_{n}, R H$, and $u$ followed a daily cycle, as shown in Figure 6.4 (only 10 days shown for clarity). The $p_{a t m}$ was the only environmental variable that did not follow this daily cycle, but showed what were (probably) weather system related fluctuations with a period of 3-4 days. All other drivers were strongly correlated with each other (Spearman correlation $>0.7$ ), except of $p_{a t m} . T_{L, 5}$ and $T_{L, 10}$ showed substantial correlation with $R H$ and $T_{a}$ (Spearman coefficient $>0.7$ ), which decreased with the depth (b.g.s.) of the sensors. The application of the high pass filter resulted in an 
increase in the overall correlations between all the variables when the daily filter was applied, while the application of the synoptic filter had some effect only on $p_{a t m}$ and a negligible effect on all other variables.

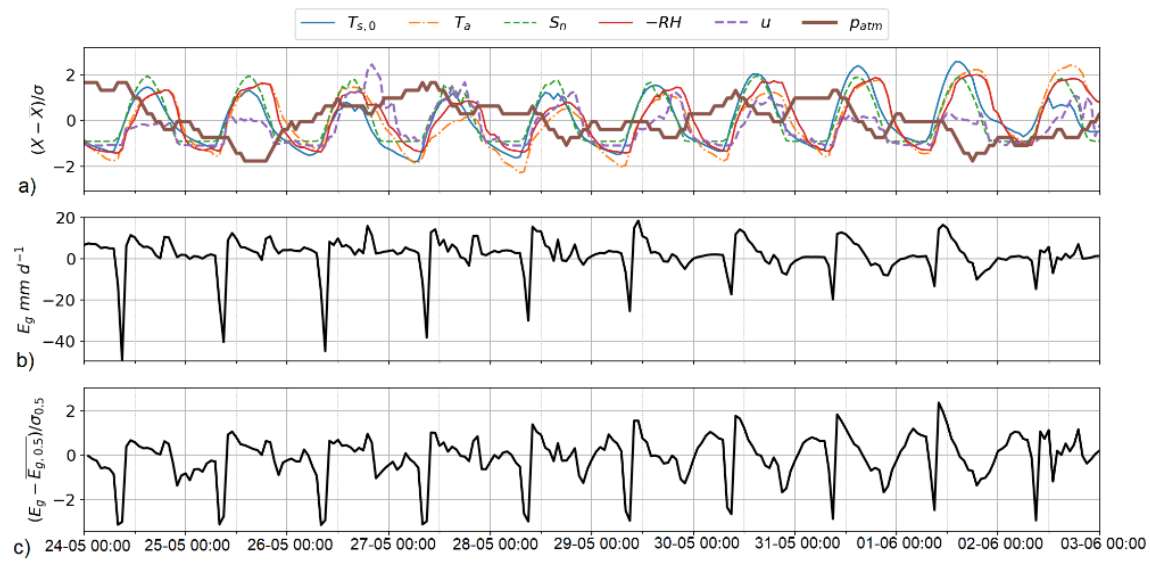

Figure 6.4: Comparison of temporal variations of environmental variables and evaporation rates during 10 days (24 May to 3 June 2012): a) potential drivers of water vapour fluxes acquired at hourly frequency, after normalization ( $X$ is the variable measurement, $\bar{X}$ the average of the variable over the period considered, $\sigma$ is the standard deviation of the variable in the same period); b) evaporation rates acquired at 5 min frequency by the Mariotte bottle $\left(E_{g}\right) ; c$ ) the evaporation rates measured by the Mariotte bottle, standardized and filtered (high pass) for daily fluctuations ( $\overline{E_{g, 0.5}}$ average of groundwater evaporation and its standard deviation, $\sigma_{0.5}$, in the time window $0.5 \mathrm{~d}$ ). Notice that $R H$ is displayed with reversed values, i.e. $-R H$. Note also that, in the Sardon study area, the local summer time (as presented) is $\sim 2.5 \mathrm{~h}$ ahead of the solar time.

\subsubsection{Correlation between forcing factors of transport processes and $E_{g}$}

All the correlation tests between forcing factors and $E_{g}$ rates were carried out for the 19-day period (23 May to 11 June 2012), also used for presenting variables in Figure 6.2.

\subsubsection{Isothermal liquid water flow}

The average $E_{p}$ was $\sim 7.5 \mathrm{~mm} \mathrm{~d}^{-1}$, with standard deviation of $\sim 1 \mathrm{~mm} \mathrm{~d}^{-1}$. As expected for the period May-June, $E_{p}$ increased towards summer peak. The correlation between $E_{p}, \Delta_{t} E_{p}$ and normalized $E_{g}$ showed low Pearson correlation coefficients $(\sim 0.2)$ and a Spearman coefficient of 0.38 between $E_{p}$ and 
normalized $E_{g}$. The best fit was found between hourly $E_{g}$ and $\Delta_{t} E_{p}$, with $\bar{R}^{2} 0.12$ and NSE 0.12.

\subsubsection{Diffusion}

There was moderate correlation (Pearson coefficient 0.4 ) between $p_{w, 0.5}$ and $E_{0.5}$. The resulting model had very low $\bar{R}^{2}(0.16)$, negative $N S E(-1.9)$ and could not properly describe the behaviour of the evaporation rates. The evaporation rate estimated using diffusion alone (calculated using Equation 6.1), with a DSL $70 \mathrm{~cm}$ thick, was $\sim 0.05 \mathrm{~mm} \mathrm{~d}^{-1}$, i.e. much smaller than the observed $E_{g}$.

\subsubsection{Soil temperature profile}

Since the change in temperature between $T_{S, 0}$ and $T_{L, 5}$ seemed relevant, it was included in the analysis, together with the difference between $T_{S, 0}$ and $T_{L, 25}$. No correlation was found between temperature gradients in the lysimeter and normalized $E_{g}$, nor with $E_{0.5}$. The resulting multiple linear regression model could not properly describe the behaviour of the normalized $E_{g}$ time series; when compared with the actual measurements, the thermal fluxes model NSE was 0.16 . Neither $E_{n}$ nor $E_{0.5}$ showed any correlation with the difference between $T_{s, 0}$ and $T_{a}$. Moreover, the inclusion of $T_{s, 0}-T_{a}$ in the multiple linear regression model as a predictor did not change the quality of the fit, and the associated $\mathrm{p}$-value was $>0.5$.

\subsubsection{Wind speed}

The normalized $E_{g}$ did not show any significant correlation neither with normalized $u$ nor with its time differential $\left(\Delta_{t} u\right)$. When focussing on the daily patterns, the $E_{0.5}$ did not show any significant correlations neither with $u_{0.5}$ nor with $\Delta_{t} u_{0.5}$ for both correlation coefficients. Therefore, no effect of wind speed on evaporation measured by the Mariotte bottle could be identified.

\subsubsection{Daily cycles of condensation and evaporation of soil moisture}

To analyse the possibility that daily cycles of a combination of environmental variables could drive the transport of water vapour in the lysimeter without a priori suggesting a specific process, multiple linear regression models were fitted with a selection of drivers to predict evaporation rates. The selected drivers were: $\bar{u}, R H, T_{L, 25}$, with the latter two substituted by $p_{w}$ as in Equations 6.2 and 6.3 , at a depth of $25 \mathrm{~cm}$. The daily cycle models were fitted on both: (a) $X_{N}$ and $X_{0.5}$; and (b) $\Delta_{t} X_{N}$ and $\Delta_{t} X_{0.5}$. The best fit $\left(\bar{R}^{2} 0.43\right)$ was found with variables $S_{n}, T_{L, 15}, T_{L, 25}$ but the resulting model could not explain the presence of the low $E_{g}$ values at 9:00. The NSE of daily cycles model was 0.08 . 


\subsubsection{Barometric effects due to $p_{\text {atm }}$ fluctuations}

The evaporation rates (both normalized $E_{g}$ and $E_{0.5}$ ) did not show any significant correlation neither with $p_{a t m, N}$, nor with $p_{a t m, 0.5}$. The evaporation rates predicted by Equation 6.5 were $\sim 0.2 \mathrm{~mm} \mathrm{~d}^{-1}$, so much smaller than the observed mean of $E_{g} \sim 1.25 \mathrm{~mm} \mathrm{~d}^{-1}$.

\subsubsection{Correlation between evaporation rates and explanatory variables}

The daily weight loss from the Mariotte bottle used to calculate $E_{g}$ in $\mathrm{mm} \mathrm{d}^{-1}$ is shown in Figure 6.4b while the standardized and filtered for daily fluctuation $E_{g, 0.5}$ in Figure 6.4c. The cumulative $E_{g}$ during the experiment lasting from 23 May to 11 June 2012 was $32 \mathrm{~mm}$ of water. In Figure 6.4 the evaporation rate shows a distinct daily pattern, with minimum evaporation rates recurring regularly every $24 \mathrm{~h}$. The Pearson coefficient was larger than 0.5 for $\Delta_{t} S_{n, 0.5}$ and $\Delta_{t} T_{s, 0,0.5}$ correlations with $E_{g, 0.5}$, while the Spearman coefficient was larger than 0.4 for $\Delta_{t} T_{L, 5,0.5}, \Delta_{t} T_{L, 10,0.5}$ and $\Delta_{t} T_{L, 15,0.5}$ correlations with $E_{g, 0.5}$. The normalization analysis showed no significant correlation improvements between any explanatory variable and evaporation rates as compared to nonnormalized values. 


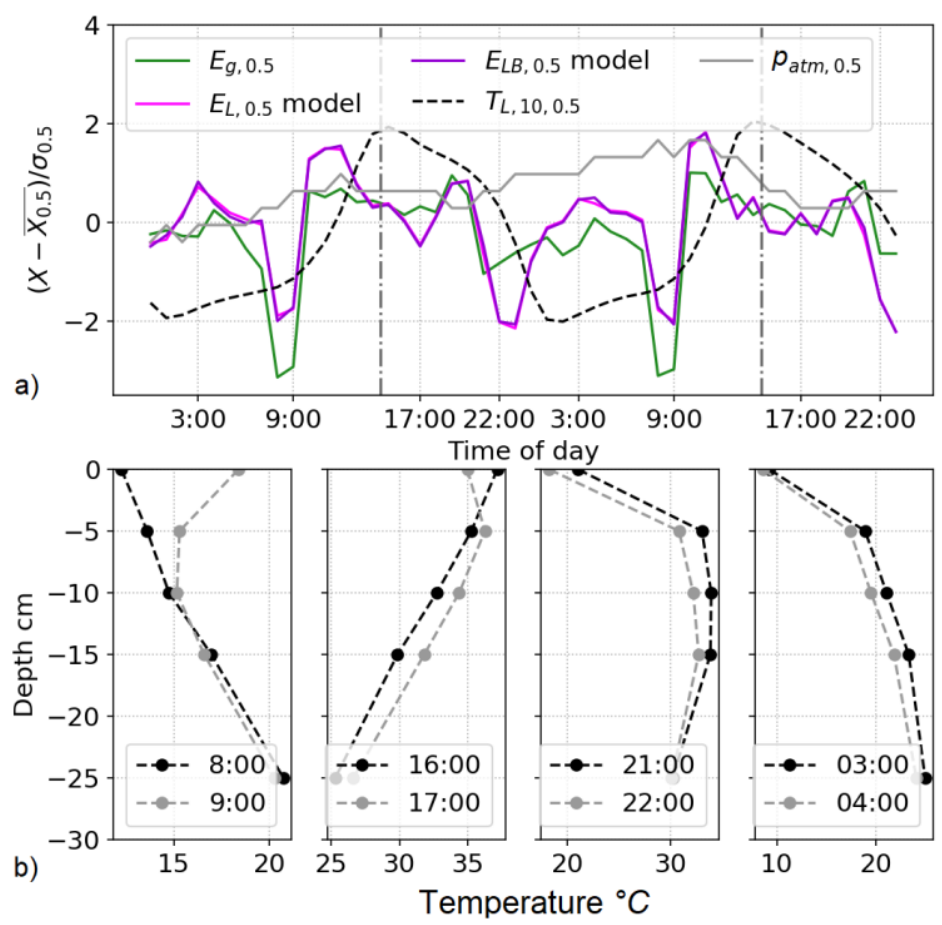

Figure 6.5: Daily variations of $E_{g}$ rates (measured and estimated) and temperatures inside the lysimeter during the example days 24 May and 25 May 2012: a) standardized and filtered (daily high pass) measured atmospheric pressure $\left(p_{a t m}\right)$, soil temperature at $10 \mathrm{~cm}\left(T_{L, 10,0.5}\right)$, and lysimeter $E_{g, 0.5}$, together with lysimeter evaporation estimated by modelling ( $E_{L}$ - estimated $E_{g}$ using soil temperature variation model; $E_{L B^{-}}$estimated $E_{g}$ using soil temperature variation combined with barometric effect model); solar noon is indicated with grey dotted lines; b) temperatures measured in the lysimeter profile at different hours of the same days. Note that in the Sardon study area, the local time is $\sim 2.5 \mathrm{~h}$ ahead of the solar time.

The typical lysimeter patterns of daily groundwater evaporation and soil temperature is presented in Figure 6.5. The $E_{g, 0.5}$ shows very low values around 9:00 a.m. local time (sunrise, Figure 6.5a). This is the same time at which $T_{L}$ profile (Figure $6.5 \mathrm{~b}$ ) changed shape from consistently increasing temperature with depth $(8 \mathrm{am})$ to skewed at 9 am within the upper $10 \mathrm{~cm}$ with substantial temperature increment at the surface between 8 and 9 am. Afterwards, between 9:00 and 19:00, the $E_{g, 0.5}$ remained approximately constant, showing 
a local minimum between 16:00 and 18:00, which corresponded to the moment when the lysimeter temperature profile changed shape again, but with smaller gradient than in the morning. The $E_{g, 0.5}$ reached another minimum at 22:00, which corresponded to the largest difference in temperature between $T_{s, 0}$ and $T_{L, 5}$. Between 22:00 and 9:00, the $E_{g, 0.5}$ rose gently (Figure 6.5a), and the lysimeter temperature profile remained stable with increasing temperature toward the deeper profile (Figure 6.5b).

The best multivariate regression model of both high and low pass filtered (daily) $E_{g}$ was defined with $S_{n}$ and $T_{s, 0}$ and with the time differentials of $T_{L}$ at all depths as predictors. As such the resulting general function was:

$E_{L}=A_{1} S_{n}+A_{2} \Delta_{t} T_{S, 0}+A_{3} \Delta_{t} T_{L, 5}+A_{4} \Delta_{t} T_{L, 10}+A_{5} \Delta_{t} T_{L, 15}+A_{6} \Delta_{t} T_{L, 25}+A_{7}$

where $A_{1}, A_{2}, A_{3}, A_{4}, A_{5}, A_{6}$ and $A_{7}$ are empirical coefficients fitted on the 2012 data, all statistically, significantly different from $0(-0.46,-0.74,1.79,-1.79$, $1.45,-0.5,-0.06$, respectively, $\mathrm{p}$-value $<0.001)$, with $S_{n}, T_{s, 0}$ and $\Delta_{t} T_{L, 5}$ accounting for $96 \%$ of the variance explained by the model. The resulting " $E_{L}$ " model (Figure 6.6) had a $\bar{R}^{2}$ and an NSE of 0.52. The $E_{L}$ model could not properly fit the very low $E_{g, 0.5}$ values observed at $\sim 9: 00$. The residuals of the model (i.e. the differences between the evaporation predicted by the model and the evaporation observed) were normally distributed; however, their correlogram revealed an autocorrelation for lags of $24 \mathrm{~h}$. This indicated that there were some other process(es) with a daily fluctuation, responsible for the daily variations of $E_{g, 0.5}$. The correlation analysis, however, did not indicate any other possible explanatory variable from those selected to be tested.

The analysis of the correlations of the low pass filtered variables was also relevant, since the processes responsible for daily fluctuations in $E_{g, 0.5}$ and the long term trend $\overline{\bar{E}}_{g, 0.5}$ may differ. A study of the correlation of $\bar{X}_{0.5}$ variables showed that $\overline{\bar{E}}_{g, 0.5}$ was moderately correlated with the three variables: $\bar{S}_{n, 0.5}$, $\Delta_{t} \bar{T}_{L, 0.5}$, and $\Delta_{t} \bar{T}_{L}$. The best fitting was obtained for $\Delta_{t} \bar{T}_{L}$, which corresponds to the low pass filtered version of the $E_{L}$ model (with $\bar{R}^{2}=0.52$ and NSE $=0.52$ ), better than for the high pass filter variables, with $\bar{R}^{2}=0.32$ and NSE $=0.33$.

The model accounts only for the DSL water vapour transport process caused by changes in the soil temperatures; this does not exclude the possibility that other processes were contributing to the total water vapour transport. Since the laboratory experiment in Chapter 5 showed the relevance of the barometric effects in similar conditions, the evaporation estimates obtained with the $E_{L}$ model estimates were added to the barometric effects estimates obtained using Equation 6.5. The model resulting from the addition of Equations 6.5 and 6.11 was referred as $E_{L B}$, and its estimates were compared to the measured evaporation. 


\subsubsection{Comparison with the Hydrus1D model estimates}

Figure 6.6 shows the measured cumulative $E_{g}$, the $E_{g}$ estimated using the $E_{L}$ and $E_{L B}$ models without and with barometric effect respectively, and the $E_{g}$ estimated by the Hydrus1D model with the SOURCE package, for the lysimeter and for the in-situ soil profile in the calibration period from 23 May to 11 June 2012 (Figure 6.6a) and in the validation period from 5 August to 21 October 2015 (Figure 6.6b).

In the calibration period (Figure 6.6a), the $E_{L}$ and $E_{L B}$ models follow very well the $E_{g}$ measurements, after 18 days indicating cumulative values 16.7 and 22 $\mathrm{mm}$ respectively. The $E_{L B}$ model only slightly underestimated $E_{g}$ (by $0.5 \mathrm{~mm}$ after 18 days), while the $E_{L}$ model clearly underestimated $E_{g}$ (by $5.8 \mathrm{~mm}$ after 18 days). The Hydrus1D model was not able to simulate the lysimeter DSL properly, forming a $5 \mathrm{~cm}$ thick, pseudo-DSL (since Hydrus1D cannot simulate an air-dry soil layer, see section 4.1) with soil moisture close to residual value, while the true DSL was $70 \mathrm{~cm}$ thick. That thin pseudo-DSL decreased the modelled evaporation rates so much that the estimated $E_{g}$ after 18 days amounted to only $3 \mathrm{~mm}$. The Hydrus1D model simulation of the in-situ conditions resulted in the formation of a much thinner DSL (only $1 \mathrm{~cm}$, much thinner than the $25 \mathrm{~cm}$ thick DSL measured in-situ); the $E_{g}$ estimated by Hydrus1D model for the in-situ soil was also very low, with cumulative $E_{g}$ of 14 $\mathrm{mm}$ after 18 days. 

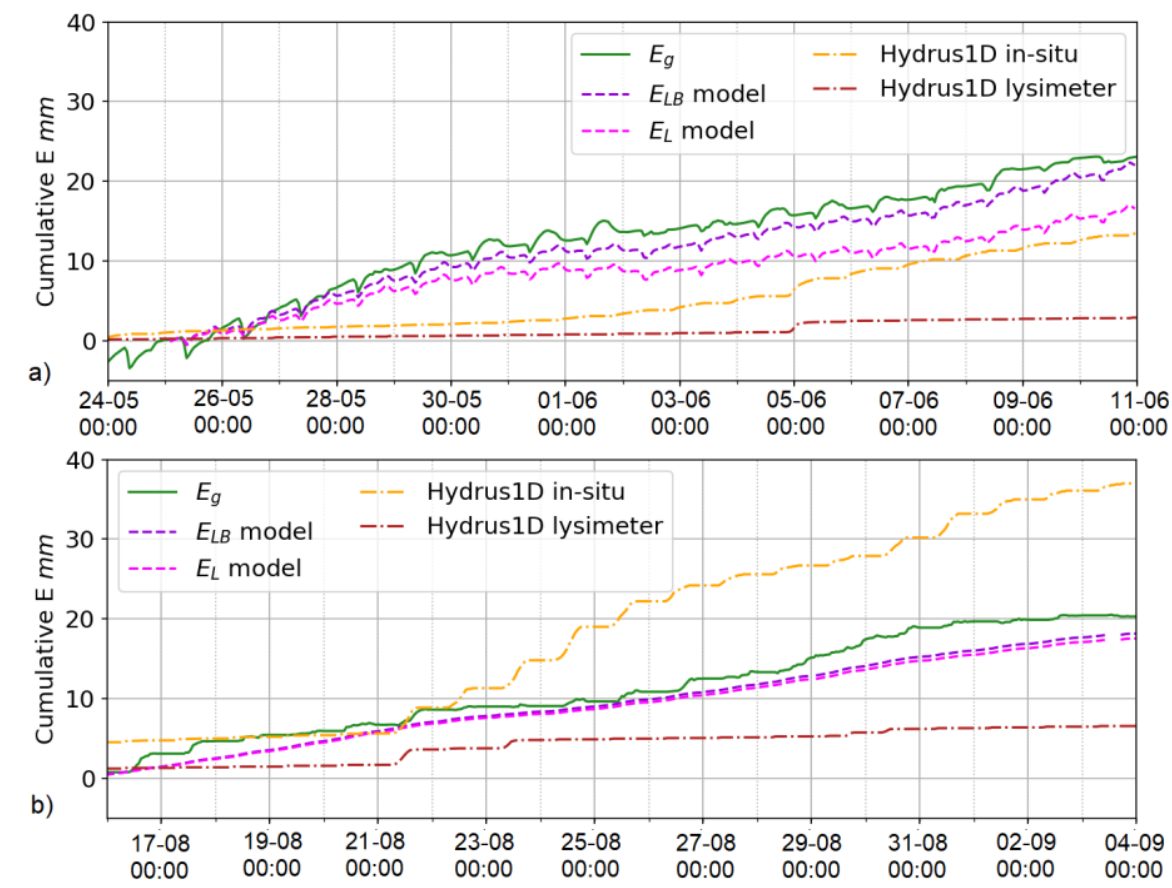

Figure 6.6: Cumulative groundwater evaporation rates: $E_{g}$ - measured; $E_{L}$ estimated $E_{g}$ using soil temperature variation model; $E_{L B}$ - estimated $E_{g}$ using soil temperature variation combined with barometric effect model; 'HYDRUS1D in-situ' and 'HYDRUS1D lysimeter'- predicted $E_{g}$ by the Hydrus1D model with SOURCE package for the in-situ and lysimeter soil profiles respectively for: a) the calibration period (23 May to 11 June 2012) and b) the validation period (5 August to 21 October 2015).

In the validation period from 5 August to 21 October 2015 (Figure 6.6b), the $E_{L}$ and $E_{L B}$ models mostly follow the lysimeter $E_{g}$ measurements, after 18 days indicating cumulative values 17.5 and $18 \mathrm{~mm}$ respectively. The two models show very similar $E_{g}$ estimates, both underestimating the measured $E_{g}$ by $2.5\left(E_{L}\right)$ and $2 \mathrm{~mm}\left(E_{L B}\right)$ after 18 days. In 2015, the $E_{L}$ model predicted only slight variations in $E_{g}$, much smaller than those predicted by the calibration dataset; therefore, the $E_{L}$ and $E_{L B}$ models do not show clear daily fluctuations in Figure 6.6b. The Hydrus1D model, in the validation period, simulated the formation of 1.5 and $0.5 \mathrm{~cm}$ thick DSL for the lysimeter and in-situ conditions (different than the 12 and $25 \mathrm{~cm}$ thick DSL measured), respectively. The $E_{g}$ estimated by Hydrus1D model for the lysimeter was very low, just as in 2012, with cumulative $E_{g}$ of $7 \mathrm{~mm}$ after 18 days. However, the $E_{g}$ estimated by 
Hydrus1D model for the in-situ soil was much larger than in 2012, being 37.4 $\mathrm{mm}$, clearly overestimating the observed $E_{g}$.

\subsection{Discussion}

\subsubsection{Measurements of evaporation through a thick DSL and comparison with soil profile measurements}

The field lysimeter experiment showed that substantial $E_{g}$ can take place in the presence of a thick DSL, not only in the laboratory conditions (Chapter 5 ) but also in the field conditions. Besides, it also proved that the main process responsible was not diffusion. The field lysimeter $E_{g}$ measured with a $70 \mathrm{~cm}$ DSL in $2012\left(1.25 \mathrm{~mm} \mathrm{~d}^{-1}\right)$ was similar to $E_{g}$ measured with a naturally formed DSL of $\sim 12 \mathrm{~cm}$ in $2015\left(1.05 \mathrm{~mm} \mathrm{~d}^{-1}\right)$. This seems to indicate that DSL thickness does not affect substantially the evaporation rates, at least when the DSL $\geq 12 \mathrm{~cm}$; this was also the conclusion in the previous laboratory experiment described in Chapter 5.

It should be pointed here that the presence of a DSL does not guarantee that $E \approx E_{g}$. The DSL develops depending on the evaporative conditions in the air above the soil and on the soil moisture conditions in the soil layer close to the soil surface. Whenever there is a dry period with no rain events and high $E_{p}$, a DSL may form at the soil surface. However, if the water table is deep enough so that the soil moisture profile is not at hydrostatic equilibrium (which is seldom in field conditions), the unsaturated zone below the DSL may have water that can travel through capillary rise to the vaporization plane, and evaporate there. For example, in Figure 1.2b, the water rising from the zero flux plane to the vaporization plane, and then lost as water vapour through the DSL, will contribute to $E_{u}$. However, in our cases of both years 2012 and 2015, the situation was similar to that presented in Figure 1.2a, i.e. where the water table was very shallow and the matric potential sensors indicated that the soil moisture profile was close to hydrostatic equilibrium. Hence, in the periods shown in Figures 6.2 and 6.3, $E \approx E_{g}$.

The field lysimeter $E_{g}$ rates were much higher than those observed in the laboratory experiment (1.25 in the field vs $0.3 \mathrm{~mm} \mathrm{~d}^{-1}$ in the laboratory condition as in Chapter 5), with the same lysimeter setup; the only difference between the two experiments were the upper boundary conditions, i.e. controlled conditions in the laboratory lysimeter experiment and environmental conditions in the field lysimeter experiment. Even though the laboratory evaporative conditions were set similar to average field evaporative conditions, there were differences in atmospheric pressure (in absolute values and in fluctuations, see Section 6.4.2) and also in diurnal changes in $R H, T_{a}, S_{n}$ and $u$. The artificial variation of $R H, T_{a}$, and $S_{n}$ in the laboratory was cyclical, and $u$ was changed only twice, while conditions in the field change in a random way, 
or due to larger changes in weather conditions. In the laboratory condition, the main driving force of the transported water vapour through the DSL, was the barometric effect. However, in the field lysimeter experiment, these were daily cycles of condensation and evaporation of soil moisture while barometric effect played secondary role (Section 6.3.3.5-6).

Other laboratory evaporation experiments with the formation of a DSL showed measured evaporation rates (mostly driven by diffusion), in general, around $0.5 \mathrm{~mm} \mathrm{~d}^{-1}$ (Lehmann et al., 2008b; Shokri et al., 2008; Shokri and Or, 2011), similar to the value measured with the lysimeter in laboratory (Chapter 5). Or et al. (2013) showed that the evaporation rates measured in the laboratory experiments, in presence of a DSL, were independent of: (i) the upper boundary conditions; (ii) soil properties; and (iii) the evaporation rate before the formation of the DSL. Since the only difference between the field lysimeter set up of this study and the laboratory setup described in Chapter 5 was in different upper boundary conditions (which rejects the first assumption of Or et al., 2013), and because the field estimate $(1.25 \mathrm{~mm} / \mathrm{d})$ was much larger than the laboratory $(0.3 \mathrm{~mm} / \mathrm{d})$, the field evaporative conditions must promote transport process or processes overlooked in laboratory studies.

An interesting observation is that, despite very similar properties of the soil in the lysimeter and in the nearby in-situ profile, the formation of a DSL was more likely to occur in the in-situ profile than in the nearby installed lysimeter, as shown by the fact that the POT sensor in-situ reached the wilting point every year. That observation is based on the lack of the DSL in the lysimeter in the years 2013 and 2014, while in 2015, when it formed, it extended only to $\sim 12$ $\mathrm{cm}$ depth. Considering the formation process of a DSL after a wet seasons, it has been observed, based on the data collected between 2010 to 2014 in the Sardon study area, that the soil used to form a $15 \mathrm{~cm}$ thick DSL already around mid-May (POT-sensor at $15 \mathrm{~cm}$ depth), and the $\theta_{25}$ measurements showed that the soil was dry around the first week of June in all four years, despite the fact that there were often some rain events in May (Chapter 3, Balugani et al., 2017). It is likely that the yearly formation of the DSL in-situ was due either to: (i) transpiration by grasses; (ii) good soil drainage (absent in the lysimeter); or (iii) a combination of both.

\subsubsection{Relevance of different transport processes}

The analysis of the drivers of the transport processes in the field lysimeter showed that the best explanatory variables for the variations in $E_{g}$ rates are the changes in the temperature profile inside the lysimeter:

$E_{g} \sim \frac{\Delta T_{L}}{\Delta z \Delta t}$

However, the physical process responsible for this correlation needs to be identified. The physical process cannot be thermal flow of liquid water and water vapour transport in the soil (Section 6.3.3.3; Du et al., 2018; Saito et 
al., 2006), since in that case the water flux depends on static, spatial differences in temperature in the soil, and the flux is usually directed downwards during the day and upwards during the night, so that there should be a minus sign in front of the Equation 6.12 (Zeng et al., 2011a, 2011b).

A possible process could be the cyclic condensation and evaporation of water in the DSL due to daily fluctuations in evaporative conditions at the lysimeter surface. The loss of water from the Mariotte bottle indicates loss of water from the saturated and/or capillary fringe (Figure 1.2), but the water evaporated can be accumulated in the DSL during the night and transported out of the lysimeter during the day. Such condensation and evaporation of water in the DSL has already been observed in field studies, where soil developed a DSL, even if only 2-3 cm thick (Assouline et al., 2013), and was able to increase the overall water transport in such thin DSL. However, no correlation was found between the daily fluctuations of evaporative conditions at the lysimeter surface and evaporation measured in the lysimeter (Section 6.3.3.5), and no changes in soil matric potentials were observed through the lysimeter profile.

Another possible process taking place in the DSL is thermal convection, as proposed in Section 4.5.5, where temperature gradients result in natural convection of the gas phase of water in the soil (Kamai et al., 2009; Nachshon et al., 2008; Rose and Guo, 1995; Schubert and Schulz, 2002; Weisbrod et al., 2009; Witkamp, 1969). Ganot et al., (2014) studied the effects of thermal convection on $\mathrm{CO}_{2}$ soil respiration using soil columns with a design similar to that presented in this study, and found that thermal convection was relevant in the presence of soil aggregates and not in the presence of loose sand (due to the relatively high Rayleight-Darcy number of the sand). However, Roland et al. (2015) measured statistically significant correlation between $\mathrm{CO}_{2}$ soil respiration rates, temperature profile in the soil, and solar radiation on a sandy-loam soil. They concluded that, under certain $u$ regimes, changes in $T_{s}$ driven by $S_{n}$ can affect bulk air transport in a soil. Since $T_{s, 0}, T_{L}$ and $S_{n}$ were also strongly correlated with $u$, it was not possible to assess the separated effects of $u$ regimes that would result in a strong coupling of gas transport with $T_{s, 0}$, which they did not measure. In this study, that coupling was confirmed. The theory of bulk air transport related to $S_{n}$ and $T_{s, 0}$ is also supported by the direct observation of strong dust devils in the study area during fieldwork (Section 4.5.5), and by infrared images recorded by an infrared camera, showing the temperature at the soil surface changing in patches, at the rate as high as $3^{\circ} \mathrm{C} \min ^{-1}$ (not shown here).

The Hydrus1D model was not able to simulate properly the presence of a DSL, only simulating thin $(5 \mathrm{~cm}$ to $1.5 \mathrm{~cm}$ thick) pseudo-DSL. In the pseudoDSL simulated by Hydrus1D the soil moisture is close to its residual values, and water moves mainly as water vapour through diffusion only; this limits the evaporation flow estimated by Hydrus1D for the lysimeter to values significantly smaller than the observed ones for both years $(0.17$ and $0.36 \mathrm{~mm}$ 
$\mathrm{d}^{-1}$ and 1.25 and $1.05 \mathrm{~mm} \mathrm{~d}^{-1}$, respectively). In the Hydrus1D simulation of the in-situ soil evaporation for the year 2012 the initial conditions were set as observed in the field, with an initial pseudo-DSL $15 \mathrm{~cm}$ thick, which was reduced in the simulation to a thickness of $1 \mathrm{~cm}$ due to upward liquid water fluxes. This $1 \mathrm{~cm}$ thick, simulated pseudo-DSL, however, was enough to limit the Hydrus1D estimated evaporation rates to $0.78 \mathrm{~mm} \mathrm{~d}^{-1}$. In the simulation of in-situ soil evaporation in 2015 by Hydrus1D, conversely, the soil initial conditions were relatively wet (the simulation was started at the beginning of May), and a pseudo-DSL only $0.5 \mathrm{~cm}$ thick formed, despite the very dry weather conditions. The main water flow through this $0.5 \mathrm{~cm}$ thick pseudo-DSL was isothermal liquid water flow, not water vapour diffusion, so that evaporation rates estimated by Hydrus1D were much larger than those in 2012 (2.06 $\mathrm{mm} \mathrm{d}^{-1}$ ). This supports the idea that Hydrus1D is not suited to properly model the measured evaporation rates in very dry soil conditions, as suggested previously in Chapter 3 (Balugani et al., 2017).

The descriptive models based on diffusion, thermal fluxes, or daily cycles of condensation and evaporation of soil moisture in the DSL (sections 6.332, $6.333,6.335)$ did not estimate evaporation rates better than the $E_{L}$ and $E_{L B}$ models, as they had lower NSE scores than both $E_{L}$ and $E_{L B}$ models. The low correlation between measured evaporation rates and the driving factors for these transport processes (diffusion, thermal fluxes, or daily cycles of condensation and evaporation of soil moisture in the DSL) may be due to: (a) the interaction between different processes resulting in a non-linear dependence of evaporation rates on different drivers; (b) the larger effect of the main process (bulk air transport driven by solar radiation), hiding the effect of the other physical processes. The interconnectedness and complexity of the different evaporation processes in dry soil is recognized in literature (Brutsaert, 2014a; Vanderborght et al., 2017); one way these processes can interact is, for example, by having wind speed and atmospheric pressure actively pumping out air from the first centimetres of a soil (Auer et al., 1996; Stauffer et al., 1997; Chapter 5), effectively decreasing the travel distance for other DSL transport processes (Auer et al., 1996; Davarzani et al., 2014). The way in which the transport processes interact is likely affected by: (a) DSL thickness, e.g. when DSL thickness is shorter than the depth from which air can be removed by wind speed or atmospheric pressure changes; (b) soil material properties, which are usually uncertain and heterogeneous in field conditions; and (c) weather conditions, with drivers having different magnitudes in different climates. The inclusion of transport processes that operate at larger depths can help to explain observed evaporation rates in dry environmental conditions.

The fact that, in this field study, the process that drives the transport of the water vapour in the DSL is different from that in the laboratory conditions (Chapter 5), despite identical columnar setup, is indicative of how complex the DSL evaporation can be. Under laboratory conditions, the main driver of the 
evaporation through the DSL was the atmospheric pressure change effect. In the field experiment, the $p_{a t m}$ was smaller than in the laboratory experiment, both in magnitude and in variation. The difference in $p_{a t m}$ magnitude, due to the different altitude above mean sea level ( $9 \mathrm{~m}$ a.m.s.l. and $p_{a t m} \sim 100 \mathrm{kPa}$ in Wageningen, Netherlands against $\sim 790 \mathrm{~m}$ a.m.s.l. and $\sim 92 \mathrm{kPa}$ of Sardon, Spain) is not expected to have had any impact on evaporation rates. The difference in $p_{a t m}$ variations between Wageningen and Sardon, reflected by different amplitude averages, i.e. 6 and $3 \mathrm{kPa}$, respectively, likely resulted in the Sardon $E_{g}$ (driven exclusively by $p_{a t m}$ ) twice lower than in Wageningen.

The estimated $E_{g}$ driven by barometric effect for Sardon $\left(\sim 0.2 \mathrm{~mm} \mathrm{~d}^{-1}\right)$ was several times lower than the measured $E_{g}$ rate $\left(\sim 1 \mathrm{~mm} \mathrm{~d}^{-1}\right)$, thus indicating its secondary role as driving force. However, the inclusion of the barometric effects in the $E_{L B}$ model improved it as compared to the $E_{L}$ model, as shown by the $E_{L B}$ quantitative estimate of $E_{g}$ (Figure 6.6). The large difference between the $E_{g}$ estimate driven exclusively by barometric effect and the measurement, indicates that the evaporation process was dominated by profile temperature fluctuations (Equation 6.11), with a significant effect of barometric effects (Equation 6.5). The dominance of the profile temperature fluctuations explains why there was very little correlation between $E_{g}$ and $p_{a t m}$.

\subsubsection{Limitations and further studies}

The correlations found between environmental explanatory variables and the measured evaporation rates in the Sardon study area, raises the question as to the validity of all the linear models fitted, since collinearity decreases the quality of the empirical coefficients, and it makes little sense to use collinear regressors. The whole region around Sardon is land-locked, with mountain ranges all around (Cantabrian Mountains in the North, the Central system in the South, the Iberian system in the East, and the Northern Meseta in the West, in Portugal). This creates an enclosed basin where wind speed, relative humidity and air temperature at $2 \mathrm{~m}$ are strongly correlated with solar radiation. This collinearity does not affect the power or reliability of linear models as a whole, but it makes very difficult to discriminate the effects of each driver on the evaporation process. Only the atmospheric pressure fluctuation was not correlated with the other drivers, and can be regarded as an independent variable.

The dataset collected in the very dry year 2012 was of very high quality, but had a small overall time span, covering only 19 days of groundwater evaporation measurements with $Z_{D S L}=70 \mathrm{~cm}$, before the Mariotte bottle emptied. The observation of groundwater evaporation in August 2015 (another very dry year), shows evaporation from the lysimeter in the presence of much thinner DSL $\left(Z_{D S L}=12 \mathrm{~cm}\right)$ and different weather conditions. Moreover, in 2012 the evaporation rates were measured using the Mariotte bottle, while in 2015 
the evaporation rates were measured by the whole lysimeter weighing system, less sensitive than the Mariotte bottle. The lower sensitiveness of the lysimeter meant that it was not possible to validate properly the high pass filter part of the $E_{L}$ and $E_{L B}$ models. Since the Lysimeter may get flooded during the winterspring, thus effectively rendering the Mariotte bottle useless, a future lysimeter experiment should drain the flooded lysimeter at the beginning of the dry season, so as to allow the formation of a DSL in a lysimeter with initial conditions of soil moisture at field capacity, more similar to those observed insitu. Moreover, to obtain a longer Mariotte bottle evaporation dataset, a bigger bottle than the 2 litre one used in this study should be used, or a more frequent site assistance to refill the Mariotte bottle should be needed. The results of the study are not easy to generalize; they should, instead, be interpreted together with the $\mathrm{CO}_{2}$ soil dynamic studies cited above as a general analysis of the transport processes for the gas phase in the soil porous medium.

It should be noted that none of the multiple linear regressions was able to model the low evaporation rates values recorded every day between 8:00 and 9:15 a.m. of local time ( $\sim 2.5 \mathrm{~h}$ ahead of solar time) and coincident with sunrise. These low values are not due to temperature effects on the load cell sensor, since they were already corrected for; also the weight measurements are taken every minute and averaged and recorded every 5 minutes, making them reliable. Looking at Figure 6.5, it seems that these low values are somehow related to the change in $T_{L}$ gradient in the first 5 or $10 \mathrm{~cm}$ of the lysimeter (Figure 6.5), probably due to disruption of the temperature-related transport process during sunrise. It is possible that one of the transport mechanisms at play in the DSL is dependent on a temperature gradient in the soil profile; the transport mechanism is then disrupted whenever the gradient between $T_{S, 0}$ and $T_{L, 5}$ becomes zero and, eventually, reverse (Figure 6.5).

\subsection{Conclusions and recommendations}

The approach presented in this study can be used to identify the most relevant factors forcing water vapour transport through a dry soil layer (DSL) in the field, by using data acquired by weather stations and a lysimeter setup method. The proposed lysimeter installation allows for direct and separate measurements of soil evaporation $(E)$ and groundwater evaporation $\left(E_{g}\right)$, while the difference between these two allows to define the evaporation from unsaturated zone $\left(E_{u}\right)$. This means that the proposed installation allows for $E$ sourcing (Eq. 1.2).

The main findings of this study are as follow:

- Evaporation of groundwater $\left(E_{g}\right)$ through the $70 \mathrm{~cm}$ DSL was clearly observed in the lysimeter installed in the field conditions; the measured $E_{g}$ was $\sim 5$-times higher than in the similar experiment conducted in the laboratory conditions in the Netherlands with the same lysimeter setup 
$\left(\sim 1.25 \mathrm{~mm} \mathrm{~d}^{-1}\right.$ in 2012 and $1.05 \mathrm{~mm} \mathrm{~d}^{-1}$ in 2015 versus $\sim 0.3 \mathrm{~mm} \mathrm{~d}^{-1}$ respectively). The only difference between the two experiments was in the driving forces, which were: in Spain natural field condition; in the Netherlands laboratory condition artificially simulating field condition.

- The dominant forcing factor best explaining variation in the $E_{g}$ rates measured in this study were the changes in lysimeter temperature profile, related to changes in solar radiation $\left(E_{L}\right.$ model). This is in contrast to the laboratory lysimeter experiment in the Netherlands, where the dominant forcing factor was atmospheric pressure fluctuation. In this field study, instead, the impact of barometric pressure effect was much smaller, predicting $E_{g}$ rates of only $0.2 \mathrm{~mm} \mathrm{~d}^{-1}$. However, the addition of the barometric effects to the $E_{L}$ model $\left(E_{L B}\right)$ improved the $E_{g}$ estimates for the field lysimeter experiment, indicating that atmospheric pressure fluctuations were also playing a role, even though secondary, in determining $E_{g}$.

- The Hydrus1D model was not able to simulate the formation and development of the DSL, greatly underestimating evaporation in the presence of a pseudo-DSL. The Hydrus1D model performed worse than the $E_{L}$ and $E_{L B}$ multivariate regression models in both years, with $E_{L B}$ performing better than $E_{L}$, because of inclusion of the barometric effect next to temperature fluctuation defined as the main driving force.

- Although the presented field dataset was fragmented due to its maintenance from the Netherlands, it was reliable and sufficient to derive the main conclusion of this study; the experimental setup used proved to be reliable and also suitable for the separate assessment of $E_{,} E_{g}$ and $E_{u}$.

- The study proved beyond any doubt that the $E_{g}$ under thick DSL was much larger than the estimates from other hydrological models like Hydrus1D.

It is recommended to replicate the experiment proposed in this study in many different dry environments, characterized by different altitudes (so different atmospheric pressures and pressure fluctuations), different weather and soil conditions, and different DSL thicknesses. In this way it will be possible to understand what are the main transport processes driving evaporation in different environmental conditions and how they interact with each other while influencing $E$. Laboratory experiments could be carried out to assess the effects of different DSL thicknesses with different evaporative conditions, in relatively large columns and initial soil moisture conditions at field capacity or at wilting point. Other experiments, both in laboratory and in the field, could focus on the formation of a DSL in a soil covered by grasses that wither and become dormant. It would also be useful to obtain direct observations of DSL formation in the field studies, with the goal of parameterizing the effect of the DSL on the evaporation process for use in land surface models. 
Chapter 7

Concluding remarks 


\subsection{Results}

Chapter 2 showed that in the presented sourcing framework, the definition of the unsaturated and saturated zone components of soil evaporation, requires a rigorous definition of "shallow" and "deep" water table. These terms are typically used qualitatively, assuming that the shallow water table influences the soil moisture regime, while the deep water table has no, or has a negligible effect on the upper soil. However, the field studies demonstrated that, under arid and semi-arid conditions, water table of even more than $200 \mathrm{~m}$ depth, can still have an effect on the measured soil surface fluxes. The definitions of shallow and deep water table were tested using the SOURCE package, developed in this study, to source (separate) unsaturated and groundwater evaporative fluxes in a set of Hydrus1D simulations. A water table was defined as "shallow" whenever $E_{g}$ was $\geq 95 \%$ of $E_{s s}$ and as "deep" when the water table was below the evaporation extinction depth (see Section 1.1.2), so that $E_{s s} \sim$ $E_{u}$. There is also an intermediate water table depth, at which both $E_{g}$ and $E_{u}$ fluxes are relevant. The modelling results suggest that such depth depends on soil properties, so that it is $0.25-0.5 \mathrm{~m}$ for sand and $0.8-6 \mathrm{~m}$ for clay. The water table fluctuation (WTF) method and the bucket methods, which could help to source evaporation, were applied in a set of numerical experiments and conditions. The WTF method could not predict $E_{g}$ whenever the simulated evaporative conditions resulted in very small water table fluctuations ( $<1 \mathrm{~mm})$, while the SOURCE package could. The "bucket" method, disregarded $E_{g}$ whenever the water table simulated was deeper than $2.0 \mathrm{~m}$ b.g.s., while the SOURCE package estimated it as $54 \%$ of $E_{S S}$.

Chapter 3 showed that the SOURCE package was able to source $E_{g}$ and $E_{u}$ components in the field experiment carried out within the period lasting from July 2009 to December 2010, at semi-arid conditions of the Sardon catchment in Spain. A set of different techniques was used to partition and source ET, i.e. to estimate all the components of ET and compare their sum with the ET defined by the eddy covariance method. The $E_{s}$ was defined by gauge measurements, the $T_{g}$ and $T_{u}$ by sap flow and stable isotope techniques, and the $E_{g}$ and $E_{u}$ by SOURCE package modelling using field measurements of microclimatic variables as driving forces, soil properties for parameterization of subsurface and soil moisture and soil temperature data for model calibration and validation. The results showed that in the period from 30 January to 7 October 2010, the $E_{u}$ was the dominant component of ET (around 60\% of 1.649 $\mathrm{mm} \mathrm{d}^{-1}$ ), mainly due to large soil moisture evaporation in autumn after the first heavy rain events and in spring, when the evaporative conditions were high and soil was still wet. It is remarkable that the $E_{u}$ was the dominant term even during the dry season; this was largely because all the infiltrated water from erratic in that season rain showers, was completely evaporated before it could even reach a depth of $15 \mathrm{~cm}$, so the recharge was absent. The $E_{g}$, 
however, was not negligible $\left(0.226 \mathrm{~mm} \mathrm{~d}^{-1}\right)$. It became the main $(60 \%)$ component of the $E T_{s S}$ during periods of drought, appearing typically just 3-4 days after the rare in dry season precipitation events, when the unsaturated zone dried up completely. The tree transpiration of the investigated area was very low $\left(0.016 \mathrm{~mm} \mathrm{~d}^{-1}\right)$ during the dry season, despite substantial transpiration of individual trees, mostly due to the low tree canopy coverage of $\sim 7 \%$.

Chapter 4 tested the quality of three different methods to estimate the dry season evaporation rates using data from the field experiment presented in Chapter 3. The three methods tested were: the daily average method (Brutsaert, 2014a); the calculation of water vapour flow assuming only Fick's diffusion (Assouline et al., 2013); and the SOURCE package (Chapter 2, Balugani et al., 2016). The three methods are based on the three different, respective assumptions: (1) that the daily changes in evaporative conditions imply a negligible effect of the dry soil layer (DSL) on evaporation rates; (2) that the evaporation through a DSL is well described by Fick's diffusion; and (3) that it is possible to estimate evaporation rates through a DSL without modelling the disruption of the liquid continuity through the soil profile. None of the three methods properly estimated the evaporation rates if taking eddy covariance tower (ECT) as the reference, although the evaporation estimates of the Hydrus1D with SOURCE package had the lowest relative error, especially during a drought $\left(\sim 0.05 \mathrm{~mm} \mathrm{~d}^{-1}\right)$. After each of the three rain events in the dry season, the evapotranspiration measured by the ECT was decreasing steadily from around $2 \mathrm{~mm} \mathrm{~d}^{-1}$ to around $0.2 \mathrm{~mm} \mathrm{~d}^{-1}$ within 40 days of drying. In addition, all the three methods predicted a strong effect of water table depth upon $E_{s s}$, which was not recorded by the ECT; for example, on 26 September 2010, the ECT showed the same evaporation rates (around $3 \mathrm{~mm} \mathrm{~d}^{-1}$ ) at shallow ( $<1 \mathrm{~m}$ b.g.s.) as at deeper $(\sim 10 \mathrm{~m}$ b.g.s.) groundwater table areas.

In Chapter 5, a laboratory experiment involved the use of two soil columns, 1 and 2 meters high, packed with oven-dry sandy materials, and connected to Mariotte bottles, forcing fixed water levels at the bottoms of the columns and weighed continuously to precisely measure groundwater evaporation $\left(E_{g}\right)$ rates. The columns clearly showed non-negligible $E_{g}$ (around $0.3 \mathrm{~mm} \mathrm{~d}^{-1}$ ), even in the presence of very thick $(70-180 \mathrm{~cm}) \mathrm{DSL}$. These high rates, could not be explained by Fick's diffusion (which estimated around $0.005 \mathrm{~mm} \mathrm{~d}^{-1}$ ), confirming that other mechanism(s) of water transport occurred. The analysis of different, tested evaporative conditions showed that neither daily cycles of condensation nor changes in wind turbulence were responsible for the high rates of water transport through the soil columns. The only environmental variable correlated with evaporation rate was the atmospheric pressure fluctuation, implying that barometric pumping and pressure-induced dispersion in the soil, were responsible for the large vapour transport through the DSL. That process consisted of compression and expansion of the gas phase in the soil, resulting in: (i) direct pumping of the gas phase close to the soil surface; 
(ii) fluctuation in the water table level; (iii) dispersion of the water vapour in the gas phase enhancing the evaporation rates.

Chapter 6 presents the same lysimeter setup as the laboratory setup described in Chapter 5, but placed in the field condition of the semi-arid Sardon study area, next to in-situ evaporation measurements, as presented in Chapters 3 and 4 . The lysimeter evaporation rates in the dry soil condition were five times larger (i.e. around $1.2 \mathrm{~mm} \mathrm{~d}^{-1}$ ) than those measured in the laboratory (around $0.3 \mathrm{~mm} \mathrm{~d}^{-1}$ ) with the same DSL $(\sim 70 \mathrm{~cm})$. This was unexpected, since the evaporative conditions in the laboratory experiment were designed to be the same as those observed in the field. Moreover, in contrast to the laboratory experiment, the field measured evaporation fluxes, did not show significant correlation with atmospheric pressure fluctuations. As such, the contribution of the water vapour flux across the DSL, estimated using barometric pumping and pressure induced dispersion alone $\left(0.2 \mathrm{~mm} \mathrm{~d}^{-1}\right)$, was small as compared to the total measured evaporation rates, which were much better correlated with solar radiation and soil temperatures. This suggested that the main process of the transport of water vapour in the dry soil layer, was the bulk air transport due to turbulence at the soil surface. Considering the in-situ evaporation measurements, a DSL of around $25 \mathrm{~cm}$ thickness, formed every dry season at each of the four assessed hydrological years (20122015), while in the lysimeter, a $12 \mathrm{~cm}$ thick DSL formed only in a very dry year (2014). This difference may be attributed to the effect of in-situ grass transpiring soil moisture from the root zone in April and May (afterwards reaching permanent wilting point and becoming dormant), thus enhancing the development of the in-situ DSL.

\subsection{Limitations}

The results of Chapters 2 and 3 are partially dependent on the model used to estimate soil evaporation. In order to account for vertical thermally driven water fluxes and water vapour diffusion, Hydrus1D, which is based on the Philip and de Vries (PdV) equations with heat and water vapour transfer, was used. These equations are widely used in evaporation studies in similar conditions (Zeng, et al., 2009b; Assouline et al., 2013; Sun et al., 2016; Du et al., 2018), although it is generally recognized that they cannot model the development of an air-dry soil layer. For example, Zeng et al. (2011b) demonstrated that the inclusion of the transport of air advection in the PdV equations, in addition to water vapour diffusion, may result in lower evaporation rates. However, Assouline et al. (2013), showed that with the DSL $<5 \mathrm{~cm}$ thick, it was still possible to properly model the soil evaporation fluxes in the lysimeter experiment with liquid flow calculated with PdV equation including water vapour transport (Saito et al., 2006). This suggests that the assumption of 
liquid water continuity, implicit in the PdV equations, may still hold whenever the DSL is less than $5 \mathrm{~cm}$ thick.

A limitation of the experiments described in Chapters 5 and 6 was that they only allowed to establish the correlation between forcing factors and evaporation rates. This was due to the difficulty of direct measuring water vapour concentration and flow within the DSL. The assumption of causality between factors forcing fluctuations and evaporation rates seems reasonable in the case of the laboratory experiment (Chapter 5), as the correlation between atmospheric pressure fluctuations and the measured evaporation rates was very clear and stable during a long period of time, under different evaporative conditions, and in both columns. Moreover, the model empirically defined in Chapter 4, coincides with the physically based Auer et al (1996) model, quantifying the effect of atmospheric fluctuations on the vapour transport in the soil. The low correlation values between evaporation rates and forcing factors in the field lysimeter experiment, and the fact that many atmospheric forcing factors were highly correlated, lowers credibility of the findings; however, the fact that the vapour transport processes identified as relevant were the same as those highlighted in $\mathrm{CO}_{2}$ respiration studies (Sánchez et al., 2008; Maier et al., 2010; Bowling et al., 2015), increases that credibility.

Another limitation, is that the main processes identified as responsible for the transport of water vapour through the DSL, differed between the laboratory and the field lysimeter experiments, despite the same experimental design (although with different external conditions of the experiment): barometric fluctuation was the main factor in the laboratory experiment but soil temperature profile variation, in the field experiment. Similar discrepancies in the identification of gas transport processes have been highlighted earlier in $\mathrm{CO}_{2}$ soil respiration studies, i.e. in the studies finding correlation of evaporation rates with: i) barometric fluctuations (Sánchez-Cañete et al., 2013); ii) with soil temperature profiles (Roland et al., 2015); or iii) other processes (Massmann and Farrell, 1992; Kuang et al., 2013; Brændholt et al., 2017). However, all those studies differed in type of soil and climate. In this study, the only difference between the laboratory and the field lysimeter experimental setup, was in the "climate" evaporative conditions: artificial semi-arid laboratory conditions in the Netherlands (Chapter 5) and field semi-arid conditions in Spain (Chapter 6). The observations from these two experiments, show that the DSL evaporation is dependent on many different, water vapour transport processes, with the main process, probably determined by a combination of weather conditions (solar radiation, air temperature, barometric pressure), DSL thickness, and soils' properties, with their importance (or contribution) varying with climate and soil type. 


\subsection{Final conclusions and future research}

Water limited environments in semi-arid and arid areas, such as the Sardon study area in Spain, keep expanding worldwide due to climate change. In the meantime, world population increase and the change in diet due to increase in global affluence, all puts a strong pressure on the agricultural sector to increase water-demanding crop production. However, it is evident that agricultural productivity increases at a slower pace than required by the increase in demand, hence the expansion of agricultural land is going to increase in the future (Ittersum et al., 2013; Bussel et al., 2015; Asseng et al., 2015; Long et al., 2006; Ray et al., 2013; Iizumi et al., 2014; Iizumi and Ramankutty, 2016). This makes the study of water balance and soil evaporation in semi-arid areas, very important for humanity as a whole.

This thesis demonstrates how to source soil evaporation into unsaturated zone evaporation $\left(E_{u}\right)$ and groundwater evaporation $\left(E_{g}\right)$. Accurate and separate (sourced) estimates of $E_{u}$ and $E_{g}$ are important to manage irrigation and groundwater resources in a sustainable manner, so to answer the strategic questions: how much soil moisture will be lost to direct evaporation, how much will remain in the root zone or concentrate close to the zero flux plane, and how much will eventually recharge the groundwater. The $E_{g}$ estimates are also important to assess net recharge, risk of salinization, and the amount of groundwater resources available for abstraction, including irrigation. The findings of this thesis show that both $E_{u}$ and $E_{g}$ should be taken into account separately, especially because the $E_{g}$ in dry conditions, is usually neglected, or underestimated by one or two orders of magnitude in hydrological models. The experiments under field conditions have shown that the $E_{g}$ in the semi-arid, dry conditions is high (from 0.2 to $1.2 \mathrm{~mm} \mathrm{~d}^{-1}$ ), even with water table depths of several metres deep, and that it cannot be predicted well on the basis of the available theories.

A very important finding of this thesis is that, in the presence of a dry soil layer (DSL), the $E_{g}$ does not show any correlation with groundwater table depth, at least in the conditions studied (water table depths between $<1 \mathrm{~m}$ to $10 \mathrm{~m}$ b.g.s.). Another important finding is that the transport of water vapour through a DSL cannot be explained by Fick's diffusion alone, since diffusion flow is inversely proportional to distance travelled by the water vapour (i.e. DSL thickness). In this study, evaporation rates measured in the laboratory and in the field did not show any correlation with DSL thickness, which ranged between 10 and $170 \mathrm{~cm}$. The forcing factors of the transport of water vapour through the DSL, were identified as: atmospheric pressure fluctuations (in both the laboratory and in the field lysimeter), and bulk transport of air due to changes in the temperature profile of the DSL during a day (in the field lysimeter only). 
Which set of conditions determines the dominant transport processes of water vapour through the DSL, and how they evolve in time with the evolution of the DSL, could only partly be answered through the experiments presented. This study took into consideration only predominantly sandy soils, while the formation and behaviour of a DSL should be expanded to other soil textures. A factorial, process-oriented, laboratory lysimeter experiment should be designed to observe the formation of a DSL with different initial soil moisture profiles, water table depths, soil materials, evaporative conditions, and presence or absence of grass to expand on the critical length $\left(L_{c}\right)$ for transition to stage 2 of evaporation, following the theory presented in Shokri et al. (2007). The same set of lysimeter experiments should be then conducted under semi-arid and arid field conditions to validate the laboratory results, but also to assess field interactions between grasses and soils throughout spring time towards the dry season, in order to evaluate the role, the grass may play in promoting the formation of a DSL. 


\section{Bibliography}

Adams, H. D., Luce, C. H., Breshears, D. D., Allen, C. D., Weiler, M., Hale, V. C., Smith, Al. M. S., Huxman, T. E. (2010) 'Ecohydrology Bearing - Invited Commentary Transformation ecosystem change and ecohydrology: ushering in a new era for watershed management', Ecohydrology, 5(February), pp. 145-159. doi: 10.1002/eco.

Allison, G. B. (1998) 'Stable isotopes in soil and water studies', Colloques et séminaires - Institut français de recherche scientifique pour le développement en coopération, pp. 23-38. Available at: http://cat.inist.fr/?aModele=afficheN\&cpsidt $=2279868$.

Allison, G. B., Barnes, C. J. and Hughes, M. W. (1983) 'The distribution of deuterium and180 in dry soils 2. Experimental', Journal of Hydrology, 64(14), pp. 377-397. doi: 10.1016/0022-1694(83)90078-1.

Anderson, R. A., Fralish, J. S. and Baskin, J. M. (1999) Savannas, Barrens, and Rock Outcrop Plant Communities of North America. Cambridge University Press.

Antoine, R., Baratoux, D., Rabinowicz, M., Fontaine, F., Bachèlery, P., Staudacher, T., Saracco, G., Finizola, A. (2009) 'Thermal infrared image analysis of a quiescent cone on Piton de la Fournaise volcano: Evidence of convective air flow within an unconsolidated soil', Journal of Volcanology and Geothermal Research, 183(3-4), pp. 228-244.

Asseng, S., Ewert, F., Martre, P., Lobell, D. B., Cammarano, D., Kimball, B. A., Ottman, M. J., White, J. W., Reynolds, M. P., Alderman, P. D., Aggarwal, P. K., Anothai, J., Basso, B., Challinor, A. J., Sanctis, G. De, Doltra, J., Fereres, E., Gayler, S., Hoogenboom, G., Hunt, L. A., Izaurralde, R. C., Jabloun, M., Jones, C. D., Kersebaum, K. C., Naresh, S., Nendel, C., Olesen, J. E., Palosuo, T., Priesack, E., Rezaei, E. E., Ruane, A. C., Shcherbak , Stratonovitch, P., Streck, T., Supit, I., Tao, F., Thorburn, P., Waha, K., Wallach, D., Wolf, J., Zhao, Z., Zhu, Y. (2015) 'Rising temperatures reduce global wheat production', Nature Clim Change 5, 143-147. https://doi.org/10.1038/nclimate2470.

Assouline, S., Tyler, S. W., Selker, J. S., Lunati, I., Higgins, C. W., Parlange, M. B. (2013) 'Evaporation from a shallow water table: Diurnal dynamics of water and heat at the surface of drying sand', Water Resources Research, 49(7), pp. 4022-4034. doi: 10.1002/wrcr.20293.

Auer, L. H., Rosenberg, N. D., Birdsell, K. H., Whitney, E. M. (1996) 'The effects of barometric pumping on contaminant transport', Journal of Contaminant Hydrology, 24(2), pp. 145-166. doi: 10.1016/S0169-7722(96)00010-1. 
Badreldin, N., and Xing, Z. and and Goossens, R. (2017) 'The application of satellite-based model and bi-stable ecosystem balance concept to monitor desertification in arid lands, a case study of Sinai Peninsula', Modeling Earth Systems and Environment, 3(1), p. 21.

Bakker, G., van der Ploeg, M. J., de Rooij, G. H., Hoogendam, C. W., Gooren, H. P. A., Huiskes, C., Koopal, L. K., Kruidhof, H. (2007) 'New polymer tensiometers: Measuring matric pressures down to the wilting point', Vadose Zone Journal, 6(1), pp. 196-202.

Baldocchi, D. D., Hincks, B. B. and Meyers, T. P. (1988) 'Measuring BiosphereAtmosphere Exchanges of Biologically Related Gases with Micrometeorological Methods', Ecology, 69(5), pp. 1331-1340.

Baldocchi, D. D. and Meyers, T. P. (1988) 'A spectral turbulence and lagcorrelation analysis of turbulence in a deciduous forest canopy', BoundaryLayer Meteorology, 45, pp. 31-58.

Baldocchi, D. D. and Meyers, T. P. (1991) 'Trace gas exchange above the floor of a deciduous forest: 1 . Evaporation and $\mathrm{CO}_{2}$ efflux', Journal of Geophysical Research, 96(D4), pp. 7271-7285. doi: 10.1029/91JD00269.

Baldocchi, D. D. and Xu, L. (2007) 'What limits evaporation from Mediterranean oak woodlands - The supply of moisture in the soil, physiological control by plants or the demand by the atmosphere?', Advances in Water Resources, 30(10), pp. 2113-2122.

Baldocchi, D. D., Xu, L. and Kiang, N. (2004) 'How plant functional-type, weather, seasonal drought, and soil physical properties alter water and energy fluxes of an oak-grass savanna and an annual grassland', Agricultural and Forest Meteorology, 123(1-2), pp. 13-39.

Balugani, E., Reyes-Acosta, J. L., van der Tol, C., Frances, A. P., Lubczynski, M. W. (2011) 'Partitioning and sourcing of dry season ET fluxes at the footprint of the eddy covariance tower in sardon semi - arid location in Spain'.

Balugani, E., Lubczynski, M. W., Reyes-Acosta, J. L., van der Tol, C., Frances, A. P., Metselaar, K. (2017) 'Groundwater and unsaturated zone evaporation and transpiration in a semi-arid open woodland', Journal of Hydrology, 547, pp. 54-66. doi: 10.1016/j.jhydrol.2017.01.042.

Balugani, E., Lubczynski, M. W., van der Tol, C., and Metselaar, K. (2018) 'Testing three approaches to estimate soil evaporation through a dry soil layer in a semi-arid area', Journal of Hydrology. Elsevier, 567(September), pp. 405-419. doi: 10.1016/j.jhydrol.2018.10.018.

Balugani, E., Lubczynski, M. W. and Metselaar, K. (2016) 'A framework for sourcing of evaporation between saturated and unsaturated zone in bare 
soil condition', Hydrological Sciences Journal, 61(11). doi: 10.1080/02626667.2014.966718.

Barnes, C. J. and Allison, G. B. (1984) 'The distribution of deuterium and 180 in dry soils. 3. Theory for non-isothermal water movement', Journal of Hydrology, 74(1-2), pp. 119-135. doi: 10.1016/0022-1694(84)90144-6.

Barnes, C. J. and Allison, G. B. (1988) 'Tracing of water movement in the unsaturated zone using stable isotopes of hydrogen and oxygen', Journal of Hydrology, 100(1-3), pp. 143-176. doi: 10.1016/0022-1694(88)90184-9.

Bavel, C. H. M. Van and Hillel, D. I. (1976) '( 1948 ), is a standard approach to the problem. Its essential objective was to avoid the need to $\mathrm{k} \mathrm{n} \mathrm{o} \mathrm{w}$ the surface temperature. Thus, in the original Penman version the surface temperature was assumed to be equal to the air temperature in estimating', 17 , pp. 453-476.

Bear, J. (1972) Dynamics of Fluids in Porous Media. New York, NY: American Elsevier.

Bittelli, M., Ventura, F., Campbell, G. S., Snyder, R. L., Gallegati, F., Pisa, P. R. (2008) 'Coupling of heat, water vapour, and liquid water fluxes to compute evaporation in bare soils', Journal of Hydrology, 362(3-4), pp. 191-205.

Bowen, I. S. (1926) 'The ratio of heat losses by conduction and by evaporation from any water surface', Physical Review, 27, pp. 779-787.

Bowling, D. R., Egan, J. E., Hall, S. J., Risk, D. A. (2015) 'Environmental forcing does not induce diel or synoptic variation in the carbon isotope content of forest soil respiration', Biogeosciences, 12(16), pp. 5143-5160. doi: $10.5194 / \mathrm{bg}-12-5143-2015$.

Brændholt, A., Steenberg Larsen, K., Ibrom, A., Pilegaard, K. (2017) 'Overestimation of closed-chamber soil $\mathrm{CO}_{2}$ effluxes at low atmospheric turbulence', Biogeosciences, 14(6), pp. 1603-1616. doi: 10.5194/bg-141603-2017.

Van Brakel, J. (1980) 'Mass Transfer in Convective Drying', in Mujumdar, A. S. (ed.) Advances in Drying. Washington, DC: Hemisphere Publishing Corporation, pp. 217-267.

Breshears, D. D. (2006) 'The grassland-forest continuum: Trends in ecosystem properties for woody plant mosaics?', Frontiers in Ecology and the Environment, 4(2), pp. 96-104. doi: 10.1890/15409295(2006)004[0096:TGCTIE]2.0.CO;2.

Brooks, J. R., Meinzer, F. C., Coulombe, R., Gregg, J. (2002) 'Hydraulic redistribution of soil water during summer drought in two contrasting Pacific Northwest coniferous forests', Tree Physiology, 22(15-16), pp. 1107-1117. 
Brooks, R. H. and Corey, a T. (1964) 'Hydraulic properties of porous media', Hydrology Papers, Colorado State University. Fort Collins CO, 3(3), p. 27 pgs. doi: citeulike-article-id:711012.

Brutsaert, W. (2005) Hydrology - An Introduction. Cambridge University Press.

Brutsaert, W. (2014a) 'Daily evaporation from drying soil: universal parameterization with similarity', Water Resources Research, 50, pp. 32063215. doi: 10.1002/2013WR014872.

Brutsaert, W. (2014b) 'The daily mean zero-flux plane during soil-controlled evaporation: A Green's function approach', Water Resour. Res, 50, pp. 9405-9413. doi: 10.1111/j.1752-1688.1969.tb04897.x.

Brutsaert, W. and Chen, D. (1995) 'Desorption and the two stages of drying of natural tallgrass prairie', 31(5), pp. 1305-1313.

Buck, A. L. (1981) 'New equations for computing vapour pressure and enhancement factor.', Journal of Applied Meteorology, pp. 1527-1532. doi: 10.1175/1520-0450(1981)020<1527: nefcvp>2.0.co;2.

Businger, J. A. (1986) 'Evaluation of the accuracy with which dry deposition can be measured with current micrometeorlogical techniques', Journal of Climate and Applied Meteorology, 25, pp. 1100-1124.

Bussel, L. G. J. Van, Grassini, P., Wart, J. Van, Wolf, J., Claessens, L., Yang, H., Boogaard, H., Groot, H. De, Saito, K., Cassman, K. G., Ittersum, M. K. Van (2015) 'Field Crops Research From field to atlas : Upscaling of locationspecific yield gap estimates', Field Crops Research. Elsevier B.V., 177, pp. 98-108. doi: 10.1016/j.fcr.2015.03.005.

Cavanaugh, M. L., Kurc, S. A. and Scott, R. L. (2010) 'Evapotranspiration partitioning in semi-arid shrubland ecosystems: a two-site evaluation of soil moisture control on transpiration', Ecohydrology, p. n/a-n/a.

Chenini, I. and Ben Mammou, A. (2010) 'Groundwater recharge study in arid region: An approach using GIS techniques and numerical modeling', Computers \& Geosciences, 36(6), pp. 801-817.

Clements, W. E. and Wilkening, M. H. (1974) 'Atmospheric pressure effects on 222Rn transport across the Earth-air interface', Journal of Geophysical Research (1896-1977). John Wiley \& Sons, Ltd, 79(33), pp. 5025-5029. doi: $10.1029 /$ JC079i033p05025.

Cohen, Y., Grifoll, J. and Gasto, J. M. (2005) 'Non-isothermal soil water transport and evaporation', 28, pp. 1254-1266. doi: 10.1016/j.advwatres.2005.04.008.

Daamen, Carl C., Simmonds, L. P., Wallace, J. S., Laryea, K. B., Sivakumar, M. V.K. (1993) 'Use of microlysimeters to measure evaporation from sandy 
soils', Agricultural and Forest Meteorology, 65(3-4), pp. 159-173. doi: 10.1016/0168-1923(93)90002-Y.

Davarzani, H., Smits, K., Tolene, R. M., Illangasekare, T. (2014) 'Study of the effect of wind speed on evaporation from soil through integrated modeling of the atmospheric boundary layer and shallow subsurface', Water Resources Research, 50(1), pp. 661-680. doi: 10.1002/2013WR013952.

David, T. S., Henriques, M. O., Kurz-Besson, C., Nunes, J., Valente, F., Vaz, M., Pereira, J. S., Siegwolf, R., Chaves, M. M., Gazarini, L. C., David, J. S. (2007) 'Water-use strategies in two co-occurring Mediterranean evergreen oaks: surviving the summer drought', Tree Physiology, 27(6), pp. 793-803.

Deol, P. K. et al. (2014) 'Inception and Magnitude of Subsurface Evaporation for a Bare Soil with Natural Surface Boundary Conditions', Soil Science Society of America Journal, 78(5), p. 1544. doi: 10.2136/sssaj2013.12.0520.

Detto, M., Heitman, J. L., Amoozegar, A., Ren, T., Horton, R. (2006) 'Soil moisture and vegetation controls on evapotranspiration in a heterogeneous Mediterranean ecosystem on Sardinia , Italy', Water Resources Research, 42(W08419), pp. 1-16. doi: 10.1029/2005WR004693.

Dhungel, R., Aiken, R., Colaizzi, P. D., Lin, X., O'Brien, D., Baumhardt, R. L., Brauer, D. K., Marek, G. W. (2019) 'Evaluation of uncalibrated energy balance model (BAITSSS) for estimating evapotranspiration in a semi-arid, advective climate', Hydrological Processes, 33(15), pp. 2110-2130. doi: 10.1002/hyp. 13458.

Dijkema, J., Koonce, J. E., Shillito, R. M., Ghezzehei, T. A., Berli, M., Ploeg, M. J. Van Der, Genuchten, M. Th. Van (2017) 'Water Distribution in an Arid Zone Soil : Numerical Analysis of Data from a Large Weighing Lysimeter'. doi: $10.2136 / v z j 2017.01 .0035$.

Du, C., Yu, J., Wang, P., Zhang, Y. (2018) 'Analysing the mechanisms of soil water and vapour transport in the desert vadose zone of the extremely arid region of northern China', Journal of Hydrology, 558, pp. 592-606. doi: 10.1016/j.jhydrol.2017.09.054.

Durner, W. (1994) 'Hydraulic conductivity estimation for soils with heterogeneous pore structure', Water Resour. Res., 30(2), pp. 211-223.

Elberling, B., Larsen, F., Christensen, S., Postma, D. (1998) 'Gas transport in a confined unsaturated zone during atmospheric pressure cycles', Water Resources Research. John Wiley \& Sons, Ltd, 34(11), pp. 2855-2862. doi: 10.1029/98WR02037.

Farrell, D. A., Greacen, E. L. and Gurr, C. G. (1966) 'vapour transfer in soil due to air turbulence', Soil Science, 102(5). Available at: 
https://journals.Iww.com/soilsci/Fulltext/1966/11000/VAPOUR_TRANSFER _IN_SOIL_DUE_TO_AIR_TURBULENCE.5.aspx.

Favreau, G., Cappelaere, B., Massuel, S., Leblanc, M., Boucher, M., Boulain, N., Leduc, C. (2009) 'Land clearing, climate variability, and water resources increase in semi-arid southwest Niger: A review', Water Resources Research, 45(7), pp. 1-18. doi: 10.1029/2007WR006785.

Fayer, M. J. and Simmons, C. S. (1995) 'Modified soil water retention functions for all matric suctions', Water Resources Research, 31(5), pp. 1233-1238.

Feddes, R. A., Kowalik, P. J. and Zaradny, H. (1978) Simulation of field water use and crop yield. New York, NY.

Fetzer, T., Vanderborght, J., Mosthaf, K., Smits, K. M. (2017) 'Heat and water transport in soils and across the soil-atmosphere interface: 2. Numerical analysis', Water Resources Research, 53, pp. 1080-1100. doi: 10.1002/2016WR019982. Heat.

Fisher, J. B., Baldocchi, D. D., Misson, L., Dawson, T. E., Goldstein, A. H. (2007) 'What the towers don't see at night: nocturnal sap flow in trees and shrubs at two Ameriflux sites in California', Tree Physiology, 27(4), pp. 597-610.

Flemisch, B., Darcis, M., Erbertseder, K., Faigle, B., Lauser, A., Mosthaf, K., Müthing, S., Nuske, P., Tatomir, A., Wolff, M., Helmig, R. (2011) 'DuMux: DUNE for multi-\{phase, component, scale, physics,...\} flow and transport in porous media', Advances in Water Resources, 34(9), pp. 1102-1112.

Foken, T., Gockede, M., Mauder, M., Mahrt, L., Amiro, B., Munger, W. (2005) 'Post-Field Data Quality Control', in Lee, X., Massman, W., and Law, B. (eds) Handbook of Micrometeorology. Springer Netherlands (Atmospheric and Oceanographic Sciences Library), pp. 181-208.

Frances, Alain P., Lubczynski, M. W., Roy, J., Santos, F. A.M., Mahmoudzadeh A., Mohammad R. (2014) 'Hydrogeophysics and remote sensing for the design of hydrogeological conceptual models in hard rocks - Sardón catchment (Spain)', Journal of Applied Geophysics. Elsevier B.V., 110, pp. 63-81. doi: 10.1016/j.jappgeo.2014.08.015.

Frances, A. P., Su, Z. and Lubczynski, M. W. (2015) Integration of hydrogeophysics and remote sensing with coupled hydrological models.

Ganot, Y., Dragila, M. I. and Weisbrod, N. (2014) 'Impact of thermal convection on $\mathrm{CO}_{2}$ flux across the earth-atmosphere boundary in high-permeability soils', Agricultural and Forest Meteorology. Elsevier B.V., 184, pp. 12-24. doi: 10.1016/j.agrformet.2013.09.001. 
Gardner, W. R. and Fireman, M. (1958) 'Laboratory Studies of Evaporation From Soil Columns in the Presence of A Water Table', Soil Science, 85(5), pp. 244-249.

van Genuchten, M. T. (1980) 'A closed-form equation for predicting the hydraulic conductivity of unsaturated soilsl', Soil Sci. Soc. Am. J., 44, pp. 892-898.

Ghimire, C. P., Bruijnzeel, L. A., Lubczynski, M. W., Bonell, M. (2012) 'Rainfall interception by natural and planted forests in the Middle Mountains of Central Nepal', Journal of Hydrology. Elsevier B.V., 475, pp. 270-280. doi: 10.1016/j.jhydrol.2012.09.051.

Göckede, M., Rebmann, C. and Foken, T. (2004) 'A combination of quality assessment tools for eddy covariance measurements with footprint modelling for the characterisation of complex sites', Agricultural and Forest Meteorology, 127(3-4), pp. 175-188.

Gökmen, M., Vekerdy, Z., Verhoef, A., Verhoef, W., Batelaan, O., van der Tol, C. (2012) 'Integration of soil moisture in SEBS for improving evapotranspiration estimation under water stress conditions', Remote Sensing of Environment, 121(0), pp. 261-274.

Good, S. P., Noone, D. and Bowen, G. (2015) 'Hydrologic connectivity constrains partitioning of global terrestrial water fluxes', Science, 349(6244), pp. 175-177.

Goulden, M. L., Munger, J. W., Fan, S., Daube, B. C., Wofsy, S. C. (1996) 'Measurements of carbon sequestration by long-term eddy covariance: methods and a critical evaluation of accuracy', Global Change Biology, 2(3), pp. 169-182.

Gowing, J. W., Konukcu, F. and Rose, D. A. (2006) 'Evaporative flux from a shallow watertable: The influence of a vapour-liquid phase transition', Journal of Hydrology, 321(1-4), pp. 77-89.

Gran, M., Carrera, J., Massana, J., Saaltink, M. W., Olivella, S., Ayora, C., Lloret, A. (2011) 'Dynamics of water vapour flux and water separation processes during evaporation from a salty dry soil', Journal of Hydrology, 396(3-4), pp. 215-220.

Granier, A. (1985) 'A New Method of Sap Flow Measurement in Tree Stems', Annales Des Sciences Forestieres, 42(2), pp. 193-200.

Granier, A. (1987) 'Evaluation of transpiration in a Douglas-fir stand by means of sap flow measurements', Tree Physiology, 3(4), pp. 309-320.

Gribovszki, Z., Szilagyi, J. and Kalicz, P. (2010) 'Diurnal fluctuations in shallow groundwater levels and streamflow rates and their interpretation - A review', Journal of Hydrology, 385, pp. 371-383. 
Grifoll, J. (2011) 'Contribucion de la dispersion del vapour de agua en el suelo al proceso de evaporacion', in Martínez Fernández, J. and Sánchez Martín, N. (eds.) Estudios en la Zona no Saturada del Suelo, vol. X, pp. 247-252.

Grifoll, J. (2013) 'Contribution of mechanical dispersion of vapour to soil evaporation', Water Resources Research, 49(2), pp. 1099-1106. doi: 10.1002/wrcr.20105.

Grifoll, J., Gasto, J. M. and Cohen, Y. (2005) 'Non-isothermal soil water transport and evaporation', Advances in Water Resources, 28(11), pp. 1254-1266.

Grunberger, O., Michelot J., Bouchaou, L., Macaigne, P., Hsissou, Y., Hammecker, C. (2011) 'Capillary rise quantifications based on in-situ artificial deuterium peak displacement and laboratory soil characterization', Hydrology and Earth System Sciences, 15, pp. 1629-1639.

Gualdi, S., Somot, S., Li, L., Artale, V., Adani, M., Bellucci, A., Braun, A., Calmanti, S., Carillo, A., Dell'Aquila, A., Déqué, M., Dubois, C., Elizalde, A., Harzallah, A., Jacob, D., L'Hévéder, B., May, W., Oddo, P., Ruti, P., Sanna, A., Sannino, G., Scoccimarro, E., Sevault, F., Navarra, A. (2013) 'The CIRCE Simulations: Regional Climate Change Projections with Realistic Representation of the Mediterranean Sea', Bulletin of the American Meteorological Society, 94(1), pp. 65-81. doi: 10.1175/BAMS-D-1100136.1 .

Guswa, A. J., Celia, M. A. and Rodriguez-Iturbe, I. (2004) 'Effect of vertical resolution on predictions of transpiration in water-limited ecosystems', Advances in Water Resources, 27(5), pp. 467-480. doi: https://doi.org/10.1016/j.advwatres.2004.03.001.

Gwate, O., Mantel, S. K., Finca, A., Gibson, L. A., Munch, Z., Palmer, A. R. (2019) 'Estimating evapotranspiration in semi-arid rangelands: connecting reference to actual evapotranspiration and the role of soil evaporation', African Journal of Range \& Forage Science. Taylor \& Francis, 36(1), pp. 1725. doi: $10.2989 / 10220119.2018 .1505779$.

Haghighi, E. and Kirchner, J. W. (2017) 'Near-surface turbulence as a missing link in modeling evapotranspiration-soil moisture relationships', Water Resources Research, 53(7), pp. 5320-5344. doi: 10.1002/2016WR020111.

Haghighi, E. and Or, D. (2013) 'Evaporation from porous surfaces into turbulent airflows: Coupling eddy characteristics with pore scale vapour diffusion', Water Resources Research, 49(12), pp. 8432-8442. doi: 10.1002/2012WR013324.

Hassan, S. M. T., Lubczynski, M. W., Niswonger, R. G., Su, Z. (2014) 'Surface - groundwater interactions in hard rocks in Sardon Catchment of western 
Spain: An integrated modeling approach', Journal of hydrology. Elsevier B.V., 517, pp. 390-410. doi: 10.1016/j.jhydrol.2014.05.026.

Hassan, S. M. T., Ghimire, C. P. and Lubczynski, M. W. (2017) 'Remote sensing upscaling of interception loss from isolated oaks: Sardon catchment case study, Spain', Journal of Hydrology. The Author(s), 555, pp. 489-505. doi: 10.1016/j.jhydrol.2017.08.016.

Heusinkveld, B. G., Berkowicz, S. M., Jacobs, A. F. G., Hillen, W., Holtslag, A. A. M. (2008) 'A new remote optical wetness sensor and its applications', Agricultural and Forest Meteorology, 148(4), pp. 580-591.

Hillel, D. (1998) Environmental soil physics. San Diego, CA: Academic Press.

Hillel, D. (2004) Introduction to environmental soil physics. Amsterdam; Boston: Elsevier Academic Press.

Ho, C. K. and Webb, S. W. (1996) 'Diffusion Mechanisms, Models, and Data - Does Enhanced Vapour-Phase Diffusion Exist?', (May).

Ho, C. K. and Webb, S. W. (2006) Gas transport in porous media, Theory and Applications of Transport in Porous Media. Edited by J. Bear. Springer. doi: $10.1017 /$ S0022112000211312.

Hsieh, C.-I., Katul, G. and Chi, T. (2000) 'An approximate analytical model for footprint estimation of scalar fluxes in thermally stratified atmospheric flows', Advances in Water Resources, 23(7), pp. 765-772.

Huang, J., Ji, M., Xie, Y., Wang, S., He, Y., Ran, J. (2016) 'Global semi-arid climate change over last 60 years', Climate Dynamics. Springer Berlin Heidelberg, 46(3-4), pp. 1131-1150. doi: 10.1007/s00382-015-2636-8.

Idso, S. B., Reginato, R. J. and Jackson, R. D. (1979) 'Calculation of evaporation during the three stages of soil drying', Water Resources Research, 15(2), pp. 487-488.

Iizumi, T. et al. (2014) 'Historical changes in global yields: major cereal and legume crops from 1982 to 2006', pp. 346-357. doi: 10.1111/geb.12120.

Iizumi, T. and Ramankutty, N. (2016) 'Changes in yield variability of major crops for 1981-2010 explained by climate change', Environmental Research Letters. IOP Publishing, 11(3), p. 0. doi: 10.1088/1748-9326/11/3/034003.

Ishihara, Y., Shimojima, E. and Harada, H. (1992) 'Water vapour transfer beneath bare soil where evaporation is influenced by a turbulent surface wind', Journal of Hydrology, 131(1-4), pp. 63-104. doi: 10.1016/00221694(92)90213-F.

Ittersum, M. K. Van, Cassman, K. G., Grassini, P., Wolf, J., Tittonell, P., Hochman, Z. (2013) 'Field Crops Research Yield gap analysis with local to 
global relevance - A review', Field Crops Research. Elsevier B.V., 143, pp. 4-17. doi: 10.1016/j.fcr.2012.09.009.

Jackson, R. D., Kimball, B. A., Reginato, R. J., Nakayama, F. S. (1973) 'Diurnal Soil-Water Evaporation: Time-Depth-Flux Patterns', Soil Sci. Soc. Am. Proc., 37(4), pp. 505-509.

Jiang, Y., Tang, R., Jiang, X., Li, Z., Gao, C. (2019) 'Estimation of Soil Evaporation and Vegetation Transpiration Using Two Trapezoidal Models From MODIS Data', Journal of Geophysical Research: Atmospheres, 124(14), pp. 7647-7664. doi: 10.1029/2019JD030542.

Jiao, J. J. and Li, H. (2004) 'Breathing of coastal vadose zone induced by sea level fluctuations', Geophysical Research Letters. John Wiley \& Sons, Ltd, 31(11). doi: 10.1029/2004GL019572.

Kamai, T., Weisbrod, N. and Dragila, M. I. (2009) 'Impact of ambient temperature on evaporation from surface-exposed fractures', Water Resources Research. John Wiley \& Sons, Ltd, 45(2). doi: 10.1029/2008WR007354.

Kampf, S. K., Tyler, S. W., Ortiz, C. A., Muñoz, J. F., Adkins, P. L. (2005) 'Evaporation and land surface energy budget at the Salar de Atacama, Northern Chile', Journal of Hydrology, 310(1-4), pp. 236-252.

Katata, G., Nagai, H., Ueda, H., Agam, N., Berliner, P. R. (2007) 'Development of a land surface model including evaporation and adsorption processes in the soil for the land-air exchange in arid regions', Journal of Hydrometeorology, 8(6), pp. 1307-1324. doi: 10.1175/2007JHM829.1.

Khalil, M., Sakai, M., Mizoguchi, M., Miyazaki, T. (2003) 'Current and Prospective Applications of Zero Flux Plane ( ZFP ) Method', Journal of the Japanese Society of Soil Physics, 95(3), pp. 75-90.

Khlosi, M., Cornelis, W. M., Douaik, A., van Genuchten, M. Th., Gabriels, D. (2008) 'Performance Evaluation of Models That Describe the Soil Water Retention Curve between Saturation and Oven Dryness', Vadose Zone Journal, 7(1), pp. 87-96. doi: 10.2136/vzj2007.0099.

Kizito, F., Campbell, C. S., Campbell, G. S., Cobos, D. R., Teare, B. L., Carter, B., Hopmans, J. W. (2008) 'Frequency, electrical conductivity and temperature analysis of a low-cost capacitance soil moisture sensor', Journal of Hydrology, 352(3-4), pp. 367-378.

Kuang, X., Jiao, J. J. and Li, H. (2013) 'Review on airflow in unsaturated zones induced by natural forcings', Water Resources Research, 49(10), pp. 61376165. doi: 10.1002/wrcr.20416.

Kwicklis, E. M., Wolfsberg, A. V., Stauffer, P. H., Walvoord, M. A., Sully, M. J. (2006) 'Multiphase, Multicomponent Parameter Estimation for Liquid and 
Vapour Fluxes in Deep Arid Systems Using Hydrologic Data and Natural Environmental Tracers', pp. 934-950. doi: 10.2136/vzj2006.0021.

Lafayette, F. B., Montenegro, S. M. G. L., Coutinho, A. P., Soares, W., Antonino, A. C. D., da Silva, B. B., Rabelo, A. E. C. de G. da C. (2019) 'Experimentation and modeling of soil evaporation in underground dam in a semi-arid region', Revista Brasileira de Recursos Hidricos, 24. doi: 10.1590/2318-0331.2431920170167.

Lampinen, M., Assad, M. el H. and Curd, E. F. (2001) PHYSICAL FUNDAMENTALS, Industrial Ventilation Design Guidebook. doi: 10.1016/B978-012289676-7/50007-2.

Lasage, R., Aerts, J., Mutiso, G. C.M., de Vries, A. (2008) 'Potential for community based adaptation to droughts: Sand dams in Kitui, Kenya', Physics and Chemistry of the Earth, 33(1-2), pp. 67-73. doi: 10.1016/j.pce.2007.04.009.

De Laurentiis, V., Secchi, M., Bos, U., Horn, R., Laurent, A., Sala, S. (2019) 'Soil quality index: Exploring options for a comprehensive assessment of land use impacts in LCA', Journal of Cleaner Production. Elsevier Ltd, 215, pp. 63-74. doi: 10.1016/j.jclepro.2018.12.238.

Lautz, L. K. (2008) 'Estimating groundwater evapotranspiration rates using diurnal water-table fluctuations in a semi-arid riparian zone', Hydrogeology Journal, 16(3), pp. 483-497. doi: 10.1007/s10040-007-0239-0.

Lawrence, D. M., Lawrence, D. M., Thornton, P. E., Oleson, K. W., Bonan, G. B. (2006) 'The Partitioning of Evapotranspiration into Transpiration, Soil Evaporation, and Canopy Evaporation in a GCM: Impacts on Land Atmosphere Interaction', Hydrometeorology, Journal O F, 8(1998), pp. 862-880. doi: 10.1175/JHM596.1.

Lehmann, Peter, Assouline, S. and Or, D. (2008) 'Characteristic lengths affecting evaporative drying of porous media', Physical Review E Statistical, Nonlinear, and Soft Matter Physics, 77(5), pp. 1-16. doi: 10.1103/PhysRevE.77.056309.

Lehmann, P, Assouline, S. and Or, D. (2008a) 'Characteristic lengths affecting evaporative drying of porous media', Physical Review E, 77(5), p.

Lehmann, P, Assouline, S. and Or, D. (2008b) 'Characteristic lengths affecting evaporative drying of porous media', Physical Review E, 77(5), p.

Lehmann, P. and Or, D. (2009) 'Evaporation and capillary coupling across vertical textural contrasts in porous media', Physical Review E, 80(4), p. 46318. 
Li, H., Wang, W., Zhan, H., Qiu, F., An, L. (2010) 'New judgement on the source of soil water in extremely dry zone', Acta Ecologica Sinica, 30(1), pp. $1-7$.

Li, H., Wang, W. and Liu, B. (2014) 'The daily evaporation characteristics of deeply buried phreatic water in an extremely arid region', Journal of Hydrology. Elsevier B.V., 514, pp. 172-179. doi: 10.1016/j.jhydrol.2014.04.025.

Liu, B. C., Liu, W. and Peng, S. W. (2005) 'Study of heat and moisture transfer in soil with a dry surface layer', International Journal of Heat and Mass Transfer, 48(21-22), pp. 4579-4589.

Liu, X., Kang, S. and Li, F. (2009) 'Simulation of artificial neural network model for trunk sap flow of Pyrus pyrifolia and its comparison with multiple-linear regression', Agricultural Water Management, 96(6), pp. 939-945.

Loheide, S. P. I. I., Butler, J. J. J. and Gorelick, S. M. (2005) 'Estimation of groundwater consumption by phreatophytes using diurnal water table fluctuations: A saturated-unsaturated flow assessment', Water Resour. Res., 41(7), p. W07030.

Long, S. P., Ainsworth, E. A., Leakey, A. D. B., Ort, D. R., No, J. (2006) 'Food for Thought: Lower-Than-', Science, Vol 312(June), pp. 1918-1922.

Lu, S., Ren, T., Gong, Y., Horton, R. (2008) 'Evaluation of Three Models that Describe Soil Water Retention Curves from Saturation to Oven Dryness', Soil Science Society of America Journal, 72(6), pp. 1542-1546. doi: 10.2136/sssaj2007.0307n.

Lubczynski, M. (2000) Groundwater evapotranspiration-Underestimated component of the groundwater balance in a semi-arid environment-Serowe case, Botswana. Balkema, Rotterdam. (Groundwater: Past Achievements and Future Challenges).

Lubczynski, M. (2011) 'Groundwater evapotranspiration : underestimated role of tree transpiration and bare soil evaporation in groundwater balances of dry lands.', in A. Baba, [et al.]. (ed.) Climate change and its effects on water resources: issues of national and global security : proceedings of the NATO advanced research workshop on effect of climate change on water resources, Izmir, Turkey, 1-4 September 2010. Springer, 2011., pp. 183190.

Lubczynski, M. W. (2009) 'The hydrogeological role of trees in water-limited environments', Hydrogeology Journal, 17(1), pp. 247-259.

Lubczynski, M. W. (2011) 'Groundwater Evapotranspiration - Underestimated Role of Tree Transpiration and Bare Soil Evaporation in Groundwater Balances of Dry Lands', in Baba, A. et al. (eds) Climate Change and its 
Effects on Water Resources: Issues of National and Global Security. Springer the Netherland, pp. 183-190. doi: 10.1007/978-94-007-1143-3.

Lubczynski, M. W., Chavarro-Rincon, D. and Roy, J. (2012) 'Novel, cyclic heat dissipation method for the correction of natural temperature gradients in sap flow measurements. Part 1. Theory and application', Tree Physiology, 32(7), pp. 894-912.

Lubczynski, M. W. and Gurwin, J. (2005) 'Integration of various data sources for transient groundwater modeling with spatio-temporally variable fluxes Sardon study case, Spain', Journal of Hydrology, 306(1-4), pp. 71-96.

Ma, Z., Wang, W., Zhang, Z., Brunner, P., Wang, Z., Chen, L., Zhao, M., Gong, C. (2019) 'Assessing bare-soil evaporation from different water-table depths using lysimeters and a numerical model in the Ordos Basin, China', Hydrogeology Journal, 27(7), pp. 2707-2718. doi: 10.1007/s10040-01902012-0.

Mahmoudzadeh, M. R., Frances, A. P., Lubczynski, M., Lambot, S. (2012) 'Using ground penetrating radar to investigate the water table depth in weathered granites - Sardon case study, Spain', Journal of Applied Geophysics, 79(0), pp. 17-26.

Maier, M., Schack-Kirchner, H., Hildebrand, E. E., Holst, J. (2010) 'Pore-space $\mathrm{CO}_{2}$ dynamics in a deep, well-aerated soil', European Journal of Soil Science, 61(6), pp. 877-887. doi: 10.1111/j.1365-2389.2010.01287.x.

Maier, M., Schack-kirchner, H. and Parent, F. (2011) 'Turbulence Effect on Gas Transport in Three Contrasting Forest Soils', Soil Sci. Soc. Am. J., 76(5), pp. 1518-1528. doi: 10.2136/sssaj2011.0376.

Mariotti, A., Pan, Y., Zeng, N., Alessandri, A. (2015) 'Long-term climate change in the Mediterranean region in the midst of decadal variability', Climate Dynamics, 44(5), pp. 1437-1456. doi: 10.1007/s00382-015-2487-3.

Massmann, J. and Farrier, D. F. (1992) 'Effects of atmospheric pressures on gas-transport in the vadose zone', Water Resources Research, 28(3), pp. 777-791. Available at: http://apps.isiknowledge.com/full_record.do?product=WOS\&search_mode $=$ Refine\&qid $=22 \& S I D=2$ CidfhE4I3hckObd1g5\&page $=1 \&$ doc $=1$.

Maxwell, R. M. and Condon, L. E. (2016) 'Connections between groundwater flow and transpiration partitioning', Science, 353(6297), pp. 377-380. doi: 10.1126/science.aaf7891.

Mccoll, K. A., He, Q., Lu, H., Entekhabi, D. (2019) 'Short-term and long-term surface soil moisture memory time scales are spatially anticorrelated at global scales', Journal of Hydrometeorology, 20(6), pp. 1165-1182. doi: 10.1175/JHM-D-18-0141.1. 
McColl, K. A., Wang, W., Peng, B., Akbar, R., Lu, H., Pan, M., Entekhabi, D., Gianotti, D. J. S. (2017a) 'Global characterization of surface soil moisture drydowns', Geophysical Research Letters, (44), pp. 1-9. doi: 10.1002/2017GL072819.

McColl, K. A., Alemohammad, S. H., Akbar, R., Konings, A. G., Yueh, S., Entekhabi, D. (2017b) 'The global distribution and dynamics of surface soil moisture', Nature Geoscience, 10(2), pp. 100-104. doi: 10.1038/ngeo2868.

Miller, G. R., Chen, X., Rubin, Y., Ma, S., Baldocchi, D. D. (2010) 'Groundwater uptake by woody vegetation in a semi-arid oak savanna', Water Resour. Res., 46(10), p. pp. 1-14. doi: 10.1029/2009WR008902.

Millington, R. and Quirk, J. (1960) 'Permeability of porous solids', Trans. Faraday Soc., 57, pp. 1200-1207.

Milly, P. C. D. (1982) 'Moisture and heat transport in hysteretic, inhomogeneous porous media: A matric head-based formulation and a numerical model', Water Resour. Res., 18(3), pp. 489-498.

Miyazaki, T. (1993) Water flow in soils. New York: Marcel Dekker, INC.

Moldrup, P., Olesen, T., Gamst, J., Schjonning, P., Yamaguchi, T., Rolston, D. E. (2000) 'Predicting the Gas Diffusion Coefficient in Repacked Soil', Soil Science Society of America Journal, 64(5), p. 1588 . doi: 10.2136/sssaj2000.6451588x.

van der Molen, M. K., Gash, J. H. C. and Elbers, J. A. (2004) 'Sonic anemometer (co)sine response and flux measurement: II. The effect of introducing an angle of attack dependent calibration', Agricultural and Forest Meteorology, 122(1-2), pp. 95-109.

Monteith, J. L. (1980) 'The development and extension of Penman's evaporation formula', in Press, A. (ed.) Hillel, D., 'Application of Soil Physics'. New York.

Monteith, J. L. and Unsworth, M. H. (2013) 'Chapter 16 - Micrometeorology: (i) Turbulent Transfer, Profiles, and Fluxes', in Monteith, J. L. and Unsworth, M. H. B. T.-P. of E. P. (Fourth E. (eds). Boston: Academic Press, pp. 289320. doi: https://doi.org/10.1016/B978-0-12-386910-4.00016-0.

Mosthaf, K., Baber, K., Flemisch, B., Helming, R., Leijnse, A., Rybak, I., Wohlmuth, B. (2011) 'A coupling concept for two-phase compositional porous-medium and single-phase compositional free flow', Water Resour. Res., 47(10), p. W10522.

Mosthaf, K., Helmig, R. and Or, D. (2014) 'Modeling and analysis of evaporation processes from porous media on the REV scale', Water Resources Research, 50, pp. 1059-1079. doi: 10.1002/2016WR018954.Received. 
Mualem, Y. (1984) 'A Modified Dependent-Domain Theory of Hysteresis', Soil Science, 137(5), pp. 283-291.

Mukherjee, S., Mishra, A. and Trenberth, K. E. (2018) 'Climate Change and Drought: a Perspective on Drought Indices', Current Climate Change Reports, 4(2), pp. 145-163. doi: 10.1007/s40641-018-0098-x.

Munger, J. W., Loescher, H. and Luo, H. (2012) 'Measurement, Tower, and Site Design Considerations', in Aubinet, M., Vesala, T., and Papale, D. (eds) Eddy Covariance. Springer Netherlands (Springer Atmospheric Sciences), pp. 2158.

Nachshon, U., Weisbrod, N. and Dragila, M. I. (2008) 'Quantifying Air Convection through Surface-Exposed Fractures: A Laboratory Study', Vadose Zone Journal. Madison, WI: Soil Science Society, 7, pp. 948-956. doi: $10.2136 / v z j 2007.0165$.

Nadezhdina, N., Čermák, J. and Nadezhdina, V. (1998) 'The heat field deformation method for sap flow measurement.', in Čermák J, N. N. (ed.) 4th International Workshop on Measuring Sap flow in Intact Plants, pp. 7292.

Neriah, A. B., Assouline, S., Shavit, U., Weisbrod, N. (2014) 'Impact of ambient conditions on evaporation fromporous media', Water Resources Research, 50, pp. 6696-6712. doi: 10.1002/2014WR015523. Received.

Or, D., Lehmann, P., Shahraeeni, E., Shokri, N. (2013) 'Advances in Soil Evaporation Physics-A Review', Vadose Zone Journal, 12(4), p. 0. doi: 10.2136/vzj2012.0163.

Paço, T. A., David, T. S., Henriques, M. O., Pereira, J. S., Valente, F., Banza, J., Pereira, F. L., Pinto, C., David, J. S. (2009) 'Evapotranspiration from a Mediterranean evergreen oak savannah: The role of trees and pasture', Journal of Hydrology. Elsevier B.V., 369(1-2), pp. 98-106. doi: 10.1016/j.jhydrol.2009.02.011.

Papafotiou, A., S. C., Lehman, P., Vontobel, P., Or, D., Neuweiler, I. (2010) 'Measurements of preferential flow during infiltration and evaporation in porous media', in 12th International Congress. Patras: Bulletin of the Geological Society of Greece., pp. 1831-1839.

Parlange, M. B., Cahill, A. T., Nielsen, D. R., Hopmans, J. W., Wendroth, O. (1998) 'Review of heat and water movement in field soils', Soil and Tillage Research, 47(1-2), pp. 5-10. doi: 10.1016/S0167-1987(98)00066-X.

Parsons, A. J. and Abrahams, A. D. (1994) 'Geomorphology of Desert Environments BT - Geomorphology of Desert Environments', in Abrahams, A. D. and Parsons, A. J. (eds). Dordrecht: Springer Netherlands, pp. 3-12. doi: 10.1007/978-94-015-8254-4_1. 
Paulson, C. A. (1970) 'The Mathematical Representation of Wind Speed and Temperature Profiles in the Unstable Atmospheric Surface Layer', Journal of Applied Meteorology. American Meteorological Society, 9(6), pp. 857-861. doi: 10.1175/1520-0450(1970)009<0857:TMROWS>2.0.CO;2.

Payne, W. A., Wendt, C. W. and Lascano, R. J. (1990) 'Bare Fallowing on Sandy Fields of Niger, West Africa', Soil Sci. Soc. Am. Proc., 54(4), pp. 1079-1084.

Peel, M. C., Finlayson, B. L. and Mcmahon, T. A. (2007) 'Updated world map of the Köppen-Geiger climate classification', Hydrol. Earth Syst. Sci., 11, pp. 1633-1644.

Perez, P. J., Castellvi, F., Ibanez, M., Rosell, J. I. (1999) 'Assessment of reliability of Bowen ratio method for partitioning fluxes', Agricultural and Forest Meteorology, 97(3), pp. 141-150.

Philip, J R and de Vries, D. A. (1957) 'Moisture movement in porous materials under temperature gradients', Trans. Am. Geophys. Un., 38, pp. 222-228.

Philip, J. R. and de Vries, V. D. (1957) 'Moisture movement in porous materials under temperature gradient', Eos Trans. AGU, 38(2), pp. 222-232.

van der Ploeg, M. J., Gooren, H. P. A., Bakker, G., de Rooij, G. H. (2008) 'Matric Potential Measurements by Polymer Tensiometers in Cropped Lysimeters under Water-Stressed Conditions', Vadose Zone Journal, 7(3), pp. 10481054.

Polade, S. D., Gershunov, A., Cayan, D. R., Dettinger, M. D., Pierce, D. W. (2017) 'Precipitation in a warming world: Assessing projected hydro-climate changes in California and other Mediterranean climate regions', Scientific Reports. Springer US, 7(1), pp. 1-10. doi: 10.1038/s41598-017-11285-y.

Poulsen, T. G. (2006) 'Waste Management \& Research'. doi: $10.1177 / 0734242 \times 06066363$

Prigent, C., Rossow, W. B. Matthews, E., Marticorena, B. (1999) 'Microwave radiometric signatures of different surface types in deserts', J. Geophys. Res., 104(D10), pp. 12147-12158.

Prunty, L. (2009) 'Soil Water Thermal Liquid Diffusivity', Soil Sci. Soc. Am. J., 73(3), pp. 704-706.

Qubaja, R., Amer, M., Tatarinov, F., Rotenberg, E., Preisler, Y., Sprintsin, M., Yakir, D. (2020) 'Partitioning evapotranspiration and its long-term evolution in a dry pine forest using measurement-based estimates of soil evaporation', Agricultural and Forest Meteorology. Elsevier, 281(October 2019), p. 107831. doi: 10.1016/j.agrformet.2019.107831.

Quilis, R. O., Hoogmoed, M., Ertsen, M., Foppen, J. W., Hut, R., Vries, A. de (2009) 'Measuring and modeling hydrological processes of sand-storage 
dams on different spatial scales', Physics and Chemistry of the Earth. Elsevier Ltd, 34(4-5), pp. 289-298. doi: 10.1016/j.pce.2008.06.057.

Raupach, M. R. and Finnigan, J. J. (1997) 'The influence of topography on meteorological variables and surface-atmosphere interaction', Journal of Hydrology, 190(3), pp. 182--213.

Ray, D. K., Mueller, N. D., West, P. C., Foley, J. A. (2013) 'Yield Trends Are Insufficient to Double Global Crop Production by 2050', 8(6). doi: 10.1371/journal.pone.0066428.

Reyes-Acosta, J. L. and Lubczynski, M. W. (2012) 'Novel, cyclic heat dissipation method for the correction of natural temperature gradients in sap flow measurements. Part 2. Laboratory validation', Tree Physiology, 32(7), p. 913.

Reyes-Acosta, J. L. and Lubczynski, M. W. (2011) 'Spatial assessment of transpiration, groundwater and soil-water uptake by oak trees in dry-season at a semi-arid open-forest in Salamanca, Spain.', in Martínez Fernández, J. and Sánchez Martín, N. (eds) Estudios en la Zona no Saturada del Suelo, vol. $X$, pp. 65-70.

Reyes-Acosta, J. L. and Lubczynski, M. W. (2013) 'Mapping dry-season tree transpiration of an oak woodland at the catchment scale, using objectattributes derived from satellite imagery and sap flow measurements', Agricultural and Forest Meteorology, 174-175, pp. 184-201.

Reyes-Acosta, J. Leonardo and Lubczynski, M. W. (2014) 'Optimization of dryseason sap flow measurements in an oak semi-arid open woodland in Spain', Ecohydrology, 7(2), pp. 258-277. doi: 10.1002/eco.1339.

Reyes-Acosta, J. L., Su, Z. and Lubczynski, M. W. (2015) Tree - water interactions at varying spatio temporal scales in a water limited environment. Enschede, University of Twente Faculty of Geo-Information and Earth Observation (ITC).

Richards, L. A. (1931) 'Capillary conduction of liquids through porous mediums', Journal of Applied Physics, 1(5), pp. 318-333. doi: 10.1063/1.1745010.

Ripple, C. D., Rubin, J. and van Hylkama, T. E. A. (1972) 'Estimating steadystate evaporation rates from bare soils under conditions of high water table', U.S. Geological Survey, Water supp, pp. 2019-A.

Rockström, J. (2003) 'Water for food and nature in drought - prone tropics : vapour shift in rain-fed agriculture Water for food and nature in droughtprone tropics: vapour shift in rain-fed agriculture'. doi: 10.1098/rstb.2003.1400. 
Rojstaczer, S. and Riley, F. S. (1990) 'Response of the water level in a well to Earth tides and atmospheric loading under unconfined conditions', Water Resources Research, 26(8), pp. 1803-1817. doi: 10.1029/WR026i008p01803.

Roland, M., Vicca, S., Bahn, M., Ladreiter-Knauss, T., Schmitt, M., Janssens, I. A. (2015) 'Importance of nondiffusive transport for soil $\mathrm{CO}_{2}$ efflux in a temperate mountain grassland', Journal of Geophysical Research: Biogeosciences, 120(3), pp. 502-512. doi: 10.1002/2014JG002788.

Rose, a. W. and Guo, W. (1995) 'Thermal-Convection Of Soil Air On Hillsides', Environmental Geology, 25(4), pp. 258-262. Available at: //a1995rg94500007.

Rose, C. W. (1968a) 'Water transport in soil with a daily temperature wave. I. Theory and experiment', Aust. J. Soil Res., 6, pp. 31-44.

Rose, C. W. (1968b) 'Water transport in soil with a daily temperature wave. II. Analysis', Aust. J. Soil Res., 6, pp. 45-57.

Rose, D. A. (1963) 'Water movement in porous materials: Part 1 - Isothermal vapour transfer', British Journal of Applied Physics, 14(5).

Rotenberg, E. and Yakir, D. (2010) 'Agricultural and Forest Meteorology Effects of spatial variations in soil evaporation caused by tree shading on water flux partitioning in a semi-arid pine forest', Agricultural and Forest Meteorology, 150, pp. 454-462. doi: 10.1016/j.agrformet.2010.01.010.

Rushton, K. R., Eilers, V. H. M. and Carter, R. C. (2006) 'Improved soil moisture balance methodology for recharge estimation', Journal of Hydrology, 318(1-4), pp. 379-399.

Sadeghi, M., Shokri, N. and Jones, S. B. (2012) 'A novel analytical solution to steady-state evaporation from porous media', Water Resources Research, 48(9), pp. 1-7. doi: 10.1029/2012WR012060.

Saito, H., Simunek, J. and Mohanty, B. P. (2006) 'Numerical analysis of coupled water, vapour, and heat transport in the vadose zone', Vadose Zone Journal, 5(2), pp. 784-800.

Saito, H., Simunek, J. and Mohanty, B. P. (2006) 'Numerical Analysis of Coupled Water, Vapour, and Heat Transport in the Vadose Zone', Vadose Zone Journal, 5, pp. 784-800. doi: 10.2136/vzj2006.0007.

Sakai, M., Jones, S. B. and Tuller, M. (2011) 'Numerical evaluation of subsurface soil water evaporation derived from sensible heat balance', Water Resources Research, 47(2), pp. 1-17. doi: 10.1029/2010WR009866. 
Sakai, M., Toride, N. and Simunek, J. (2009) 'Water and Vapour Movement with Condensation and Evaporation in a Sandy Column', Soil Science Society of America Journal, 73(3), p. 707. doi: 10.2136/sssaj2008.0094.

Sánchez-Cañete, E. P., Kowalski, A. S., Serrano-Ortiz, P., Pérez-Priego, O., Domingo, F. (2013) 'Deep $\mathrm{CO}_{2}$ soil inhalation/exhalation induced by synoptic pressure changes and atmospheric tides in a carbonated semi-arid

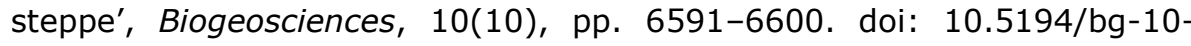
6591-2013.

Sánchez, J. M., Kustas, W. P., Caselles, V., Anderson, M. C. (2008) 'Modelling surface energy fluxes over maize using a two-source patch model and radiometric soil and canopy temperature observations', 112, pp. 11301143. doi: $10.1016 /$ j.rse.2007.07.018.

Sanderson, J. S. and Cooper, D. J. (2008) 'Ground water discharge by evapotranspiration in wetlands of an arid intermountain basin', Journal of Hydrology, 351(3-4), pp. 344-359.

Scanlon, B., Healy, R. and Cook, P. (2002) 'Choosing appropriate techniques for quantifying groundwater recharge', Hydrogeology Journal, 10(1), pp. 18-39.

Scanlon, B. R. (2000) 'Uncertainties in estimating water fluxes and residence times using environmental tracers in an arid unsaturated zone', Water Resources Research, 36(2), pp. 395-409.

Scanlon, B. R. (2000) 'Uncertainties in estimating water fluxes and residence times using environmental tracers in an arid unsaturated zone', Water Resources Research, 36(2), pp. 395-409.

Scanlon, B. R. et al. (2006) 'Global synthesis of groundwater recharge in semiarid and arid regions', Hydrological Processes, 20(15), pp. 3335-3370.

Scanlon, B. R., Keese, K. and Reedy, R. C. (2003) 'Variations in flow and transport in thick desert vadose zones in response to paleoclimatic forcing (0-90 kyr): Field measurements, modeling, and uncertainties', 39(7). doi: 10.1029/2002WR001604.

Scanlon, B. R. and Milly, P. C. D. (1994) 'Water and Heat Fluxes in Desert Soils .2. Numerical Simulations', Water Resources Research, 30(3), pp. 721-733.

Scanlon, B. R., Reedy, R. C. and Tachovsky, J. A. (2007) 'Semi-arid unsaturated zone chloride profiles: Archives of past land use change impacts on water resources in the southern High Plains, United States', Water Resources Research, 43(6), pp. 1-13. doi: 10.1029/2006WR005769.

Schery, S. D. and Petschek, A. G. (1983) 'Exhalation of radon and thoron: the question of the effect of thermal gradients in soil', Earth and Planetary Science Letters, 64(1), pp. 56-60. 
Schlaepfer, D. R., Bradford, J. B., Lauenroth, W. K., Munson, S. M., Tietjen, B., Hall, S. A., Wilson, S. D., Duniway, M. C., Jia, G., Pyke, D. A., Lkhagva, A., Jamiyansharav, K. (2017) 'Climate change reduces extent of temperate drylands and intensifies drought in deep soils', Nature Communications. Nature Publishing Group, 8. doi: 10.1038/ncomms14196.

Schlünder, E.-U. (1988) 'On the mechanism of the constant drying rate period and its relevance to diffusion controlled catalytic gas phase reactions', Chemical Engineering Science, 43(10), pp. 2685-2688. doi: https://doi.org/10.1016/0009-2509(88)80012-5.

Scholes, R. J. (2020) 'The future of semi-arid regions: A weak fabric unravels', Climate, 8(3), pp. 1-11. doi: 10.3390/cli8030043.

Schubert, M. and Schulz, H. (2002) 'Diurnal radon variations in the upper soil layers and at teh soil-air interface related to metereological parameters', Health Physics, 83(1). Available at: https://journals.Iww.com/healthphysics/Fulltext/2002/07000/DIURNAL_RADON_VARIATIONS_IN_THE_UP PER_SOIL_LAYERS.10.aspx.

Scott, R. L., Watts, C., Payan, J. G., Edwards, E., Goodrich, D. C., Williams, D., James S. W. (2003) 'The understory and overstory partitioning of energy and water fluxes in an open canopy, semi-arid woodland', Agricultural and Forest Meteorology, 114(3-4), pp. 127-139.

Scott, R. L. (2010) 'Using watershed water balance to evaluate the accuracy of eddy covariance evaporation measurements for three semi-arid ecosystems', Agricultural and Forest Meteorology, 150(2), pp. 219-225.

Scotter, D. R. and Raats, P. A. C. (1969) 'Dispersion of water vapour $n$ soil due to air turbulence', Soil Science, 108(3). Available at: https://journals.Iww.com/soilsci/Fulltext/1969/09000/DISPERSION_OF_W ATER_VAPOUR_IN_SOIL_DUE_TO_AIR.4.aspx.

Shah, N., Nachabe, M. and Ross, M. (2007b) 'Extinction Depth and Evapotranspiration from Ground Water under Selected Land Covers', Ground Water, 45(3), pp. 329-338.

Shahraeeni, E., Lehmann, P. and Or, D. (2012) 'Coupling of evaporative fluxes from drying porous surfaces with air boundary layer: Characteristics of evaporation from discrete pores', Water Resources Research, 48(9), pp. 115. doi: $10.1029 / 2012$ WR011857.

Shahraeeni, E. and Or, D. (2012) 'Pore scale mechanisms for enhanced vapour transport through partially saturated porous media', Water Resources Research, 48(5), pp. 1-16. doi: 10.1029/2011WR011036.

Shaw, T. M. (1987) 'Drying as an Immiscible Displacement Process with Fluid Counterflow', Physical Review Letters, 59(15), pp. 1671-1675. 
Shokri, N., Lehmann, P., Vontobel, P., Or, D. (2008) 'Drying front and water content dynamics during evaporation from sand delineated by neutron radiography', Water Resources Research, 44(6).

Shokri, N., Lehmann, P. and Or, D. (2009) 'Critical evaluation of enhancement factors for vapour transport through unsaturated porous media', Water Resources Research, 45(10), pp. 1-9. doi: 10.1029/2009WR007769.

Shokri, N., Lehmann, P. and Or, D. (2010) 'Evaporation from layered porous media', Journal of Geophysical Research: Solid Earth, 115(6), pp. 1-12. doi: 10.1029/2009JB006743.

Shokri, N. and Or, D. (2011) 'What determines drying rates at the onset of diffusion controlled stage-2 evaporation from porous media?', Water Resources Research, 47(9), pp. 1-8. doi: 10.1029/2010WR010284.

Shokri, N., Or, D. and Lehmann, P. (2007) 'Characteristic lengths affecting evaporation from porous media: The roles of pore size distribution, gravity and wettability', Environmental Engineering, (November).

Shokri, N. and Salvucci, G. D. (2011) 'Evaporation from porous media in the presence of a water table', Vadose Zone Journal, 10, pp. 1309-1318.

Simunek, J., Sejna, M., Saito, H., Sakai, M., van Genuchten, M.Th. (2009) 'The HYDRUS-1D software package for simulating the one-dimensional movement of water, heat, and multiple solutes in variably-saturated media. Version 4.08. HYDRUS Softw. Ser. 3.', Dep. of Environ. Sci., Univ. of Calif., Riverside., (January), p. 332. doi: 10.1007/SpringerReference_28001.

Simunek, J., van Genuchten, M. T. and Sejna, M. (2005) The HYDRUS-1D software package for simulating the movement of water, heat, and multiple solutes in variably saturated media, version 3.0, HYDRUS Software Ser. 1.

Simunek, J., van Genuchten, M. T. and Sejna, M. (2008) 'Development and Applications of the HYDRUS and STANMOD Software Packages and Related Codes', Vadose Zone Journal, 7(2), p. 587. doi: 10.2136/vzj2007.0077.

Smith, K. A., Ball, T., Conen, F., Dobbie, K. E., Massheder, J., Rey, A. (2003) 'Exchange of greenhouse gases between soil and atmosphere', European Journal of Soil Science, 54(December), pp. 779-791. doi: 10.1046/j.13652389.2003.00567.x.

Smits, K. M., Cihan, A., Sakaki, T., Illangasekare, T. H. (2011) 'Evaporation from soils under thermal boundary conditions: Experimental and modeling investigation to compare equilibrium-and nonequilibrium-based approaches', Water Resources Research, 47(5).

Soylu, M. E., Istanbulluoglu, E., Lenters, J. D., Wang, T. (2011) 'Quantifying the impact of groundwater depth on evapotranspiration in a semi-arid 
grassland region', Hydrology and Earth System Sciences, 15(3), pp. 787806.

Stauffer, P. H., Auer, L. H. and Rosenberg, N. D. (1997) 'Compressible gas in porous media: A finite amplitude analysis of natural convection', International Journal of Heat and Mass Transfer, 40(7), pp. 1585-1589. doi: 10.1016/S0017-9310(96)00222-0.

Sun, P., Ma, J., Qi, S., Zhao, W., Zhu, G. (2016) 'The effects of a dry sand layer on groundwater recharge in extremely arid areas: field study in the western Hexi Corridor of northwestern China', 24, pp. 1515-1529. doi: 10.1007/s10040-016-1410-2.

Suzuki, M. and Maeda, S. (1968) 'On the mechanism of drying of granular beds: Mass Transfer from Discontinuous Source', Journal of Chemical Engineering of Japan, 1(1), pp. 26-31. doi: 10.1252/jcej.1.26.

van der Tol, C. et al. (2003) 'Average wet canopy evaporation for a Sitka spruce forest derived using the eddy correlation-energy balance technique', Journal of Hydrology, 276(1-4), pp. 12-19.

van der Tol, C. (2012) 'Validation of remote sensing of bare soil ground heat flux', Remote Sensing of Environment, 121, pp. 275-286.

Van Der Tol, C., Gash, J. H. C., Grant, S. J., McNeil, D. D., Robinson, M. (2009) 'An integrated model of soil-canopy spectral radiances, photosynthesis, fluorescence, temperature and energy balance', Biogeosciences, 6(12), pp. 3109-3129. doi: 10.5194/bg-6-3109-2009.

Tsujimura, M., Numaguti, A., Tian, L., Hashimoto, S., Sugimoto, A., Nakawo, M. (2001) 'Behavior of subsurface water revealed by stable isotope and tensiometric observation in the Tibetan Plateau', Journal of the Meteorological Society of Japan, 79(1B), pp. 599-605.

Tuller, M. and Or, D. (2001) 'Hydraulic conductivity of variably saturated porous media: Film and corner flow in angular pore space ( approximately The crossover region', 37(5), pp. 1257-1276.

Twarakavi, N. K. C., Simunek, J. and Seo, S. (2008) 'Evaluating interactions between groundwater and vadose zone using the HYDRUS-based flow package for MODFLOW', Vadose Zone Journal, 7(2), pp. 757-768.

Tweed, S., Leblanc, M., Cartwright, I., Favreau, G., Leduc, C. (2011) 'Arid zone groundwater recharge and salinisation processes; an example from the Lake Eyre Basin, Australia', Journal of Hydrology, 408(3-4), pp. 257-275.

Vanderborght, J., Shahraeeni, E., Pohlmeier, A., Merz, S., Jonard, F., Graf, A., Rothfuss, Y., Bruggemann, N., Vereecken, H. (2014) 'Monitoring of Soil Evaporation and Drying at Different Scales', in. Available at: http://juser.fzjuelich.de/record/172374. 
Vanderborght, J., Helmig, R., Fetzer, T., Mosthaf, K., Smits, K. M. (2017) 'Heat and water transport in soils and across the soil-atmosphere interface: 1. Theory and differentmodel concepts', Water Resour. Res, 53, pp. 10571079. doi: 10.1002/2016WR019983. Heat.

Vanderborght, J. and Vereecken, H. (2007) 'Review of Dispersivities for Transport Modeling in Soils', Vadose Zone Journal, 6(1), p. 29. doi: 10.2136/vzj2006.0096.

Vereecken, H., Huisman, J. A., Bogena, H., Vanderborght, J., Vrugt, J. A., Hopmans, J. W. (2008) 'On the value of soil moisture measurements in vadose zone hydrology: A review', Water Resources Research, 44, p.

Verhoef, A., De Bruin, H. A. R. and Van Den Hurk, B. J. J. M. (1997) 'Some Practical Notes on the Parameter kB-1 for Sparse Vegetation', Journal of Applied Meteorology, 36(5), pp. 560-572.

Verstraete, M. M. and Schwartz, S. A. (1991) 'Desertification and global change', Vegetatio, 91(1-2), pp. 3-13. doi: 10.1007/BF00036043.

Villegas, A. N. and Morris, R. A. (1990) 'Zero Flux Plane Recession under Monocropped and Intercropped Cowpea and Sorghum', Agron. J., 82(4), pp. 845-851.

Villegas, J. C., Dominguez, F., Barron-Gafford, G. A., Adams, H. D., GuardiolaClaramonte, M., Sommer, E. D., Selvey, A. W., Espeleta, J. F., Zou, C. B., Breshears, D. D., Huxman, T. E. (2015) 'Sensitivity of regional evapotranspiration partitioning to variation in woody plant cover: Insights from experimental dryland tree mosaics', Global Ecology and Biogeography, 24(9), pp. 1040-1048. doi: 10.1111/geb.12349.

Walker, G. R., Hughes, M. W., Allison, G. B., Barnes, C. J. (1988) 'The Movement of Isotopes of Water during Evaporation from a Bare Soil Surface', Journal of Hydrology, 97(3-4), pp. 181-197.

Wallace, H. (1997) 'Soil evaporation from tiger-bush in south-west Niger', journal of hydrology, 188-189, p. 16.

Walvoord, M. A., Plummer, M. A., et al. (2002a) 'Deep arid system hydrodynamics-1. Equilibrium states and response times in thick desert vadose zones', Water Resources Research, 38(12), p.

Walvoord, M. A., Phillips, F. M., et al. (2002b) 'Deep arid system hydrodynamics-2. Application to paleohydrologic reconstruction using vadose zone profiles from the northern Mojave Desert', Water Resources Research, 38(12), p.

Wang, L., Caylor, K. K., Villegas, J. C., Barron-Gafford, G. A., Breshears, D. D., Huxman, T. E. (2010) 'Partitioning evapotranspiration across gradients of woody plant cover: Assessment of a stable isotope technique', 
Geophysical Research Letters. John Wiley \& Sons, Ltd, 37(9). doi: https://doi.org/10.1029/2010GL043228.

Wang, X. (2015) 'Vapour flow resistance of dry soil layer to soil water evaporation in arid environment: An overview', Water (Switzerland), 7(8), pp. 4552-4574. doi: 10.3390/w7084552.

Warren, A. (1996) 'Desertification', in Adams, W. M., Goudie, A. S., and Orme, A. R. (eds) The physical geography of Africa. Oxford UK: Oxford University Press, pp. 342-355.

Webb, S. W. (2000) 'A simple extension of two-phase characteristic curves to include the dry region', Water Resources Research, 36(6), pp. 1425-1430.

Webb, S. W. and Ho, C. K. (1998) 'Review of enhanced vapour diffusion in porous media', in SAND-98-1819C; CONF-980559.

Wei, Z., Yoshimura, K., Wang, L., Miralles, D. G., Jasechko, S., Lee, X. (2017) 'Revisiting the contribution of transpiration to global terrestrial evapotranspiration', Geophysical Research Letters, 44(6), pp. 2792-2801. doi: 10.1002/2016GL072235.

Weisbrod, N., Dragila, M. I., Nachshon, U., Pillersdorf, M. (2009) 'Falling through the cracks: The role of fractures in Earth-atmosphere gas exchange', Geophys. Res. Lett., 36(2), p. L02401.

White, W. N. (1932) 'A method of estimating ground-water supplies based on discharge by plants and evaporation from soil: results of investigations in Escalante Valley, Utah', US Geol Surv Water, Suppl Pap.

Wilkinson, D. (1986) 'Percolation effects in immiscible displacement', Physical Review A, 34(2), pp. 1380-1391. doi: 10.1103/PhysRevA.34.1380.

Wilks, D. S. (2006) Statistical Methods in the Atmospheric Sciences. 2 Edn. Edited by A. Press.

Williams, D. G., Cable, W., Hultine, K., Hoedjes, J. C. B., Yepez, E. A., Simonneaux, V., Er-Raki, S., Boulet, G., de Bruin, H. A. R., Chehbouni, A., Hartogensis, O. K., Timouk, F. (2004) 'Evapotranspiration components determined by stable isotope, sap flow and eddy covariance techniques', Agricultural and Forest Meteorology, 125(3-4), pp. 241-258.

Wilson, K. B., Hanson, P. J., Mulholland, P. J., Baldocchi, D. D., Wullschleger, S. D. (2001) 'A comparison of methods for determining forest evapotranspiration and its components: Sap-flow, soil water budget, eddy covariance and catchment water balance', Agricultural and Forest Meteorology, 106(2), pp. 153-168. doi: 10.1016/S0168-1923(00)00199-4. 
Witkamp, M. (1969) 'Cycles of Temperature and Carbon Dioxide Evolution From Litter and Soil', Ecology. John Wiley \& Sons, Ltd, 50(5), pp. 922-924. doi: $10.2307 / 1933713$.

Xu, C., McDowell, N. G., Fisher, R. A., Wei, L., Sevanto, S., Christoffersen, B. O., Weng, E., Middleton, R. S. (2019) 'Increasing impacts of extreme droughts on vegetation productivity under climate change', Nature Climate Change, 9(12), pp. 948-953. doi: 10.1038/s41558-019-0630-6.

Yaseef, N. R., Yakir, D, Rotenberg, E., Schiller, G., Cohen, S. (2010) 'Ecohydrology of a semi-arid forest: partitioning among water balance components and its implications for predicted precipitation changes', Ecohydrology, 3(2), pp. 143-154.

Yaseen, Z. M., Al-Juboori, A. M., Beyaztas, U., Al-Ansari, N., Chau, K. W., Qi, C., Ali, M., Salih, S. Q., Shahid, S. (2020) 'Prediction of evaporation in arid and semi-arid regions: a comparative study using different machine learning models', Engineering Applications of Computational Fluid Mechanics, 14(1), pp. 70-89. doi: 10.1080/19942060.2019.1680576.

Yepez, E. A., Huxman, T. E., Ignace, D. D., English, N. B., Weltzin, J. F., Castellanos, A. E., Williams, D. G. (2005) 'Dynamics of transpiration and evaporation following a moisture pulse in semi-arid grassland: A chamberbased isotope method for partitioning flux components', Agricultural and Forest Meteorology, 132(3-4), pp. 359-376.

Yiotis, A. G., Boudouvis, A. G., Stubos, A. K., Tsimpanogiannis, I. N., Yortsos, Y. C. (2003) 'Effect of liquid films on the isothermal drying of porous media', Phys. Rev. E, 68(3), p. 33.

Yiotis, A. G., Tsimpanogiannis, I. N., Stubos, A. K., Yortsos, Y. C. (2006) 'Porenetwork study of the characteristic periods in the drying of porous materials', Journal of Colloid and Interface Science, 297(2), pp. 738-748. doi: $10.1016 /$ j.jcis.2005.11.043.

Zeng, Y., Wan, L., Su, Z., Huang, K., Wang, X. (2007) 'The Variation in Soil Temperature and its Effects on the Movement of Water Vapour in the Surface Zone'. MSc Thesis. ITC, Twente University, the Netherland.

Zeng, Y., Su, Z., Wan, L., Yang, Z., Zhang, T., Tian, H., Shi, X., Wang, X., Cao, W. (2009a) 'Diurnal pattern of the drying front in desert and its application for determining the effective infiltration', Hydrology and Earth System Sciences, 13(6), pp. 703-714.

Zeng, Y., Wan, L., Su, Z. B., Saito, H., Huang, K. L., Wang, X. S. (2009b) 'Diurnal soil water dynamics in the shallow vadose zone (field site of China University of Geosciences, China)', Environmental Geology, 58(1), pp. 1123. doi: 10.1007/s00254-008-1485-8. 
Zeng, Y., Su, Z., Wan, L., Wen, J. (2011a) 'A simulation analysis of the advective effect on evaporation using a two-phase heat and mass flow model', Water Resources Research, 47(10), pp. 1-18. doi: 10.1029/2011WR010701.

Zeng, Y., Su, Z., Wan, L., Wen, J. (2011b) 'Numerical analysis of air-waterheat flow in unsaturated soil: Is it necessary to consider airflow in land surface models?', J. Geophys. Res., 116(D20), p. D20107.

Zhang, K., Kimball, J. S. and Running, S. W. (2016) 'A review of remote sensing based actual evapotranspiration estimation', Wiley Interdisciplinary Reviews: Water, 3(6), pp. 834-853. doi: 10.1002/wat2.1168.

Zhang, S., Wen, X., Wang, J., Yu, G., Sun, X. (2010) 'The use of stable isotopes to partition evapotranspiration fluxes into evaporation and transpiration', Acta Ecologica Sinica, 30(4), pp. 201-209. doi: http://dx.doi.org/10.1016/j.chnaes.2010.06.003. 


\section{Summary}

Water is a scarce resource in semi-arid and arid areas, where it is used by both fragile ecosystems and humans. Water can also become a scarce resource in other climates, whenever a period with no or rare precipitation events continues for too long. Climate change is predicted to increase the extent of semi-arid and arid areas, and to increase the frequency and magnitudes of droughts worldwide. Therefore, recent studies recognized the importance of accurate estimates of the various components of the water balance in semiarid areas, and attempted the partitioning of evapotranspiration into the transpiration and evaporation components. Most of these studies tend to neglect soil evaporation whenever a dry soil layer develops at the soil surface; moreover, most soil hydraulic models assume only liquid water flow, or assume that Fick's diffusion is the only process responsible for the transport of water vapour in the soil. However, there have been direct observations of soil evaporation taking place in deserts with very thick dry soil layers.

The objective of this thesis is to estimate the components of soil evaporation, i.e. unsaturated zone and groundwater evaporation, to increase the accuracy of water balance calculations in semi-arid areas and in dry conditions in general. To do so, these two components need to be defined in a framework consistent with the other components of the water balance, especially plant transpiration from the unsaturated zone and from the groundwater. The framework, then, should be tested in field conditions, focussing on dry conditions. Finally, the effect of the formation of a dry soil layer on soil evaporation should be analysed, especially addressing the problem of its simplification, for example by neglecting it when averaging over a whole day, or by assuming that Fick's diffusion is the only transport mechanism for water vapour.

The first objective was addressed with an extensive literature review on studies on soil evaporation and ecosystem evapotranspiration from different scientific perspectives: hydrology, soil physics, ecology, atmospheric sciences. A framework with the definition of the soil evaporation components was defined in a way to be consistent across these disciplines. This framework was then implemented in a post processing package connected with a soil hydraulic model to estimate the soil evaporation components individually. This framework was tested in a field study conducted near Salamanca, Spain, in a semi-arid area with the following characteristics: marked dry conditions during summer (June-September); savannah-like dehesa landscape, with few trees surrounded by grass that becomes dormant in summer; relatively shallow (0.5$10 \mathrm{~m}$ ) water table, and mostly sandy soils. The field study required the combination of different techniques in order to quantify all the various components of the water balance in the area: the evapotranspiration was estimated using an eddy covariance tower, transpiration was estimated using sap flow measurements for the two species of trees in the area, and the soil 
evaporation components were estimated using the soil hydraulic model and the post processing package. The hydraulic model was set up by using: the soil properties in the area around the tower determined by sampling of soil and interpolated using geostatistics; the upper boundary conditions determined at $2 \mathrm{~m}$ height by a weather station close to the eddy covariance tower; the lower boundary condition of groundwater depth determined by soil piezometers in the area, and datasets of soil moisture, soil temperature and matric potential obtained by various soil monitoring profiles.

The study of the air-Dry Soil Layer (DSL) required various steps: (1) direct observation of DSL to study its behaviour; (2) setup of a laboratory experiment to reproduce the DSL observed in the field and to test it with various boundary conditions, to determine the main process involved in the transport of water vapour in the DSL; (3) use of the same experiment setup in field conditions, so as to include the complex interaction of the evaporative conditions of field conditions. To overcome the problem of lack of direct water vapour observations in the soil profile, the same approach as in $\mathrm{CO}_{2}$ respiration studies was used, i.e the study of the correlation between different possible driving factors and the observed evaporation.

The above framework was able to properly partition and source the soil evaporation in the semi-arid area. Soil evaporation was the bigger component of the evapotranspiration all year round, since the scattered trees (canopy coverage $7 \%$ ) transpired only a minimal amount of water (6\%). Groundwater evaporation was the main component of soil evaporation flow in a year 4 to 5 times larger than unsaturated zone evaporation. When a $25 \mathrm{~cm}$ thick dry soil layer develops in the area during May the two soil evaporation components becomes decoupled: the (rare) precipitation events tend to wet only the first centimetres of the soil and quickly evaporate, so that the unsaturated zone evaporation was equal to precipitation, while the groundwater continued to evaporate when the upper soil was dry, at a slow rate independent from the water table depth, at least in the depths observed in the field $(0.5-10 \mathrm{~m})$. The effects of the dry soil layer on soil evaporation were not negligible, even when averaging over a whole day; moreover, the evaporation estimates using only Fick's diffusion could not predict groundwater evaporation in the area.

The laboratory experiment showed evaporation taking place in sand even with a $70-180 \mathrm{~cm}$ thick DSL. The evaporation flow was independent from: the thickness of DSL in the range explored, the change in wind speed, and the change in radiation available at the soil surface. The evaporation rates observed were one to two orders of magnitude larger than those calculated on the basis of Fick's diffusion. Evaporation rates were correlated with atmospheric pressure fluctuations, and could be modelled as the result of barometric effects on the gas phase flow in the dry soil layer.

The field experiment confirmed the observation of evaporation even in the presence of a $70 \mathrm{~cm}$ thick DSL. The evaporation rates recorded were 5 times those observed in the laboratory conditions with similar DSL thickness and 
potential evaporation conditions. The evaporation rates correlated well with the change in solar radiation and temperature at the soil surface and at $5 \mathrm{~cm}$ depth. A linear model based on these driving factors was able to estimate the evaporation rates magnitude and behaviour; the inclusion of soil temperatures at other depths improved the linear model (all variables with $p<0.001$ ) but only marginally. The main process for the transport of water vapour, therefore, was attributed to be the bulk transport of the gas phase in the dry soil layer due to temperature instabilities at the soil-atmosphere surface. When left on the field unattended, the experiment formed a dry soil layer only during a dry year and only $\sim 12 \mathrm{~cm}$ thick; in contrast the soil in the area, consistently formed a dry soil layer $25 \mathrm{~cm}$ thick every year; this is probably due to the action of grasses that transpire the unsaturated zone water in the root zone until the wilting point is reached, and then go dormant in the dry season. 


\section{Samenvatting}

Water is een schaars productiemiddel in semi-aride en dorre gebieden, waar het essentieel is voor de kwetsbare ecosystemen maar ook voor de mens. Ook in andere klimaten kan water een schaars goed worden, wanneer een periode met weinig of geen neerslag te lang aanhoudt. Door klimaatverandering zullen volgens de voorspellingen de semi-aride en dorre gebieden toenemen en zal ook de frequentie en duur van droogtes wereldwijd toenemen. Daarom wordt in recente studies op het belang gewezen van nauwkeurige schattingen van de verschillende componenten van de waterbalans in semi-aride gebieden, en is geprobeerd de evapotranspiratie op te splitsen in de componenten transpiratie en verdamping. De meeste van deze studies verwaarlozen de bodemverdamping wanneer zich aan het bodemoppervlak een droge bodemlaag ontwikkelt; bovendien gaan de meeste bodemfysische modellen alleen uit van de stroming van vloeibaar water, of gaan zij ervan uit dat de diffusie van Fick het enige proces is dat transport van waterdamp in de bodem bepaalt. Er zijn echter directe waarnemingen gedaan van bodemverdamping in woestijnen met zeer dikke droge bodemlagen.

Het doel van dit proefschrift is om de componenten van bodemverdamping, d.w.z. de verdamping uit de onverzadigde zone en uit het grondwater, te schatten om de nauwkeurigheid van waterbalansberekeningen in semi-aride gebieden en in droge omstandigheden in het algemeen te vergroten. Daartoe moeten deze twee componenten worden gedefinieerd in een theoretisch kader dat ook de andere componenten van de waterbalans bevat, met name transpiratie door plant gevoed door de onverzadigde zone en het deel dat vanuit het grondwater onttrokken wordt. Dit theoretisch kader moet vervolgens worden getest in veldomstandigheden, met de nadruk op droge omstandigheden. Tenslotte moet het effect van de vorming van een droge bodemlaag op de bodemverdamping worden geanalyseerd, waarbij met name het probleem van de beschrijving en de parametrisering moet worden aangepakt, bijvoorbeeld door deze te verwaarlozen bij middeling over een hele dag, of door aan te nemen dat de diffusie van Fick het enige transportmechanisme voor waterdamp is.

De eerste doelstelling werd bereikt met een uitgebreid literatuuronderzoek naar studies over bodemverdamping en ecosysteemverdamping vanuit verschillende wetenschappelijke invalshoeken: hydrologie, bodemfysica, ecologie, atmosfeerwetenschappen. Een kader met de definitie van de bodemverdampingscomponenten werd gedefinieerd op een manier die aansluit op deze disciplines. Dit kader werd vervolgens geïmplementeerd in een post processing pakket gekoppeld aan een bodemfysisch model om de bodemverdampingscomponenten afzonderlijk te schatten. Deze beschrijving werd getest in een veldstudie die werd uitgevoerd in de buurt van Salamanca, Spanje, in een semi-aride gebied met de volgende kenmerken: uitgesproken droge omstandigheden tijdens de zomer (juni-september); savanne-achtig 
dehesa-landschap, met weinig bomen omringd door gras dat in de zomer in rust gaat; relatief ondiep $(0,5-10 \mathrm{~m})$ grondwater, en overwegend zandige bodems. Het veldonderzoek combineerde noodzakelijkerwijs verschillende technieken om de verschillende componenten van de waterbalans in het gebied te kwantificeren: de evapotranspiratie werd geschat met behulp van een eddy covariantie toren, de transpiratie werd geschat met behulp van sapstroommetingen voor de twee boomsoorten in het gebied, en de bodemverdampingscomponenten werden geschat met behulp van het bodemfysisch model en het nabewerkingspakket. Voor het model waren de volgende invoeren nodig: de bodemeigenschappen in het gebied rond de toren bepaald door bemonstering van de bodem en geïnterpoleerd met behulp van geostatistiek; de bovenrandvoorwaarden bepaald op $2 \mathrm{~m}$ hoogte door een weerstation in de buurt van de eddy correlatie toren; de onderrandvoorwaarde - de grondwaterdiepte - werd bepaald door piëzometers in het gebied, en datasets van bodemvocht, bodemtemperatuur en vochtspanningspotentiaal werden verkregen door verschillende bodemmonitoringprofielen.

Het onderzoek van de DSL vereiste verschillende stappen: (1) directe waarneming van de DSL om het gedrag ervan te bestuderen; (2) opzetten van een laboratoriumexperiment om de in het veld waargenomen DSL te reproduceren en te testen met verschillende randvoorwaarden; dit om het belangrijkste proces in het transport van waterdamp in de DSL te bepalen; (3) gebruik van dezelfde experimentele opzet in veldomstandigheden, om de complexe interactie tussen drijvende variabelen in veldomstandigheden mee te nemen. Om het probleem van het ontbreken van directe waterdampwaarnemingen in het bodemprofiel te ondervangen, werd dezelfde aanpak gebruikt als bij CO2-respiratie studies, d.w.z. de analyse van de correlatie tussen verschillende mogelijke causale factoren en de waargenomen verdamping.

Het bovenstaande kader was in staat om de bodemverdamping in het semiaride gebied goed te bepalen, en te verdelen over de verschillende bronnen. Bodemverdamping leverde de grootste bijdrage aan de evapotranspiratie gedurende het hele jaar, aangezien de verspreide bomen (bedekkingsgraad $7 \%$ ) slechts een minimale hoeveelheid water transpireerden $(6 \%)$. Verdamping uit het grondwater leverde de belangrijkste bijdrage aan de bodemverdamping in een jaar- deze was 4 tot 5 maal groter dan verdamping uit de onverzadigde zone. Wanneer zich in mei in het gebied een $25 \mathrm{~cm}$ dikke droge bodemlaag ontwikkelt, worden de twee componenten van bodemverdamping ontkoppeld: de (zeldzame) neerslag bevochtigt meestal alleen de eerste centimeters van de bodem en verdampt snel, zodat de onverzadigde zoneverdamping gelijk is aan de neerslag, terwijl het grondwater blijft verdampen wanneer de bovenste bodemlaag droog is. Dit gebeurt in een langzaam tempo dat onafhankelijk is van de grondwaterspiegeldiepte, althans in de dieptes die in het veld zijn waargenomen (0,5-10 m). De effecten van de droge bodemlaag op de bodemverdamping waren niet te verwaarlozen, zelfs 
niet wanneer het gemiddelde over een hele dag wordt genomen; bovendien konden de verdampingsschattingen waarbij alleen gebruik werd gemaakt van de diffusie van Fick, de grondwaterverdamping in het gebied niet voorspellen.

Het laboratoriumexperiment toonde aan dat er verdamping plaatsvond in zand, zelfs met een 70-180 cm dikke DSL. De verdamping was onafhankelijk van de dikte van de DSL in het onderzochte bereik, de verandering in windsnelheid, en de verandering in de beschikbare straling aan het bodemoppervlak. De waargenomen momentane verdamping was één tot twee ordes groter dan die berekend op basis van de diffusie van Fick. De momentane verdamping waren ook gecorreleerd met atmosferische drukschommelingen, en konden worden gemodelleerd als het resultaat van barometrische effecten op de gasfase-stroming in de droge bodemlaag.

Het veldexperiment bevestigde de waarneming van bodemverdamping, zelfs in aanwezigheid van een $70 \mathrm{~cm}$ dikke DSL. De waargenomen momentane verdamping was vijf maal zo hoog als die in het laboratorium werd waargenomen bij een vergelijkbare DSL-dikte en vergelijkbare potentiële verdampingsomstandigheden. De momentane verdamping correleerde goed met de verandering in zonnestraling en temperatuur aan het bodemoppervlak en op $5 \mathrm{~cm}$ diepte. Een lineair model gebaseerd op deze drijvende factoren was in staat om de grootte en het gedrag van de momentane verdamping te schatten; de opname van bodemtemperaturen op andere diepten verbeterde het lineaire model (alle variabelen met $p<0,001$ ), maar slechts minimaal. Het belangrijkste proces voor het transport van waterdamp kon daarom worden toegeschreven aan het bulktransport van de gasfase in de droge bodemlaag ten gevolge van temperatuur instabiliteit en aan het bodematmosfeeroppervlak. Wanneer het experiment onbeheerd op het veld werd achtergelaten, vormde het alleen tijdens een droog jaar een droge bodemlaag van slechts $\sim 12 \mathrm{~cm}$ dik; de bodem in de omgeving vormde daarentegen elk jaar consequent een droge bodemlaag van $25 \mathrm{~cm}$ dik; dit is waarschijnlijk te wijten aan de werking van grassen die het water uit de onverzadigde zone in de wortelzone transpireren totdat het verwelkingpunt is bereikt, en die dan in het droge seizoen in slaap vallen. 
